PROTEST AND SOCIAL MOVEMENTS

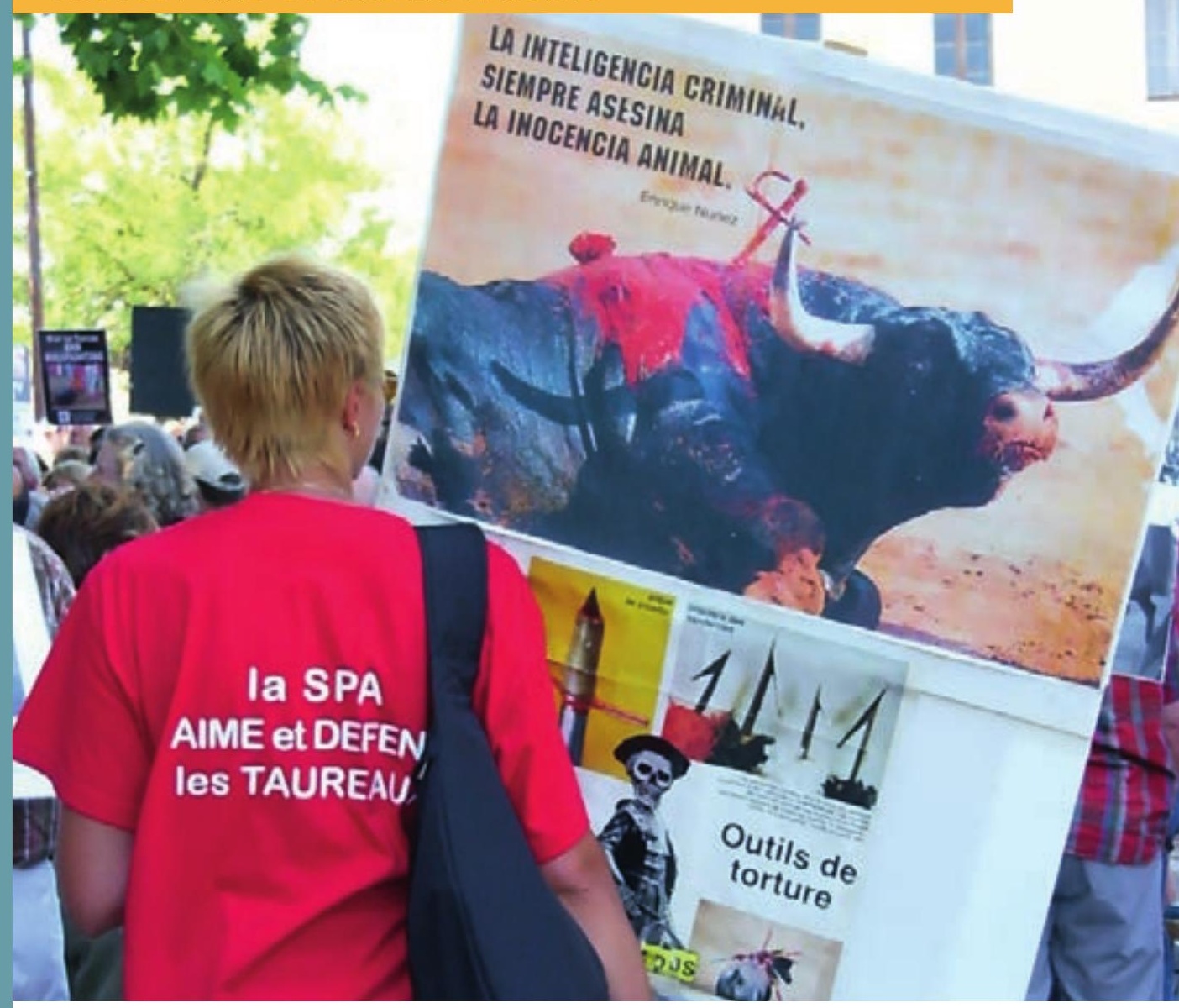

Christophe Traïni

\title{
The Animal Rights Struggle
}

An Essay in Historical Sociology 
The Animal Rights Struggle 


\section{Protest and Social Movements}

Recent years have seen an explosion of protest movements around the world, and academic theories are racing to catch up with them. This series aims to further our understanding of the origins, dealings, decisions, and outcomes of social movements by fostering dialogue among many traditions of thought, across European nations and across continents. All theoretical perspectives are welcome. Books in the series typically combine theory with empirical research, dealing with various types of mobilization, from neighborhood groups to revolutions. We especially welcome work that synthesizes or compares different approaches to social movements, such as cultural and structural traditions, micro- and macro-social, economic and ideal, or qualitative and quantitative. Books in the series will be published in English. One goal is to encourage nonnative speakers to introduce their work to Anglophone audiences. Another is to maximize accessibility: all books will be available in open access within a year after printed publication.

\section{Series editors}

Jan Willem Duyvendak is professor of Sociology at the University of Amsterdam. James M. Jasper teaches at the Graduate Center of the City University of New York. 


\title{
The Animal Rights Struggle
}

\author{
An Essay in Historical Sociology
}

Christophe Trä̈ni 
Originally published as La cause animale. Essai de sociologie historique (1820-1980), 2011

(c) Presses Universitaires de France

Text translated by Richard Jemmett

Cover illustration: Photography by Christophe Traïni, Fréjus, July 2005

Cover design: Coördesign, Leiden

Typesetting: Crius Group, Hulshout

Amsterdam University Press English-language titles are distributed in the US and Canada by the University of Chicago Press.

$\begin{array}{ll}\text { ISBN } & 978 \text { 90 } 89648495 \\ \text { e-ISBN } & 9789048527038 \text { (pdf) } \\ \text { DOI } & 10.5117 / 9789089648495 \\ \text { NUR } & 740\end{array}$

(C) Christophe Trä̈ni / Amsterdam University Press B.V., Amsterdam 2016

All rights reserved. Without limiting the rights under copyright reserved above, no part of this book may be reproduced, stored in or introduced into a retrieval system, or transmitted, in any form or by any means (electronic, mechanical, photocopying, recording or otherwise) without the written permission of both the copyright owner and the author of the book. 


\section{Table of contents}

Introduction

1 A long and complex struggle 11

$\begin{array}{ll}\text { The pioneering influence of the British model } & 11\end{array}$

$\begin{array}{lr}\text { Equivocal, evolving and cumulative engagements } & 14\end{array}$

2 Noble gentleness, vile cruelty $\quad 17$

$\begin{array}{ll}\text { The sensibility of distinguished men } & 17\end{array}$

The banning of repugnant spectacles 20

3 To act as an enlightened philosopher 29

$\begin{array}{ll}\text { Neither sentimentality nor affectation } & 29\end{array}$

"From the point of view of self-interest properly understood" 33

4 To enlighten the ignorant, to refine the barbarian 39

A pedagogy of gentleness in order to prevent crime $\quad 39$

$\begin{array}{lr}\text { Discipline, reward and punish } & 46\end{array}$

$\begin{array}{ll}\text { Assisting the authorities } & 53\end{array}$

5 “Us," the animals and "them" 59

$\begin{array}{ll}\text { Repulsive beasts } & 59\end{array}$

$\begin{array}{ll}\text { Distinctive national virtues } & 62\end{array}$

The established, the challengers and the excluded $\quad 78$

6 The rise in the power of tenderness 93

Animality, equality, fraternity 93

$\begin{array}{lr}\text { Pets, refuges of intimacy } & 104\end{array}$

Imaginary beings and children's soft toys $\quad 121$

7 (Animal) victims and social domination $\quad 125$

At the heart of the revolt against the powerful $\quad 125$

Expose the torturers, help the victims $\quad 138$

$\begin{array}{ll}\text { Emotions, countermobilization, delegitimation } & 147\end{array}$ 
8 A decreasingly “wild” nature 157

From the exploitation to the contemplation of species 157

$\begin{array}{lr}\text { Technological ferocity, industrial slavery } & 171\end{array}$

$\begin{array}{ll}\text { Bringing moral philosophy up to date } & 177\end{array}$

$\begin{array}{lr}\text { Conclusion } & 185\end{array}$

$\begin{array}{ll}\text { Bibliography } & 187\end{array}$

A brief chronology 193

$\begin{array}{lr}\text { Index } & 197\end{array}$ 


\section{Introduction}

What motivates moral protest? Why do some individuals rally to the defense of others? How can we explain why some people are willing to offer their time and give money to improve the lot of creatures who are forgotten, and "without a voice"? The study of animal rights activism, like the study of humanitarian activism, is a good way of examining what underlies all militant movements which claim to be based on altruism, solidarity and other ethical principles. It should be noted from the outset that the animal protection movement is highly varied and complex. According to the records of the Conseil national de la vie associative, in France each year since 1998 an average of 532 associations, falling into the category of "friends of the animals," have been registered. This is equivalent to twice the corresponding figure for the period 1975 to 1990 . Although these statistics would seem to indicate that the animal rights movement has been expanding over recent years, a detailed analysis of militant organizations leads us to be wary of jumping to conclusions regarding the causes which lie behind this growth in activism. Indeed, any comprehensive survey of activists involves encounters with an amazing variety of individuals from all social backgrounds. There are the volunteers, often women, who work in animal refuges, where they take care of abandoned cats or dogs. Then there are the campaigners who concern themselves with the plight of endangered wild animals - such as whales, gorillas, rhinoceroses and polar bears - whose natural habitats may be thousands of miles away. There are also philosophy students who, on graduation, decide to champion animal rights or antispeciesism. ${ }^{1}$ There are also the vegans ${ }^{2}$ who, at Sunday markets, approach passers-by in order to draw their attention to the suffering inflicted on poultry by foie gras producers. In so-called alternative or autonomous punk circles, anarchists scream their disgust at the systematic exploitation of animals. So the range of militant activities engaged in by animal rights campaigners is enormous: feeding and taking care of animals; writing manifestos or works of moral philosophy; distributing tracts; producing documentaries - some intended to shock, others choosing to inform the viewer, using a more measured scientific tone, of the plight of certain wild species, as well as the fate of animals butchered for their meat, or used in laboratory experiments;

1 See below for an examination of what is meant by antispeciesism.

2 Vegans eliminate all animal products from their diets, not only meat but also eggs, milk, cheese and honey. 
organizing petitions; staging demonstrations outside bullrings, circuses, animal testing laboratories, as well as outside the premises of restaurant chains who source meat produced in factory farms; lobbying the authorities to make regulations to protect animals; organizing commando operations to liberate animals being used for testing purposes by the pharmaceutical industry, or, in the case of minks, being farmed for their fur.

Communicating a clear picture of the animal protection movement in all its complexity is further hindered by the fact that it is often associated with a number of stereotypes and sensational images. Indeed, this cause, which has a particularly long and complex history, seems destined to be reduced in the public mind to Brigitte Bardot's media outbursts, and night raids on mink farms by animal liberationists. In this essay we will seek to replace this reductive image, using a number of tools which will enable the reader to negotiate the labyrinth of the animal rights movement. With this objective in mind, the issues being examined first need to be placed in their historical context. Like a geologist who seeks to uncover the mysteries of the ground beneath their feet, the sociologist of the animal rights movement has to trace the history of successive sedimentations, sedimentations which have modeled the forms which contemporary activists reuse and adapt. "Historical sociology is a field which promises to enlighten us, and that is because it obliges the researcher to constantly historicize their reasoning, and take account of the 'dead hand of the past'" (Déloye, 2007, p. 23). Certainly, this approach is not unproblematic. The historical records available to the researcher can be scarce and patchy. While there is quite a lot of material in English covering the developments of campaigns to protect animals over the course of the 19th century, few French historians have chosen to work in this field. ${ }^{3}$ Given these gaps in the record, I decided to directly consult the archives in the French National Library, in particular the "Bulletins de la société protectrice des animaux," published between 1855 and 1937, and the "Bulletins de la sociétéfrançaise contre la vivisection" which appeared between 1884 and $1898 .{ }^{4}$ In conjunction with a survey of current activists - which will give rise to future publications - this archive work

3 We should mention, however, an excellent article by Maurice Agulhon, "Le sang des bêtes: le problème de la protection des animaux en France au XIX ${ }^{\mathrm{e}}$ siècle," Histoire vagabonde, vol. 1 (Paris, Gallimard, 1988), pp. 243-282; and Eric Pierre's history PhD thesis, Amour des hommes, amour des bêtes. Discours et pratiques protectrices dans la France du XIX $X^{e}$ siècle (University of Angers, 1998).

4 In the rest of the book the Bulletin de la société protectrice des animaux will be abbreviated as "BSPA," the Bulletin de la société française contre la vivisection as "BSFCV," and the Bulletin de la société impériale zoologique d'acclimatation as "BSIZA." 
will give us a valuable picture of the evolution of the animal rights cause over an extended period of time. Furthermore, the analysis of the evolution of collective mobilizations for the protection of animals sheds light on a number of phenomena at the heart of some of the classic concerns of political science, namely: mechanisms for the control of violence; the work of sociologist Norbert Elias; the role of moral entrepreneurs and judicial norms in the evolution of moral values; the development of philanthropy; the level of legitimacy of collective mobilizations; rivalries between groups whose status may be rising or declining; the way religious belief informs the views of political activists; the gendered nature of certain forms of activism; and the emergence of the ideologies of political ecology.

In order to better analyze the successive developments in animal rights campaigning this work, wherever possible, relies on a Franco-British comparison. It is further limited not only by its length, but also by lack of data and the extent of the author's historical expertise, which preclude an equally detailed treatment of the two cases. A more complete and nuanced account would extend further back in time, and include comparisons with other European and North American states, as well as with other countries elsewhere in the world, such as India and China. So the present survey can make no claims to being comprehensive. My objective when writing it was a more modest one: to convince the reader that the study of animal rights deserves much more attention than it has hitherto received. ${ }^{5}$

5 I would like to take the opportunity to thank Florence Faucher for kindly reading a first version of my manuscript. The responsibility for any errors and omissions in this work remain, of course, the author's. 



\section{$1 \quad$ A long and complex struggle}

\section{The pioneering influence of the British model}

Although England is commonly credited with the invention of modern sport (Elias and Dunning, 1994), the role of the British in the genesis of the animal protection movement is less well known. It is, nevertheless, a well-established fact that any campaign to improve the way humans treat animals can trace their origins to the work of 19th-century English activists. As early as 1809, a group of prominent Liverpudlians set up the Society for the Suppression of Wanton Cruelty to Animals. Although this society soon folded, a similar organization, founded in London in 1824 , was destined to be less short-lived: the Society for the Prevention of Cruelty to Animals still exists today, and indeed is still the largest animal welfare organization in the world. In the period after its formation the SPCA quickly managed to attract the support of many respected individuals, including members of the aristocracy and prominent figures from the ranks of the upper-middle classes, as well as numerous clergymen and members of Parliament. In 1840 the society obtained the patronage of Queen Victoria herself, which led to its adoption of its current name: the Royal Society for the Prevention of Cruelty to Animals (RSPCA). Embraced by large sections of the Establishment (Harrison, 1973), ${ }^{6}$ "the RSPCA became perhaps the most influential voluntary organization in Great Britain in the second half of the century" (Turner, 1980, p. 177). These animal rights pioneers were largely preoccupied with lobbying legislators, and campaigning for the introduction of laws which, by banning certain practices, would change public attitudes. Indeed, even before the foundation of the RSPCA, a number of its founder members had participated in campaigns to put pressure on Parliament to enact legislation for the protection of animals. In 1821, a group of MPs led by Richard Martin, and including William Wilberforce and Thomas Fowell Buxton, introduced a bill "to prevent the cruel and improper treatment of cattle." A law was enacted the following year, largely thanks to the support of the clergy and a group of London magistrates. An "Act to Prevent the Cruel and Improper

6 In current usage, "The Establishment" is a contested term. In this book it will be used to indicate the 19th-century British ruling classes, comprising the Crown, the Royal Court, members of the aristocracy, the Church, members of Parliament, the Judiciary, Oxbridge, the heads of the armed forces, as well as top bankers, industrialists, business leaders, and City financiers. 


\section{Graph 1}

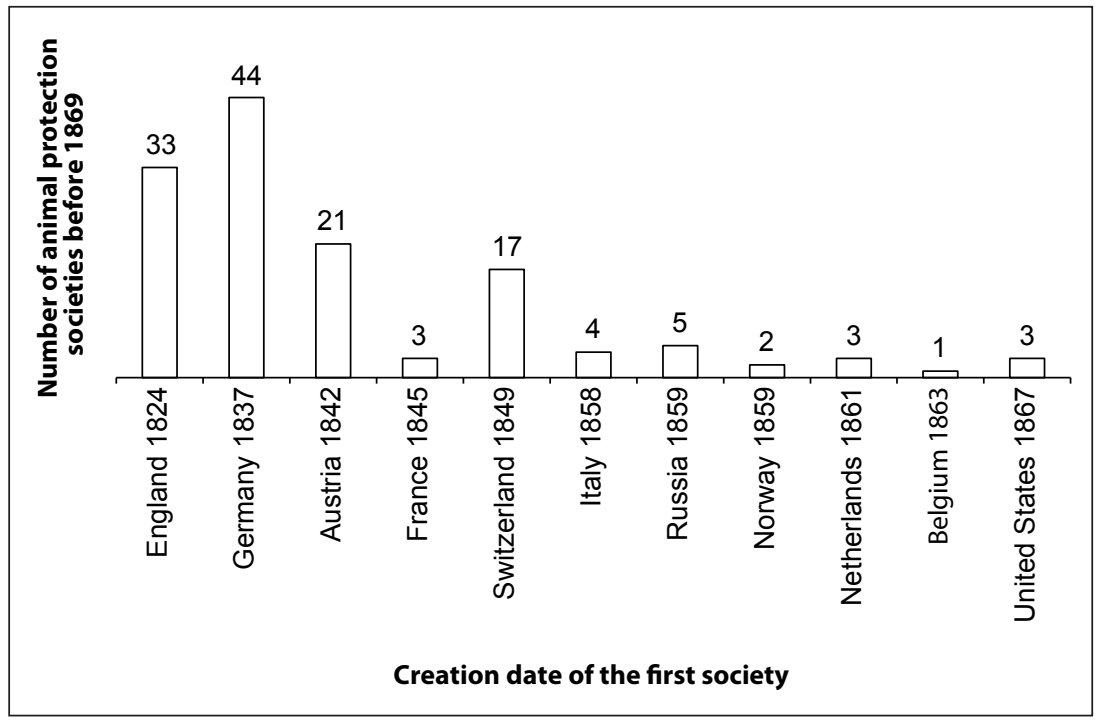

Source: Graph plotted by the author using a list published in 1868 by the Bulletin de la société protectrice des animaux (BSPA)

Treatment of Cattle," also known as "Martin's Act," protected only "horses, mares, geldings, mules, asses, cows, heifers, steers, oxen, sheep and other cattle."

The presence of prestigious supporters among the RSPCA membership provided a model which groups in other countries sought to emulate. Societies for the protection of animals were soon established in Germany, Austria and Switzerland. Other countries, which seemed to be lagging behind, were targeted by British campaigners. In 1834, Sir John de Beauvoir, an RSPCA committee member, traveled to Paris with the mission of encouraging the creation of a sister organizations in France. It was not until ten years later, however, that the Société protectrice des animaux (SPA) was set up in Paris, later followed by groups in Lyon and Fontainebleau. One of the founders of this new society was Viscount Pinon Duclos de Valmer, who "married an Englishwoman and, during his stay in London, took the opportunity to observe the SPCA at work" (Pierre, 1998, p. 290). The founding statement of the SPA, written on 2 December 1845, makes clear its intention to model itself on well-established foreign organizations: "We hereby found, in Paris, a society which, like those already existing in Bavaria and England, aims to pursue, by all means at our disposal, the outlawing of maltreatment of 
animals." By 1855 , the Paris branch of the SPCA already had six representatives of the London RSPCA among its honorary members (BSPA, 1855). In 1891, Queen Victoria made a donation of 2,500 francs to help set up a branch SPA in Biarritz, with Princess Frederica of Hanover as its patron (Fleury, 1995, p. 161).

In Italy the creation of societies modeled on the RSPCA also owed a lot to the involvement of British people, shocked by the maltreatment of animals which they had witnessed while holidaying in the "Bel Paese." Their indignation caught the attention of polite society in cities such as Florence, Turin, Rome, Naples and Brindisi (Tonutti, 2007, p. 73 and 81). Even in countries where British campaigners were not directly involved in the creation of societies for the protection of animals, they still often exerted influence through the experience and expertise they were able to offer fellow activists on the Continent. In Amsterdam, in 1859, the British Consulate in the Netherlands received a request for details of the British law relating to the protection of animals, with a view to similar legislation being enacted in the Netherlands. In Belgium, the RSPCA was consulted prior to the drafting of legislation outlawing the cruel treatment of animals. The birth of the animal protection movement in the United States was also inspired by the English model. Henry Bergh, the son of a wealthy New York shipbuilder, and a key early figure in American animal advocacy, was deeply shocked by the treatment of animals in Russia, where he had witnessed several shocking incidents of cruelty to animals during a brief appointment as a diplomat in Saint Petersburg. On his way back to the United States from Russia he made a stopover in London, where he attended a meeting of the RSPCA. He was very favorably impressed, and in the following year, 1866 , created the American Society for the Prevention of Cruelty to Animals (ASPCA).

On the other side of the English Channel, in Paris, the beginnings of a similar movement saw the establishment of an animal protection society, as well as the adoption of legal provisions which made the mistreatment of animals punishable by the law. In 1850 General Jacques Philippe Delmas de Grammont introduced a bill which was clearly inspired by the objectives laid out in the founding articles of the SPA. The loi Grammont (Grammont Law) which was put onto the statute books on 2 July 1850 , provided for the punishment, by a fine of between 1 and 15 francs and a prison sentence of one to five days, of "persons guilty of publically maltreating animals" (Agulhon, 1988). Once more, although the protection offered was limited to domestic animals, this legislation established an important precedent for animal protection legislation for the remainder of the 19th century. 
In the final quarter of the 19th century, British campaigners were again at the forefront of efforts to regulate the use of vivisection for scientific experimentation. As we will see, the protests around this issue provide a clear demonstration of the main reorientations of the movement, without which we cannot understand the complexity of present-day animal rights cause. In London in 1875 Frances Power Cobbe founded the Society for the Protection of Animals Liable to Vivisection. The Society for the Abolition of Vivisection was set up soon afterward. The following year the RSPCA noted that there already existed ten antivivisection associations in England (Tonutti, 2007, p. 55). Once again, like-minded people in other European countries were largely inspired to set up similar organizations by the example of British pioneers. By 1885 there were twenty-six antivivisection societies in Europe: fifteen in Great Britain, three in Switzerland, two in Germany, and two in France (BSFCV 3 [1885], p. 52). The translation and distribution of British antivivisection pamphlets by campaigners, eager to have an impact on public opinion, extended the influence of the British model across Europe. In Germany and Switzerland (Tröhler and Maehle, 1987), as well as in Sweden (Bromander, 1987), vivisection was widely discussed and debated in the national parliaments. In France, however, in spite of the creation, in 1883, of the Société française contre la vivisection and the Ligue populaire contre la vivisection, antivivisection campaigners struggled to generate interest in their cause among the wider public. Once more, the members of the Société française contre la vivisection declared that their movement was an extension of the struggle initiated by like-minded British people.

But, given that we here in France want to closely follow the generous example offered to us by our neighbors on the other side of the Channel, our French society must do more than make a vague statement of aspirations, and develop a clear strategy for tackling the serious problems it seeks to resolve. (BSFCV 1 [1884], p. 4)

\section{Equivocal, evolving and cumulative engagements}

Emphasizing the essential contribution of British trailblazers is not to suggest that the first animal protection movements were the work of anglophiles, who were simply mimicking their neighbors from across the Channel. Our brief historical summary was intended to stress, as a preliminary point, that the cause of animal protection has always been a transnational movement. As a consequence of this, it is indispensible to clearly distinguish 
watchwords used internationally from forms of appropriation which vary considerably in different national contexts. To this first level of complexity it should be added that campaigns claiming to be motivated by a desire to protect animals have always been deeply ambiguous. By that we mean that analysis of the organization of campaigns reveals a host of reasons and motives. $^{7}$ Under such conditions the historical sociology of Nobert Elias seems to us to provide with the best theoretical tools for taking account of the interdependent evolutions, which involve multiple heterogeneous configurations. We decided to analyze the history of the animal rights movement from this perspective, as a cumulative succession of forms of indignation over the ways animals are treated. Thus, throughout this book, we shall endeavor to identify what it is about the treatment of animals which appears - in the eyes of a generation, or group of activists - to be sufficiently improper, scandalous or disturbing to warrant the organization of collective action, with the aim of putting a stop to that particular practice. ${ }^{8}$ Our analysis will therefore attempt to identify the sociological conditions which lead to a situation where certain individuals feel that there is an intolerable discrepancy between what is and what ought to be. The fact that we accord attention to sociological factors in no way implies a conception of individuals as passive agents of superior and irresistible forces. Indeed, our guiding hypothesis, which in itself constitutes an implicit rejection of mechanical determinism, is that animal protection activists, through their militant engagements, actively endeavor to transform affective states which are unpleasant, even distressing, into opportunities for experiencing socially valued and gratifying emotions. For this reason we will explore at some length the sensitizing devices used by militants at various points in the history of the animal rights movement. By sensitizing devices, we mean to refer to "all the material support, the placement of objects, and the staging techniques that the militants exploit, in order to arouse the kind of affective reactions which predispose those who experience them to join or support the cause being defended" (Traïni, 2009, p. 13). This concept is useful in

7 I use reasons to indicate the causes and justifications that militants refer to in their discourse, in order to emphasize the seriousness of their engagement. Motives, on the other hand, refers to the determinants of the engagement, which do not generate discursive justifications from the actors being studied but have been reconstituted by the researcher, as hypotheses, using the cross-checking of information gathered during the course of his investigations.

8 In other words we will make a detailed study of the contexts of this scandalization, or calls to act virtuously, which, along with appeals to the greatest number and to the lessons of science, constitutes one of the three ways in which collective causes are publicized and legitimated (Offerlé, 1994, p. 112). 
that it obliges us to make a clear distinction between, on the one hand, the emotions that moral entrepreneurs endeavor to generate in order to attract support for their cause, and, on the other hand, the affective reactions actually generated, which may be different from the reactions the activists themselves anticipated. In fact, the sensitizing devices generally provoke a range of equivocal and ambivalent emotions which escape the control of those who stirred them up. As a consequence, as we shall see, mobilizations and countermobilizations are interdependent, and militant engagements can have social effects which go far beyond their original strategic aims. 


\section{$2 \quad$ Noble gentleness, vile cruelty}

The first societies dedicated to animal protection were notable for the respectability and prestige of their supporters, the high membership fees putting off less wealthy potential members. In the 1830 s the RSPCA could boast as members not only Queen Victoria but also her mother, the Duchess of Kent, as well as numerous eminent and rich individuals, including the fabulously wealthy Quaker banker Samuel Gurney (Turner, 1980, p. 44). The Parisian SPA, for its part, enjoyed the support of such prominent personages as Prince Jerome Napoleon and his sister Princess Matilda, Prince Adalbert of Bavaria, Grand Duke Nicholas of Russia and the bankers James and Arthur de Rothschild, as well as Alexis de Tocqueville (Fleury, 1995). This would indicate that any investigation of the sociogenesis of animal protection needs to analyze the evolution of the emotions and conduct accepted and valued by the upper echelons of society. In this connection the work of Elias once more provides a particularly pertinent and didactic theoretical framework.

\section{The sensibility of distinguished men}

The sociology of Norbert Elias calls for the taking of certain methodological precautions, which have been examined elsewhere (in Heinich, 1997, for example). Here I will confine myself to recalling a number of principles which are indispensible for the analysis of the motivations underpinning the animal welfare movement. The key insight of the German sociologist in this regard was to draw attention to the indissociable nature of two series of evolutions which, because of the misleading dichotomy drawn between sociology and psychology, had been considered separately. They were, on the one hand, the centralization of power and the monopolization of legitimate violence by state and judicial institutions, which had the task of resolving conflict following codified and predictable procedures, and, on the other, the evolution of manners or, more precisely, of thresholds which defined what kinds of behavior were or were not to be tolerated in society. By the expression "The Civilizing Process" Elias indicated a general widespread trend whereby certain behaviors, which were once acceptable, come to be regarded as improper, inappropriate, shocking, even disgusting. One particular historical trend saw violence and public and bloody physical confrontations increasingly become regarded as unacceptable. This led in 
turn to the depreciation of the "desire to attack" (Angriffslust), the lowering of the threshold of tolerance toward aggressiveness, which accounts for the increasing prohibition of not only actual violence, but also the removal of the right to witness violent acts as a spectator. Generally speaking "Elias noted that the propensity of people to derive pleasure from participating in or directly observing acts of violence was in long term decline in Western Europe" (Elias and Dunning, 1994, p. 314). This evolution clearly manifested itself in the gradual disappearance of such practices as duels, vendettas and other examples of private justice, as well as the use of the stocks, torture and public executions.

The civilizing process is by no means limited to a growing revulsion at attacks on the physical integrity of the human body. It also extends to a growing tendency to take offence at the visibility of natural bodily functions. In this connection we can note that the norms offered to readers of books of etiquette in the Middle Ages differ significantly from the advice given in equivalent modern manuals regarding such questions as how to sit properly at the meal table, how to talk about one's sexual needs, and how to wipe one's nose, spit, urinate or defecate. Many acts which used to be performed in public without the slightest embarrassment called for more and more discretion. Given the analysis that follows it is necessary to point out, at the risk of putting off the reader, that this evolution in thresholds of tolerance explains the increasing repulsiveness ascribed to blood, as well as sweat, mucus, spittle and feces. We should note that this general trend also led to a growing propensity for death to be considered as a "dirty and unseemly" thing (Ariès, 1977, p. 277). Symbolic representations of death, the dying, and rotting dead bodies used to be an integral part of daily life. Many ritual practices contributed to making the end of life a familiar, if still harrowing, phenomenon. As the civilizing process proceeded, familiarity with death was replaced by the development of feelings of shame, embarrassment and repulsion, leading to the dead and the dying to be screened from view. In the modern world death is regarded as strange and monstrous, requiring it to be kept away from public life, thus depriving individuals of collective emotional conventions which may help them to come to terms with it (Elias, 1987).

In focusing on what he calls the curialization of warriors, the German sociologist draws our attention to a crucial fact, namely that the original impulse behind the civilizing process originated from within the ruling elites of the European monarchies (Elias, 1975). This was because it was these very elites who were the first affected by the decreasing use of war as a means to resolve conflicts: the power of a small number of princely houses 
were no longer regularly threatened from all sides, dueling was replaced by the king's justice, civil war by parliamentary debates, and vendettas were banned after the establishment of a system of tribunals and forces of law and order. Previously, in the age of chivalry, nobles were required to display the knightly qualities needed to survive and win the succession of battles which determined the fate of their houses. As societies became more peaceful, bravery in combat, martial zeal and even the cruel streak required to strike fear into one's opponents no longer appeared to be the qualities required to win the esteem of the people who mattered. As the ability to behave in an aggressive and spontaneous fashion came to be of limited value those moving in higher circles had more regard for individuals who were discreet, self-controlled, measured, thoughtful, and tactful in their dealings with others. Gentlemen were now refined individuals with a gracious and delicate bearing, capable of feeling and appreciating in others discreet and subtly expressed emotions. Expressions of anger and explosions of rage, which in Ancient Greece were expected of great men, were now associated with men of coarse and contemptible character. In order to make his mark in society a gentleman was required to demonstrate the ability to not only repress his most powerful feelings, but also to express, using the established codes, the emotional states which showed that he possessed the required degree of self-control.

Though from a different theoretical perspective, Albert Hirschman brilliantly demonstrated the extent to which the decline in the acceptability of the loud and explosive expression of passionate feelings facilitated the emergence of the economic thinking characteristic of capitalism. Discussions of the "Civilizing Process" and the development of the "Spirit of Capitalism" both mention as integral to these processes a growing aversion to affective reactions with potentially harmful consequences, as well as a common appreciation of inoffensive, constant and predictable conduct, especially when they seem to be universally shared. While Elias examined the evolution of conditions within the ruling elites, Hirschman was concerned with retracing the intellectual history at the origins of a "new distinction which sets up in opposition the interests of man and his passions, [and which now] contrasts the happy consequences of activities dictated by interest with the calamities which follow from giving free rein to passions" (Hirschman, 1980, pp. 33-34). This led to "lucrative activities such as commerce and banking - which had been disapproved of and held in contempt for centuries, because they were seen as the incarnation of greed, the love of money and avarice - coming to be regarded as honorable" (Hirschman, 1980, p. 13). For Max Weber, the fact that this complex set of 
developments was as much about morality as economic practices was linked with the rationalization and secularization of Christianity evidenced by the development of Protestantism (Weber, 1999).

Over the following chapters the theoretical framework suggested by the work of Elias, Hirschman and Weber will be indispensable for our account of the succession of developments which have influenced the directions taken by the animal welfare cause, from its earliest beginnings to the present day. In contrast to metaphysical historicist approaches, we will examine the influence on the evolution of sensibility thresholds of the accumulated efforts of a succession of moral entrepreneurs with very different sociological profiles. In retracing the various key contributions and reorientations which have marked the history of the animal cause I hope to clarify an aspect of this history which Norbert Elias failed to address satisfactorily: his analysis, in focusing on the evolution of sensibilities within the upper classes neglected to discuss in detail the mechanisms which led to the diffusion, appropriation and modification of these sensibilities within increasingly wide sections of society.

\section{The banning of repugnant spectacles}

The first stirrings of the animal protection movement coincided with the birth of urbanization, industrialization and the capitalist economy. Once again, these changes occurred first in Great Britain, several decades before they reached other European countries. "In 1851, for the first time in British history, more people were living in towns and cities than in rural areas" (Charlot and Marx, 1978, p. 85). While in 1801 city-dwellers represented only $16.9 \%$ of the British population this figure rose to $50.1 \%$ in 1851 and then $72 \%$ in 1891. This increasing concentration of the population in urban areas was, as is well known, a result of the industrial revolution, which, as Friedrich Engels noted, began in England "with the invention of the steam engine and machines used in cotton production" (Engels, 1960, p. 21). The undoubted importance of these technological innovations should not, however, lead us to imagine a new urban environment where the cohabitation of humans and animals, characteristic of rural and agricultural life, swiftly became a thing of the past. In fact, far from being replaced by machines, animals were still very present in urban contexts, principally because economic and demographic change led to the large-scale trading in and transportation of cattle for the purposes of feeding the new urban populations. Slaughter animals continued to be raised in the countryside, but they still had to be 
transported to and butchered in the cities, where their meat was consumed by the ever-growing urban populations. Moreover, draught animals greatly contributed to the development of the first waves of industrialization by transporting the raw materials and the finished products to and from the centers of industrial production. Certainly, with the growth of the railway network, animal-drawn transportation was progressively replaced by the train, but horses, mules, donkeys and oxen remained indispensible for the short distance haulage needs of numerous sectors of the economy. Thus, in the urban zones where trade and industry flourished there was a constant traffic of carriages and carts transporting goods for, among others, the mining, wool and brewing industries. Furthermore it should be added that, before the introduction of the internal combustion engine at the beginning of the 2 oth century, urban dwellers were reliant on hackney carriages and other horse-drawn vehicles for their own transportation needs. So, it was in this context that the exposure of the urban upper classes - with their distinctive sensibilities - to the shocking, noisy and malodorous spectacle of the exploitation of animals significantly contributed to the birth of the animal protection movement.

In fact, many of the protests by early animal welfare activists were manifestations of NIMBYism avant la lettre. Indeed, individuals were scandalized not by the suffering of animals per se, but by the fact that it occurred in public places, and that the sensibilities of delicate gentlemen could therefore be exposed to shocking and repugnant spectacles of ill-treatment. It was this assault upon their senses which caused delicate individuals to roundly condemn the sight, noise and smell caused by the manner in which their fellow, more coarse citizens behaved toward animals.

In this connection, the affective reactions to the way animals were butchered were highly revealing. In fact, for Norbert Elias, the clearest indications of the evolution of sensibilities could be found in such apparently insignificant phenomena as changing attitudes to food, and to meat in particular. "The way meat was presented at table changed considerably between the Middle Ages and the modern era. The nature of these changes is most instructive. The upper echelons of medieval society had whole animals or quarters of meat brought to the meal table. This was the usual way of serving fish, birds - sometimes unplucked - hares, sheep and calves. Large game, pigs and oxen would be roasted whole on a spit (Elias, 1973, p. 169). For the elites, who prided themselves on their martial and hunting prowess, there was nothing disgusting about cutting up a large piece of meat which closely resembled a live animal. On the contrary, as late as the 17 th and even the 18th century, etiquette manuals stipulated that the ability to 
carve up a whole animal was a skill required of a well-brought-up man. At the beginning of the 19th century, though, when the moral protests which concern us started to make themselves heard, the quartering of an animal began to provoke very different affective reactions. "The orientation of this change was very clear: the original norm, whereby the sight of a dead animal being carved up at the meal table was regarded as agreeable, or at least in no way unpleasant, was replaced by another norm which dictated that the connection between a plate of meat and a dead animal should, as far as possible, be forgotten" (Elias, 1973, p. 171).

In England, this evolution is clearly reflected in the criteria applied to the preparation and naming of meat. In the 16 th and 17 th centuries the increasing use of horses as draught animals facilitated a rise in the consumption of beef, to the point where roast beef came to be considered as a symbol of the nation. Nevertheless, British people's taste for rare meat was subsequently largely replaced by a preference for boiled meat, whose appearance was less evocative of a butchered animal (Thomas, 1985). It is, moreover, significant that the English language often has two different words for an animal and its meat - ox / beef; calf / veal; sheep / mutton; pig / pork - a semantic subterfuge which helps one forget that the meat is the product of a process which includes the violent butchering of a live animal. In France, a similar evolution was behind the setting up, in 1809, of the first abattoirs. Before then butchers would slaughter animals near their market stall, behind their shop, or even in a nearby street, leaving animal blood and guts on the ground in full view of passers-by (Agulhon, 1988). As sensibilities changed the sights and situations created by these practices increasingly became regarded as intolerable. As well as the unpleasant sight of blood and eviscerated carcasses there was also the risk of wounded animals escaping and running down the street, knocking over everyone and everything in their paths. In order to remove this butchery from the troubled gaze of passers-by and people living in the neighborhood the authorities decided to set up premises on the outskirts of Paris purpose-built for the slaughter of animals. These places were called "abattoirs." Once again, an activity which had been long regarded as acceptable and normal came to generate a level of disgust which required it to be hidden and confined to places out of the public eye. The removal of these practices from the public view contributed to intensifying the defamiliarization with and repugnance toward violence and the butchery of animals.

Certain evidence clearly indicates that the evolution of sensibilities regarding the deadly violence used in the production and preparation of meat for human consumption was a significant motivating factor behind 
the earliest animal welfare activism. Consider, for example, a speech made at a meeting of the Society for the Protection of Animals on 4 April $185^{2}$. According to one of the zoophiles present, ${ }^{9}$ the SPA needed to continue its struggle, in order to make further progress, as its achievements to date were insufficient and risked being overturned.

The creation of five abattoirs in Paris under the reign of Napoleon I certainly performed a great service to the population in terms of food safety and public health. Our eyes are now no longer treated, as they were at the beginning of the century, to the distressing sight of blood flowing along in the gutters of the city, in particular in the streets adjacent to the butcheries of Saint-Honoré and Saint-Germain, among others. We no longer have to suffer the pestilential, nauseating and putrid smells which rose up, with a particular intensity in the warmer summer months, from these narrow, winding scenes of slaughter, which, even after being rinsed down with abundant bucketfuls of water, still left an unhealthy smell in the air. It was also formerly the case that, on certain days of the week, the melting of tallow in scalding tubs gave off a stench of vile fumes, tormenting those unfortunate enough to live in the in or near the same building as a butcher. (Huré, 1855 , pp. 48-49)

A British visitor, who had been sent by the RSPCA, echoed these sentiments and stressed the importance of the setting up of abattoirs, which did not yet exist on the other side of the English Channel:

Ours was certainly the Mother society, and yours the daughter, but, as often occurs, Sirs, with parents and children, the latter may turn out to be better than their predecessors, which indeed seems to happened here in the case of your society [...]. Without wishing to flatter your country, or accuse my own of negligence and indifference, I feel oblige to admit, since a good cause can only benefit from the truth being told, that France has overtaken England with regard to the level of humanity shown toward animals. For centuries, and up to the present day, we have allowed animals to be goaded through crowded streets to the central market, named Smithfield Market, which is terribly overcrowded. There they are beaten, covered in bruises and maimed for hours on end. In your country, on the

9 We should point out that at that time the term "zoophile" did not carry any of the clinical and pejorative connotations is it would subsequently acquire in France. On the contrary, zoophilia was initially considered to be one of the most advanced kinds of philanthropy. 
contrary, such animals are never forced to walk through the streets and tortured by being squashed together in a central market; you have decent abattoirs on the outskirts of the city. (Huré, 1855, pp.15-16)

Indeed over a number of years there had been a succession of protests and campaigns calling for the closure of London's Smithfield Market (Kean, 1998). Each week 35,00o sheep and cattle were driven through some of the more chic parts of the city, before reaching their destination: a butcher's stall in Smithfield Market, which was located in the heart of the city. The people who lived along the routes taken by these animals were horrified by the spectacle of cattle being shouted at and beaten by their drivers. Many of those who lived in the immediate vicinity of the market complained about the horrible, sinister, nightly din, produced by large numbers of distressed and sick animals herded together in cramped conditions. Her Majesty's subjects were indignant at seeing the French give the British a lesson in common sense, and called for all butchering activities to be moved to the outskirts of the city, exactly as had been done in Paris. In 1828 a petition presented in Parliament calling for the closure of Smithfield Market was signed by many tradesmen, bankers and local people, but also by some of the pioneers of the animal protection movement, including Richard Martin who, six years earlier, had been instrumental in the passage of the first ever piece of animal protection legislation.

Of course, the fact that Paris had abattoirs before London did not constitute a real challenge to the British SPA's reputation as pioneers of the animal protection cause. Indeed, at a meeting of the French SPA on 4 April $185^{2}$ it is clear that no one took the kind words of their English guest at face value:

I desire more than I hope that this premature praise will one day be deserved [commented the Chairman of the meeting]. For now, however, I see no one worthy to be the recipient of such praise. Animals, calves in particular, continue to be driven, if no longer through our streets, then still along the boulevards which encircle the city, tied, bound and tortured, in carts which are frequently too small to accommodate the number of beasts which are crammed into them. (Huré, 1855, p. 16)

In fact these arguments were not new: the topic had often been used in questions for the entrance examination of the Institut de France, founded en 1795, which, in 1802, asked candidates for the morality essay prize to answer the following question: "To what extent is the barbaric treatment of animals a matter of public morality? and should laws relative to such behavior be passed?" 
Who has never, while trying to enjoy a quiet day alone [complained one of the exam candidates], been unexpectedly and unavoidably confronted with the sight of a butcher - covered in blood, armed with a knobbly stick, and accompanied by ferocious dogs foaming at the mouth - indiscriminately beating animals who, stunned by the noise, let out horrible bellowing sounds. (Quoted in Pelosse, 1981, p. 13)

The unseemly behavior of tradesman and butchers had long provoked indignation and continued to do so over an extended period. The gradual confinement of violence to within abattoirs had the effect of lowering thresholds of sensibility, so leading people to come to be shocked by practices which they had previously found quite acceptable. In 1875, a member of the SPA complained that in his country insufficient advances had been made in this area: "future generations will be puzzled by the fact that in this century, marked by so much social progress, we have remained, as regards our relations with animals, in state of barbarism. I invite you to visit and observe the situation in our markets, great and small!" (BSPA, 1875, p. 114). We should note that it was an aversion to the public visibility of blood and the bruised bodies of animals which caused the first animal welfare activists to call for the banning of practices which had been long considered to be perfectly normal. Further clear evidence of this can be found in the campaigns launched against the use of dogs as draught animals. Criticisms of this practice were not essentially a show of sympathy for this domestic animal. In fact, those who condemned this particular use of dogs were first and foremost critical of the repugnant spectacles which resulted from this practice. Dogs were forced to drag loads which were far too heavy for animals of their size and strength. Individuals who could not afford to buy a horse, a mule or an ox would overload the carts which the dogs were pulling, causing the exhausted animals to become deformed. Thus, at a meeting of the RSPCA in June 1854, the Marquess of Westminster, after arguing that this use of dogs was inappropriate from a technical point of view, denounced the repugnant fact that "the soles of the animals' paws, which carry a lot of weight, come into contact with pebbles and stones, causing such bleeding that the vehicle [they are pulling] leaves a trail of blood behind it" (BSPA, 1855). ${ }^{10}$

10 In England the RSPCA managed to obtain the prohibition of the use of dogs as draught animals in 1839. The French SPA were behind a similar ban in the region of Nord et Pas de Calais in 186o (Fleury, 1997), but the practice continued in many French departments, as evidenced by a number of prefectoral orders, made in 1895, prohibiting dogs to be used for this purpose since "the states of exhaustion which these animals are forced to suffer make them more vulnerable to rabies, particularly when they are on heat" (BSPA, 1895, p. 81). 
Nevertheless, throughout the 19th century, it was the treatment meted out of horses which generated the most indignation among animal welfare activists. Because of their imposing stature and extensive use for the transportation of both passengers and freight, horses were an ever-present feature of the urban landscape, even in the narrowest of streets. Furthermore, going as far back as to ancient times, the association of horses with the aristocracy made them a symbol of nobleness. Many nobles thus regarded the manner in which horses were exploited solely for the maximization of economic returns as an undeserved fall from grace of an animal previously associated with the social preeminence of their own class. The capitalist economy initially developed in an anarchic fashion, and large numbers of horses found themselves in the hands of a "sort of lumpenproletariat who were coarse and without any education or qualifications, and who relied solely on the whip and insistent clamorous shouting" (Agulhon, 1988, p. 250). Beasts of burden were usually under the control of workers who were themselves exploited and put under pressure by bosses eager to make quick profits. In such a context, it was rare for coachmen and carters to show any concern for the fate of these animals, which they tended to regard as no more than simple tools placed at their disposal. These attitudes led to frequent scenes where carters ill-treated their horses which, after being starved, injured and overworked to the point of total exhaustion, finally collapsed and lay dying for hours before anyone took the trouble to remove them from the thoroughfare. Those who witnessed such scenes were as angered by the drivers' foul language as by their physical abuse of the horses. The survival in the French language of the expression "to swear like a carter" is evidence of the impression left by the coarseness of the language they used. What was even worse was that their excessive use of the whip caused a horrible and exasperating atmosphere to prevail in cities and towns. Thus, in 1839, Frances Maria Thompson, one of the patronesses of the Animal Friends' Society, complained that: "acts of cruelty committed in our streets have become so frequent that every time one leaves one's home one is confronted with scenes which shock and hurt our feelings" (Kean, 1998, p. 6o). In France, Dr. Dumont de Monteux was motivated to organize the protests which led to the foundation of the SPA as a direct result of the moral shock he had suffered on witnessing a carter subjecting a horse to abuse. ${ }^{11}$ Scandalized, this upstanding citizen wrote to the Paris

11 Regarding the care which needs to be taken in the use of the term moral shock, which is sometimes used by specialists in collective action to explain the recruitment to certain causes, I would direct the reader to an earlier article (Traïni, 2010). 
Prefect of Police a letter which was subsequently published in La Réaction agricole. The successful mobilization of public opinion was such that on 5 October 1843 the Prefect of Police signed an order making it a criminal offence to strike a horse with the handle of a whip (Fleury, 1995, p. 20). Just over two years later the same Dr. De Monteux drafted the statutes of the SPA, which was set up largely in order to continue to campaign against the maltreatment of horses. The suppression of repugnant scenes involving the abuse of horses remained a constant preoccupation of the society and its members right up to the beginning of the 2oth century, when horse-drawn vehicles came to be largely replaced by motorized transport. Thus in 1876 "the SPA Committee for Horses recommended that a prize of 500 francs be awarded to the inventor of the best machine for the transportation of wounded horses" (BSPA, 1876, p. 122). Nearly thirty years later, in 1904, the protection society had at its disposal "two vehicles for the transportation of wounded horses [...] placed at the disposal of the public, day and night, and free of charge" (BSPA, 1904, p. 179). The same year the board of the SPA decided to finance the creation of two new relay stations for horse-drawn vehicles to add to the five that were already in existence. Over a period of just over a year these stations, located at the foot of the steepest streets in Paris, facilitated 18,554 ascents of urban inclines by offering assistance to teams of horses pulling heavy loads.

It should be stressed that the measures recommended by the first animal protection campaigners were aimed less at decreasing animal suffering than at prohibiting those scenes of exploitation likely to shock the sensibilities of passers-by and local residents. In the light of this it is unsurprising that the Martin Act and the Grammont Law only punished ill-treatment of domestic animals carried out in public. This would suggest that the campaigning of animal protection activists may be seen as being a continuation of the same trend as the setting up of abattoirs, insofar as it led to the banning from public spaces of scenes of animal exploitation which involved violence, bodily injury and slaughter. In prohibiting the public display of long-familiar practices, in the name of protecting their own delicate sensibilities, members of the animal protection movement contributed to the lowering of the tolerance threshold toward violence among increasingly broad sections of society. 



\section{To act as an enlightened philosopher}

\section{Neither sentimentality nor affectation}

In England, the early defenders of the animal welfare cause tended to enjoy close relations with members of the judiciary and the clergy. Most of their French counterparts, on the other hand, were doctors and veterinarians, working in alliance with aristocratic landowners who had been reduced to managing their country estates, having been sidelined by the July monarchy (Pierre, 1998). Indeed among the ten founding members of the SPA - to whom, almost forty years later, the society's membership would pay tribute - there were no fewer than six doctors, two veterinarians and an agronomist (BSPA, 1881). Representatives of these professions continued to wield a great deal of influence well into the last quarter of the 19th century, and the SPA would accordingly present itself in terms of its essential contribution to the progress of the applied sciences

[The works of the SPA] can be put into two categories. The first involves the definition of your mission, explaining its significance, making it popular and attractive, generating righteous fervor; they constitute your literature and your philosophy. The rest of your work, which is within the domain of the applied sciences, addresses particular questions concerning the methods of application, in real life, of your declared principles. (BSPA, 1855, p. 104)

Thus, in the early days of the SPA the society made annual awards, promoting inventions and apparatuses which, by reducing all counterproductive suffering, facilitated the work of domesticated animals. In 1875, for example, the society honored the designers of a variety of devices, including a drinking bottle for helping horses swallow medicine, a collar to protect young chicks from being attacked by cats and other small predators, a spring-loaded trap to be used by clay pigeon shooters, and a new muzzle which was lighter and less likely to hurt the animal wearing it than previous designs (BSPA, 1875, p. 182). Henri Blatin, a doctor who was for many years a leading figure in the association, himself invented a number of devices which ensured that if a draft horse collapsed the tongue of its harness would become unbuckled, and the animal immediately freed of its heavy load. Veterinarians within the SPA were able to participate in broader initiatives which aimed to have the work of veterinarians recognized as an activity requiring scientific 
expertise gained through studies, which led to a professional qualification (Hubscher, 1999). The promoters of veterinary science, which had hitherto been considered an auxiliary activity in the field of agronomy, undertook to distinguish the work of professional veterinarians from the less prestigious work of blacksmiths, as well as clearly disassociating veterinarians from the numerous healers, bonesetters, and medicine men operating in rural areas, who claimed to be able cure animals of their various ailments. Thus, one SPA member, when calling for the work of veterinary medicine to be recognized as a science, roundly condemned the "the widespread negligence and ignorance of those who treat sick animals [...], the empirics who, despite having no medical training, prescribe remedies prepared in an irrational manner, to the great detriment of the owners of animals and the public purse" (BSPA, 1855, p. 178). The monthly meetings of the SPA provided a forum for preparing arguments, to be presented to the French authorities, for reserving the medical treatment of animals to practitioners who had the requisite scientific training. Here "science" was understood in terms of its capacity to operate free of the irrational prejudices, beliefs and superstitions which had too often shaped mankind's dealings with animals. Animal protectionists, drawing on their scientific worldview, were proud of their ability not to be influenced by impulsive emotional reactions which could undermine the progress of reason and humanity.

Allow me to acknowledge something, namely that hitherto you have admirably managed to avoid a trap which lies in wait for all the best causes, for nobody can accuse you of either sentimentality or affectation. You have enhanced the reputation of the animal protection cause by guiding it into the domains of science and industrial applications. (BSPA, 1855, p. 7)

While harsh treatment of animals offends the sense of justice present in all our hearts, we are equally outraged by the excessive sentimentality that makes men forget their dignity and lose sight of the true purpose of animals. Those afflicted by this ridiculous tenderness frequently neglect to behave justly to their fellow humans. It is not uncommon for a needy person to be turned away from the door of a home where a pugdog, suffering from severe indigestion, is unable to swallow the biscuit which his mistress has dunked in her coffee before offering it to him. We vigorously reject such sentiments and regard them as moral aberrations. Such sentimentality, which excludes true compassion, has been stigmatized by Nicolas Gilbert in his poem "Fragments du dix-huitième siècle". (BSPA, 1855, p. 50) 
It therefore becomes clear that, in this particular historical context, it would be anachronistic to give the same meaning to the expression "animal protection" as we do today. Initially, the main aim of protection societies was to work for the good of humanity, and not primarily for animal welfare. The earliest animal protection activists believed that the suggestion that the fate of animals was anything other than secondary to that of men would involve accepting the validity of representations quite alien to the views of enlightened philanthropists: "we have no intention of following the example of those bigots in Surat in India, who built a hospital for rats and insects" (BSPA, 1855, p. 50).

More than any other campaign in the 19th century, the mobilization in favor of eating horse meat provides a demonstration of the intellectualized relationship with the animal protection cause which was, for an extended period, characteristic of the views of the most influential members of the SPA. For centuries horse meat had been considered a "shameful meat" (Leteux, 2005). The practice of eating horse meat, which was associated with pagan rituals, was banned by an order of Pope Gregory III in $73^{2}$. More importantly, the horse came to be regarded as an aristocratic animal, associated with the nobility. As a result it enjoyed a special status, and the consumption of its meat became taboo. On occasion horse meat was eaten when food was scarce, in particular during sieges or arduous military campaigns; this contributed to it being regarded as a food eaten only as a last resort by individuals threatened by extreme hunger or starvation. Furthermore, because of its taboo status, horse meat has frequently been sold by traffickers, who have fraudulently passed it off as beef or venison (Pierre, 2003).

Lettres sur les substances alimentaires et particulièrement sur la viande de cheval (Letters on foodstuff, and on horse meat in particular) by Isidore Geoffroy Saint-Hilaire was published in 1856 . As well as being a member and director of the SPA Saint-Hilaire was also a member of the French Academy of Sciences, director of the National Natural History Museum where he was also a professor, a member and honorary inspector of the Council for Public Instruction, professor of zoology at the Faculty of Sciences, and president of the Acclimatization Society of Paris. In this text, which expanded on some lecture notes, the distinguished naturalist presented a defense of the practice of eating horse meat. Quoting statistics which showed that a sizeable proportion of the French population, particularly the working classes, were undernourished, he argued that horse meat could provide an accessible and relatively inexpensive source of nourishment. He also points out that, contrary to popular prejudice, horse meat is actually quite 
palatable and healthy and cites as evidence of this the "hippophagic meal" organized by Professor Renault at the Alfort veterinary school during which eleven guests dined on the meat of an old paralytic horse (Pierre, 2003). The legalization of horse meat butchers' shops was also considered to be desirable from the point of view of public morality, insofar as it would also put a stop to the illegal trade in horse meat. The open sale of horse meat by licensed butchers would indeed put a stop to

the furtive dealing in "suspect meat," in attics, in cellars, by passers-by, by smugglers, by prostitutes, and by disreputable individuals without a profession! These transactions take place out of reach of the long arm of the law, by those who fear and flee the police! Instead of honest business conducted openly, we have fraudulent deals struck in the shadows, in "mass graves" hidden deep in the dwellings of the poor! (Saint-Hilaire, quoted in Pierre, 2003)

The naturalist's response to those who were angered at the thought of such a familiar animal being cut up by a butcher was that conferring upon an old horse economic and nutritional added value was the best way of ensuring that it suffered a more gentle death than animals sent to rendering plants. Saint-Hilaire's position attracted a great deal of support, particularly from within the scientific community.

Although, for reasons which will be analyzed below, a number of members opposed the campaign for the legalization of horse meat, the celebrated naturalist's views were generally warmly received within the SPA. Émile Decroix, a trustee and committee member of the SPA before becoming its president between 1886 and 1888, soon became one of the leading advocates of hippophagy. The former army veterinarian, who founded the French Association against Tobacco Abuse and was also a member of the French Society against Alcohol Abuse, campaigned for better public health by organizing hippophagic banquets in order to demonstrate the health benefits of eating horse meat. Between 1863 and 1895, he wrote and had published a number of works praising the virtues of horse meat, including a text entitled "The Prejudices against Eating Horse meat," which he read to a meeting of the Society for the Protection of Animals on 21 January 1864. During this campaign another eminent member of the SPA, Dr. Henri Blatin, took over the Presidency of the Committee for the Propagation of Horse meat. The members of the committee went to great lengths to make their message heard: brochures, lectures and banquets organized "in the public interest," as well as the weekly cutting up of a horse for distribution of the 
meat to poor families. In June 1866, their efforts were rewarded when the Prefecture of Police passed an edict authorizing and regulating the sale of horse meat for human consumption.

\section{"From the point of view of self-interest properly understood"}

In Chapter 1 we noted, echoing Albert Hirschman, the extent to which upper-class sensibilities evolved in such as way that passions were discredited, and strictly economic interests became an ever more central concern. These changes were regarded as having the virtue of fostering inclinations which were both harmless and very predictable. Having adopted this way of thinking themselves, the ruling elites felt duty bound to propagate it among the lower classes, from which they recruited their wealth-generating industrial workforce. The importance of the ruling classes' preoccupation with "protecting" their workforce needs to be stressed for the emergence of the first animal protection mobilizations to be properly understood. Indeed members of the British establishment began to mobilize to denounce and ban popular pastimes involving animals as long as twenty years before the creation of the world's first animal protection society.

In 1800 and 1802 Parliamentary bills were introduced attempting to have bullbaiting suppressed. Bloodsports involving bulls were still widely practiced in rural communities in Britain and, as was the case in other European countries at the time (Saumade, 1994 and 1998), they provided an opportunity for displays of a sense of community. At the time of Great Britain's early industrialization, such events were organized in urban areas where there was a high density of rural emigrants who had come to the city to find work. The fact that bullbaiting gave rise to a lot of drinking as well as creating a great commotion in the proximity of workshops and factories was a source of anxiety for the both custodians of public morality and industrialists. The pious Society for the Suppression of Vice, which was founded in 1802, considered bullbaiting to be an activity which corrupted men's minds by stimulating their appetite for questionable sensual pleasures. This practice was shocking, therefore, not on account of the suffering it caused to bulls, but because it encouraged people to develop a taste for excessive drinking, noisy behavior, and disorderly conduct in public, and also provoked in spectators insatiable and unpredictable urges to be cruel (Turner, 1980, p. 22). So, in 1835, under pressure from the Society for the Prevention of Cruelty to Animals, Parliament voted to ban bearbaiting. In 1849 another act was passed banning cockfighting. 
In fact what made these outlawed activities all the more intolerable was that they undetermined the worker discipline necessary in increasingly regulated industries.

In the seventeenth and eighteenth century much of the pressure to eliminate cruel sports stemmed from a desire to discipline the new working class into higher standards of public order and more industrious habits. It has often been remarked upon (and was even noticed at the time) that it was the sports with a strong proletarian following which were outlawed - cock-throwing, bullbaiting and cock-fighting - whereas the gentlemen's fox-hunting, fishing and shooting survived unscathed. (Thomas, 1985, p. 242)

The concern to create a disciplined workforce of unskilled laborers, necessary to ensure good economic returns, was also one of the motives behind the creation of the Metropolitan Drinking Fountain and Cattle Trough Association (MDFCTA). This association, based in London and founded in 1859, was made up of rich donors who decided to finance the construction and upkeep of fountains and drinking troughs throughout the city. This initiative won the admiration of the SPA membership, who paid tribute to "the charitable men, motivated by the desire to alleviate the suffering of not only their fellow men, but also of animals" (BSPA, 1876, p. 140). Nevertheless, the installation of numerous fountains and drinking troughs in English cities also aimed to divert carters and coachmen from the drinking establishments where they would often stop - too often for the liking of their employers - to drink beer. "Most carters [warned the French author of the Manual for Owners and Drivers of Draught Animals] have fallen into the habit of stopping off at every inn and tavern along their way. Those who frequent these hotbeds of drunkenness and dens of iniquity are soon dragged down into stupefaction and destitution" (Roche, 188o, p. 8). The workers in question were clearly perfectly aware that behind invitations to quench their thirst at these fountains and water troughs there was a disciplinary intent, and they also undoubtedly felt humiliated at being invited to drink alongside their cattle. Indeed, on occasion the fountains and water troughs were vandalized, leaving those who had funded them indignant, and outraged at such irresponsibility and ingratitude. In 1876 the SPA membership registered their dismay at the problems faced by their counterparts in New York City and Philadelphia who, having had the good sense to follow the lead of English animal protectionists and set up drinking fountains in their cities, "nevertheless saw many of the fountains 
vandalized, sometimes so badly that they ceased to function properly" (BSPA, 1876, p. 359).

While the first French activists undertook to discourage the brutal treatment of animals by the lower classes, they were also motivated by a desire to maximize wealth creation. Indeed, an SPA bulletin reminded members of one of the vital objectives of their combat, namely "to instruct the ignorant, to appeal to their generosity and, above all, to make them realize that the adoption of such generous sentiments was in their own interests" (BSPA, 1881, p. 182). So, in this case, the promotion of the gentler treatment of animals was tantamount to exhorting the masses to demonstrate the strict economic rationality vital to the creation of the wealth of nations.

This gentleness brings other advantages, if considered from the point of view of self-interest properly understood. The animals which will help us in our work will be stronger and more docile, and they will live longer. Our animals will be healthier, and will provide us with food of a higher quality. Finally, thanks to more enlightened treatment, we will see improvements in all breeds of domesticated animal. (BSPA, 1855, p. 52)

By propagating and defending the principles outlined above our work will promote better public morals, and greater public prosperity. By taking better care of our herds we will have less reason to fear the outbreaks of epizootics which in the last fifty years alone have cost out country over two billion francs. With more domesticated animals the country becomes more prosperous and agriculture flourishes. (BSPA, 1904, p. 155)

The ever-present preoccupation with optimizing economic performance explains the close relationship which the SPA cultivated for over a century with many organizations involved in the exploitation of animals. In the first place, as we have already seen, the SPA had close ties with the veterinary profession, which was establishing itself at the time, and regarded veterinary science as vital to the field of zootechnics, because of its contributions to progress in the rearing of livestock and draught animals. Moreover, a number of SPA bulletins quoted in full deferential letters from horse-drawn transport companies, eager to express their sympathy for the society's campaigns. In fact, for these companies, campaigning against the ill-treatment of these animals was linked to a wish to protect carriage horses from the negligence of those employees who were insufficiently committed to maximizing their employers' profits. Finally, it is significant that a number of leading figures in the animal protection movement, including General 
Grammont and the president of the SPA the Viscount of Valmer, were also titular members of the Société zoologique d'acclimatation. This association, which was founded in 1854 by the celebrated naturalist Saint-Hilaire, and soon changed its name to the Société impériale d'acclimatation, brought together scholars and other enlightened individuals with the purpose of, firstly, "introducing, acclimatizing and domesticating animal species, both useful and ornamental," and, secondly, "perfecting and breeding newly introduced and domesticated animals" (BSIZA, 1854, p. 15). In other words this society shared the goals of both veterinary science - improving animal breeding methods - and the French colonial project, which sought to exploit to the full the resources of the territories covered by the French Empire. Society members offered to contribute their zoological expertise to the systematic investigation of the possibility of acclimatizing animal species native to France's colonies, such as silkworms, yaks, angora goats, leeches, ostriches and dromedaries. Throughout the 19th century articles published in the SPA reflect a high level of interest in both scientific prestige and in the work of the Société Impériale Zoologique d'Acclimatation.

The earliest animal protectionists' conviction that they were working for the common good was therefore strengthened by the knowledge that they were providing, and helping to spread, the expertise required to establish the kinds of relationships with animals which would take into account the varying impact different species had on the economy. This prioritization of economic concerns explains the importance that was attached to a system of categorization which set up so-called "useful animals" in opposition to "pests." Efforts to rehabilitate a number of species which had come to be the victims of unfair prejudice, such as bats, hedgehogs and toads - who, as insectivores, were in fact the farmer's invaluable allies - went hand in hand with calls to exterminate animals which "damaged land occupied by man" (BSPA, 1861, p. 118). When seen in this light, the violent treatment of animal species classified as pests is not inappropriate, insofar as it constitutes a response to the unacceptable economic damage they cause. This also explains why it was seen as "important to draw up an exhaustive list [of pests], in order to target such harmful beasts as the squirrel" (BSPA, 1908, p. 102).

In addition to this, SPA members frequently emphasized the need to teach children to properly distinguish between species which were useful, and therefore deserving of protection, and those which needed to be ruthlessly exterminated. In 1875 the SPA awarded its silver medal to the author of a "publication [which] makes an important contribution to animal protection doctrine" by producing tables to be used in natural history lessons: thanks 
to these tables, which were hung up in over two thousand school classrooms and study rooms, "around three thousand children are now able to identify useful animals, and rethink some of their, sadly, widely held prejudices" (BSPA, 1875, p. 172). In 1882 the sixth edition of Les Martyrs du travail (le cheval, l'ane, le mulet, le boeuf): notions de médecine vétérinaire: conseils aux agriculteurs à propos des animaux utiles et nuisibles (Martyrs to work: Horses, donkeys, mules and oxen: An introduction to veterinary medicine: Animals that are useful and animals that are harmful to agriculture) by A. Édouard Roche, was published. Roche's book received an award from the SPA, and the Chief Commission of the Ministry of Public Instruction placed a copy of it in every school library in France. The Commission also recommended that the book not only be widely read, but also offered at school prize-givings. It was also communicated that teachers should take special care that the book should not be put in the hands of a child until he or she had the necessary intellectual maturity to clearly distinguish useful animals from harmful animals. That is why an SPA spokesman recommended "removing the names of fierce animals [from the tables which distinguished the various species]. Nursery schoolchildren are too young to understand the role of these animals in God's plan, and why, while they use to serve the purpose of decreasing the surplus population of certain species, in areas inhabited by man they are now regarded as useless pests" (BSPA, 1861, p. 118).

Once the age of reason has been reached, the discriminatory treatment reserved for animals, which classifies them as "useful" or as "pests," appears sufficiently self-evident as to go unquestioned. In 1896 Émile Zola reported on the enthusiasm demonstrated at an SPA prize-giving ceremony for "the star of the show, a young 16-year-old shepherdess, Mlle Camille Camelin, from Trion in Yonne, who risked her life by standing up to a wolf, in order to protect her flock. She was given an ovation by those present, and I was most honored to be one who presented her with her medal" (BSPA, 1896, p. 218). It is clear that animal protectors were quicker to respond to the admirable and exemplary character of human beings than to express concern for the fate of nonhuman animals - such as wolves or sheep - who are evaluated, very unequally, according to their economic usefulness. In other words, they were still a long way from a world where a species like the wolf could become one of the emblematic figures of the animal protection movement. 



\section{To enlighten the ignorant, to refine the barbarian}

\section{A pedagogy of gentleness in order to prevent crime}

Growing fears regarding violent and unpredictable behavior fed a powerful stereotype which became a constant preoccupation of animal welfare activists, namely that brutal treatment of animals inevitably leads to the brutal treatment of human beings; accustoming oneself to violent behavior toward animal is equivalent to preparing oneself to perpetrate criminal acts on fellow human beings. As early as 1751, the English painter William Hogarth published a series of engravings entitled The Four Stages of Cruelty which enjoyed great popularity and a lasting influence. Each engraving represents a stage in the life of the fictional Tom Nero. The first print, showing one of the poorest quarters of London, depicts him as a child torturing a dog. In the second plate Tom Nero, now an adult, is a hackney coachman and is shown beating a horse which has collapsed to the ground. In the third plate he is being arrested for the brutal murder of his mistress, and in the fourth, The Reward of Cruelty, the body of Tom Nero, who does not deserve to be given a proper Christian burial, is cut up and dissected in an anatomical theater. A passing dog devours Nero's heart, which is lying on the floor among his entrails. The success and very wide distribution of these prints, which sold for a shilling a piece, contributed greatly to propagating the idea that children who are cruel to animals grow up to become violent criminals (Turner, 1980; Lansbury, 1985a). In 1782, The German pastor Christian-Gotthilf Salzmann mentions the instructive story of Tom Nero in Elements of Morality for the Use of Children, a book which enjoyed a great deal of success in Great Britain. By the 1820s, around the time the RSPCA was founded, the idea that cruelty to animals, particularly when perpetrated by children, would be a prelude to cruelty directed toward human beings was therefore by no means a novel notion (Grier, 1999). In 1876, the SPA bulletin commented at great length on The Four Stages of Cruelty, so remarkably described by Hogarth, and paid tribute to the way the work made a vital contribution to the spread of awareness of animal welfare issues in Britain: "the reproductions of these drawings were distributed throughout England and made a deep impression on the people who saw them" (BSPA, 1876, p. 78).

It is easy to imagine the anxiety that such a stereotype, if widely believed, could generate. In towns where the spectacle of animals left to the mercy of 
members of the least educated classes was so widespread that any coachman, carter, shopkeeper or butcher who roughly handled an animal was in danger of being taken for another Tom Nero, whose criminal instincts could rise to the surface at any time. The name chosen for the very first animal welfare organization in Europe is highly significant in this regard. For the sake of linguistic convenience and because of the need for terms which could be used throughout this book I have used the expressions "the animal cause" or "animal welfare activists." In fact it is clear that the RSPCA - the Royal Society for the Prevention of Cruelty to Animals - was not initially concerned with "animal welfare" in the sense that the term would later be understood. The scandalous state of affairs which activists were determined to remedy was not the suffering of animals but the widespread cruelty of those individuals who, having maltreated animals, threatened to behave in a similar way toward humans. The upper echelons of British society were convinced of the need to act as quickly as possible because they feared that allowing the working classes to become accustomed to the shedding of animal blood could lead the social order to be threatened. The organization of societies dedicated to the prevention of cruelty - all cruelty not only cruelty toward animals - were partly motivated by fear of social change: "fear of imminent revolution, of a society increasingly dominated by a 'barbarous and brutal' crowd; in short, the fear of anarchy" (Turner, 1980, p. 54). This fear of social change gave the membership of the first animal welfare organizations a predictable-class profile. It also meant that the only activities which caused concern were those practiced by members of the lowest and least-educated strata of society.

In France, a country which had lived through numerous revolutionary episodes, there was also a fear of violence which would lead to threats to the social order. More than the elites in any other European country, the French upper classes were haunted by shocking images of uncontrollable bestial crowds (Barrows, 1990). If this widespread concern over the control of political violence had not been present animal welfare campaigners would have struggled to convince others of the urgency of their cause. Indeed it is significant that in $185^{\circ}$

as political tension in the Second Republic was at its height, with the obsession with struggle between classes which were supposed to gather their forces for the assault of 1852, and right in the middle of debates around the Falloux Law, the National Assembly still found time to pass the Grammont Law, which made the ill-treatment of domestic animals a criminal offence. This demonstrates that people at that time believed that 
cruelty toward animals made a significant contribution to the prevalent climate of violence, cruelty and barbarity. (Agulhon, 1988, p. 245)

There were other instances of mobilizations against cruelty toward animals occurring in a context of fear provoked by revolutionary riots. On 6 July 1802, the question of barbaric treatment of animals was brought up in the Institut de France at a moment when there was a clear desire to avoid any further revolutionary disorder. Similarly, it would seem that the closure of the amphitheaters in the Place du Combat in Paris where dogs, which often belonged to butchers' assistants, fought bulls, mules, wild boar, bears and wolves - was partly motivated by the tense, violent atmosphere created by the riots of 1830-1832 (Pierre, 1998, p. 114). Furthermore, it is clear from the following statement by the Bishop of Nîmes, which condemns bullfighting, that the protection of animals was closely associated with concerns about social disorder and political violence:

The sight of blood excites an unquenchable thirst for more blood. In a country like ours, where there is so much mobility within the social order, where revolutions are sparked so easily and so frequently, it is a bad thing to nurture fierce instincts which could later be exploited in a moment of trouble and chaos, and allow our nation to tear itself apart in bloody saturnalia. (Quoted in BSPA, 1883, p. 223)

Thus, in France and in Great Britain, the passage of legislation for the protection of cattle was facilitated by the widely held belief that brutal treatment of animals can arouse criminal instincts, leading to behavior which causes harm to humans. In the course of the speech he made to propose his bill, Jacques Philippe Delmas de Grammont mentioned a recent incident where a young boy slit his little sister's throat, shortly after witnessing, as a fascinated spectator, a pig being slaughtered (Agulhon, 1988, p. 249). In the SPA bulletins it is striking how often three arguments recur. Firstly, that it is necessary to prohibit violent spectacles because they can provoke, particularly among the more uneducated, instincts which may give rise to unpredictable outbursts of brutality; secondly, that it is a matter of urgency that animals be protected in order to protect the whole society from horrible outbursts of criminal violence; and thirdly, that particular vigilance is required where children are involved, because habits acquired at an early age prefigure behavior which will persist and recur throughout adulthood. 
We often see, particularly in villages and small towns, butchers slaughtering a calf or a sheep in the middle of the street. Children flock to witness the spectacle and take their first lessons in cruelty. (1802, quoted in Pelosse, 1981, p. 14)

But in Luchon the thing that aroused our indignation the most was the sight of children being allowed to witness the butchering of animals. We even saw babies playing right next to where calves were having their throats cut. Is it not immoral to accustom children to the sight of blood and to prematurely harden those who are made to feel pity? Furthermore, there were women helping their husbands with their unhappy task, either by tying up or by holding down the animals. Is it not an absolutely shameful and repugnant thing for members of the sex which is above all made for feelings of gentleness and humanity to witness bloody orgies, and in so doing serve an apprenticeship in crime? (BSPA, 1886, p. 306)

Thus, the protection of the sensibilities of refined men, discussed above, is not the only reason for banning the public ill-treatment of animals. Indeed, such men, who take an interest in the common good, are particularly concerned that if appropriate measures are not taken a terrible outbreak of violence will occur which it will not be possible to stamp out. Since the beginning of the 19th century, and right up to the present day, animal welfare activists have always seen their struggle as a way of thwarting mounting individual cruelty, as well as the spread of cruelty on a collective scale.

All our efforts must be directed at preventing the perpetration of ill-treatment of animals by men, even when such ill-treatment is committed out of anger, impatience or stupidity rather than wickedness. If we succeed in reducing the number of these brutal acts then that will constitute an important achievement. We will lessen the number of cases of ill-treatment, firstly all those incidents which we prevent directly, and then all those which would have been the consequence of bad examples followed. It is worth noting that anger is in a way, like certain nervous conditions, contagious. We must, as far as possible, protect children from these impressions, and not excite their curiosity with the spectacle of tortured animals struggling. It is healthy to cultivate the habit of being kind to animals not only for the present, but also and especially for the future. (BSPA, 1855, p. 51) 
Protection societies, which have been set up all around the world, are increasingly aware of the importance of integrating animal welfare into the education of children and young people. A child has many more opportunities to protect or to ill-treat animals than adults do. He uses animals to test his strength. If he starts off by showing kindness, one can be optimistic about his future; if, on the contrary, the child indulges in acts of cruelty, care must be taken to prevent such habits from developing. If nothing is done the danger will be that, having spent his tender years tormenting animals, his first subordinates, he will go on to spend the rest of his life bullying anyone who is put under his command. [The behavior will be the same], the only thing that will change will be the victims. (BSPA, 1875 , p. 185)

Faced with such a terrible danger, we can easily understand how mobilizations for animal protection could be presented as part of a civilizing mission of the greatest importance. Activists for the cause believed themselves to be working toward nothing less than the improvement of men and, as a consequence, the improvement of human beings' ability to live together on good terms, in a society free of conflict. In their opinion "there seems to be no doubt that being kind, in particular toward pets, improves people, [and] makes their manners more gentle" (BSPA, 1855, p. 52). In 1886, the president of the SPA made a point of quoting "the stirring words of General Grammont pronounced at the sitting of the legislative assembly during which the law to which he gave his name was passed: "The prevention of ill-treatment is as much about the moral improvement of men as the physical improvement of animals!" (Loud applause)" (BSPA, 1886, p. 140). Thus, zoophilia can present itself as one of the most advanced forms of philanthropy because it aims to constitute a "propedeutics of gentleness," the most suitable elementary basis for the cultivation of the love of men, which is indispensible for the progress of humanity (Agulhon, 1998; Pierre, 1998). Thus the earliest animal welfare activists thought of themselves and presented themselves as educators who, because of their knowledge and experience, offered to instruct and guide others for the benefit of the community. In Great Britain this attitude was closely linked to a large number of moral campaigns inspired by religious convictions, both Anglican and Evangelist. In France, a much more secular country, the earliest mobilizations against the ill-treatment of animals foreshadow the "demopedic fervor" (Rosanvallon, 1992, p. 355) which - particularly between 1880 and 1900 - promoted the education of the people, aiming to tear them away from their vilest habits, and thus enabling them to participate in the improvement of the civic order. 
Why, [wrote Dr. Pariset in the introduction to the statutes of the SPA, which he drafted in 1848], would men so quick to get angry with an animal for no good reason not act in the same way toward their fellow men? Here is an important message to communicate, and to teach people. By a gradual and inevitable change in his sentiments an individual would go from showing gentleness, pity and fairness toward animals to experiencing the most tender compassion for his family and all people. Once these saintly habits were adopted they would no doubt save people from the shameful excesses their intemperate behavior could lead to. (Quoted in BSPA, 1904, p. 152)

Thus, confirming the Eliasian hypothesis which we have adopted, one of the most powerful motives behind animal welfare mobilizations was the growing revulsion with which members of the upper classes of society regarded violence. It should be stressed that this disgust at brutality was so great that it influenced the way in which the moral entrepreneurs of the cause conceived of the ideal way of absorbing it. They considered that using persuasion to convince the people to adopt civilized behaviors was all the more praiseworthy because it avoided the use of coercion (Foucault, 1975). Arguing for obtaining change forcibly would implicitly rehabilitate the use of force and violence, which had been so heavily criticized. What is more, analysis of authoritarian approaches revealed them to be irrational and even counterproductive, because "the punishment often fails to achieve its objectives" (BSPA, 1855, p. 54).

In people of bad character punishment produces bitterness which always seeks vengeance; it causes indignation in the false spirits who are unable to recognize that it is in the man's own interest that he receive the punishments, which he brings down upon himself. (BSPA, 1861, p. 182)

That is why the entrepreneurs of the cause celebrate the ability of those able to tame the fiercest and most stubborn natures with gentleness, tact, diplomacy and delicateness. To achieve this they use sensitizing devices which will be discussed below. For now, it is important to note the continuity that the moral entrepreneurs establish between controlling human violence and the domestication of animals. Refining the habits of humans and taming the savage nature of animals are part of one and the same civilizing mission.

No More Collars Which Use Force; Train a Dog of Any Age, Even the Most Difficult Animal, to Retrieve within a Few Days, was the title of a brochure which Monsieur Ferez, a shopkeeper in Lalinde, entered in our 
competition. The title of this work gives a good indication of the spirit in which it was composed: the welfare of the animal was of primary concern. The principles which the author advocates regarding the training of dogs to retrieve seem very simple, and the Protection Society will work to have them adopted more generally. The author repeatedly recommends gentleness, calmness, and patience. The prize committee therefore saw fit to award Monsieur Ferez's brochure its bronze medal. (BSPA, 1875, p.173)

Subduing a yak [...]. If anyone has any doubts about the effects softness, patience and good treatment have on animals they have to follow our society's useful works and see the positive contribution they makes on morality, agriculture and commerce; allow me to submit a note which will inform you of one more fact to be added to so many other similar observations. [There follows the description of the soft method used to subdue a troublesome yak]. That was the method I used to control an animal which had been considered untamable and dangerous [...]. But, I have always noticed that to achieve success patience and gentleness have always been absolutely indispensible. Repression must be used sparingly, tactfully and at the right time, otherwise not only will it not obtain the desired results, but it can actually be counterproductive. (BSPA, 186o, p. 80)

Along similar lines, we can note the enthusiasm with which members of the SPA greeted the news of the creation of a new hornless breed of cattle, named Sarlabot II and Sarlabot III.

The protection society can only applaud the devotion and perseverance of our colleague Monsieur Dutrone who hastened the realization of this great agricultural progress, namely the substitution of bovine breeds for dangerous breeds who are armed with horns. (BSPA, 1860, p. 140)

There is no doubt that a general increase in the number of hornless breeds would lead to the suppression of more or less violent coercive methods in the handling of cattle, in the same way as the greater knowledge of rabies as set out in Monsieur Sanson's work, and the appreciation of its probable causes led to the suppression of the chains and muzzles, which bothered the poor dogs on which they were used. (BSPA, 1861, p. 189) 12 $^{12}$

12 It is worth noting that in the 19th century, before Pasteur's discoveries in this field, rabies in dogs was thought to be caused by brutal ill-treatment by men: "In fact we are the very ones who cause the madness and then the rabid condition of our dogs. The protection society must 
Here we can see the extent to which the attention given to domestication techniques, as well as the acclimatization of new animal species, is closely linked with the explicitly stated desire to reduce the various kinds of violence which threaten social order. Significantly, acts of cruelty committed by domestic animals tend to be attributed to lack of self-control on the part of those who attempt to train them. The perseverance and tact of animal protectionists are presented as the best qualities needed to combat this violence, and to pave the way toward an ideal world, inhabited by animals without horns, chains or muzzles who obey peaceful, affable men. One has no difficulty in seeing how this ideal could echo political watchwords relating to the nature of the relations which should prevail between men: praising good domestication "has become the archetype of other kinds of social subordination. It is a paternalist model in which the sovereign is the good shepherd. Docile loyal animals obeying a thoughtful master set an example for all the servants" (Thomas, 1985, p. 55).

\section{Discipline, reward and punish}

"Remind uncertain souls, [and] undecided hearts of the righteous path," "make them understand the great significance of the work which we carry out with such ardor and courage" (BSPA, 1881, p. 182). As we have already noted, a mission of such benevolence aimed to be able to do without coercion and rely more on the use of rewards, a method which was far more in tune with the way of thinking which animated and motivated the servants of the cause.

Punishment often does not achieve its stated aim. When the shorttempered and brutal coachman gets back to the stables after being punished he may well take it out on his horse. A punishment can imitate certain characteristics which gentleness corrects. A man who receives a punishment does not boast about it, whereas one who obtains a reward is happy to talk about it; he shows his medal to his workmates. He will not only be encouraged to act well, but he will also encourage the others to imitate him; he will become an apostle for our good works. He will be a very useful helper since his advice will carry a lot of weight with men of the same profession; his words will be listened to more attentively, and 
better understood than our own. Let us, therefore, continue with this policy, which was pioneered by the Paris and Munich societies. (BSPA, 1855, p. 54)

A large proportion of the sensitizing devices put in place by the first protection societies were, therefore, prizes, distinctions, and bonuses whose aim was to "offer rewards in order to inspire gentleness in men" (BSPA, 1855, p. 66). Throughout the 19th century "prizes," "encouragements" and "bonuses" often constituted, after running costs, the largest item of expenditure of the French SPA.

Every year the society holds a special meeting for the distribution of awards: bonuses, medals and honorable mentions. Rewards are presented in the following categories:

- Farm boys, coachmen-grooms, animal drivers, butcher boys, and any other person who has demonstrated a high level of good treatment and intelligent care and compassion toward animals

- Inventors and promoters of devices designed to decrease the suffering to working animals [...]

- Authors of memoirs regarding topics suggested by the society, or of literary, scientific, artistic or economic publications or works which make useful contributions to its work (BSPA, 186o, p. 1)

As we can see, the award-giving initiatives mentioned here were underpinned by two distinct yet complementary logics. For inventors and authors of memoirs, receiving an award gave them the feeling of joining the ranks of people of superior knowledge and intelligence. The bonuses awarded to those who showed compassion to animals in the course of their work constituted, on the other hand, initiatives designed to stimulate - outside the core activist group - the emotions needed for the propagation of the cause. This use of rewards is quite openly presented as a sort of moral orthopedics aiming to reform the behavior and attitudes of those categories of the population who are more likely to abuse animals. So, in 1876 , the Frankfurt protection society "offered bonuses to butcher's assistants who use the Bruneau [mask] for slaughtering cattle" in order to encourage them to kill the animal more "humanely" with a single blow from a mallet (BSPA, 1876, p. 364). In London, from 1880 to the beginning of the 2oth century, animal welfare campaigners organized a parade during which street sellers were encouraged to "consider their humble donkeys as a spectacle, an object worthy of visual attention - and humane care" (Kean, 1998, p. 76). 
The owner of the best-turned-out donkey received a prize offered by the queen, or distinguished lady patronesses such as Baroness Angela BurdettCoutts. The Paris SPA, for its part, organized a school where coachmen were taught that gentleness was a defining feature of the elite members of their profession: "the first quality required of a carter is compassion. Even if a carter possesses all the other requisite qualities in abundance, if he is not compassionate, he will never be other than a vulgar driver who can behave unjustly or inhumanely on the slightest pretext" (Roche, 1880, p. xii). In 1908 , the SPA leadership was proud to announce that they had trained no less than three hundred Paris coachmen: "each of our most serious students was presented with a certificate which he will be able to use as a kind of passport in employment agencies" (BSPA, 1908, p. 116).

Nevertheless, the fact that the award scheme induced the changes in behavior which animal welfare campaigners were demanding was not the only reason it was prioritized. Another important function, indeed the most important function, of prize-giving initiatives was that they gave the entrepreneurs for the cause the opportunity to experience gratifying feelings.

Finally it is necessary to reward those who are already on the right track, those whose hearts are so sensitive that every kind of suffering causes them to suffer and who should, consequently, have their names recorded in the annals of the animal welfare movement. Yes, awarding these prizes is a most agreeable and consoling role for us, and you will soon discover that there are indeed numerous good souls among us. (BSPA, 1881, p. 182)

An "agreeable" and "consoling" role: in other words the use of rewards has the advantage of testing an emotional economy which is the source of much of the satisfaction that activists derived from their involvement in the movement. In fact the charitable act established a relationship system between two agents: on the one hand the individual who acts in a benevolent way, the benefactor, on the other hand the individual who benefits from their action, the beneficiary, who cannot fail to show the gratitude which for the philanthropist is central to the "the total feeling of pleasure one experiences when carrying out a charitable action" (Helvétius, quoted in Duprat, 1993, p. xx). ${ }^{13}$ Animal welfare campaigners demonstrate even higher levels of moral excellence because they are able to replace their initial feelings of repugnance toward the wrongdoers with an attitude of 
charitable indulgence. Their intention is to lead these offenders back to the right track by rewarding them, which, in turn, increases their own feelings of self-worth. When the benefactors reward farm boys, coachmen, butchers and others who - rejecting the cruel practices which were then common in their lines of work - show compassion toward animals, they expect the award winners to make a show of gratitude, which in turn is gratifying for the benefactors themselves. In other words, the use of awards establishes an emotional economy which reaffirms the moral preeminence of the benefactors, and the asymmetry of the reciprocal expectations which joins them to the beneficiaries of their actions. By accepting to be rewarded for having respected the stipulated norms the "repentant deviants" play their part in reaffirming the superior social status of the moral entrepreneurs (Gusfield, 1986, p. 66). This is further proof, if any was necessary, that the first animal protectors were as preoccupied with relations between men as they were with relations between men and animals.

It goes without saying that the emotional economy which the prizegiving initiatives were intended to establish was an ideal which was not always achieved. Indeed such an emotional economy appeared to be far too delicate and subtle to be in a position to influence "certain brutes with human faces" (BSPA, 1883, p. 168). Such individuals were quite unmoved by the benevolence of the animal protectionists, would reprimand those who remonstrated with them, and sometimes even mocked the compassion which was being advocated. Far from being moved in a constructive way by gentleness, or by bonuses bestowed by generous benefactors, these heartless unintelligent creatures only understood force. This is why statements by animal protectionists made repeated references to the fact that coercive measures are a necessary evil, a second choice, a "regrettable necessity" to which, because of the urgency of their mission, good men are sometimes forced to resort.

Repression, which is a back-up option, is unfortunately all too necessary in our country, a country so proud of its civilization, where the cruel treatment of animals led a compatriot to make this following painful admission: "I have never seen anything as bad as this, even in Russia." (BSPA, 1855, p. 108)

The agents of the authority, faithfully following their instructions to the letter, every day contribute zeal and devotion to the great cause of animal protection. They conscientiously apply the law of 2 July $185^{\circ}$, the Grammont Law, without which our society would be deprived of its main purpose, and of the right to call itself, as it does with such pride, the Society for the 
Protection of Animals. We can always rely on them to be there when it is necessary to remind certain brutes with human faces that men do not have the right to cruelly take advantage of their moral and physical superiority over innocent creatures which nature put in their care. (BSPA, 1883, p. 168)

In fact there is a repressive aspect to the work of animal welfare societies which should not be overlooked. These societies did not content themselves with merely lobbying for the first legislation which outlawed cruelty to animals, they also dedicated a significant part of their budget to funding projects which ensured that the law was applied. Once more it was the RSPCA which took the lead, setting an example for its continental counterparts to follow. The RSPCA appointed two inspectors as early as 1832 . Their job was to patrol the streets of London, and identify and report anyone guilty of committing offences under the provisions of MartinError! No bookmark name given.'s Act. Since that time the role of RSPCA inspectors has been substantially redefined and their number has continued to rise, in order to maximize the amount of the country covered by the organization: in 1974 there were two hundred inspectors in England alone, with Scotland and Northern Ireland covered by inspectors from their own animal protection societies. In France the institutionalization of methods of control and repression of those who violated animal protection legislation came in two distinct stages. Initially the SPA conferred a surveillance role to its members. This was facilitated by the fact that the public authorities acknowledged that SPA members were particularly competent in this regard. "In 1856 the police prefect authorized each member to carry a special card. The card specified their function and enabled them to call for the intervention of public law enforcement agents" (BSPA, 1884, p. 276). Four years later this special card was described as a "diploma" and was proof of membership of the SPA: "Members are presented with a diploma. With their diploma the new member receives a card which entitles them to request the intervention of police officers for the purpose of certifying contraventions of the Grammont Law" (BSPA, 186o, cover page). In other words, once again, the awarding of a special card amounts to a distinctive honor which enables members to experience the pride of belonging to an elite dedicated to promoting justice and upholding the law, as well as authorizing them to track down and expose any wrongdoings committed by their fellow citizens. In fact, at SPA meetings some of the more zealous members would proudly report having been instrumental in the recording of a large number of police statements. In order to encourage these kinds of action the SPA bulletin published a model complaint form for "members of the protection society who found themselves obliged to require 
a police officer to issue a fine for cruelty" (BSPA, 1886, p. 124). In order that as many offences as possible were punished the SPA organized the awarding of bonuses "to law enforcement officers who were zealous in their application of the laws and regulations governing cruelty to animals" (BSPA, 1876, p. 364). Thus the bulletin of the society would publish lists of the police officers to whom they had awarded bonuses, which were calculated by counting the number of breaches of the Grammont Law they had dealt with.

Later, from 1881 onward, the SPA adopted the British model and financed a team of uniformed inspectors who patrolled the streets of the French capital. They recruited individuals with qualities not normally associated with respectable members of the SPA: successful applicants needed not only to be experienced around horses, but also be "perfectly prepared to respond to carters in their own language, to be able to intimidate them despite their bravado, to tackle them physically, and not to be put off by anything in the course of taming these savage beasts" (BSPA, 1879, quoted in Pierre, 1998, p. 260). The number of inspectors in both the "repression department" and the "inspection department" was constantly on the increase. Nevertheless, [shouted an SPA official at a meeting] "in 1884-1885 ten inspectors is not enough. At least twenty are needed, one per arrondissement. It is now the second highest item of expenditure, along with awards" (BSPA, 1885, p. 34). In fact, from then onward the combined budgets for the "repression department" and the "inspection department" - including salaries, bonuses and uniforms - took up an ever-increasing proportion of spending on animal welfare.

Thus, the legal effectiveness of the Grammont Law was for a long time one of the major preoccupations of animal welfare campaigners, who regularly monitored and commented on the way the courts applied the law, and tended to closely associate the defense of their cause with a substantial advance in the law. Thus the sentences handed out in animal welfare cases came to be regarded as an indicator of how the cause was progressing, and something which activists could be proud of.

There have been over 950 offences committed under the provisions of the Grammont Law. We firmly believe that this figure will fall until the day, the day we are looking forward to, when, as a result to the impact of our doctrines on public morality, the law will no longer be needed because cruelty [toward animals] will have stopped. (BSPA, 1883, p. 138)

On the plus side, this year there have been far fewer contraventions than in previous years, which is clear proof that abuse and cruelty are in decline. (BSPA, 1904, p. 180) 


\section{Graph 2 Membership for the SPA}

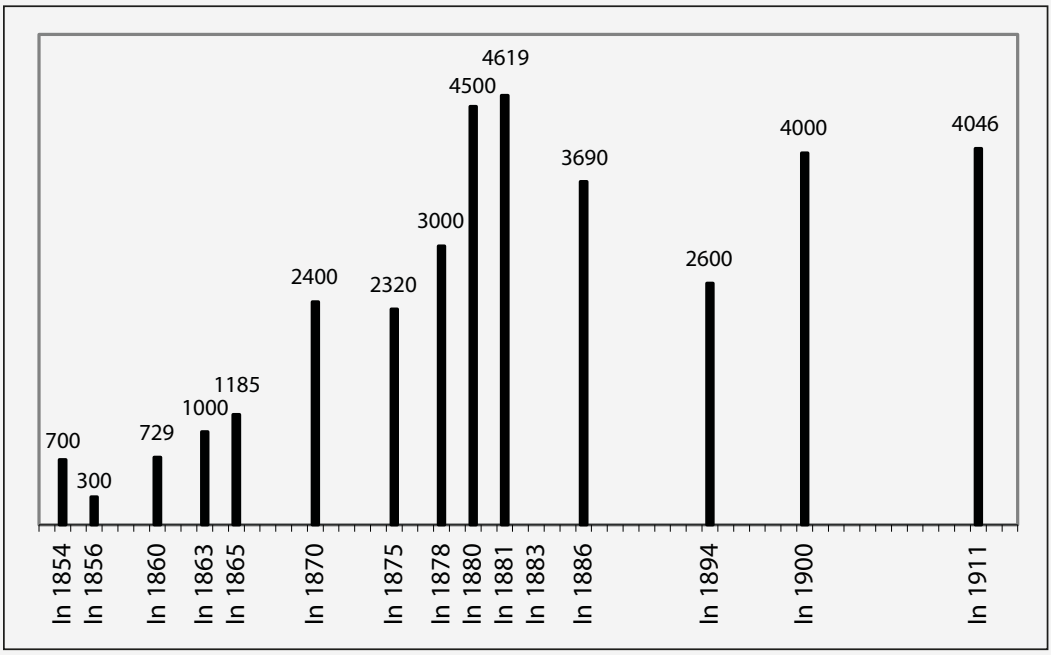

Source: Graph produced by the author

Generally speaking, the estimation of the evolution in the number of members of campaigning organizations constitutes a particularly tricky exercise. Indeed, the researcher can never be sure of the accuracy of the figures at his disposal (methodical count or approximation? Actual or inflated membership count?). Moreover, and it is the case here, the information available may be far from complete. Throughout the 19th century mention of the total membership numbers only appear in SPA bulletins irregularly and fortuitously: in a president's speech, a secretary general's report, in the counting of subscription charges contributing to the income of the organization, etc. Despite the fact that the information gathered is incomplete and of questionable reliability, a number of conclusions may be drawn from it.

Although the long-term trend was that the number of members steadily rose, there were periods when membership dropped. Aside from the quantitative aspect of these variations, the significant turnover of activists - namely the constant flux of those who join, stay in, and leave - should not be forgotten (Fillieule, 2005). As it happens, as we shall see below, the sociological profile of SPA activist membership, as well as that of the wider animal welfare movement, changed radically.

Secondly, in the 19th century the SPA was not a mass movement. Its leadership only became preoccupied with maximizing recruitment at the beginning of the 2oth century, and then in order to make changes which we will examine below. 


\section{Assisting the authorities}

The earliest animal welfare organizations, whose membership was made up of highly respectable and prominent personalities, certainly did not need the support of large numbers of activists to obtain the ear of the public authorities. Throughout the 19th century animal welfare campaigners concentrated on exploiting their connections within the political decisionmaking elite. We have already mentioned how in Britain there were close ties between the RSPCA and the nobility, the judiciary, the clergy and members of Parliament. In France proximity to the authorities may be inferred from the fact that from 1845 onward "from the time of its formation the SPA was authorized to hold meetings in the Paris Town Hall" (BSPA, 1904, p. 56). Furthermore, as we have noted, the French SPA, like its British counterpart, had a team of inspectors, which amounted to a private police force authorized to assist the official forces of order in a domain which was, in principle, under the control of the state. Registered as a charity in 1861, the SPA also managed to extend its influence into the public administration two other key domains: agriculture and public education.

In 1876 , the SPA award-giving program obtained the official support of the Ministry of Agriculture and Trade (BSPA, 1876, p. 226). Moreover, the animal welfare organization received an annual grants from this ministry, and from the Ministry of Education (BSPA, 1875, p. 150). It is worth stressing the privileged relations the SPA enjoyed within the ministry which formulated national education policy: they go a long way to explaining how the earliest animal protectionists managed to exert considerable influence on a number of political decisions which had a transformative effect on French society. The close natural affinities between the SPA and those who administered the education system were to do with the obsession with pedagogy which was characteristic of European animal welfare activists throughout the 19 th century. As early as 1855 Dr. Blatin recommended "the formation of a propaganda committee whose mission would be to influence the minds of children, either by arousing interest in our cause among schoolmasters and primary school teachers, or by spreading our doctrines in the many useful collections of articles, published with a view to entertaining and instructing the young" (BSPA, 1855, p. 40). From that time onward, the urgent necessity to distribute pedagogical materials suitable for the younger generations would become a recurrent theme in discussions among SPA activists.

In fact, the kind of instruction which enables men to make a living and prosper through work can sometimes become dangerous when it 
is not moderated and completed by, and above all directed toward the cultivation of goodness by education. Current teaching does not include a program for education of this kind; and the cultivation of the heart is left up to the good faith and spontaneous initiatives of individual primary school teachers. It is therefore important to ensure that we obtain the cooperation of these men, who are entrusted with the development of our children's hearts. It is for this reason that we have recently sent round a circular to all the schools affiliated to our organization in which, after summarizing our doctrines and principles, we explain that a prize will be given each year to the pupil who has best put into practice these doctrines and principles. Our circular is accompanied by a poster on which there is the text of the Grammont Law and the conditions which must be fulfilled in order to be eligible for the prize we are offering. We would like this poster to prominently displayed in the school all the year round. (BSPA, 1875, p. 150)

By sowing the seeds of zoophilia in children's hearts we will reap the harvest in the hearts of men. There is no surer method of improving humanity. (BSPA, 1933, p. 28)

Many different methods were employed to reach this crucial objective. Firstly, the SPA offered special subscription rates to people who worked with children: while most members paid 10 francs, "for clergymen, ministers of recognized religions, primary school teachers and schools the subscription charge is reduced to 5 francs" (BSPA, 1875 , cover page). Furthermore, discussions at SPA meetings often centered on defining the didactic strategies best suited to influencing the children. In 1858, "the conclusions of the report, beautifully written by the Countess of Corneillan, [express] the wish that nursery schools be provided with prints and books which would encourage the love of animals": three years later a member of the SPA, curious to know if these recommendations had been acted upon, visited several Paris nursery schools and was concerned when he found no materials of this kind. The response to this unsatisfactory state of affairs was immediate: "it would be desirable if Monsieur Hachette [a school textbook publisher], who is one of our members, would be good enough to modify these materials, which he publishes. If he agreed, a committee could be given the task of deciding on the content of the replacement materials" (BSPA, 1861, pp. 117-118). These attempts to influence the educational establishment seemed to have been a success: in the second third of the 19th century the French SPA and the administrators of the national education system worked together very 
closely. Victor Duruy, who was Minister of Education from 1863 to 1869, introduced animal welfare into the training of primary school teachers, and demonstrated his favorable attitude to the animal welfare organization in a number of ways: the purchase of multiple copies of animal welfare textbooks, the establishment of awards for teachers who were particularly zealous in the promotion of the cause, and the inclusion of a letter from the SPA in a collection of administrative acts (Pierre, 1998, p. 535). Later, in 1871, Claude Auguste Valette, Chief Inspector of Education, became president of the SPA and managed to recruit two education ministers to the society (Pierre, 1998, pp.113 and 178). Furthermore, and even more importantly, the message of SPA doctrines was widely relayed by French schoolteachers, who quickly adopted pedagogical devices similar to those used by the British Bands of Mercy. ${ }^{14}$

Every year we hear of schoolchildren forming new animal welfare organizations. One primary school teacher found a clever name for them: the little league for the public good. Statistical inventories are sent to us which clearly show the number of bird's nests which are protected by these societies, the numbers of chicks which have survived and flown away, as well as how many have been stolen from the nests [...]. There are so many of these zealous protectors of animals that, in several schools, the teacher, having promised prizes for the most deserving children, has felt obliged to have the children draw lots, as all of them appeared to be deserving. (BSPA, 1875, p. 185)

Societies for animal welfare in schools: influenced by our doctrines, a certain number of schoolteachers, who were members of our society, organized the pupils in their schools into animal protection societies. Their example was followed by other teachers who, though not members of our group, nonetheless contributed to the spreading of its doctrines. We cannot encourage the development of this propaganda network enough. The formation of societies for the protection of animals in schools will not only help our principles to be applied, it will also serve to teach the children, from an early age, the duties and benefits of cooperation. From

14 In 1875 , British evangelists, soon followed in 1882 by a similar American group, organized Bands of Mercy, groups of children who were invited to work for animal welfare in order to promote Christian morality. According to Catherine Smithies, the founder of the first Band of Mercy: "the teaching of children to be kind and merciful to God's lower creatures is preparing the way for the gospel of Christ" (quoted in Li, 2000, p. 8). 
childhood they will be accustomed to work in groups to carry out joint projects for the greater good of the nation. (BSPA, 1876, p. 166)

At its annual award-giving ceremony the SPA set up two prizes: a special prize for primary school teachers who had introduced the teaching of animal welfare in their schools, as well as the Grosselin prize for children: "the winner, who was aged 8, received a bronze medal and 25 francs put in a savings account, the 2nd and 3 rd placed children were given 15 francs and 10 francs respectively, also put in savings accounts" (BSPA, 1875, p. 190). As wellinformed pedagogues, the SPA leadership also make every effort to increase awareness of their cause among children by encouraging the emulation of virtuous conduct: "as well as the normal Society for the Protection of Animals awards, every year a special prize is given to a pupil of one of the schools involved in our good works, who is nominated by his schoolmates for his exceptional gentleness toward animals. This year there were twenty candidates for the prize" (BSPA, 1876, p. 387).

The SPA's various schools initiatives received staunch support from a succession of Education ministers: "in the lists of award-winners were schoolteachers and pupils, nominated by school inspectors who, in 1896, received reports directly from the SPA regarding how many candidates each school had put forward, and containing the information necessary for their application to be properly examined" (BSPA, 1904, p. 220). In 1881, the president of the SPA requested and obtained the support of Jules Ferry, the Minister of Education, for the project of having the Grammont Law displayed in every school (Pierre, 1998, pp. 533-534). Fourteen years later close relations with the public authorities had been maintained:

[T] he Ministry of Education [the secretary general of the SPA is happy to announce] has consented to contributing to the delivery costs of the 40,000 Grammont Law posters which were sent to every primary school teacher in France. The Ministry of Agriculture authorized that the posters be printed on official paper at the national printing works. (BSPA, 1895, p. 217)

Given the generally favorable attitude toward the SPA among the teaching profession it is likely that a significant proportion of new members recruited at the beginning of the 1880 were schoolteachers (see Graph 2). The importance attached to this rise in membership was reflected in the fact that the detailed account of recent recruitment published in the SPA bulletin included a special column dedicated to the primary schoolteachers 
and the schools who had rallied to the cause. In fact the doctrines of the SPA seem to have been entirely incorporated into the demopedic mission which French republicans conferred on the country's "brave army" of primary school teachers. Thus, Chapter 4 of Alfred Mézières's textbook Éducation morale et instruction civique à l'usage des écoles primaires (Moral and civic education for the use of primary schools) outlines men's duties toward animals, and explains to children the contents of the Grammont Law as well as the mission of the SPA:

It is said that at your age you have no pity children [the author writes]. You are certainly without pity when you are ignorant. If you were aware of the harm that your actions cause, you would not commit them. If you think for a moment that animals are sensitive, that they suffer like you, they love like you, then you will not dream for a moment of pulling a little bird's wings off, of breaking the eggs that you find in a bird's nest, or of depriving mothers of the children they are raising. You will do some soul-searching. You will remember that you too are afraid of suffering, of loneliness, of being abandoned. (Mézières, 1883, p. 89)

Following three chapters about duties to oneself, to the body and to the soul, the "elementary morality" lessons advocated gentleness toward animals with a view to molding a citizen who masters himself, demonstrates selfcontrol, does not allow himself to behave with intemperance, and is in control of his conduct, his emotions and his passions (Déloye, 1994, pp. 8889 ). This widespread appropriation of animal welfare by the pedagogues of the Republic undoubtedly modified the significance and the influence of the original demopedic register advocated by elites, who were far more conservative. The animal welfare movement, which had initially been preoccupied with controlling popular violence, was co-opted by advocates of a republican civic order constituted by morally autonomous and responsible citizens. This meant that the integration of animal welfare into the program of moral instruction in the Republic's compulsory education system inevitably had a major impact on the evolution of the sensibilities of the French population over several generations, making shameful certain behaviors which children had indulged in and which, over time, would be made to appear increasingly "monstrous" (pulling birds' wings off, destroying eggs found in birds' nests, etc.). 



\section{5 "Us," the animals and "them"}

\section{Repulsive beasts}

In order to better understand the phenomena described in the preceding chapters it is necessary to examine, going at least as far back as the Renaissance, the changes, in European societies, in both representations of animals and people's emotional reactions to animals. Once again, rather than attempting to relate this story in all its complexity, we should identify a number of general trends which will form the basis for our analysis of the motives underlying the development of mobilizations in favor of the protection of animals. Within the framework of the civilizing process, which we have placed at the heart of our analysis, animality is often set up in opposition to civilized humanity. For Erasmus, for example, there could be no doubt that "differentiation from animals is the very essence of good table manners" (Thomas, 1985, p. 44). As a general rule, the bodily impulses frowned upon in well-mannered society were regarded as spontaneous uncontrolled animal impulses. Indeed, the pejorative notion of bestiality gradually imposed itself as a yardstick used to stigmatize any human behavior which resembled animal behavior either because of its aggressiveness, or its absence of modesty, or, last but not least, its expression of sexual desire. These developments represented not only a modification in the monitoring of manners, but also a significant transformation of human relations with animals.

Popular representations of the animal kingdom and aristocratic heraldic bestiaries were both characterized by a multiplicity of distinctions, positive or negative, flexible, reversible, and independent of one another. The evaluation of animal species - as with the establishment of hierarchical status between humans - depended on a mix of variably applied criteria. Evidence of this complexity can be made out from the frescoes which decorate the walls of the Palace of Justice in Padua. Constructed in 1218, this building used to house the city administrative offices and tribunals, and contains a series of representations of animal figures, both real and fantastic. Some of these figures were associated with the different levels of the tribunal, while others presented allegories of Justice and the Law. The dog, the cock, the panther and the centaur depict the moral virtues men must show in order to live in harmony, in the order established by their creator. This kind of representation of the animal world - rich in distinctions and associations and packed with a wide variety of connotations - was gradually replaced 
by a radical separation of human and nonhuman animals: a rigid division was established between virtuous humanity and repulsive bestiality. In fact, association with pure animality gradually became a way of discrediting behavior which was judged inappropriate. Thus, reformers who mobilized against bullbaiting, the brutality of coachmen, etc., aimed to do more than simply proscribe those repulsive spectacles which upset their sensibilities, and advocate the discipline needed to generate wealth (see previous chapters). They were also motivated by what they saw as the need to make men more human, and to work toward the systematic humanization of their conduct. This strange pleonasm derives from the belief that a man's level of civilization of men is dependent on their capacity to break free of a tenacious and untrustworthy animality. The continuing existence of the practices condemned by moral reformers demonstrated that some men give in to their instincts and show themselves incapable of mastering their latent animality. Once again, this conviction often draws on older religious conceptions, according to which it is man's destiny to be tempted by the forces of the devil. Thus, for example, for William Wilberforce, who was an evangelical Protestant, to tolerate bullbaiting would be "to defend a practice which degraded human nature to a level with the brutes" (quoted in Turner, 1980, p. 24). For William Smith, another leader of the campaign against bullbaiting, to abolish this cruel pastime, would not only civilize the manners of the lower orders, but even make them "rise in the order of living things" (quoted in Turner, 1980, p. 24).

Contrary to what might have been expected, this determination to put pressure on people to abandon animality was in no way shaken by new representations provoked by observations of the animal world, or advances in a number of fields which would, at first sight, seem to support the idea that nonhuman and human animals were closer than had previously been thought. Comparative anatomy, in the wake of pioneering work by Edward Tyson, found that, notwithstanding differences between species, there were numerous similarities between organisms, notably between chimpanzees and human beings. Jean-Baptiste Lamarck's theory of evolution, and to an even greater extent Charles Darwin's The Origin of Species (1859) "encouraged the view that men were only beasts who had managed to better themselves" (Thomas, 1985, p. 173). Nevertheless these observations - attesting to the closeness between humans and animals - far from allaying fears regarding man's bestiality, actually strengthened the convictions of those who were determined to work to improve the mores of their insufficiently civilized contemporaries. Indeed, Darwin's theory of evolution was quickly assimilated by the most conservative sections 
of the British social elites, albeit in a watered down form which made it compatible with religious belief. It is notable that when members of the RSPCA referred to Darwinism it was not to discuss its scientific validity, but to draw moral consequences from it, regarding the duty to be kind to animals and to struggle against the bestiality of men (Turner, 1980, pp. 6o-62). A strong prejudice established itself in animal welfare circles, namely that a remedy needed to be found for the fact that some human beings, more than others, shared the ignominious brutish properties of animals, where a brute is understood to be "an animal devoid of reason" or "an animal considered in terms of its least human characteristics" (Littré, 2004, p. 654). In fact, the first animal protection movements were built on an ambivalent representation of the relationship of humans with animals. On the one hand being kind to animals was regarded as being a distinctive feature of respectable milieus: "Pity, compassion and a reluctance to inflict pain, whether on men or beasts, were identified as distinctly civilized emotions" (Thomas, 1985, p. 245). At the same time the discrediting of certain social groups - "faithless lawless brutes," "savages," "primitives," "barbarians" - led them to be associated with the most repulsive features of animality. Such prejudices underpin, firstly, the success of physiognomy, as theorized by Cesare Lombroso, who claimed to be able to identify common facial traits in criminals, anarchists and the great apes, and, secondly, the prejudices of colonial anthropology, according to which the Indo-European peoples are largely devoid of animality, whereas even an intelligent dog would be capable of thinking on a par with that of a Bushman or an Indian (quoted in Turner, 1980, p. 65). In contrast to later developments, which will be discussed below, the main initial effect of the methodical observation of the similarities between animal species and certain humans was not to generate sympathy for animals, but to infantilize and attribute a lower status to peoples who allegedly resembled animals.

Monkeys, especially those from the old world, [writes Dr. Monin, for the attention of his colleagues at the SPA] are better at reading facial expressions than children; they sympathize with the pain of threatened animals and go to their aid, and they dream, which is a sign of a vivid imagination. They also have an idea of what property is. Like children and savages they love shiny things, they have a basic grasp of weight, numbers, and colors. They even have their own special language, a kind of murmuring made up of vowel sounds, which bears a striking relationship to the primitive languages of certain savages. (BSPA, 1883, p. 50) 
Thus, it is apparent that there is a close articulation between, on the one hand, the stigmatization of the bestiality of certain humans, and, on the other hand, the processes of setting "Them" up in opposition against "Us." These processes of differentiation, as we shall see, came in various forms which relied on the definition of national qualities, the perception of regional differences, and the competing legitimization strategies of dominant groups.

\section{Distinctive national virtues}

Disgust at the bestiality attributed to certain humans, pride at distinguishing oneself by one's gentle treatment of animals: the emotions experienced and displayed by the first animal protection activists sets up a clear differentiation between "Them" (the brutes, in the way they treat animals) and "Us" (the righteous, in the way we treat animals). In the century of triumphant nationalism, it was inevitable that distinctions of this kind would be associated with the praising of virtues which, supposedly, characterized the people to which the animal protectors were proud to belong. Thus it was not uncommon for British pioneers of the animal welfare cause to mention the need to "purify the country from foul and disgraceful abominations" which were common practice in Europe (quoted in Li, 2000, p. 268). From this perspective, ill-treatment of animals was symptomatic of more generally depraved behavior or, even worse, irreligiosity and revolutionary spirit worthy of a Frenchman, no less! Thus, in a sermon titled "On National Cruelty" the Reverend Thomas Greenwood from Trinity College Cambridge, one of the founders, in 1830, of the Association for Promoting Rational Humanity toward the Animal Creation, attributed "the awful calamity [the 1789 Revolution] which has befallen the nominally Christian France" to its twin atavistic demons of effeminacy and cruelty: a "compound of the monkey and the tiger" (Li, 2000, p. 268). The tone of these attacks was all the more virulent because the moral reformers who congregated in the animal protection societies considered the irreligiousness and Jacobinism imported from France as intolerable threats to the alliance between the Church and the State, which they regarded as the twin pillars of the English nation. In fact, the first animal protection mobilizations took place within a historical context deeply marked by hostility toward the French Revolution and an intense religious revival. The idea that the protection of animals in Britain was something which distinguished it from other, less advanced nations persisted, however, for the rest of the century. Thus, in a sermon given in 
1860, the Anglican vicar Thomas Jackson claimed that bullfighting, which was popular in other European countries, appealed to an archaic fierceness which was absent from the English character and which would remain so, providing his countrymen remained true to their religious convictions.

In modern times the peoples who indulge in bullfighting are the same peoples who enjoy the unhappy distinction of having surpassed all the other peoples of the earth in the arts of torture, as well as having invented the most ingenious methods for inflicting horrible and long-lasting pain on men, women and children. On our own island, the taste for the gallows and the mutilation of traitors has disappeared, along with bearbaiting and the brutal treatment of cattle being dragged to the abattoir; if ever religion and morality went into decline in our land and the old fever for ferocity returned, you can be sure that a renewed inhumanity toward animals would be one of its first symptoms. (BSPA, 186o, p. 334)

Throughout the 19th century national pride and evangelical missionary spirit merged to the point that the protection of animals was equated with the magnificent British oak - traditional symbol of the nation - and contributed to justifying its extension well beyond the boundaries of the Empire. Thus, at the annual conference of the RSPCA in 1933, one speaker chose to emphasize the extent to which compassion for animals and religion were intimately bound up with the civilizing mission which it was incumbent upon England to pursue.

If, when the banner of England is unfurled on distant shores in the cause of Christianity, missionaries inculcate these doctrines of mercy to the brute creation which we labor to diffuse then humanity will flourish, not only at home, but abroad, and the branches of a glorious tree will also extend, so that animals who cannot describe their woes, will find shelter, and sleep under its shade. (Quoted in Li, 2000, p. 271)

Antivivisectionism, more than any other issue, provides evidence of the way in which indignation stirred up by animal suffering frequently sets in motion a process whereby British virtues and continental abominations are differentiated. Although vivisection - the dissection of living animals for experimental purposes - has a long history, its practice only became widespread over the course of the 19th century. Positivism, according to which knowledge should be verified according to experimentation, was widely embraced by scientists working in the fields of physiology, biology, 
toxicology and medicine, and provided the philosophical basis for the use of a practice now regarded as being the most reliable means of achieving scientific progress. The British medical profession, however, unlike scientists in Germany, France and Russia, resisted the use of vivisection. When, in 1824, François Magendie - who operated on live dogs as part of research into the differences between motor and sensory nerves - performed public demonstrations of vivisection it provoked a scandal in London, where his methods were regarded, and described, as being barbaric and belonging to another century. Richard Martin, who sponsored the first legislation to protect cattle from ill-treatment, denounced vivisection in a speech in the House of Commons. For British animal protectors what these foreigners were doing, supposedly in the name of science, seemed as horrible as anything butcher boys got up to, if not more so. The idea that such horrible practices could be imported to a country which hitherto distinguished itself by the gentleness of its mores helped recruitment to the cause. In a sermon from 1860 the Anglican priest Thomas Jackson issued a warning: "Humankind blushes at the cruelties committed in cold blood on animals by certain physiologists and, until quite recently, it was to be feared that our medical students in the English and Scottish capitals would follow this deathly training!" (BSPA, 1860, p. 337). The danger was thought to be so great that animal protectionists considered it wise to take preventive measures and counter the vivisectionist threat by treating the countries of Europe as "mission territories," where this evil had to be destroyed at its source, before it has the chance to spread: "Mr. Harrison, a member of the Victoria Street Society [...] added that another reason to choose Paris over London as the host of the first congress is that cruel vivisection experiments take place in Paris, and that it is in Paris where there is an urgent need to react quickly" (BSFCV 2 [1884], p. 6).

One of the fiercest attacks against vivisection was launched by Frances Power Cobbe, the daughter of a landowning Dublin magistrate, himself descended from a prominent Anglo-Irish family: many members of the Cobbe family had distinguished themselves in either the British Army or the ChurchError! No bookmark name given. of England (she had at least five archbishops among her forebears). After the death of her father, Cobbe took a trip comparable with the "grand tours" undertaken by well-to-do young men from the 17th century onward. Traveling through Italy was, of course, an essential part of the itinerary of any grand tour, and, on her return, Cobbe wrote an account of her Italian travels: Italics: BriefNotes on Politics, People, and Places in Italy, the tone of which left the author in no doubt as to the superiority of British civilization. In 1863, while she was 
staying in Florence, Cobbe, who had recently published an article entitled "The Rights of Man and the Claims of Beasts," launched a campaign against the German physiologist Moritz Schiff, who used vivisectionist techniques. She wrote a memorial address, which was signed by 785 Florentines, as well as a letter of protest to the Daily News which was picked up and published shortly afterward by the Florence newspaper La Nazione (Guarnieri, 1987). Cobbe's comments suggest that she envisaged a campaign to enact laws in Italy, modeled on the legislation already in force in Britain.

Inquiring last winter of the probabilities regarding a "Martin's Act" for Italy, I was informed, by gentlemen well acquainted with the country, that the passing of such a law might be effected, but that its practical use, even in Tuscany, would be null [...]. I do not feel sure, however, that my informant was right in this matter, seeing that 785 persons, from the highest to the poorest in Florence, were found willing, last winter, to attach their names to a memorial against the practice of vivisection at the Specola. (Cobbe, 1864, p. 103)

The experience of attempting to spread British mores abroad made a mark on Cobbe and, over a decade later, she went on to found, in London, the Society for the Protection of Animals Liable to Vivisection, this time with the aim of combating the spread of the practice within Britain itself. In doing so Cobbe contributed to the mobilization, which thus resulted from the indignation over an experiment conducted in public by a foreign scientist. In 1874, the French psychiatrist Valentin Magnan, who had been invited to the annual meeting of the British Medical Association to present his work on the effects of alcohol, was preparing to induce epilepsy in a dog by injecting it with absinthe when several members of the audience intervened violently to put a stop to the operation (Hamilton, 2004, p. xxii). Magnan was obliged to leave the country in some haste, to avoid being the subject of legal proceedings: the RSPCA had lodged a complaint against the French psychiatrist and the organizers of the meeting, accusing them of cruelty under the provisions of Martin's Act. Over the next two years a dozen or so antivivisection societies were created across the whole country, although Cobbe's organization, now renamed the Victoria Street Society, remained the most influential. To the members of the antivivisectionist movement the fact that the practice had now begun to become more widespread in British scientific circles made their cause more urgent. In 1873, Burdon Sanderson wrote the Handbook for the Physiological Laboratory, intended for British students, while significant numbers of British scientists started 
to use vivisection in an effort to catch up with their European counterparts. From around this time, British opponents of vivisection were largely engaged in stirring up two complementary fears: firstly, the concern that, in the absence of vigilance, a practice regarded as alien would intrude onto British soil, and, secondly, that experiments on animals would soon lead to experiments on human beings.

Let nobody think [writes Cardinal Manning, the Archbishop of Westminster] that we are somehow exempt from the terrible mistakes which are being committed on the continent. I love my country and my compatriots, but I would be wary of the idea that things which take place abroad will not or could not happen here; and, if I thought that at the moment England had been granted a partial exemption, I would say: "Let us be careful not to suffer the effects of what is happening on the continent, as it is inevitable that whatever happens abroad will soon after happen here, unless we make it impracticable." (BSFCV 2 [1885], p. 29)

It starts with animals and continues with humans [...]. Sir [writes a reader of the Zoophilist], allow me to draw to your attention the serious danger to which our hospital patients are exposed. With each passing day it becomes clearer that, once experiments have been performed on live animals, the next step is experimenting on poor people who have no family or friends. And with each passing day it becomes clearer that these experiments, which have become so common abroad, meet with the approval of certain circles within the medical profession in England. (BSFCV 12 [1898], p. 16)

French animal protectionists showed themselves to be no less keen than their British counterparts to frame their struggle in terms of a defense of customs, customs which distinguished the French from other peoples, judged to be more "barbaric." From this perspective, the role of foil to the civilized Frenchman, threatening to invade France, belonged to the people who lurked just over the Pyrenees. Indeed, as early as in 1855 members of the SPA were expressing alarm at the idea that bullfighting could be allowed to spread onto French soil.

In the course of the work of [the SPA] a worrying and unexpected rumor has come to our attention. Apparently there have been discussions regarding the introduction into France, indeed into Paris itself, at the very heart of the civilized world, those pleasures which, because of the 
gentleness of our customs, we have hitherto kept at bay. (BSPA, 1855, p. 114)

A rumor was going around that in the very near future bullfights - Spain's national shame - were going to be held in Paris, and you were very upset, you and all the societies in Europe; but, thank heavens, this glorious period, crowned by the Universal Exposition, will not be tarnished; the Minister of the Interior was against it; Monsieur Billault replied to the entrepreneurs who approached him by categorically refusing to authorize the holding of a spectacle which is anathema to our customs. (BSPA, 1855, p. 110)

Bullfighting - the "shame of Spain," "an anathema to our customs" - scoffed at the beliefs of animal protectionists "at the very heart of the civilized world"; during the first fifty years of its existence the SPA never ceased to rail against the introduction onto French soil of Spanish-style bullfighting, a form of bullfighting in which the bull is killed. An understanding of the history of moral protests against bullfighting requires an appreciation of both the heterogeneity and the evolution of the underlying reasons and motives of such protests. An evolutionary perspective is all the more necessary because the codification of bullfighting went through many changes over time. In order to avoid anachronisms, we should therefore carefully identify the "victims" of bullfighting, whose suffering provoked the indignation of its opponents. It is clear that, at first, the fate of the bulls was in no way regarded as a cause for concern, even by animal protectionists. The stabs that the bull inevitably received did not allow it to have any claims to the status of victim, which initially, in the minds of the animal protectionists, was reserved for horses.

The bull is destined to be eaten, as it is established in advance that his meat will feed men. It is true - and it is a health argument which the Protection Society should add to its list of arguments for stopping these combats - it is true that, because of the states of fatigue and overexcitement of the animal preceding its death, there is a risk that its meat will not be palatable, or even healthy. It is therefore distributed among members of the lower classes, who eat it at their risk and peril: but it is nonetheless true that in a certain way it fulfills its destiny when it dies in the arena. The stabs which it receives are not deep wounds and are only intended to agitate the bull. Furthermore the animal is almost invariably killed outright thanks to the remarkable skills of the matador. (BSPA, 1855, p. 117) 
Until their final hour, the victims of the cruel games which we have studied - stags hunted with hounds, pigeons used for shooting, fighting cocks and bulls used in corridas - have all "lived their lives." This is emphatically not the case for THE HORSE. The real victim of the arena only yesterday worked our fields, transported the stones used to make our houses, and was our companion on the front. He worked in the town and in the countryside, he toiled, he suffered, he grew old in the service of men, he lived side by side with us, he gave us his all. And now, today, for the depraved delectation of the spectators in the arena, the picador will put a blindfold over his right eye, to remove any chance of him being saved. He will use him as a shield, and he will be offered up, a living target, to the bull's horns. (BSPA, 1933, p. 10)

In this regard it is worth recalling that for many decades the picadors' horses were equipped with absolutely no protection against the often deadly attacks of the bulls, so that the goring of horses was a common sight at bullfights. The SPA, whose membership included many horsemen, often of aristocratic stock, felt that they had no choice but to take a stand against the ill-treatment of this particularly noble animal: "the sad fate reserved for the horses which participated in these bloody celebrations had attracted the attention of the society for some time" (BSPA, 1855, p. 114). In fact the description of the suffering of the picador's mounts, their cries and their desperate attempts to flee as they tripped over their own guts, as well as the horrified accounts of spectators, constituted a sensitizing device which was frequently mobilized in order to provoke emotional reactions of shock, disgust and revulsion, which would lead to calls for the immediate prohibition of bullfighting.

The dismounted picador walks away, and the bull, distracted for a moment, wastes no time coming back to the horse, laying in the sand, and goring him once more. So the real martyr, the principal victim, in this bloody spectacle is the horse. (BSPA, 1855, p. 117)

"It was during a bullfight, I was in the front row of the terraces, two meters away, against the fence. A picador had come to lean against his old black horse. One of the horse's eyes was blindfolded, so that he could not see the arena. The other eye which was on the side of the horse next to me, was uncovered, gentle, vaguely concerned, vaguely sad. Suddenly, the bull charged, and with a soft thud, its horn went straight through the horse's belly and made a knocking sound as it made contact with 
the fence. The horse did not budge, did not cry out, the skin on his bony neck just wrinkled a little. But his eye, the eye which was looking at me, was getting bigger, swelling horribly, and, as the bull dug his horn deep into the belly of the creature who was dying in stoic silence, I could see in his eye the horrible surprise that man could be so cruel and ungrateful." This is what bullfighting is like - this is the fate that horses used in bullfighting sometimes suffer; sometimes, because, more often than not, they suffer an even worse fate. In fact the horse is sometimes not killed outright. Life clings to him and, despite having been gored, the animal has to continue to provide entertainment for the crowd. We then witness a double treason. The horse - who was raised with care by men, has worked alongside men, is used to men's voices which he has quietly obeyed, and has trusted men - still does not comprehend the tragic event of which he is the victim. He cannot believe that the person who was his master could be capable of such a despicable act and once more he turns, mutilated, losing his blood and his guts, to men, and once more, he is betrayed. (BSPA, 1933, p. 11)

Recourse to such an sensitizing device was bound to have an effect. Firstly, these initiatives certainly helped stir up the emotions which were needed to fuel collective mobilizations and the sense of moral reward for the activists opposed to bullfighting (Traïni, 2009). Furthermore, as sensibilities evolved, criticism of the fate of the horses used in bullfighting seemed to have convinced the majority of aficionados themselves that the treatment of these animals was scandalous, and called for reform. In 1928, the dictator Primo de Rivera, who was keen for Spain to be regarded as a modern civilized country, made it obligatory for horses to be equipped with protective padding, to "avoid these horrible spectacles which so disgust foreigners and tourists" (quoted in Baratay, 1997). Now that horses were afforded protection from being gored by the bull, opponents of the corrida were robbed of an argument which had, throughout the 19th century, been central to their cause. Several decades went by before the status of victim would be claimed on behalf of the bull itself, as the suffering it experienced came to be part of the sensitizing devices used by antibullfighting campaigners. Today it is not rare for the activists to take the sensitization process regarding the horrors of the corrida a step further, by inviting the public to imagine things from the point of view of the bull. Such an attitude, which accords the bull the status of a victim worthy of compassion - which would have been inconceivable to animal protectionists in the 19th century - was only conceivable after a series of developments which will be examined in our final chapter. 
For now we should note that in the 19th century, while opponents of the corrida were certainly angered by the ill-treatment of horses in bullfighting arenas, their principal concerns were over the emotional states of some of the aficionados in the crowd. This should come as no surprise: opposition to all styles of bullfighting, not just Spanish-style bullfighting where the animal is killed, was very much part of the wider movements to control popular violence which have been analyzed in previous chapters. We have already mentioned that the very first British animal protection campaign expressly undertaken to combat the brutality of the masses - was conducted in 1820 , and sought to suppress bullbaiting, which was reasonably common in England at the time. Like their English counterparts, members of the French SPA were steadfast in their opposition to any regional and popular traditions liable to whet the appetite of the working classes for cruelty and violence: "as regards cockfighting and bullfighting we have every reason to be surprised [...], that the efforts of the society, the decrees handed down by civil servants, and the successive edicts of the Interior and Agriculture Ministries have obtained so few results" (BSPA, 1883, p. 38). Bullfighting in the South of France and cockfighting in the North were equally subject to condemnation because of the large gatherings of common people that such deadly fighting spectacles could attract. The SPA could not "remain indifferent to these forms of entertainment in which defenseless animals die, after being cruelly tortured for the amusement of crowds who have come looking for excitement" (BSPA, 1855, p. 114). Once more, the scandal being denounced here was less to do with the suffering inflicted on animals than the worrying predispositions and uncontrollable urges these activities were suspected of provoking in those who enjoyed watching them. Tolerating spectacles of this kind would have involved ignoring one of the most powerful rallying calls of the earliest animal protectionists, namely the need to avoid the spilling of blood in public, "hide killing in order not to put the idea of killing into people's heads" (Agulhon, 1988, p. 249). Bullfighting was presented as "the worst school of cruelty and nothing more than a succession of acts of torture. How can it be, when all over France bylaws forbid the slaughtering of animals in public places, in front of children, that there are those who call for the legalization of such bloody, scandalous performances?" (BSPA, 1895 , p. 71). Once again, the accusation was that cruel spectacles performed within arenas contribute to violence and delinquency, which threatened to break out on every street corner:

And here is the crime that you, lovers of bullfighting, want the law to leave unpunished! It is indeed the moment for such tolerance! When crime 
rates are steadily rising, when most assassins and criminals are between the ages of 17 and 20, when carrying a knife is becoming more common, you want these hateful, bloody, sickening and demoralizing spectacles to be allowed to take root in France, and declared legal! (BSPA, 1895, p. 70)

And so with these COCKFIGHTS do we sink further down the scale of cruel games [...]. The owner of the cock is not only preoccupied with taking care of the "material," he also educates the animal, he does his best to pass on his talent for wickedness, he nurtures the bird's fighting instincts [...]. The knife of the man is hidden under the feathers of the bird [...]. It is a villainous pleasure. The thug is in his element, he looks for and finds his own instincts, he judges the attacks, the parries and the low blows, he celebrates the victory of the strong. (BSPA, 1933, p. 10)

We should note that these familiar well-rehearsed arguments were initially not confined to bullfighting. Before focusing their campaigning efforts on the Spanish corrida, with picadors and the killing of the bull, 19th-century moral entrepreneurs expressed a wide-ranging aversion to any form of entertainment suspected of leading people to abandon the disciplined behavior and peaceful manners expected of them: the list of these activities included fights between animals, the game of burying geese up to their necks and then stoning them, as well as all the different styles of bullfighting. Thus, in 1873, the Beulé circular, in the context of the reestablishment of moral order dear to MacMahon, after drawing a distinction between bull-running and bullfighting, proposed that both these activities should be prohibited:

This kind of spectacle, which is likely to lead to serious accidents [...] and which is also of a barbaric nature, can but accustom the people to seeking to experience violent and unhealthy emotions associated with the sight of blood. Given that such a trend, and the kind of stimulations which could perpetuate and strengthen it, are, in my opinion, likely to have harmful consequences for the habits and customs of the nation, I invite you to withhold permission to hold bullfights and bull-running. (Quoted in Pierre, pp. 610-611)

In 1876 , the members of the SPA were angered by what they saw as the first steps toward a potential climb-down, implicit in the distinction drawn in the circular, insofar as it could eventually lead to the prohibition of "bloody" sports, but would not extend to games of skill much loved by the working 
classes but viewed with suspicion by the social elites (Pierre, 1998, p. 612). As we have already noted, the belief that working-class violence must be repressed was one of the earliest and most commonly stated motives behind the campaigns of all the pioneering animal protection societies in Europe. In France, however, moral protest against working-class games has another dimension, resulting from the country's cultural and political centralism. Throughout the 19th century and well into the 20 th the French animal protection movement was a largely Parisian phenomenon, and struggled to make inroads into the rest of the country: in $1870,60 \%$ of SPA members were from the capital, in $187772 \%$, in $189278.2 \%$, and as late as $191177.2 \%$ (Pierre, 1998, p. 170). It can be adduced from the writings of certain eminent members of the SPA that the very Paris-centered nature of the movement led animal protectionists to regard the provinces as mission lands to which the animal protectionist word needed to spread. This is made very clear by documents such as "Project for the Extension of the Society for the Protection of Animals," discussed at the annual general meeting of the SPA in 1886, or "The Protection of Animals in the South of France," presented the following year by the secretary general of the society. The long extracts from these documents quoted below give a clear picture of the extent to which the French regions in which the Spanish corrida gained in popularity at the very end of the 19th century were formerly regarded as "barbarian" lands because of their attitude toward animals and blood:

Thanks to its large membership and its financial resources, the society has succeeded in exerting a healthy influence in Paris. Ill-treatment of domesticated animals is constantly monitored, reported or stopped, and, it must be said, to the credit of France's first city, that these kinds of incidents are becoming increasingly rare there. The same cannot be said, however, for the provinces [...] one witnesses so many shocking scenes of such cruelty and brutality to domestic animals that one wonders whether those who have no fear of committing them in public are not still savages and barbarians. We must work against these kinds of abuse; we must combat and eradicate these rough manners, these violent habits, these deep-rooted traditions. The society would not be equal to the task which has been given it, and would not live up to public expectations if it did not carry out its investigations outside the city limits, and extend its mission, in order to protect all the victims of the fierceness of a few people, as far as France's frontiers! (BSPA, 1886, pp. 277-278) 
Last year, at the same time of the year, we opposed bull-running in the South of France [...]. Encouraged by this recent campaign on the Spanish border, and convinced that this kind of animal protection tour can greatly benefit the cause that all of us here defend with all our might, we considered it important to undertake another peregrination this year. We should say immediately that although we have observed a great deal of progress it is also true that in certain localities people are unaware of the existence of the protection societies or the provisions of the Grammont Law. The temperament of Southerners, which is well known, seems to close their hearts to human feelings, to that loveable goodness and that universal love that we must have for everything that suffers [there follows a description of three Basque bear tamers]. Two children, dressed in the Spanish style, who could not have been more than twelve years old, led their little carriage, which was drawn by a donkey, across the town esplanade. We soon noticed that these children were not only dressed like our neighbors from the other side of the Pyrenees, but that they were displaying the same lack of sensitivity. Indeed, they prodded their animals with a stick which had a nail attached to the end. The nail was more than 10 centimeters long. (BSPA, 1887, pp. 281-282)

[Commenting on a description of children and women who, at Luchon, watched the butchers at work.] This is a faithful account of our trip in the South of France. We have noticed that a great deal of progress has been made there; we intend to spread and develop ideas about animal protection, bringing new reforms and new improvements every year; the authorities are supportive, they will help us and we have grounds to be hopeful that the South of France, so cruel, so blind, so resistant to all human feeling, will in time allow itself to be enlightened by the protective beacon of our society, which guides men toward the path of morality and justice. (BSPA, 1887, p. 307)

During corridas horses were ill-treated, and crowds were whipped up to dangerous levels of excitement; these practices seemed to be particularly welcomed by "those cruel people in the South of France." We can understand why several generations of French animal protectionists prioritized campaigns outlawing bullfighting. With the rise of nationalism, protests against the corrida took on an even greater intensity. Imported from Spain, bullfighting with picadors and the killing of the bull provided an instance of foreign barbarity, and hence a means of highlighting, by contrast, the distinctive virtues of the French nation. To the long list of reasons to be 
repelled by this practice could be added its national origins: the indignation provoked was further fueled by the fact that it was regarded as a harmful foreign custom intruding onto French soil.

What is going on? Will some citizens, emboldened by the impunity they are enjoying, be permitted to break the law to the point that they can offer the public the kind of monstrous spectacle we criticize our neighbors on the other side of the Pyrenees for performing? Monstrous spectacles so at odds with the religious spirit they claim is theirs, and which, in any case, cast a shadow over our civilized mores. (BSPA, 1883, p. 38 )

I appeal to the souls of the deceased volunteers of ' 92 , the heroes of the Republic and the Empire, to those of 1870, who sleep on the battlefields, along the border, and of the heroes of Tonkin and Dahomey. Ask the souls of our children who will spill their blood in Madagascar! Ask them whether - in order to serve under the French flag and be killed defending the honor of the nation - they need to remember the ephemeral glory, the dangers and the excitements of the arena! Oh gentleman, let us leave Spanish customs to the Spanish! Let us remain first of all and in all ways French. It is the best course of action and enough for us. (BSPA, 1895, p. 72)

All the indications are that before very long bullfighting on French soil will be no more than a bad memory. For this we owe a debt of gratitude to Mr. Ulrich. I believe that, in his struggle to defend our doctrines, he performed patriotic works. Defending one's territory from foreign attack and defending it from harmful foreign customs are identical acts which serve the honor of the nation. (BSPA, 1896, p. 136)

Like vivisection in England, the corrida was described as a regression unworthy of the gentle manners which - thanks to the vigilance and commitment of animal protectionists - set the French nation apart. Thus, just as Valentin Magnan was forced to flee England in 1875, Mazzantini, a Spanish matador who was preparing to fight a bull in Bayonne, was deported by the French government in 1895. The condemnation of foreign bestiality, driven back across the borders, often goes together with the celebration of a national community, among whose many qualities kindness to animals occupies pride of place.

This luxuriant flowering of fine disinterested feelings is the pride of our age, and, above all, the pride of our country. But who does not see that 
one of the foremost of these creations is the work of the Society for the Protection of Animals? Who does not sense that the love of animals is one of the best and one of the purest of these many admirable, patriotic virtues? The protection of animals is an integral part of our complete, rich and varied intellectual and moral heritage, which we will pass on to the 2oth century, which is soon to dawn, but whose course is so uncertain! (BSPA, 1886, p. 141)

In the 2oth century, and particularly in the context of the rise of xenophobic nationalistic movements in the 1930s, the tone of these declarations hardened. SPA newsletters bristle with hostility toward the figure of the foreigner, whose ways threaten to corrupt the country. Members of the SPA are outraged that towns in the South of France demand "every summer, their bloody festivals. And [that] when troops of Spaniards arrive, a lot of money is spent. We are aware that when we campaign against bullfighting, and all other cruel sports, we are campaigning for the improvement of the race, for respect for life, and for peace" (BSPA, 1933, p. 12). Senator Louis Martin, for his part, expressed his indignation that efforts were being made "to put on bloody spectacles, a development which runs counter to the generosity of our race" (BSPA, 1935, p. 9).

It is therefore clear that opposition to the introduction of the corrida to France has a long and bitter history, making the fact that it became established in certain French regions perhaps something of a surprise. In fact, it would seem that, paradoxically, opposition to bullfighting actually helped the cause of its apologists, by resulting in it being associated in people's minds with other styles of bullfighting which were well established and appreciated in a number of towns in the South of France. Indeed, as we have already noted, the expression of opposition to bullfighting, by the SPA in Paris and the public authorities, began long before the introduction of Spanish-style bullfighting in 1854. A variety of traditional sports involving bulls - courses provençales, courses landaises, taureau à la corde, bouvines, etc. - sometimes not fully codified, and associated with seasonal rural festivals, had been a matter of some concern to local authorities, who regularly sought to ban them, on the grounds that they were a threat to public order. During the Second Republic, the crowds which assembled for these festivals would turn into democratic mobilizations against the authoritarian regime, which was regarded as being distant and arrogant. The mobilizations were further fueled by popular anger at the harassment by those prefects who tried to ban these events (Agulhon, 1988, p. 276). Under the Second Empire, the authorities, having succeeded in stamping 
out the opposition of republican agitators, were less worried about popular gatherings and thus willing to tolerate bullfighting. The first corrida where the bull was killed was held in 1854, in Saint-Esprit-lès-Bayonne, under the benevolent gaze of Empress Eugénie de Montijo, who had Spanish ancestry. Because of the patronage of the empress, members of the SPA could not be too openly critical of the practice, for fear of incurring the displeasure of the emperor himself. Under the Third Republic, the controversy surrounding bullfighting mounted, and took on new meanings which would ultimately strengthen the position of its apologists. On the one hand, it was once again possible to directly criticize the corrida, on the grounds of its "bestiality" and the fact that it was alien to the French national genius, and in 1881, 1884 and 1886 the SPA managed to have the practice prohibited. These bans were generally respected throughout the country, including the South, and proper bullfighting events - such as the one organized in Paris in 1887 by a charitable organization, in aid of flood victims in the South of France - were actually quite rare at this time (Pierre, 1998, p. 615).

Contrary to a myth subsequently devised and promulgated by bullfighting aficionados, there was no suggestion at that time that there were definite affinities between the corrida tradition and the South of France (Baratay, 1997). In fact the 189 os witnessed a turning point in the history of bullfighting in France, with key initiatives taken by protagonists on both sides of the debate. On the one hand bullfighting impresarios redoubled their efforts to be allowed to operate all over the country; the first bullfighting reviews were published in 1888 (Le Picador and Le Toréador) and in 1889 (Le Torero); and bullfighting clubs were founded in Nîmes (1896), and Arles (1897). On the other hand, opposition to tauromachy intensified, bringing together such motley characters as the president of the SPA, the chief veterinary officer of the army, Ulrich, and the libertarian journalist, Séverine. The prioritizing of combating bullfighting in the Paris SPA was aided by the fact that it was a cause which generated indignation throughout the society and thus served to unite it, whereas issues such as the eating of horse meat and shelters for dogs had been divisive. The fierceness of the campaign, essentially launched from the SPA's Parisian stronghold, quickly elicited a reaction from the Southern citizens, for whom liberty and the protection of regional specificity were powerful rallying cries. The memory of the bans regularly imposed in the past on traditional French bullfighting facilitated the assimilation of the Spanish corrida with "traditions" treated with contempt by a centralized power scornful of the South. So, although the corrida had only been an established presence for a few years, it came to symbolize local freedoms. In October 1894, the radical socialist mayor of Dax and 
future Minister of the Colonies, Raphaël Milliès-Lacroix, was dismissed by the president of the Council of Ministers and the Minister of the Interior for authorizing the staging of a Spanish-style bullfight (Traimond, 1995). On 16 July 1895, the mayor of Mont-de-Marsan and his deputies handed in their resignations to the Prefect of Landes as a protest against the prohibition of corridas in their town.

Under the Third Republic, supposedly a "regime of liberty," but where in fact there is certainly less liberty than under the Empire, we are ruthlessly deprived of our most cherished liberties, local liberties. Since, despite the solemn and benevolent promises of the authorities, we have not been able to put on at our local festivals the spectacles which our fellow citizens love above all others, and which we solemnly promised would be held. (BSPA, 1895, p. 122)

This rapid rise of the corrida to the status of local tradition was given further impetus by the development of regionalist movements which promoted a wide range of cultural practices which were presented as capturing the essential spirit of the place: language, cuisine, clothing, music, festivals, the art of hunting, etc. When the Félibrige movement was at its height, Frédéric Mistral, although no fan of bullfighting, and well aware of the contrived nature of comparisons between Provençale games and Spanish bullfighting, attended the corrida organized in 1894 in order to register his protest against the presidential circular prohibiting them (Baratay, 1997, p. 321). Thus, the context was particularly favorable to the corrida. Being increasingly the target of criticism from its detractors from the North eased its assimilation within a Southern cultural heritage, justifying mobilizations against what was seen as dangerous meddling by central government, judged to be contemptuous and authoritarian. Some of the declarations made by opponents of bullfighting, quoted above, reveal that one of the favorite arguments of the countermobilization movement, namely the idea that people in the South were treated with condescending paternalism, had plenty of basis in fact. Bullfighting impresarios, aficionados, promoters of regionalism, and defenders of local freedoms experienced common emotions, and called for the denunciation of an insult to a group whose dignity needed to be reaffirmed (Traïni, 2003a). In such a context defenders of the corrida were able to benefit from resources, resulting from what some specialists in collective action term frame alignment (Snow et al., 1986). This indicates that they were able to promote the idea that the defense of tauromachy is indissociable from other typically Southern preoccupations: local freedoms, 
the culture unique to the félibriges, the development of regional pride, the desire to influence the center, and the kind of rebellious spirit which would soon, in 1907, find expression in the revolt of winegrowers in Languedoc, etc.

Given that these mobilizations occurred in the heart of one of its most loyal electoral strongholds, the young Republic could not take the risk of alienating its electorate over a matter judged, at the end of the day, to be of secondary importance. Indeed, certain politicians whose constituencies were in the South of France lobbied to block the repressive policies which the opponents of bullfighting were calling for. Thus in 1896, after the formation of a government in which the Interior and Justice Ministries were occupied by deputies from the South, the government decided that the corrida would be tolerated. Loud expressions of dissent from opponents, noisy debates in parliament, and legal arguments over whether the Grammont Law applied to the corrida (Mieussens, 2005) periodically broke out over the next fifty years. In the 1920 s and 1930s, as criticism of the strangeness of the Spanish corrida intensified, aficionados were able to count on the support of intellectuals and artists who, like Montherlant, Bataille, and Leiris, emphasized the sublime nature of bodies fighting and of confused emotions, thus providing an aesthetic appreciation of the corrida ${ }^{15}$ (see Boltanski on the aesthetic topic [1993]). The endless debates between opponents and supporters of bullfighting were finally addressed by legislators on 25 April 1951. The new law represented a compromise: bullfighting was found to fall within the provisions of the Grammont Law and therefore pronounced illegal, except in places where an "uninterrupted local tradition" of such fights could be established. The withdrawal of this exception in the law has been subsequently campaigned for by antibullfighting associations such as the Comité radicalement anti-corrida, the Fédération des luttes pour l'abolition de la corrida, and the Alliance pour la suppression des corridas, all created between 1991 and 1994 .

\section{The established, the challengers and the excluded}

Hitherto the elites behind the first mobilizations in favor of the protection of animals have been presented as the members of a group united by their revulsion at the bestiality of the lower orders. It is now important for us to correct the misleading impression that animal protectionists

15 About the aesthetic topic see Boltanski [1993]. About the controversy that aesthetic appraisal of corrida can provoke see Heinich [1992] and Traïni [2003b]. 
were a homogenous group, by offering a ternary distinction - between the established group, the challengers and the excluded - which reflects the variety of motives of the first animal protectionists. This perspective relegates the lower classes to the role of passive targets of those who attempt to exclude them, because of their supposed inferiority (Elias and Scotson, 1997). The upper classes, on the other hand, are divided into two subgroups on the basis of the two competing forms of accreditation which they sought to promote. Here accreditation indicates the behaviors and discourse through which the members of these groups "attempt to present their own qualities, expertise and experience as making them uniquely qualified to determine the common good of the community" (Traïni, 2003a, p. 4). Thus, on the one hand, the established group endeavors to maintain the primacy of the qualities on which their dignity, self-respect, power and respected status rest. On the other hand, the challengers, or "the middle classes operating on two fronts" (Elias, 1985, p. 302), did their utmost to emphasize the qualities which enabled them to question the superiority of the upper classes while not challenging what distinguishes them from the lower orders. This phenomenon made an important contribution to the spreading and intensification of the civilizing process, insofar as the challengers attached ever-increasing importance to methodical and constant self-control, the mastering of impulses, and promotion of introspection. Between the $17^{\text {th }}$ and 19th centuries relations between the establishment figures, with their connections within the aristocracy and the clergy, and the challengers, whose origins were bourgeois, presented very different balances of power and forms of accreditation within the various European national configurations (Elias, 1973, 1996).

In England, the bourgeois middle classes operating on two fronts - who managed to move up the social scale in the direction of the establishment - tended to present themselves as champions of moral excellence inspired by Christianity. Indeed, the upward social mobility of the bourgeois classes seemed closely linked to the proliferation of religious movements and Protestant sects which developed in parallel to the Church of England. ${ }^{16}$ Thus the challengers particularly valued close study of the Gospels and their practical application in everyday life. The challengers aimed to embody and display Christian rectitude, to not only distinguish themselves from the

16 Several specialists on the history of England have noted that in the Victorian era many members of the upwardly mobile middle classes had a nonconformist Protestant, often Methodist, background (Bédarida, 1990, pp. 128-134; Charlot and Marx, 1978, p. 19). Subsequently, membership of these movements spread well beyond its core social base. 
barbarous masses but also, albeit in a rather more subtle way, from indolent aristocrats. For these champions of Christian morality, being a religious person was not enough: the first principle laid down by the Redeemer ("To Go about Doing Good") requires one to engage in works founded on continual vigilance and discipline. In order to live as a Christian one must not only do good deeds, but demonstrate an unusual capacity to free oneself from habits and temptations which are often regarded as insignificant. The best Christians can be recognized by their temperance and self-discipline, as well as their belief in the power of individual resolve, and in the possibility of continual self-improvement, as part of a quest for perfection. From this perspective, any dealings an individual has with an animal present an opportunity to surpass the standards of those at the very top of the social scale. Thus John Wesley (1703-1791), the founder of Methodism, used a slack rein when on horseback, in order to publicly demonstrate the care and attention which he paid to the consequences of all his actions (Kean, 1998, p. 21). At the end of the 19th century for other evangelists, who were equally keen to display "a high degree of self-awareness and self-control," treatment of insects and other "lower animals" [frogs, minnows, toads and snakes] "became important precisely because that treatment seemed so trifling" (Grier, 1999, p. 104). Furthermore, relationships with animals also provide an individual with an opportunity to test their thoroughly puritanical ability to turn their back on immediate sensual gratification: alcohol, gambling, reading novels, "amusements which violently inflame and gratify [men's] appetites" (Grier, 1999, p. 98). By the same token, as we have already seen, a wide range of popular practices, such as bullfighting or cockfighting, were roundly condemned. The moral excellence of evangelists caused them, like John Wesley, to go further in their rejection of self-indulgence, by giving up wine and meat. Refraining from eating meat appeared particularly virtuous, firstly because meat production involved inflicting violence on animals, and, secondly, because meat constituted an important part of the kind of copious and luxurious diet only the rich could afford.

Thus, the accreditation procedures of the middle classes operating on two fronts, by praising their qualities of rigor and optimal moral vigilance, contributed to the emergence of a new type of animal protectionist. To the prescripters, who were characterized by their aptitude for formulating norms to which deviants should conform, may be added the ascetics, who are able to control and modify their own behavior, with a view to improving the moral order of the world. In Great Britain these accreditation procedures based on ascetic qualities have undoubtedly greatly contributed to the spread of vegetarianism, whose values are widely accepted in Britain, 
particularly among animal protection activists. It is certainly important, once again, when considering the motives for adopting a vegetarian diet, to take into account that some of these motives have a longer history than others, and that they can be heterogeneous, and vary over time. Nevertheless, two particular bodies of evidence explain how the intensification of the civilization of manners contributed to vegetarianism becoming associated with campaigns to outlaw cruelty to animals. Firstly, the decision to give up eating meat can have its origins in feelings of disgust at breaches of the integrity of an animal's body which result in bleeding, injury and death. Thus, John Oswald, a British soldier who had no doubt been deeply affected by horrors witnessed on the battlefield, and was the author of the 1791 work Cry of Nature, recommended the adoption of a vegetarian diet as way of avoiding the sight of animals shedding blood (Turner, 1980, p. 18). Sir Richard Phillips, on the other hand, in the entry on "Diet," in his Dictionary of the Arts of Life and Civilisation, published in 1833 , refers to the traumatic incident which led him to want to distance himself from meat eaters: "at twelve years of age the author of this volume was struck with such horror in accidently seeing the barbarities of a London slaughterhouse, that since that hour he has never eaten anything but vegetables" (Phillips, 1833, p. 571). Secondly, as we have already established, giving up meat could also be a course of action, inspired by Protestantism, which enabled ascetics from the middle classes operating on two fronts - exercising superior moral fortitude - to demonstrate gentler habits than those prevalent among members of the establishment. In fact the creation in 1847 of the Vegetarian Society was largely the initiative of members of nonconformist churches, such as the Bible Christian Church (Tonutti, 2007, p. 65). For nonconformists eating meat, which was often regarded as a "sin of the flesh," represented the antithesis of temperance, on which they sought to base their primacy (Gusfield, 1986). During later phases in the history of animal protection these forms of accreditation, based on ascetic rigor, which required the observation of a particular diet became more widespread, although Christian references progressively disappeared from the rhetoric. ${ }^{17}$ Thus, nowadays, animal protection activists, even more than ecological activists (Faucher, 1998), equate the rigorousness of their dietary regime with the intensity of their commitment to their cause. If they are vegetarians they eat no meat or fish; dietary vegans, also known as strict vegetarians, take their stand against animal exploitation a step

17 This disappearance of Christian references manifests itself in a process of secularization, accompanied by a reinterpretation of the representations which, in Eastern religions, notably Hinduism, provide justifications for following a vegetarian diet. 
further by eating no eggs, milk or cheese, as well as no meat or fish. Ethical vegans, on the other hand, are also careful to avoid using anything whose production caused animal suffering of any kind. This can affect their choice of clothing and footwear, as well as other products they use, and leisure activities, etc. An ethical vegan avoids all animal-derived products, such as leather, wool, fur, or cosmetic and household products which have been tested on animals. ${ }^{18}$

In France, the accreditation procedures of the middle classes operating on two fronts who joined the animal protection movement obviously do not have the same affinities with the ascetic practices inspired by the Protestant reformers. The bourgeois members of protection societies were much more likely to make reference to applied sciences and the philosophers of the Enlightenment than the revelation of the messages of Christ. Thus, as we have already noted above, doctors, veterinarians and hygienists made up a large proportion of the first cohorts of SPA activists. For them, their involvement in the animal protection cause represented an extension of the accreditation procedures through which they attempted to establish the collective value of their professional skills and knowledge. Throughout the 19th century such initiatives caused tension, controversy and conflict within the SPA, where members of the large establishment contingent, who generally had aristocratic backgrounds, were, for their part, anxious to regain the status which had declined during the revolutionary period. Thus, dissenting voices, heard within the society when attempts were made to promote the consumption of horse meat, were a manifestation of underlying power struggles over status within the animal protection movement. Doctors, veterinarians and hygienists from the upwardly mobile middle classes - such as Dr. Blatin, the first vice president of the SPA - believed that the debate over whether or not to eat horse meat provided them with an opportunity to demonstrate the social utility of scientific expertise and knowledge, which guided their own relations with animals. Other members of the SPA, who had aristocratic backgrounds, considered that eating horse meat degraded an animal which the nobility traditionally used to associate with its exceptional status and with its prowess on the battlefield. The resonance of such representations should not be underestimated, especially when we recall, for example, that the first president of the SPA, from 1854 to 1865 , Viscount Pinon Duclos de Valmer, joined the animal protection movement after a career in the military: he had risen to the rank of captain in the lancers during the Bourbon

18 See the website Un monde vegan. pour les animaux, les etres humains \& la planète, http:// www.veganisme.fr/index.html. 
Restoration. Even more exemplary in this regard was another of the leading figures in the SPA, Jacques Philippe Delmas de Grammont, who, apart from giving his name to the first piece of French animal protection legislation, was also a cavalry general and the founder, in 1850, of the French League for the Protection of Horses. In fact, throughout the 19th century many of most influential and highly regarded members of the French SPA were horsemen and, keen to cultivate their upper-class connections, were proud to count among their number a Spanish grandee who enjoyed the unusual privilege of being allowed to enter churches on horseback (Fleury, 1995, p. 33). Under such circumstances it is not difficult to imagine how this kind of activist - already concerned by the way burgeoning industrialization was marginalizing horses - could be outraged by a campaign which reduced this noblest of animals to a mere source of protein - and for the humblest members of society! While eating horse meat prolongs the accreditation initiatives of upwardly mobile sectors of the bourgeoisie, it also excites fears of loss of status among the members of the established group, who stress their links with the aristocracy and its equestrian culture.

Clearly, the motives we have hypothesized are linked to gnawing, illdefined fears and did not necessarily give rise to an intense discursive formulation of the reasons for an aversion to eating horse meat. Moreover - providing further evidence of the heterogeneity of the underlying motives and reasons for animal protection campaigns - opposition to eating horse meat, even within the SPA, was not confined to the indignation of horsemen and horsewomen attached to the prestige traditionally associated with equestrianism. As we shall see in Chapter 7 , there were other SPA members whose indignation was linked to their own subordinate status, which led them to identify with overworked draught animals. For others, their opposition to eating horse meat came out of a more reasoned understanding of basic principles as to what constitutes civilized practices and behavior. In any event, critics of the practice attacked promoters of hippophagy and their claims to have a perfectly rational approach to animal protection, using a procedure which we have already clearly identified, by associating the eating of horse meat with excluded domestic groups or foreign atrocities. Thus, for Dr. Robinet, the public health and economic arguments advanced by hippophages are based on the false premises of an argumentation which, taken to its logical conclusion, could only result in a regression to the cannibalistic practices resorted to by our primitive ancestors. For Georges Noguès, "the [adoption of] hippophagy [which] comes from the Caucasus and Dagestan" should be seen not as civilizational progress, but as a step backward toward the obsolete practices of peoples distant in time and place: 
Members of the Circassian race are sickly, ignorant and superstitious, and as regards commerce and industry restrict themselves to trafficking their young women, who are brought up to be sold into servitude. [... The Circassians who have settled in Constantinople in the Tophane neighborhood, spend their time smoking and shaking off their vermin, and when they have enough money to indulge in a little debauchery will get together with a few of his compatriots, have a whip round and go to Albazar to buy a horse which is no longer fit for work. The animal is slaughtered, and prepared for consumption. No learned society dedicated to the thankless task of trying to popularize the eating of horse meat has derived as much satisfaction from converting people to their cause as the Circassians obtain from feasting on this national delicacy. Here we have an example of a practice presented as an example of European progress which in fact originates from another tradition. (Noguès, 1865, p. 24)

It would seem that humans did not stop eating horse meat because of its taste or any difficulty they had digesting it but that, as they evolved from being savage - in other words in the primitive state where, as a hungry carnivore, they devoured all prey (even other humans) - to offering protection, and a certain level of respect to those nonhuman species who were close enough to them to be able to share their domestic or public lives [...]. After the horse it will be the turn of the dog, despite the fact that its meat is quite unpalatable; and who knows, perhaps even anthropophagy will become acceptable. (Fremaux, 1864, p. 1308)

Statements of this kind, and other evidence, make it easy to imagine the kind of sharp exchanges of views which the topic of eating horse meat must have provoked within the SPA. Indeed, a row ensued after it was suggested that a bust should be commissioned to honor Dr. Blatin's contribution to the society. The project was abandoned due to the fact that this tireless activist had stood on a committee for promoting the consumption of horse meat. The comparison between France and Britain provides further confirmation of the importance of the struggles for status which underlie the debates between supporters and opponents of eating horse meat. The campaign in France in favor of eating horse meat had no British equivalent. The continuing prestige of the aristocracy, and acceptance of the established order of the monarchy by the bourgeoisie, further strengthened opposition to the idea that the horse, an animal whose reputation for nobility was particular well-entrenched in Britain, could be regarded as merely a source of meat. Almost one hundred and fifty years later, both the French and the British 
still had difficulties understanding the very different attitudes to eating horse meat which prevailed on the other side of the Channel. Thus, when, in February 2013, there was a scandal, in England then in the rest of Europe, after some frozen beef burgers were revealed to contain Romanian horse meat, in France the coverage of the scandal focused on the tricking of consumers and food traceability, whereas in England there was the added element of the undeclared meat being a taboo food. The British popular press seized the opportunity to compare the French habit of eating horse meat to other repulsive local cuisines from around the world: deep-fried monkey toes in Indonesia, bull testicles in Spain, squirrel brains in the United States (Hamilton, 2013).

Debates over vivisection provide even clearer evidence of competition between the opposing accreditation enterprises of the established group and the challengers. In the previous section antivivisectionism appeared to be essentially underpinned by nationalist motives, setting up British gentleness in opposition to the horrors perpetrated on the Continent. Revulsion at a practice defined as "foreign" was intensified by the fact that it was a way of proclaiming one's pride at being English. Of course, there were other motives behind opposition to vivisection; to neglect other, complementary, explanations would be highly reductive. Indignation at the practice also appeared to be a way for the traditional dominant classes to react against the accreditation enterprises of the scientific community, put in place by the upwardly mobile bourgeoisie. As we have already seen, the leaders of the first societies to denounce vivisection in terms of a regression toward barbarity of the most horrifying kind came from the aristocracy, the judiciary and the clergy. The members of the dominant classes who engaged in charitable works to help the poor reacted particularly sharply to the threat represented by scientists and physicians, who claimed that their work presented a greater contribution to improving the lot of humanity because to their ability to push back the boundaries of science. The Victoria Street Society, formed to campaign against vivisection, included such prominent members of the establishment as Cardinal Manning ${ }^{19}$ and Lord Shaftesbury. ${ }^{20}$ Frances Power Cobbe, before founding the society, had

19 Henry Edward Manning was the son of a merchant who served as a director then governor of the Bank of England, and sat on the Conservative benches of the House of Commons for nearly thirty years. Manning himself, after graduating from Oxford University, embarked on a career in holy orders during which he attempted to orient Christianity toward the promotion of social justice.

20 Anthony Ashley Cooper, the seventh Earl of Shaftsbury, a prominent philanthropist, who was elected to Parliament in 1829, played a leading role in the passage of a wide range of social reform 
already been engaged in much more conventional philanthropic works. At Mary Carpenter's school in Bristol she had worked with young women who had been in prison, workhouse inmates, prostitutes and other unfortunates. She had also been involved in visiting hospices, to comfort the sick, which was, at that time, one of the more common ways of engaging in philanthropy (Duprat, 1993). One can easily imagine that, in the course of these traditional charitable activities, Cobbe crossed the path of doctors who, having a high opinion of their own scientific knowledge, had a correspondingly low regard for what they regarded as old-fashioned charitable works. In other words, vivisection debates were largely fueled by competition between conceptions of charity based on antithetical accreditation enterprises. On the one hand, the traditional elites call, with magnanimous indulgence, for respect to be shown to a long-established and harmonious order, within which the powerful are under an obligation to protect those beneath them in the hierarchy. On the other hand, the technical competence resulting from new scientific discoveries allowed some members of certain professions to aspire to leadership roles, in order that a social order - purged of the most persistent kinds of poverty - might be founded.

Challenged in this way, the established group was bound to react with the utmost hostility. Thus, in "The Medical Profession and Its Morality," Cobbe described doctors as a class of parvenus who scoff at values such as patience and compassion and extolled the kind of scientific progress which did not necessarily work for good of humanity, but which certainly did facilitate their personal enrichment. Furthermore, scientists and doctors who display no sensitivity when practicing vivisection will be unlikely to treat their patients in a humane way: "a patient is to the doctor what a rock is to a geologist, or a flower to a botanist - the much desired subject of his studies" (quoted in Dardenne, 2003, pp. 213-214). Elsewhere Cobbe vehemently denounced the hygiolatry which resulted from efforts made by doctors to convince their contemporaries to attach more importance to the physical health of their bodies than their moral virtue. The antivivisection struggle was given an added urgency by the fact that it was part of a bigger fight against the scandalous "takeover" plans of the "new priests": "today there is no one to stand up to the French Medical Board, which occupies a position strangely comparable with that of the priesthood in ancient times" (quoted in Dardenne, 2003, p. 158). It should be noted that, as a rule,

legislation, regarding the treatment of the insane, the employment of women and children in coal mines (Mines Act of 1842) and the limitation of the working day to ten hours (Ten Hours Act of 1847). 
antivivisectionists were less hostile toward science per se, than toward the "experimental method," which posed a serious threat to the knowledge on which the best established authorities relied. ${ }^{21}$ The idea that medical students should be taught that the acquisition of knowledge should depend, not on unquestioningly accepting the authority of one's glorious predecessors, but on investigating and revealing the unknown, was profoundly troubling and controversial. This attempt to pervert young people was seen as not only an attack on the gentleness of customs, but also the faith on which Christian morality is built. ${ }^{22}$ Once again, attacks on the practice of vivisection often conjure up images of uncontrolled violence, whose effects are unpredictable and irreversible:

The child takes a watch and breaks it in order to get to the "little animal" inside that intrigues it, just as a vivisectionist takes a living being and submits it to horrible suffering, in the hope of solving life's elusive mystery: it will no doubt elude him for a long while yet, and it is not presumptuous to predict that, if one day human science does succeed in fully explaining organic life, it will be the result of the patient and protracted observation of its normal functioning, combined with the painstaking and meticulous disassembling and observation of organisms, and not by the work of a brutal and destructive hand on a living creature, which involves the perturbation of all natural phenomena. (BSFCV 1 [1884], p. 5)

Vivisection, for its detractors, represents less a contribution to advances in the medical field than a promotion of unhealthy curiosity and insensitivity to the pain of other living things. Such attitudes, they argue, are incompatible with the qualities required of a doctor. Training medical students to cultivate the detached attitude necessary to engage in the dissection of live animals can only result in them becoming immune to the suffering of their future patients (Turner, 1980, pp. 79-121). The idea appears all the more

21 This led some doctors and hygienists, particularly older ones, to support the antivivisectionist movement. For them, supporting the cause was a way of protesting against experimental medicine's questioning of the authority of practitioners whose research had involved many years of patient clinical observation. Such practitioners, who had their own motives, rejected vivisection, defending a body of knowledge which they regarded as being more reliable, but whose credibility went into a long decline in the last decades of the 19th century, as a string of medical discoveries were made thanks in whole or in part to animal experimentation.

22 We have observed that the British middle classes operating on two fronts placed a lot of emphasis on a view of moral excellence inspired by Christianity. As a consequence the antivivisection movement in Britain - unlike its French counterpart - had support within the very middle classes where the vivisectionist movement was strongest. 
worrying when one considers that these medical practitioners will surely be invited into civilized homes in which it is increasingly common for a dog or dogs - the main victims of vivisection - to be treated as one of the family. ${ }^{23}$

Given the wide variety of beliefs held by members of protection societies, it is unsurprising that the issue of vivisection gave rise to heated debates and to regroupings and even splits within these societies. These debates became more heated when, at the beginning of the 1870 s, as we have already noted, vivisection was no longer confined to continental Europe, and British scientists, in an attempt to catch up with their German and French counterparts, made efforts to establish the use of vivisection in the scientific research throughout Britain. In 1875, Cobbe convinced the RSPCA to put pressure on the British government to pass antivivisection legislation. The government duly set up a Royal Commission to investigate the issue and, after numerous hearings, they produced a report which formed the basis for the Cruelty to Animals Act, enacted by Parliament in 1876. As we shall see later, the vociferousness of the antivivisectionist campaign provoked the scientific community to mount a concerted countermobilization, which subjected the government to intensive lobbying. In fact the provisions of the act represented a compromise which satisfied neither the promoters of vivisection - who felt that the legislation seemed to reflect the views of those who suspected them of immorality - nor its detractors, who were scandalized that scientists would not be subjected to external controls. Sickened by the conciliatory attitudes of both the government and the RSPCA, Cobbe established that the policy of the Society for the Protection of Animals Liable to Vivisection would be clear and uncompromising: anything less than the total abolition of the practice would be unacceptable to them. Over the next two decades, the stance of the pasionaria of the antivivisection movement became increasingly radical and estranged from mainstream elements of the animal protection movement, who were worried that her excessively aggressive criticisms of science were giving animal protectionism the reputation for being reactionary and dogmatic. Increasingly marginalized within the society she herself had founded in 1875, Cobbe went on to found, in 1898, the British Union for the Abolition of Vivisection. ${ }^{24}$

23 In Chapter 7 we will examine the extent to which the increasing popularity of companion animals and the feminization of animal protection greatly influence subsequent antivivisection campaigns.

24 The British Union for the Abolition of Vivisection (BUAV) is still active today. 
In France, within the SPA, opponents of vivisection experienced far greater difficulty in having their point of view accepted. It should be noted that of the sixteen committee members tasked with formulating policy on vivisection no fewer than five were doctors. The committee concluded that "a morally sound appreciation of this issue could not consider vivisection techniques used exclusively for scientific purposes as constituting acts of cruelty to animals. This kind of experimentation may be justified by reference to its noble aims, its usefulness, and the immense scientific progress enabled by it" (BSPA, 1861, p. 180). French protectionists openly admitted to their embarrassment at the offensive launched by their British counterparts: "Delegates from the London society, believing that they were providing us with support, did not hesitate to provide testimony of the repugnance felt in England for vivisectionist practices [...]. The argument that the use of vivisection is unavoidable necessity, which is attacked and denied by English doctors, and supported by the French medical profession, left us greatly perplexed" (BSPA, 1861, p. 180). In conclusion the committee recognized, except where abuses occurred, that the legitimacy of vivisection depended on the careful consideration of the underlying principles guiding the protection of animals: "If the protection of animals is the duty of every human who has an honest heart, we are also obliged to obey the divine law to love and bring relief to our neighbor, being guided by our motto:Justice and compassion for animals, Love and devotion for our fellow men" (BSPA, 1861, p. 180). As one would have expected, this timorousness provoked particular criticism from the Marquis of Mostcick-Gozom, who was the vice president of the SPA. In his opinion the commission, which contained a large contingent of doctors "gave in to all the demands of the animal experimentation lobby, and rejected the demands of the animal protectionists" (BSPA, 1861, p. 365). "Their blindness, which results from a culpable esprit de corps, represents a denial of the true nature of a practice which constitutes "the art of prolonging both suffering and life, [of] endless torture cruelly inflicted on gentle obedient animals, on poor beings who are defenseless and speechless" (BSPA, 1861, p. 366). To fail to strenuously oppose vivisection was to lose sight not only of the essential mission of animal protectionists, but also of the fact that the actions of these scientific parvenus were no less brutal than those of the carters from whom they claimed to be quite different:

On the contrary it is up to the animal protection societies to protest in the strongest possible terms, and to do everything in their power to put a stop to the multitude of sterile experiments which demonstrate nothing, 
except the presumptuousness and cruelty of the men who perform them [...]. How can we, on the one hand, show serious concern for the whipping and overloading of animals and, on the other, solemnly declare that we do not wish to oppose the horrible suffering inflicted on other animals. I am not talking about operations of true anatomists, who are few and far between, but (and this is the great evil) by ignorant individuals, who vainly ape science, or by depraved voyeurs who derive pleasure from watching pain being inflicted! (BSPA, 1861, p. 367)

Over the following decades pro- and antivivisectionists managed to coexist within the Society for the Protection of Animals. In 1877, Mme la Comtesse Antonin de Noailles, patroness of the society, offered a prize of 1,500 francs to the best essay attacking the practice of vivisection (BSPA, 1877, p. 142). In 1883, notwithstanding denials from the president of the SPA, antivivisectionists claimed that they had been prevented from expressing their views within the society. They also called for the SPA to provide funding for the French Society against Vivisection (BSPA, 1883, p. 104). In fact, that same year not one but two societies solely dedicated to denouncing vivisection were created in France. The stated mission of the French Society against Antivivisection was to "provoke, by all legal means, a groundswell of public opinion, in order to alert the authorities to the danger that the practice of vivisection would have a negative impact on the development of national mores" (BSFCV, 1884, p.1). The thirty members of the first board of directors of the society included seven titled noblemen and noblewomen, fourteen women and three doctors. For her part, Marie Huot founded the Popular League against Vivisection which she used as a platform to attack both perverted medical practices and bullfighting aficionados. In 1901, Baron de Knyff founded an International Union which was authorized to add to its title that of Popular League (BSPA, 1908, p. 260) and in the 1910s the Russian countess, Mme de Yourkevitch, well known in Paris high society well for her beauty and elegance, was the president of the National Union against Vivisection (Le Figaro, 25 June 1910). Although antivivisectionists were involved in the movement for a wide variety of reasons, they were united in their shared aversion to the faith which French people increasingly placed in experimental medicine. Thus, in 1885 , at the annual conference of the French Society against Vivisection, Maria Deraismes set out "to attack the aforementioned method in the shape of its most fervent advocate, Claude Bernard, the great high priest of experimental psychology" (BSFCV 4 [1887], p. 31): 
The only motives behind [Bernard's] overwhelming passion for experimentation are the desire to put his name to a so-called discovery, and, equally importantly, use it to his personal advantage. Vivisection is to be denounced and renounced, as it does no good, on the contrary it is force for evil. We cannot accept the assurances of Claude Bernard that experimenting on human beings is motivated by a desire to relieve the suffering of humanity. There is a great deal of evidence to show that the curiosity which drives these so-called scientists is often of an unhealthy nature. (BSFCV 4 [1887], p. 31)

Thus, between 1870 and 1930 - the period when the use of animals in laboratories first came in for widespread criticism - the experimental method, which the members of the middle classes operating on two fronts invested in for accreditation purposes, provoked the indignation of increasingly heterogeneous groups of opponents. While it was certainly the case that early mobilizations well fueled by the anger of conservative upper-class representatives of the animal welfare establishment, as we shall see later open hostility to the rising prestige of scientific medicine came, progressively, to take on other unprecedented, complementary meanings. 



\section{The rise in the power of tenderness}

In the previous chapters we have noted that the earliest animal protection campaigns did not focus on the suffering of animals. We will now examine the extent to which, over the second half of the 19th century, there was a turning point in the history of the movement, with increasing direction of compassion toward mistreated animals.

\section{Animality, equality, fraternity}

In view of our aims, the theoretical framework hitherto adopted would suggest an approach combining the perspectives of Norbert Elias and Alexis de Tocqueville (Déloye and Haroche, 2006, p. 110). The French aristocrat argued that the greater equality characteristic of the democratic era implies a softening of manners as well as an extension of sympathy. Drawing on the philosophical tradition, he takes sympathy to mean the intersubjective communication of feelings, of which the best example is compassion, namely the state of being affected by the suffering of others (Wilhelm, 2007, p. 72). "Sympathy is thus a phenomenon of identification by projection - of projective identification - by which we imagine being in the other person's body, and suffering, albeit to a lesser degree, what we - with our own sensibility - would suffer if put in a similar situation" (Wilhelm, 2007, p. 75). For Tocqueville, the growing sensitivity to the suffering of others cannot be dissociated from the fact that hierarchical discrimination - which affirms that all persons are not equally worthy of respect - was becoming increasingly unacceptable: "[T] here are several causes which can concur to make the manners of people less rude; but, among all these causes, the most powerful one seems to be the equality of conditions" (Tocqueville, 1993, p. 229). Tocqueville notes, in support of this argument, that "when the chroniclers of the Middle Ages, who all, by their birth or their habits, belonged to the aristocracy, report the tragic end of a nobleman, there are infinite sorrows; while they recount in one breath and without batting an eye the massacre and tortures of the men of the people" (Tocqueville, 1993, p. 231). Thus he also notes the matter-of-fact way in which the Marquise de Sévigné, writing to her daughter in 1675 , related the torture used in the putting down of a popular antitax revolt in Brittany. For Tocqueville, this "cruel banter," showing indifference to the suffering of the lower orders, was a consequence of the hierarchical mentality typical of aristocratic societies, 
"for there are real sympathies only between similar people; and in aristocratic centuries only members of one's caste were regarded as being similar [...]. Mme de Sévigné clearly did not understand what suffering was when one was not a gentleman" (Tocqueville, 1993, pp. 231-233). As egalitarianism developed, anyone who showed such insensitivity to human suffering would be greeted with widespread condemnation. Indeed, democratic mores require a very different emotional economy which, Tocqueville stresses, implies a close interdependence between equality of status, introspection, identification with others and finally "general compassion for all members of the human species" (Tocqueville, 1993, p. 233).

When ranks are nearly equal among a people, since all men have more or less the same way of thinking and feeling, each one of them can judge in a moment the sensations of all the others; he glances quickly at himself; that is sufficient. So there is no misery that he cannot easily imagine and whose extent is not revealed to him by a secret instinct. Whether it concerns strangers or enemies, his imagination immediately puts him in their place. It mingles something personal in his pity, and makes him suffer as the body of his fellow man is torn apart. (Tocqueville, 1993, p. 233)

In order to better understand the evolution of the emotional economy underlying animal welfare, we need to examine the extent to which the general trend described by Tocqueville - namely the gradual replacement of a hierarchical mentality, which encouraged differences in status between individuals, with compassionate egalitarianism - progressively extended to relations between humans and animals. Hitherto violence inflicted on animals had provoked fear and repugnance. Now, such acts also increasingly began to evoke compassionate feelings, thanks to the ability to feel, though empathy, another being's suffering. In other words the development of democratic compassion is closely linked to a process of reduction of alterity, meaning that the other - in particular the animal - far from being regarded as being irreducibly different, is confused with oneself: "sympathy leads to losing the other by bringing it to oneself" (Wilhelm, 2007, p. 77). Animal welfare thus increasingly had affinities with the anthropomorphic tendency to attribute to animals the same feelings experienced by humans.

It was, of course, the Romantic poets who first contributed to awakening the imagination necessary to feel tenderness toward the misfortune of animals, regarded as our alter egos. In 1785, in "To a Mouse: On Turning Her up in a Nest with a Plow," Robert Burns describes the plight of the animal 
left homeless as a result of the action of a man, who apologizes for what he has done:

Wee, sleekat, cowran, tim'rous beastie

Thou need na start awa sae hasty [...]

Which makes thee startle

At me, they poor, earth born companion

An' fellow mortal!

In 1794, William Blake, in "The Fly," compares his fate with that of the insect:

Little fly

Thy summer's play

My thoughtless hand

Has brushed away*

Am I not

A fly like thee

Or art thou not

A man like me?

For I dance

And drink and sing

Till some blind hand

Shall brush my wing.

Four years earlier, Samuel Taylor Coleridge, full of enthusiasm for the promise of the French Revolution, addresses a young ass:

Poor little foal of an oppressed race [...]

Thou poor despised forelorn!

I hail thee brother [...]

And fain would take me, in the Dell

Of peace and mild Equality to dwell.

We can see that the feelings of the poets and the animals, similarly exposed to the unjust treatment of men, are closely related. Hence the aversion to discrimination and domination, as well as the antithetic recognition of the language of law, should provoke the solemn proclamation of the equal dignity of all animals. Thus, as early as 1789 , Jeremy Bentham, in his Introduction to the Principles of Morals and Legislation, expressed the idea 
that the egalitarianism which led the French revolutionaries to abolish slavery should be extended to animals:

[T] he day may come when the rest of the animal creation may acquire those rights which never could have been withholden from them but by the hand of tyranny. The French have already discovered that the blackness of the skin is no reason a human being should be abandoned without redress to the caprice of a tormentor. It may one day come to be recognized that the number of the legs, the villosity of the skin, or the termination of the os sacrum are reasons equally insufficient for abandoning a sensitive being to the same fate. (Bentham, 1907, p. 311)

In fact, it would be mistaken, on the basis of accounts of animal welfare campaigns in the preceding chapters, to reduce the story of animal protection in the 19th century to the acts of a succession of conservative, even reactionary, moral entrepreneurs. Practically from the birth of the animal welfare cause, and increasingly as the century unfolded, the animal welfare movement included campaigns by progressive activists whose aim was to struggle against inequality and relations of dependence. In Britain, one of the leading figures in this tradition was Henry Stevens Salt (Dardenne, 2005). The son of a colonel in the British army, Salt was born in India in 1851. After distinguishing himself academically at Eton and Cambridge, he returned to Eton as a master and, at the beginning of the $188 \mathrm{os}$, became particularly interested in the ideals of justice and equality championed by the socialist intellectuals of the time. He joined the Fabian Society and, in 1900, was involved in the founding of the Labour Party. Salt had a revelation which led him to regard the meat eaten by humans as nothing more than dead flesh, produced by the slaughter of shocking numbers of animals. In 1886, the Vegetarian Society - founded nearly forty years earlier - published his book, A Plea for Vegetarianism. ${ }^{25}$

In 1891, Salt founded the Humanitarian League in the name of the need to reject violence, and to show compassion to all creatures. With these objectives in mind, the members of this new society campaigned on numerous fronts: for reform of the criminal law and the prison system; for the abolition of both capital punishment and corporal punishment; for an educational system which taught the obligation to be kind to all sentient beings, and - last but not least - for more wide-ranging and strictly enforced animal welfare

25 In his autobiography Gandhi claims that as a direct result of reading this book, when he was a student in England, he realized that it was his moral duty to became a vegetarian. 
legislation. In 1892, Henry Salt wrote Animals' Rights: Considered in Relation to Social Progress, a book now considered as a precursor of antispeciesism, which will be discussed at length below. For now, we should note that Salt's "humanitarianism" may be distinguished from preexisting philanthropic societies: he rejected a condescending kind of charity which took pleasure in looking down on the unfortunate objects of its compassion from a superior standpoint of "irreproachable respectability" (Li, 2000, p. 278). Moreover he aimed to extend the principles of socialism by treating the exploitation of men and animals as manifestations of the same problem. Thus, the members of the Humanitarian League declared that they were struggling against "the cruelties inflicted by men, in the name of law, authority, and traditional habit, and the still more atrocious treatment of the lower animals, for the purpose of 'sport,' 'science,' 'fashion,' and the gratification of an appetite for unnatural food" (quoted in Dardenne, 2005). Certain campaigns led by members of the Humanitarian League managed to accuse members of such august and well-established animal welfare societies as the RSPCA of hypocrisy. Thus Henry Salt was critical of certain elegant ladies who became indignant at the behavior of coachmen while, out of a desire to appear fashionable, they adorned themselves with animal skins or hats decorated with bird feathers (Kean, 1998, p. 117). In a chapter dedicated to hunting in his book Animal Rights, entitled "Sport, or Amateur Butchery," Salt went much further, denouncing the fact that a so-called gentleman can consider massacring certain species of animal as "an agreeable and gracious pastime. ${ }^{2{ }^{26}}$ So, members of the Humanitarian League alerted their contemporaries to two aspects of animal abuse, hitherto neglected, as being worthy of their indignation. Firstly, they pointed out that wild animals were also victims of human violence, and had the right to be treated with compassion; until then animal welfare campaigners had confined their efforts to the protection of domesticated species. ${ }^{27}$ Secondly, while RSPCA members were principally concerned about working-class violence, League members did not hesitate to condemn the fundamental brutality of a number of practices which were the preserve of the privileged classes: hunting, wearing fashionable clothing, and having a diet rich in meat.

26 In 1914 the Humanitarian League published a collection of essays, edited by Salt, entitled Killing for Sport, in which various authors, including George Bernard Shaw, Edward Carpenter and George Greenwood, challenged various attempts to justify the so-called art of hunting.

27 It is certainly true that, as we have seen earlier, the fate of wild insectivore species had already been addressed. Nevertheless, the previous scandals arose out of concern about the economic consequences of the destruction of organisms beneficial to agriculture, and not concern for the suffering of the creatures themselves. 
Comparing SPA newsletters over an extended period serves to confirm the growing importance of a kind of fraternal compassion which was increasingly sensitive to the suffering endured by animals. Once again, the poems admired by animal protectionists provide invaluable evidence of this trend. While it is certainly true that the editors of the very first SPA bulletins already sought fit to allocate space to poetry, the poems they published were spiritual stories modeled on the fables of Aesop or La Fontaine. In these earlier texts animals are allegorical figures used to illustrate a moral. By the 1880 s, the poems vaunted by animal welfare campaigners aimed to promote "kindness toward animals" (BSPA, 1883, p. 30). Just noting the titles of some of these poems gives a flavor of the compassionate tone which was then widely favored: "The Death of a Bullfinch" by Brizieu, "The Doe Has Lost Its Fawn" by Ernest Fouinet, "Pity" by Coran, "The Nest" by Berquin, "The Poor Man and His Dog" by Ducis. As in England, the influence of Romantic poets was felt, and facilitated the use of sensitization apparatuses which aimed to trigger the imaginative leap needed to perceive, through empathy, the unjust suffering of animals. It should be said that, as early as 1837, Alphonse de Lamartine wrote poems such as "You Will Conclude a Pact with the Beasts" and "You Will Not Spill a Drop of Blood," and called for the fraternal kindness desirable between men to be extended to animals:

You will not raise your hand against your brother

And you will not spill a drop of blood on the earth,

Neither human blood or blood of herds

Nor blood of fish, or blood of birds

A dull cry in your heart forbids you to spill it. (Lamartine, 1837, p. 77)

Another famous quotation from Lamartine, who was involved in politics during the Second Republic, has been frequently quoted by animal welfare activists from the 19th century right up to the present day: "We have not two hearts, one for the animals and the other for man. We either have a heart or we do not." By presenting engagement with tenderness in a positive light, the Romantics enabled animal welfare campaigners - who were, however, initially suspicious of "oversensitiveness" - to trust their emotional reactions "although the author [of a book praised by the SPA] only had to listen to his own personal sentiments to write the page which we reproduce below, as he wrote he would surely have remembered these tender words of Lamartine: '[O]bliging men to treat animals with the same kindness as they are required to treat one another is to improve mankind itself'" (BSPA, 1883, p. 30). 
As Maurice Agulhon has pointed out, it was precisely this call to the development of universal compassion which led supporters of political egalitarianism and secular anticlerical republicanism to join the animal welfare movement (Agulhon, 1988). Some of the leading progressive intellectuals of the time, including Pierre Larousse, Jules Michelet and Victor Hugo, gave their backing to the often controversial cause of animal protection. For these writers, who cared deeply about tackling the most intractable problems of social inequality, "[where there is] the desire to pity and defend those who have been victimized, to whatever degree, one does not pick and choose," "and the pity shown, in descending order, to the proletariat, women, children and animals, are all no more than different aspects of universal pity" (Agulhon, 1988, pp. 273 and 267). So, in 1850, when General Grammont sought to introduce a piece of animal protection legislation, his bill received, to his surprise, more support from left-wing deputies than from his own right-wing colleagues. Almost thirty years later, confirmation that animal protection, in outlawing the brutal domination of the weak by the strong, is closely bound up with the watchwords of equality and fraternity may be found in a speech, made at the SPA: "[A]longside philanthropy and fraternity, which in our times have flourished and triumphed, it is natural that there is an important place dedicated to affection toward animals. Love for animals is the consequence of love for men, and complements it. (Applause)" (BSPA, 1886, p. 141). In 1899, Adrienne Neyrat founded the review L'Ami des bêtes, whose support committee included some of the leading republican and socialist figures of the day: Anatole France, Georges Clemenceau, Jean Jaurès, and, last but not least, Émile Zola. Zola, who will go down in history as one of the most courageous French intellectuals for his principled stands against injustice, had no hesitation in rallying to the animal welfare cause. On 24 March 1896, Le Figaro published an article by the famous novelist, entitled "The Love of Animals," in which he reported the emotional effect the plight of animals had on him. "Shaking of the heart," "pity full of anguish," "surge of fraternal compassion" constitute such strong emotions that they provoke the author's moral questioning: "Why are all the animals on the earth related to me, why does the mere idea of them fill me with mercy, tolerance and tenderness? Why are animals, like men and as much as men, all in my family?" A year before his involvement in the Dreyfus Affair, Zola made a speech at the annual prize-giving ceremony of the SPA at the Cirque d'hiver which went even further:

Let us love them [animals], because they are our little sisters, crippled and incomplete, without words to speak of their ills, without the faculty 
of reason to use their gifts; let us love them, because we are the most intelligent [creatures], which has made us the strongest; let us love them; in the name of fraternity and justice, to honor creation which is in them, to respect the work of life and make our blood triumph, the red blood which is the same blood that flows through their veins and ours. (BSPA, 1896, pp. 139-141) ${ }^{28}$

I did not know how to demonstrate courage, because the animal cause is for me more noble, [and] closely linked to the cause of men, to the point that all improvements in our relations with animals surely mark an increase in human happiness. If one day all men on earth are going to be happy, you can be sure that all animals will be happy too. In the face of pain we have a common fate which cannot be broken, it is a matter of minimizing the suffering of all life. (BSPA, 1896, p. 217)

This growing affirmation of universal pity invites us to examine in more detail the influence on the animal protection movement of another leading figure on the republican left. As everyone knows, the works of Victor Hugo had a massive impact on their time, thanks to their creativity, lyricism, engagement with political struggles and social issues, and, perhaps most importantly, because of their sympathy for the fate of the poor. Hugo - idolized by the republican left and more or less regarded as the official poet of the Third Republic - took humble characters and transformed them into heroes - Quasimodo, the hunchback; Jean Valjean, the convict; Gavroche, the street urchin, etc. - and he created a body of work whose outstanding characteristic was its ability to provoke great pity in the reader. In line with this, compassion, often combined with the author's pantheism, is described as being all the more praiseworthy when it expresses itself through zoophilia - pity for animals - which thus appears to be the most advanced form of charity. Indeed, in 1884, the president of the French antivivisection society requested the support of Victor Hugo, "whose name is an inspiration for those who struggle to defend the rights of the weak against the violence of the strong" (BSFCV 1 [1884], p. 2). The poet replied

28 This extension of compassion to animals, although real, is obviously relative and dependent on distinctions regarded at the time as being self-evident. Hence the fact, noted in Chapter 3 , that Émile Zola was moved by the lot of sheep and the lot of wolves to very different degrees. It is clear from the article, published by Le Figaro on 24 March 1896, that Zola's compassion toward animals was reserved for those domesticated species which live together with humans. 
with a short letter ${ }^{29}$ with which the campaigners were more than happy: "[A]mid these illegitimate uses of force, a [single] word from Victor Hugo would be enough to provoke a cry for justice. [The voice of the poet] may not always be listened to when it addresses the blind selfishness of the Crown; but it would certainly be heard by the great judge to which our society is answerable: public opinion" (BSFCV 1 [1884], p. 2). To this very day, animal rights activists, in particular antibullfighting campaigners, draw inspiration from the words of Victor Hugo, and often carry signs with quotations from his work when they hold street demonstrations (Traïni, 2010b): "You will never be, whatever the circumstances, completely unhappy if you are kind to animals" and, most famously, "Torturing a bull for pleasure or amusement is more than torturing an animal, it is torturing a conscience." Nevertheless, the work which best illustrates Victor Hugo's preeminent role in feeding the imagination necessary for the emotional economy on which, since the end of the 19th century, the animal protection movement has increasingly relied, is a text published in 1859: "Le Crapaud" (The toad). This long poem, containing 162 verses, from the epic collection La Légende des siècles (The legend of the ages), is positioned between two other poems extolling pity, "Après la bataille" (Before the battle) and "Les pauvres Gens" (The poor), and describes the agony of an unfortunate/ugly and pathetic creature. A pair of absent-minded passers-by, a priest and an elegant lady, step on the toad and put out one of its eyes, then a group of children play cruel games with it. As the little bullies continue to torment the toad, a cart approaches, pulled by an "exhausted, lame and miserable donkey," itself the victim of cruel treatment from its carter. The children come up with the idea of squashing the dying toad under one of the heavy wheels of the cart, but the donkey performs an unexpected act, which adds a further moral and pathetic dimension to the poem:

The donkey saw the toad, and, sad, - alas! leaning

Over one who was yet sadder, - heavy, broken, doleful, flayed,

He seemed to sniff at it with his stooped head;

This slave, this wretched, patient creature, showed mercy;

He gathered up his strength, and, stiffening

His chain and his halter on his bloody muscles,

Resisting the donkey-driver who was shouting walk on!

29 In reply to the letter of the president of the SFCV, Victor Hugo wrote, "Your letter is excellent, because it is eloquent. Give your opinion on this serious matter, and I will echo it" (BSFCV 1 [1884], p. 2). 
In his weariness accepting the challenge,

Pulling the wagon and lifting the pack saddle,

He frantically turned the unyielding wheel,

Sparing the life of this wretched creature,

Before, under the whip, continuing on his way.

Then, letting the stone fall from his hand,

One of the children - the one who is telling this story -

Under the infinite vault, both blue and black,

Heard a voice which said: be good!

This quotation, though lengthy, nicely draws attention to one of the most important historical turning points in the history of animal protection. From the end of the 19th century onward the animal protection movement took on a more equivocal character, not only because it was joined by supporters of the republican left, but also, and more importantly, because of a significant shift in its underlying emotional economy. The extolling of love for animals, the pity shown toward the most despised animals, was part of a wider evolution which could be termed the leveling of compassion. The poem "Le Crapaud" may be regarded as exemplary, insofar as it celebrates the commiseration of the most humble animals with other unfortunate creatures: "[T]he humble soul coming to the aid of somber soul / the stupid creature leaning over, moved by a horrible sight / The goodness of the accursed giving the cruel chosen one cause for reflection!" In other words, here we part company from that asymmetric pity, which is downward-looking and one-sided, which enables the upper strata of society to reaffirm their preeminent status. To counter this aristocratic emotional economy, Victor Hugo's contemporaries appealed to "goodness," a democratic and horizontal pity which, rejecting the hierarchical model, affirms a beneficial solidarity which is equally accessible to those at the top and at the bottom of the social ladder.

Thus from the 188 os onward, SPA activists increasingly noted both their sensitivity to this sympathy for the suffering of animals, and their firm belief that the nurturing of such sympathy can encourage the development of solidarity between men. This change led to a significant modification in the pedagogical approach that they chose to adopt. Their aim was no longer to merely curb children's tendency to be cruel; they now aimed to make them aware - through the mediation of the relationship with the animal - of the pleasures of tenderness, regarded as a civic virtue of the highest importance.

There is a reason [writes a member of the SPA, while discussing a treatise on moral and civic instruction for the use of young girls] why it is said 
that friends of animals are friends of men. Kindness appears in the little details. If you get into the habit of being kind to animals you will soon be kind to everyone. (BSPA, 1883, p. 30)

To our schoolchildren, [... "It is not necessary to be rich to be charitable: showing kindness gives lasting pleasures, which continually renew themselves, and which are a delight to recall." Yes, my children, Monsieur de Dégur is right, we can be charitable even if we are not rich, because charity is not only expressed with gold. It is an innate quality which dominates the human heart, whatever a person's station. A poor man can therefore practice charity because, alas, there is always someone worse off than oneself [...]. [C]harity is thus a virtue which leads us to doing good to our neighbor, and to those dumb devoted creatures who, with such generosity, lend us their strength to help us in our rude labors, and give us pleasure in different ways [...]. Yes, young friends, learn early to be fervent apostles of charity, the offspring of kindness and love for humanity [...] and within humanity one must include domestic animals, our half brothers. (BSPA, 1883, p. 162)

Statements of this kind demonstrate the extent to which the inclusion of animal protection in the republican project to educate the masses - discussed in Chapter 4 - cannot be disassociated from the increasing diffusion throughout society of a form of emotional economy which was previously marginalized. In other words, the effort made to connect, through empathy, with the suffering of animals, and the recognition that the hardships animals are subjected to are a scandal requiring action have undoubtedly contributed to the intensification, and spreading throughout society of these very general trends, theorized by Alexis de Tocqueville and Norbert Elias. Kindness to animals probably constitutes one of the missing links in the chain, indispensible to the better understanding of the close interdependence between democratic leveling and the spreading of the changes in social attitudes beyond the aristocratic circles where they first took root. Through their campaigning, animal welfare protectionists have worked to assimilate, on the one hand, repulsion toward violence, requirements of self-restraint, self-control, reserve and tact and, on the other, "aspiration toward an equal division of recognition" between all creatures (Haroche, 2001, p. 105). Thus in 1904 members of the SPA were proud to apply what they called a "pedagogy of animal kindness":

in schools, we will engage in propaganda by distributing praise and all kinds of rewards. We will sow the seeds of animal protection to reap the 
harvest of humanity and compassion. We try to take children and turn them into good, fair-minded people, by teaching them to know animals, to appreciate the contributions animals make, and to recognize their intelligence. (BSPA, 1904, p. 183)

\section{Pets, refuges of intimacy}

Over the previous chapters, it has become apparent that animal protectionists were initially mainly preoccupied with the mistreatment of cattle, horses, and other draught animals. Over the course of the 19th century, however, the movement developed in a new direction, as a result of the place now given to dogs, and later cats, by the upper classes. Previously, humans had used domesticated dogs to carry out a variety of tasks: finding game, pulling carts, turning roasting spits, and, above all, guarding property from intruders. In those earlier days, the treatment of dogs - and indeed the treatment of men - depended on the attitudes of their powerful masters, which varied greatly. Hunting dogs, whose skills were highly valued by their aristocratic masters, were often better fed and more comfortably lodged than the servants (Thomas, 1985, p. 136). From the late Middle Ages onward, another category of domesticated dogs enjoyed special status, namely the small dogs which noble ladies kept as pets. Indeed the terms "pet" or "household pet" date from this time, and are applied to an animal having no other function than to be decorative, and to keep its master or mistress company, thus distinguishing it from both wild animals, and domesticated creatures who are assigned useful tasks..$^{\circ}$ Originally, this kind of animal, the "Lady's favorite," was especially close to its mistress, and was used in games of seduction developed within a civilizing process which exalted sweetness, a sense of propriety, and tactfulness. "Sweet smiles, affectionate glances, "innocent caresses," and "lively games [...], these compassionate feminine gestures are all messages directed at men. The animal is thus given a new role in domestic space: it mediates a propedeutics of sentiment" (Corbin, 1987, p. 482).

Nevertheless, once again, the importance of these new relations with a companion animal must be understood in the context of the modifications these relations go through as they are adopted by more and more people.

30 Originally the word pet-derived from the French word petit-indicated a spoilt, pampered child. From 1584 onward, the meaning of the term began to be also used to refer to cats and dogs, as well as the young of farm animals (Palmatier, 1995, p. 287). 
Very quickly, the rising social classes, eager to resemble the aristocracy, also kept animals which they treated with care, thus distinguishing themselves from the common people, who tended to be violent toward animals. The decorative dog, and then the lapdog, fulfilled a display function: individuals used ownership of such animals to enable their owners to "define themselves as being extremely respectable" (Kean, 1998, p. 80). This explains the importance attached to being able to identify different breeds of dog, as well as the prestige of dog shows reserved for animals of the finest pedigree: people with taste cannot pretend to appreciate mongrel dogs. The first ever dog show was held in 1859, in Newcastleupon-Tyne, and was reserved for pointers and setters. In 1866, George R. Jesse published the first history of dog breeds, and between 1867 and 1886 Dogs of the British Isles by John Henry Walsh went through no fewer than five editions. In 1873, the Kennel Club was formed, followed shortly afterward by the Ladies' Kennel Club (Kean, 1998, p. 93). In the latter club Pomeranians were particularly in vogue, no doubt largely due to the fact that the queen owned several: the Pomeranian soon became the breed of choice for ladies who were keen to appear highly respectable, such as Frances Power Cobbe, the pasionaria of the antivivisection movement. Generally speaking, "the structures that evolved in the third quarter of the nineteenth century to regulate the breeding and showing of pedigree dogs figuratively expressed the desire of predominantly middle-class fanciers for a relatively prestigious and readily identifiable position within a stable, hierarchical society" (Ritvo, 1989, p. 104). Furthermore, attachment to dogs became more widespread, thanks to the increasing popularity of stories praising the extraordinary loyalty of canine companions. Like the legendary hound Gelert or Greyfriars Bobby (Kean, 1998), dogs were all the more deserving of kindness as they appeared as "idealized servants who never complained or model children who never grew up" (Thomas, 1985, p. 155). French enthusiasts set up clubs for purebred dogs, following once again in the footsteps of British pioneers, although their organization departed from the British model in several respects, which are analyzed in Kathleen Kete's excellent book on the subject (Kete, 1994). In 1881, the Central Society for the Improvement of Canine Races was founded, and dog shows became fashionable among the more comfortably-off strata of society.

Nevertheless, the role of companion dogs was certainly not simply to be an ostentatious marker of social status. As they became more commonly welcomed into middle-class homes, pet dogs took on new and determinant 
meanings in the historical evolution of animal welfare. ${ }^{31}$ As is well known the middle classes, unlike the aristocracy, tend to favor a clear separation between public and private spaces, and between the world of work and the family unit. From this perspective, the family home - "Home sweet home" - is the most private of places, where one can spend time with, and show affection to one's children. Indeed, the cozy bourgeois habitat is often elevated to the status of (place which is not simply private but also as) a "haven in a heartless world" (Jasper and Nelkin, 1992, p. 17), a restful retreat where one can temporarily escape from the cold calculation of interest which dominates the workplace. Thus pets "the dumb creatures that always return love for love" (Turner, 1980, p. 76), are all the more easily integrated into the family circle because the relations of affinity which tie them to the children and parents of the family contribute to the affective economy which distinguishes the household from the rest of the world. "By creating the modern pet - the cuddly puppy, the cute kitten - animal lovers manufactured an animal designed to quell savage nature with the balm of love" (Turner, 1980, p. 76).

Thus, from the last quarter of the 19th century onward, SPA newsletters devoted more and more space to reports, anecdotes or poems which underlined the extent to which members of the canine species display "qualities of the heart" which are far superior to those of certain men: "a heroic bitch who refuses to escape a fire if it means leaving her puppies behind" (BSPA, 1875 , p. 256); “a kind, gentle creature [...] offering its teats to a hungry child" (BSPA, 1886, p. 68); a dog who saves a little girl from drowning (BSPA, 1875, p. 342); another dog who saves a violent man who, just a few moments before, had been mistreating it (BSPA, 1875, p. 222); two dogs who stopped fighting to save a little girl who had fallen in the water (BSPA, 1905, p. 407); when a man is drowning as the result of a suicide attempt, "his little dog jumps in the river after [him], as if he would rather die than live without his master" (BSPA, 1875 , p. 256$) \cdot{ }^{32}$ Once again, the use of poetry shows the increasing value attached to emotions, which results from regular contact with "darling doggies" (BSPA, 1904).33

31 Once again, this trend appeared in Great Britain well before other European countries. According to Keith Thomas, as early as the 16 th and 17 th centuries, "pet animals were established as part of the middle-class household, particularly in urban areas" (Thomas, 1985, p. 144).

32 It is worth noting that canine heroics were considered sufficiently praiseworthy that, at the 5 2nd annual prize-giving ceremony of the SPA, "collars of honor" were presented to two particularly deserving dogs (BSPA, 1904, 209).

33 These stories and poems are good examples of what we have termed a sensitizing device. From the comments which sometimes accompany them, it is clear that, in the view of activists, 
TO MY LITTLE FRIEND / Is it possible without being ridiculous, / In the eyes of the world, to cry over one's departed dog? / Without hesitation, and without qualms, /I confess, alas, that I cry over mine. / Yes, I cry over my faithful friend / Who waited for me, every day / Like a vigilant sentry / Awaiting then celebrating my return. / My pain is sharp and deep; / Yes, my grief is quite genuine; / What do I care what people say? / I cry for my little “Kid." (BSPA, 1886, p. 69)

Turk was a loyal dog / The best guard dog you could have [...] / Obedient, he came when called [...] / Sensitive to the smallest act of kindness, / He showered you with the gifts / Of his tireless, boundless enthusiasm / As discreet as he was kind / He would, I believe, have died of hunger, / Rather than touch anything / Which he had not been told he could take, / Accepting everything, demanding nothing [...] / Kind reader, listen well,/ Let me just sum up in a few words / What is the best thing about man? The dog. (BSFCV 6 [1888], p. 4)

Do not harm dogs, they are human beings. Frou-Frou was a little English griffon with bushy whiskers, whose head was half black and half white. She had large eyes and a penetrating, expressive gaze [...]. Frou-Frou was buried in Asnières cemetery, and on the block of white marble which covered her tomb, the following simple words were engraved, in gold lettering: FROU-FROU, WHO DIED OF GRIEF THE DAY AFTER THE DEATH OF HER MISTRESS. 1896-1908. (BSPA, 1909, p. 168)

Now try to live just with other humans [wrote Émile Zola], now that you have allowed animals into your home, and you will immediately see that you are cutting into your own flesh, and that you are removing a relative. [These animals] have become family members, and getting rid of them would be like tearing out a piece of your heart. (BSPA, 1896, p. 139)

In fact, the dog, far from solely being for display purposes, now - in the private sphere of bourgeois interiors - played a soothing role, being always available to offer comfort: 
Ah! Creatures who are just, Creatures who console, who dress the wounds inflicted by men! Creatures, with your instinctive innocence, you are able to distinguish true merit and show indulgence to the weaknesses of the ambitious! Animals who, without getting involved in judging literature, you take in, by the simple goodness of your hearts, the candidate in distress! Animals, my sisters, how you have filled me with pride! Finally crowned! (Émile Zola, "L'Amour des bêtes," Le Figaro, 30 May 1896, quoted in BSPA, 1896, p. 219)

[Regarding the increase of the tax on dogs] We would like the administration to understand that these dogs, which it regards as luxuries, are actually lifesavers and as such should benefit from a preferential rate. When we talk of a life-saving dog, we are not thinking of those brave creatures who, on one exceptional occasion in their lives, accomplish a glorious feat, but of those who every day, every minute, carry out their charitable mission of accompanying lonely souls, distressed souls, the underprivileged of this world, warming with their generous breath households which are struggling in adversity. (BSPA, 1933, p. 26)

We should note the extent to which the growing place given to "these creatures who live by ours sides and who, when life disappoints, are there to console us" (BSPA, 1905, p. 176) cannot be disassociated from the related evolution in the status of women from the rising middle classes. The bourgeois distinction between the public and private spheres is associated with a restricted definition of "true womanhood," and the confinement of women to clearly delimited spaces: from this perspective public life is the exclusive domain of men, whereas private life is the women's realm, or rather the "gilded cage" reserved for women (Knibiehler, 1992, pp. 407 and 423). The social existence of respectable women is strictly confined to roles - mistress of the house, wife and mother - which have close links to the matrimonial home. ${ }^{34}$ Women were tasked with supervising harmony in the home, and lavishing care on all family members, cats and dogs included. Men, on the other hand, while benefiting from the pleasant environment at home, also had the option of visiting brothels or seeing women, less virtuous then their wives, who could offer them sexual and sensual pleasure. In other words, limiting women's role to that of homemaker entailed unprecedented

34 This requirement that respectable wives remain in the private sphere was so strong that the French expression femmes publiques (public women) became a derogatory term applied to "fallen women," who were living a "bad life," i.e., engaged in prostitution. 
restrictions on women's sexuality. The Victorian era - synonymous with prudishness and corset-clad women - was characterized by developments in gynecology which led doctors to seek to confine women's sexuality to its procreative function (Knibiehler, 1992, pp. 398-406). In this context, relations between women and their pets assumed complex and ambivalent meanings. Caring for a puppy or a kitten, by awakening the "maternal instinct," was perceived as being one of the best ways of preparing little girls for their future role as housewives. Nevertheless we could equally present the hypothesis that showing tenderness to animals could be a convenient way of evading the group of representations according to which sexual relations with men can only have two outcomes: childbirth or debauchery. Far from constituting a language of seduction addressed - in a euphemistic form - to the male suitor, the tenderness lavished on an animal could have been the best way to elude the frightening sexuality of men..$^{35}$ Thus, Marie Huot - who invented the Malthusian slogan "strike of the wombs" described the caress given to an animal as a source of satisfaction bordering on the sublime:

It is a moving and curious spectacle; when the pussies have finished their meal you should see how they rub their backs against the dresses of their benefactress, jump on her shoulders, asking with their pink muzzle to be kissed or stroked, as if this were the dessert (of the meal). This proves that animals do not live by material sustenance alone either, and that they too have a heart to satisfy (Huot, 1890a, p. 12)

I add that it is because I felt my thoughts leave the limbo of the material, because I felt my intelligence grow and develop, as my senses became keener; because I felt my soul open and bloom more loving, and softened in the fragrance of sympathy; all this explains, dare I say it, why I cherished the animal I had met. Because often a caress is enough to make gush forth from this being, plunged in the shadows of bestiality, the embryonic soul trapped in its passive flesh (Huot, 1887, p. 50).

35 We should not forget that Victorian prudery, in order to preserve the innocence of young girls, excluded from their education any information which would have prepared them for the sexual relations which marriage held in store for them. In fact, from the testimony of the activist journalist Séverine - whom we will come back to presently - the events of their wedding nights were often a shocking and traumatic experience for young brides. 
Thus, the relationships that women of that time had with their pets resulted from conditions which offered them few options. They could either resign themselves to having the social existence of a procreating spouse confined to the matrimonial home, or escape - by choice or force of circumstances - from being subordinate to a husband, and live in cruel social isolation. Articles in SPA newsletters, starting at the end of the 19th century and becoming more common at the beginning of the 2oth, show the extent to which many women came to consider their dog or cat as the only being which provided some relief from the loneliness and torments of their dismal existences.

\begin{abstract}
$\mathrm{M}^{\text {me }}$ Séverine was awarded a gold medal for the delightful book The Memoirs of a Dog [...]. She tells us that only women feel a special tenderness toward animals because they are more often alone than men, and when they come home to an empty house, they are happy to find someone waiting for them, who greets them, scolds them for their absence, and celebrates their return. (BSPA, 1904, p. 208)
\end{abstract}

In fact the gifts made to the SPA by generous female donors increasingly seemed to be intended to be expressions of gratitude to dear departed companions: short homages to the loyal pet can be found, alongside details of the sums given: "in memory of Zézette," "in memory of Ponnette," "in memory of Friquet." Bequests became an even more significant source of funding for the protection societies than gifts. In 1933, no fewer than seven of the ten donors who "made the necessary provisions in their wills to aid the continuing work of the SPA" were women (BSPA, 1933.)

A woman of some importance recently sent the Boston Society the following letter: "Please find enclosed a check for a thousand dollars which I would like the Massachusetts Society to accept, as a token of gratitude to my dog who, during my fourteen years of reclusion and suffering, was my constantly loyal friend and devoted companion." If everyone who found comfort from the company of these dumb animals followed my example, what great relief could be brought to the daily undeserved suffering of those who we miss so much! (BSPA, 1886, p. 63)

Thus for women whose social condition provided them little feeling of self-worth, animal welfare - and in particular the care offered in cities to stray dogs and cats - took on a special significance. In actual fact, the help given to animals in distress contributed to the dualist posture which the 
early feminists used to exploit as best they could the bourgeois polarization of masculine and feminine functions: they demanded the right to intervene in the public sphere, "in order to highlight the power of the private sphere, as well as subvert its boundaries by introducing so-called private questions into the public sphere" (Käppeli, 1992, p. 576). This accreditation strategy - relying on supposedly typically feminine qualities - is used to good effect when applied to those practices which consist of transforming the domestic responsibility for household pets into a more general concern for the way animals are treated outside the context of the family. At the end of the 19th century it was women who pioneered the initiatives which still constitute the main activities of many animal protection organizations: caring for abandoned dogs, feeding the homeless neighborhood cats, and putting down newborn young "to [better] protect individuals and to avoid an increase in the number of abandoned animals" (Huot, 189oa, p. 14). In a public lecture, in June 189o, Marie Huot, president of the Popular AntiVivisection League, praises a "another kind of zoophile protection which if we did not create, we did encourage it - to the extent that this devotion is in need of encouragement" (Huot, 1890a, p. 11).

Sometimes in the evening, by waste ground, gardens and public buildings, we can see the silhouette of a woman, a basket over her arm, standing in the shadows, quietly calling to invisible creatures. To this call, which they know so well, a host of cats, appearing from everywhere, rush up to the mysterious stranger, who hands out a portion of food - served on a piece of paper - to each one of these famished creatures [...]. Without having discussed this among themselves, women and girls, young and old, beautiful and ugly, rich and poor, are all prompted by a spontaneous feeling. These abandoned creatures provoke the same maternal instinct, this sacred instinct, innate to the hearts of women, that makes them join in compassion, and lean down lovingly toward all that suffers and all that call out for help. (Huot, 1890a, p. 11)

For the speaker, these "sisters of charity," these "humble and holy women," these "devoted servants of the cause of pity," are the "apostles of a new religion," the pioneers of a world where men "open their hearts to the same emotions, and do not believe that their manly dignity will be threatened if they show kindness to creatures who are crushed and tortured by life, even when those creatures are animals" (Huot, 1887; 1890a, p.11). In our next chapter we will analyze in greater detail the extent to which this new form of animal protection was a revolt against the overwhelming prestige 
and abuses of the "stronger sex." For now, we should note the significance of changes in the animal protection movement which resulted from the growing importance of showing tenderness toward pets.

Apart from the foundation of animal protection societies, the most significant development in the history of animal protection was undoubtedly the institutionalization of refuges to shelter and care for abandoned dogs. According to James Turner, the first establishment of this kind was established in London in 1860 and moved to its Battersea site in 1871 (Turner, 1980, p. 122). The fact that it was referred to as a "Dog's home" attests to the influence of those representations which incite women to denounce a public scandal in terms of roles which are allocated to them within the private sphere. Here, the aim is to come to the aid of animals in need of a family by finding them a suitable new home, after their former owners have abandoned them. In Paris, a number of women such Mesdames Donon, Masson and Dessinge become known for establishing refuges for abandoned animals (Fleury, 1995, p. 141). Marie Huot claims that the Popular League against Vivisection, of which she was the president, set up the first "zoophile refuges, which are often described in the press, where lost dogs and cats are sheltered and cared for until their owners can be found" (Huot, 189oa, p. 6). The SPA hierarchy, under pressure to open a refuge by a growing proportion of the membership, showed little enthusiasm for the project; they considered it to be motivated by a thoroughly feminine "oversensitiveness," which a serious protection society should not allow itself to be influenced by. Nevertheless, after numerous discussions, the members finally bowed to the pressure from activists and agreed to provide occasional funding for the kennels of the ladies mentioned above.

In spite of continuing opposition, at the 8th International Congress of Animal Protection Societies, held in Brussels in 1880, the supporters of refuges found grounds for optimism. In one of its reports, the congress expressed the wish that "animal protection societies, following the lead of the Women's SPCA in Philadelphia, will persuade the authorities to allow them take over the running of animal pounds, or at least those facilities where dogs are sheltered" (BSPA, 1882, p. 79). An examination of the terms used to describe the "refuges," which were intended to replace the municipal "pounds," reveal that this recommendation was open to conflicting interpretations among the increasingly heterogeneous grassroots membership. For the older members such initiatives were simply aimed at continuing to apply measures on the basis of a well-established emotional economy. Indeed, the Women's SPCA in Philadelphia was campaigning to put an end to the sight of offensive acts of violence committed by municipal pound 
employees, who often behaved as badly as the worst coachmen: "the capture and killing of stray unmuzzled urban dogs, by city employees, was carried out in a revoltingly cruel way" (BSPA, 1881, p. 76). The ladies' recommendations - that lassos be replaced with nets, and that the killing the dogs, by asphyxiation, be carried out in a more humane way - aimed to "decrease the suffering of an animal which is, after man, one of God's most noble creations." But they did not in any way question the thinking behind one of the most long-standing concerns of the SPA: to campaign against the multitude of dogs in cities which uselessly consume food, offend people with their unsavory appearance, and generate fear about the spreading of rabies and other harmful miasmas. ${ }^{36}$ It is clear, however, that newer recruits to the movement, influenced by the increasingly close relationships people enjoyed with pets in a domestic context, saw the collection of abandoned dogs in a very different light. This new perspective among activists is apparent in the following touching account, which describes in detail the feelings that a visit to the animal pound, recently opened by the SPA in Arcueil, could provoke in visitors.

Perhaps in the way they look, full of curiosity, at the visitor, one can discern a vague expression of hope. These dogs remember an absent person who they belonged to, someone they loved. Who can be sure that they do not think every day of the master they have lost, or who lost them in order to have one less mouth to feed, one less burden on their meager household budget? Each one of them has a story - perhaps poignant, perhaps wonderful - but which unfortunately will never be written. In any case the hearts of those dogs, heavy with all the suffering they have experienced, will be quick to love those who will give them back, as well as their liberty, the joy of having a home. (BSPA, 1884, p. 202)

Just as the use of phrases celebrating the loving qualities of dogs became more widespread, sensitizing devices of this kind paved the way for an emotional economy quite different from the antisentimentalism which the founders of the first protection societies claimed adhered to. The imagination grasping the distress experienced by the abandoned animal; the care that the benefactors offered to comfort him; the spectacle of his immediate and immense gratitude, as well as the promise of the development of a

36 It should be remembered that, as early as 1855 , hygenist ideas, widely held among doctors and vets in the SPA, led the society to recommend a tax on dogs, which was duly introduced by the public authorities. 
growing joy shared in his new home, now allowed emotions to be shown which fall within a register of pity (Boltanski, 1993). The possibility of experiencing these emotional states attracted new members to the SPA who knew practically nothing about the preoccupations of older members. These senior members were indignant, and deeply concerned by the influx of the newcomers, who threatened to deflect the society from its original, noble aims. While the more determined of the old guard fought the growing influence of these new members - who were flocking to the SPA to wallow in pity - many of the longest-serving members preferred to leave the society now that, as the "dog lover" contingent grew, there were fewer opportunities to rub shoulders with erudite, enlightened individuals. ${ }^{37}$ The criticism directed at the supporters of the refuge by the widow of Dr. Blatin - for many years a leading figure among enlightened animal protectionists gives a good indication of the kind of opposition provoked by the fact that unprecedented importance was now attached to the emotional register of tenderness.

If one was willing to take the trouble to go back and consult the past papers, and the newspapers, even when they were critical, they clearly show not only that the society is not playing its proper role when it ostensibly and officially involves itself in a question of sentiment; but in fact if you study the matter, it is clear that the society promised not to become a women's club, namely, as everyone knows, a purely sentimental society, and only recruited serious members on the understanding that this would not be the case. [If it becomes a women's society] it also means that there will never be men who are good enough to mix with these women [...]. Look at the large majority of women on the refuge committee [...]. Who are the people who are so vigorously demanding the creation of a refuge, which is a wholly sentimental initiative? It would be difficult to find any public utility in it, as there is a pound which already takes care of such problems. These are people who may have little knowledge of administrative matters, indeed the ladies themselves willingly admit as much, and yet [this initiative] will cause nothing but problems, administratively speaking! There are also the new arrivals in our society, who have been members for two or three years at the most, and who are not concerned that there are many other outstanding questions, all of the utmost utility,

37 This clearly shows the extent to which the emotions approved of by the sensitizing devices within the organizations determines the turnover of activists, i.e., those who enter, stay in, or leave the organization (Fillieule, 2005). 
concerning the animals we are protecting, but as they know nothing about these questions yet, they cannot appreciate them. All other matters are made to wait, while we decide about the future well-being of the cats and dogs of Paris! And if we gave in, Ladies and Gentlemen, if we no longer formed a majority, believe me that another overwhelming and dangerous majority would soon materialize, a majority which would be new and consequently ignorant of the intrigues in our society; in this case any question which appeals to sentiment will be well received, and it will be a matter of who does the most, of who is the most extreme. After a refuge has been built they will ask for a building fit for these dear animals, then kennels decorated with golden fringes, and silver-gilt drinking bowls [...]. The doctors have already withdrawn [from our society], and the veterinarians are no longer shown respect in the "sentimental assembly." What will become of us? (BSPA, 1883, p. 222)

If the tone is alarmist, it is because of the significant amount of pressure that the new wave of activists was able to exert on the leadership of the society. First in 1881, then in 1885, the SPA opened refuges (Fleury, 1995, pp. 141 and 149) because the board of the society, despite serious reservations, was obliged to "defer to the consensus" among the membership (BSPA, 1885, p. 200). Nevertheless, the complaints within the old guard that [the purpose of] "this costly creation had been misunderstood" (BSPA, 1886) resulted in Émile Decroix, president of the society and leading advocate of hippophagy, shocked by the high running costs of the refuge, decided, in 1888, to close and sell the establishment (Fleury, 1995, p. 151)..$^{8}$ This demonstrates that this time there were still enough supporters of the "demopedic register" in key positions in the society for the changes initiated by the "supporters of tender feelings" to be halted. Nevertheless, despite this gallant last stand by the pioneers of animal protection, from the following decades until the second half of the 2oth century, the forebodings of Dr. Blatin's widow were confirmed. On the one hand, caring for abandoned dogs and cats became a central preoccupation of the membership, not only of the SPA, but also, and to an even greater extent, of many other, newer, animal welfare

$3^{8}$ As we can see from Graph 3, below, the one-off payment for the shelter is reflected in the SPA accounts for the year 1886 . Because of the way the society hierarchy reacted to this, it was not until the first years of the following century that assistance to animals - back-up horses and dog pounds - once again accounted for a large part of the society's expenditure. The drop in spending that can be observed in the 1930 s is due to the advent of automobiles, which dramatically reduced the number of horses: from then on the SPA activities were more focused on helping dogs. 
Graph 3 Allocation of resources obtained from the accounts or the provisional budgets of the Society for the Protection of Animals

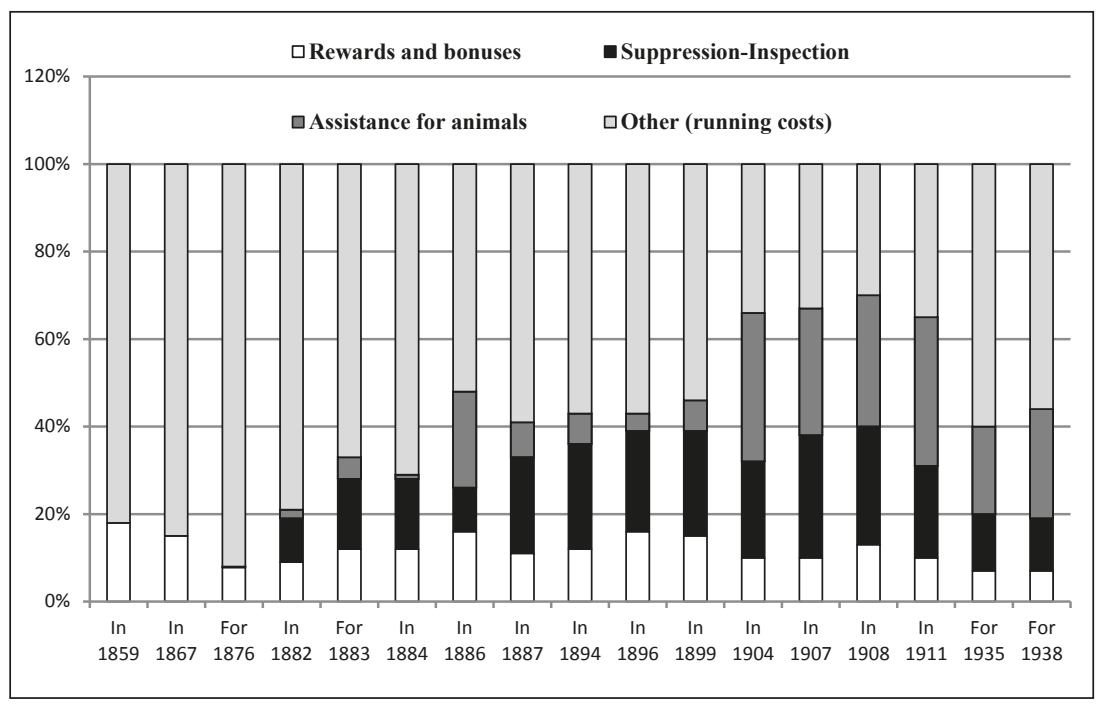

Source: Graph plotted by the author based on the bulletins of the SPA

organizations. In 1899, a charity named L'Assistance aux animaux, was founded. One of its key objectives was to run an animal shelter at Gennevilliers: its membership rose from 1,500 in 1903 to 6,00o in 1909 (Pierre, 1998, p. 735). In 1908, an animal shelter was set up in Saint-Maur and administered by an organization called La Protection française, founded by the famous beauty Madame de Yourkevitch (Fleury, 1995, p. 237). The SPA branches set up in various French cities, which were registered as nonprofit organizations long after the Paris center, also prioritized animal shelters and the emotional register of tenderness. ${ }^{39}$

Our account of the history of the very first mobilizations in favor of animal protection reveals the major shift in emphasis within the movement, from the outlawing of ill-treatment of cattle and horses, to the advocacy of tenderness in the treatment of dogs and cats. Key changes modified not only the emotional economy of animal protection, and the sociological profile of the grassroots campaigners, but also the financial and organizational constraints on protection societies. Indeed, the high cost of running shelters and caring for abandoned animals required the society to spread its nets

39 The SPA for Lyon and the southeast was registered as a nonprofit organization in 1893; the Normandy SPA and the Nice SPA in 1930; the central France SPA in 1934. 
widely in search of donors, in marked contrast to the first protection societies, who prided themselves on being somewhat select organizations. As we saw above, the development of the register of tenderness is closely bound up with the increase in donations and bequests which members made in recognition of their closest companion. But providing care for animals requires not only more funding, but also organizational logistics with which the first activists, whose principal concern was reforming the mores of their contemporaries, did not need to concern themselves.

As the register of tenderness attracted a growing numbers of the kind of affiliated members who favored very costly initiatives, campaigning organizations were caught in what some regarded as a vicious circle, others a virtuous circle: they were forced to concentrate on recruiting more and more members and donors. Hence, at the very beginning of the 20 th century, the former policy of selective recruitment of worthies was abandoned by SPA management in favor of rewarding activists who attracted funds by recruiting new members: "[T]he board has decided that at the annual prize-giving ceremony a bronze medal will be awarded to members who have presented ten individuals who have accepted to join the society." (BSPA, 1904, flyleaf)

Unsurprisingly, the prioritization of caring for domestic pets inevitably resulted in a feminization of the animal protection cause; this trend has continued to intensify right up to the present day. Evidence of the increase in the proportion of women members can be found in SPA records: in 1875, the minutes of the 23 rd annual public prize-giving ceremony noted the presence of "more than 400 people, of whom women were in a very large majority" (BSPA, 1875, p.129). Similarly, the list of the generous gifts received in 1894 reveals that $65 \%$ of gifts were from women, and $35 \%$ from men (BSPA, 1895, p. 30). Nevertheless, the feminization of the membership did not extend the SPA boardroom which, despite protests from women members, continued to remain a male domain:

Mlle Laurent asked for confirmation that women were eligible to sit on the board. Women have shown themselves, in the running of the animal shelter and on the dog committee, where they are in a majority, to be not without administrative abilities. The president replied that nothing in the regulations indicated that women could not be appointed to administrative posts. While they could not be named to the presidency, or one of the vice presidencies, if members wish to vote for a woman to represent them on the board, there was absolutely nothing in the statutes or the rules to prevent them from doing so. (BSPA, 1886, p. 12) 
A number of female members sought to obtain representation on the board of directors in the hope of making their voices more clearly heard. In 1902, when one of them said that she was standing for election to the board of directors her announcement was greeted with a certain amount of sniggering, and she only managed to obtain 14 votes, whereas the last male candidate had won more than a hundred (Fleury, 1995, p. 217). There were five women candidates to replace the third of board members standing down in 1904: three of them obtained 14, 10 and 1 votes respectively, whereas the successful candidates won 165 votes (BSPA, 1904, p. 28). The following year the only female candidate won 21 votes, compared to 137 for the successful candidates (BSPA, 1905, p. 9). So, although a woman won double the number of votes of previous female candidates, at that time it still seemed inevitable, even among the swelling ranks of women members, that the positions of responsibility in the organization would continue to be reserved for men. Then, remarkably, at the beginning of the 1930s, the balance of power, which seemed destined to remain in the hands of men, swung in favor of women. It is true that the register of tenderness and the welfare of dogs had become such priorities for most members that any candidate for a leadership role was obliged to take them seriously. In 1925 François Friry was elected president in 1925 after campaigning in favor of the extension of the Gennevilliers animal shelter (Fleury, 1995, p. 272). Four years later, Camille du Gast, who had been the owner of this shelter for a number of years obtained 627 proxy votes and was elected president of the SPA. This power shift was all the more striking since du Gast's election was accompanied by the voting of eleven women onto the thirty-six-seat board of directors (Fleury, 1995, p. 275). Subsequently, this change within the SPA, in terms of gender composition, has seemed irreversible: between 1976 and 2008, four out of five occupiers of the presidential office were women.

Therefore feminization of the animal welfare movement, from the leadership down to the grass roots, coincided with an increasing focus on abandoned dogs and cats. As a consequence of these trends today, in both England and France the biggest animal welfare organizations in terms of membership and resources - the RSPCA, the national and regional branches of the Société protectrice des animaux, the Fondation Brigitte Bardot, the Fondation assistance aux animaux, etc. - all have animal shelters whose running costs take up a sizeable part of their budgets. ${ }^{40}$ At this point it is

40 The SPA alone runs fifty-seven refuges, permitting around 40,000 animals to find a new home each year, as well as twelve free clinics, which conduct 120,000 veterinary consultations annually, for animals whose owners have limited resources. 
worth commenting upon how the history of animal protection is closely linked to certain related changes in the work of veterinarians. It is firstly worth recalling that veterinary science originally developed as zootechny, dedicated to making improvements in the breeding and keeping of livestock and draught animals (Hubscher, 1999). The rising status of domestic pets within urban families therefore offered veterinarians the opportunity to increase the prestige of their profession, as it became less dependent on farming and commerce. Where a veterinarian's work once consisted of assisting carters, cattle breeders, and various actors along the agri-food chain as far as the butcher, he could now lay claim to the more gratifying status of doctor, responsible for the health of animals, now regarded as family members. The opportunity for the veterinary profession to reinvent itself could, however, have been missed, had it not been for a number of enterprising practitioners who strove to promote not only animal protection, but also the social standing of their profession. In this regard, the career of Fernand Méry was exemplary.

Méry was born in the first decade of the 2oth century in a family of wine merchants in the Hérault, and as a child he offered no clues as to his future calling. But then, in 1914, heartbroken by the government's requisition of his pony for the war effort, he made the decision to become an army veterinarian (Lescure, 1995). After completing his studies, he became the assistant of a Paris veterinarian whose practice specialized in treating horses, which were still a very common at the time in the city. Then, more or less by chance, Méry was invited offer his services to the pets of some of the wealthiest dog owners in Paris. The provincial vet was not slow to see the business opportunity that this market represented, at the very moment when the development of motorized transport heralded the imminent decline of predominantly equine practices. At the same time, having had the chance to move in prestigious circles, far removed from the world of carters, Méry was moved to express outrage at "the way his profession is not held in high enough esteem," "how veterinarians are regarded as mediocre, and often enjoy no prestige whatsoever in the eyes of the public" (Lescure, 1995, p. 46). For the rest of his long career Méry worked tirelessly - as a practicing veterinarian, journalist and, last but not least, animal welfare campaigner - to raise the standing of a profession which, in his opinion, did not receive the recognition it deserved.

Méry first set up in private practice by opening a surgery in the Faubourg Saint-Honoré quarter of Paris. The fact that he castrated male cats under general anesthetic - which was quite an unusual practice at the time - enabled him to rapidly build a clientele among the high society ladies who lived in the area. His practice thrived to such an extent that he was 
obliged, in 1934, to move into larger premises in the 17th arrondissement, where, in the Croix bleue clinic "he treated the animals of the great and the good from the worlds of politics, diplomacy, show business, literature and the arts" (Lescure, 1995, p. 57). The veterinarian built up considerable social capital, which he was able to draw on for the rest of his career. ${ }^{41} \mathrm{In}$ 1949, the veterinarian's pleasant manner got him a meeting with Pierre Desgraupes and Georges Delamarre, who invited him to present a weekly three-minute radio show on the Actualités de Paris, Ici les bêtes, which ran for twelve years, and was a great success with radio listeners. From $195^{2}$ to 1984 he wrote a column in Point devue-Images du monde, a weekly magazine largely devoted to the lives of celebrities and royalty. This column gave Méry the opportunity to exercise his talent for increasing public interest in companion animals. He also wrote over twenty books, in a similar vein: Bêtes et gens devant l'amour (For the love of people and animals, 1952), Sa Majesté le chat (His majesty, the cat, 1956), Notre ami le chien (Our friend the dog, 1957), Médecin des bêtes. Le roman d'une vocation (Animal doctor: The story of a vocation, 1962), etc. In 1953, the veterinarian created the association "Friends of the Animals" and managed to recruit his His Serene Highness Prince Ranier of Monaco and a number of famous people to serve on the support committee. Only a year after coming into existence, and after a televised gala performance, supported by Line Renaud and Georges Brassens, the association could already boast a membership of over 10,000. Throughout his career, Fernand Méry used his influential connections and media fame to lobby for legislation regulating the treatment of animals. In 1950, the centenary of the Grammont Law, he helped coordinate the drafting of a text, in consultation with a number of animal protection associations, which was intended to form the basis of an animal welfare act. ${ }^{42}$ In 1970 the self-styled "doctor to the animals" founded the National Council for the Protection of Animals (CNPA), an organization which led veterinarians to consider themselves to be in the front line of the struggle to protect animals.

41 Social capital may be defined as "the aggregate of the actual or potential resources which are linked to possession of a durable network of more or less institutionalized relationships of mutual acquaintance and recognition" (Bourdieu, 198o, p. 2).

42 In fact, it would another ten years before the objectives of this mobilization - to extend the provisions of the loi Grammont (Grammont Law) - were finally reached. The decree of 11 September 1959 specified the penalties for ill-treatment of animals. The law of 19 November 1963 outlawed acts of cruelty, and specified provisions for sentencing. The law of 10 July 1976 widened the scope of the law to cover serious ill-treatment of an animal and willful abandonment of an animal. It also authorized state-approved animal protection organizations to institute civil proceedings, and to obtain compensation for those on whose behalf they are acting. 
In 1974 Fernand Méry involved the CNPA in a campaign to circulate the text "Man's Twelve Duties toward Animals," which mobilized the French national union of veterinarians, the newspaper Le Parisien libéré, the weekly magazine Point de vue-Images du monde, and the radio station RTL. A petition in support of the text garnered more than two million signatures. This campaign led Jacqueline Thome-Patenôtre, a parliamentary deputy and the president of the SPA, to organize a parliamentary group which invited a number of veterinarians - including Fernand Méry - to draw up an animal charter. This charter formed the basis of the law passed on 10 July 1976.

Having traced the emblematic career of Fernand Méry, we should note the extent to which the evolution of animal protection over the course of the 2oth century was closely linked to the increasing focus of veterinary medicine on family pets, the ownership of which became increasingly common over that period. As we will see below, the subsequent extension of the right to veterinary treatment to wild animals also represented a important development in the history of animal protection.

\section{Imaginary beings and children's soft toys}

We have already observed that the progressive subordination of protection societies to the emotional register of tenderness cannot be understood independently of the continuing rise of domestic pets, not only as a presence within the home, but also, and even more importantly, in children's education. The promotion of dogs, cats, guinea pigs, budgerigars, etc., to the role of indispensible tutors, entrusted with a key role in the emotional and social development of children is an underlying motivation for the involvement of later generations in the animal protection movement. From the end of the 19th century onward, companion animals are regarded as providing invaluable help in making children aware of the virtues of gentleness, selfrestraint and mutual trust (Grier, 1999). For young girls, looking after a small dog or cat is thought of as a way of awakening the "maternal instinct" of future wives and mothers (Knibiehler, 1992, p. 409). Among the initiatives to provide a propedeutics of kindness, women at the end of the 19th century could turn to a relatively novel source for raising awareness: a number of fictional works retelling the life stories of an animal which would swiftly achieve the status of classics of children's literature. ${ }^{43}$ These books differ 
from earlier texts - such as the stories of Reynard, or the fables of Aesop or La Fontaine - in that the animal character itself is the narrator, enabling it to tell its own story in the first person. These stories told from the point of view of the animal do not simply anthropomorphize animals, but also invite the reader to sympathize and identify with them.

In 1867, Frances Power Cobbe, whose crucial role in the antivivisection movement we have already stressed, wrote The Confessions of a Lost Dog Reported by Her Mistress, the biography of a Pomeranian, told in the first person, in which the dog recounts how it suffered at the hands of men, before being rescued by some charitable women (Kean, 1998, p. 89). Then in 1871, Anna Sewell, who was born into a devout Quaker family and suffered from fragile health for all her adult life, started writing her only novel: Black Beauty: The Autobiography of a Horse. Sewell was virtually bedridden at this time in her life, and dictated the book to her mother. The central protagonist Black Beauty, who appears first as a young foal and grows into a fine adult horse, recounts a series of adventures involving encounters with human beings, some of whom are kind to horses, others cruel. On publication in 1887 the book became an instant bestseller; in two years a million copies were sold in Britain alone, and in the 2oth century it was translated into many languages and became a classic of children's literature. Its great potential for helping the animal cause, by raising awareness of cruelty to animals, was immediately recognized, and the RSPCA financed several additional editions of the book. In the United States, the American Humane Society handed out free copies to coachman and dubbed Black Beauty the "Uncle Tom's Cabin for horses." In England the book's success actually had a real impact on the lives of horses. The depiction in Black Beauty of the use of bearing reins, which forced carriage horses to keep their heads up, contributed to the successful campaign to have these devices outlawed. Use of these devices, though ensuring posture which was aesthetically appealing to some people, could also be tiring and painful for the horse: (Kean, 1998; Lansbury, 1985a). In 1893, Margaret Marshall Saunders, inspired by Black Beauty, wrote BeautifulJoe, the misadventures of a dog, told from the animal's viewpoint. The book was a massive bestseller and is considered to have made a major contribution to exposing and denouncing cruelty to dogs. In 1903, Séverine, who throughout her life combined political activism alongside Jules Vallès with commitment to animal protection, wrote Sac-à-tout: mémoires d'un petit chien (Sac à tout: The memoir of a little dog). ${ }^{44}$

44 In her memoir of her childhood, Line (1855-1867), Séverine emphasizes the importance of a book she read as a young girl, Mémoires d'un âne. "As the child became an adult she conserved 
As we have seen, the pioneers in the use of the innovative narrative technique which consisted of having an animal tell a story in the first person included a number of animal protection activists. This type of story has become so common that it would be almost impossible to draw up an exhaustive list of the countless works which allow rabbits, bears, mice, lions, little pigs, etc., to speak directly to children. Indeed, the cognitive and emotional development of children has been accompanied by animals to an even greater extent since the animated cartoon industry - starting with the Walt Disney Studios in the 1930s - has allowed them to regularly engage with narratives recounted by animals. ${ }^{45}$ The center role played by fictional animals during the earliest stages of socialization also owes a lot to another noteworthy 19th-century pedagogical innovation. Around the middle of the century dolls, which previously looked like adult figures, were increasingly were made to represent infants. A baby doll, often equipped with a bottle, was a new toy which, like a little cat or dog, required care and so served as a kind of "apprenticeship for the maternal role; a renewal of the intentions which a new childish gesture translates, as a prelude to a school of home economics" (Corbin, 1987, p. 482). From 1880 on, Margaret Steiff, a German toy manufacturer, made stuffed animals using leftover material from her uncle's factory. In 1902, her nephew persuaded her to take some sketches he had just made of bears at a zoo in Stuttgart and use them as inspiration for the creation of a soft toy which could appeal to both girls and boys. The following year, at the Leipzig Trade Fair, a major American importer bought a large batch of the toys. When they were released onto the American market the toys quickly sold out. The commercial success of this first toy bear, which was soon renamed Teddy Bear, encouraged other manufacturers to produce all manner of soft toys in the shape of rabbits, kittens, tigers, monkeys, lion, etc. The craze for these objects is intensified by the fact that children were able to use them as a substitute for their first "transitional object," namely an object which, according to Donald Winnicott, offers an infant the emotional support necessary to gradually free itself from its anxiety-inducing dependence on its mother. Once again,

this faded, battered book like a relic. It became a lifelong source of her great friendship for animals, and of the pity she felt for the suffering inflicted upon them by cruel, selfish humans" (Séverine, 1921, p. 107).

45 In 1995, a psychologist, Evelyn Goodenough, collected 360 stories written by seventy girls and sixty-seven boys in order to explore the thoughts, desires and fears which people children's imaginations. Animal characters appeared on average in $65 \%$ of the stories written by 2 to 4 year olds and, more precisely, in $80 \%$ of those written by 3 year olds and $85 \%$ of those written by 5 year olds (Melson, 2009, p. 188). 
soft toys in the shape of animals are now so commonplace that it is difficult to evaluate their - probably decisive - influence on how representations of and attitudes toward the animal kingdom evolved. In the world of soft toys which children are given to play with, wild animals - such as bears, lions, or wolves - may be found alongside domesticated species such as dogs, cats, pigs and cows. In other words, the world of play of young children challenges the conception of wild animals as embodiments of a hostile and threatening ferociousness. In children's bedrooms soft animal toys, fictional characters from comic books or cartoons, and real dogs and cats which they take care of, are all regarded as reassuring and positive presences. Of course, relationships with real pets appear to be particularly influential, given their capacity to nurture "the feeling that other beings love you, appreciate you and take care of you. It is clear that animals - especially interactive animals like dogs - play this role for many children" (Melson, 2009, p. 95).

This set of developments, which have shaped children's socialization, has had an influence on the development of sensitizing devices now widely used by animal protection activists. Soft toys, stickers, children's drawings, photographs and film clips are often used to evoke the tender feelings generally closely associated with the very young. In this regard, three complementary scenes regularly appear. Firstly, images of puppies, kittens, bear cubs and fox cubs, or other "little balls of fluff," trying to attract their parents' attention, or rolling around playfully. Secondly, the representation of mutual bonds of tenderness between mothers and their young: a lioness grooming her cubs, does suckling their fawns, a litter of polar bear cubs tagging along behind their mother, etc. Finally, the scenes depicting the exceptionally close complicity which can develop between animals and children: a bird perched on the shoulder of a little girl, a small child and an enormous Saint Bernard cuddling each other, exchanging a lick for a kiss on the nose, etc. Of course the impact of such images is increased insofar as they evoke caresses exchanged during childhood, between children and real animals or soft toys given them by kind parents. In other words, the encouragement of children from a young age to show kindness toward animals may be a vital way of motivating them to subsequent rally to the animal protection movement. Thus, in 1998, according to the responses to a questionnaire filled in by 270 protesters at a demonstration against animal experimentation, $98 \%$ of the activists interviewed stated that they own a pet and/or had one when they were a child and $72 \%$ of them owned several animals (Jasper and Nelkin, 1992, p. 38). 


\title{
7 (Animal) victims and social domination
}

As we have seen in previous chapters, most of the first animal welfare campaigners were moral entrepreneurs preoccupied with promoting selfcontrol, discipline and social stability. In the last third of the 2oth century, however, other voices - of protest, even subversion - were increasing raised in support of the animal cause. In order to better understand what lies behind this development we should examine in more detail certain effects of the leveling of compassion and of the extension of universal sympathy to animals. In fact, by this time protectors of animals no longer confined themselves to seeking to define and promote certain standards in the domain of mores and morality, by taking on preceptor or ascetic roles. Neither were they necessarily satisfied with the alternative role of a rescuer - namely one who seeks to alleviate the immediate suffering of loving and loved creatures - which we examined in the previous chapter. In fact, a growing number of animal protection initiatives were undertaken by activists who saw themselves as avengers, undertaking to defend the weak, to expose the impunity of the powerful, and to stop the most revolting cases of domination.

\section{At the heart of the revolt against the powerful}

\begin{abstract}
At the root of my revolt against the powerful I find, as far back as I can remember, a feeling of horror at the torture inflicted on animals. From the frog that peasants chop in two, leaving the top part of the body to drag itself along in the sun, its eyes bulging horribly, its arms trembling, trying to escape by burying itself in the ground, to the goose whose feet have nails stuck through them, to the horse exhausted by leeches or gorged by the horns of a bull, animals suffer appallingly at the hands of men. And the more a man behaves fiercely toward animals, the more he grovels to the men who dominate him. (Michel, 1976, p. 97)
\end{abstract}

Louise Michel, a leading figure in the Paris Commune, and an icon to anarchists and the libertarian left, believed that her commitment to revolution, which was the driving force of her life, could be traced, at least in part, to the affective reactions she experienced from a very early 
age at the sight of animals being tortured. As we have seen, the founders of the first societies for the prevention of cruelty to animals were outraged by the violence of men and were motivated by the desire to soften their mores. From the final third of the 19th century onward, some animal protectionists became so scandalized at the suffering of animals that their anger seemed to fuel their revolt against the abuses of power. Thus, in Louise Michel's view, her feelings of compassion for animals who are victims of domination by men fed into her determination to challenge tyranny and injustice: "the kind of cruelty one sees being inflicted on animals in the countryside, and the horrible sight of their condition, gave rise to my pity for them, as well as my understanding of 'crimes of force.' Those who control the peoples of the world behave toward them in the same way!" (Michel, 1976, p. 97).

It often happens to me, thinking back to the origins of certain things, to experience again a sharp sensation whose force has not diminished over the years. Thus, the sight of a decapitated goose, walking along with its bleeding neck upright and rigid, with the red wound where the head should have been; a white goose, with blood spattered on its feathers, walking like a drunkard while its decapitated head lay on the ground, eyes closed, thrown down in a corner, had a lasting impact on me. I must have been very young at the time, because Manette held me by the hand to cross the hall as if we were going on a journey. It was impossible then for me to use reason to justify this impression, but I find it at the root of my pity for animals, as well as for my horror at the death penalty [...]. Everything must be set free, all creatures and the world, or [perhaps I should say] all worlds, who knows? Wild animals that we are! (Michel, 1976, p. 163)

"Wild animals that we are!": Louise Michel's concluding exclamation indicates a form of identification with animals which live under human domination, as well as a celebration of the figure of the untamed beast which resists being domesticated and living as a slave for the sole purpose of providing comfort to its master. A similar mixture of feelings is also evoked in the dedication at the beginning of the childhood memoir of Séverine, another heroine of the revolutionary left, who was a journalist and editor of the daily newspaper Le Cri du peuple: "to your dear memory, grandmother $[\ldots]$ and also for all the little wild chicks hatched in the henhouse, for all those whom the spirit of revolt kisses on the forehead when they are in the cradle" (Séverine, 1921). 
In drawing an analogy between, on the one hand, the wild creatures who man attempts to domesticate and, on the other, their own rebellious temperaments, Louise Michel and Séverine enable us to better understand the ambivalent attitudes toward animal protection which were characteristic of the revolutionary left in the 19th century. Animal protection societies aroused suspicion in many supporters of proletarian revolution, due to the fact that the ranks of these societies were largely populated by what they saw as their bourgeois class enemies. In the Communist Manifesto, 1848 political pamphlet by German philosophers Karl Marx and Friedrich Engels, animal protection is grouped together with reformist counterrevolutionary movements, which were promoted by philanthropists and humanitarians, whose sole aim was alleged to be the strengthening of bourgeois society (Agulhon, 1988, p. 244). Indeed, the partisans of proletarian revolution often claimed - putting forward an argument as old as the cause of animal protection itself - that the more animal protectionists were moved by the suffering of animals, the more they were oblivious to the suffering of men, in particular the suffering of the very workers they themselves were unscrupulously exploiting. In 1840, Flora Tristan, in London Walks; or, The English Aristocracy and Proletarians, denounced the duplicity of members of the RSPCA who, in the name of universal charity, claimed that they wanted to prevent people from beating horses, donkeys and dogs, whereas their real aim was "to organize ways of spying on the servants who were looking after the animals" (Tristan, 1978, p. 199). Socialist militants could be even more outraged by the fact that workers received nothing like the care and attention lavished on their horses by their bosses: "an industrialist pays 40 to 50 pounds for a horse, whereas the country provides him with men free of charge!" (Tristan, 1978, p. 121). In the 15 September 1883 edition of journal Le Revolté the author of the article "Thoughts of a Proletarian about Vivisection" developed an argument which aimed to stir up public revolt by revealing that the dominant classes could display far more compassion toward animals than toward human beings, whom they exploit (in 1888 Jules Jouy wrote a song about the SPA which explored the same theme):

And the campaign against vivisection! Is this not yet more evidence of the kindheartedness of our bosses? I read the list of the members of this new society of dog lovers: there was not a single worker! Our miserable hearts are too hard for such refined sentiments. [...] Yes, not one worker, and yet the members come from a wide range of backgrounds: bankers and manufacturers, ministers and deputies, even Counts and Countesses [...]. You say [comrades] that all these good and sensitive hearts, who 
cannot bear to see the tiniest suffering inflicted on a little dog, remain criminally indifferent to the sorrow of the thousands and thousands of human beings who provide them with their livelihoods; you say that in the times we are living in each man should struggle not against the vivisection of animals, but against the vivisection of men, women and children, vivisection which does not stop, day after day, night after night, vivisection which does not stop for a minute, which never takes a holiday, vivisection on the land and on the sea, vivisection in workshops, in factories, in the mines, a slow but horrible vivisection which every minute sacrifices hundreds and hundreds of our brothers.

At dawn I go to the factory / Sweating, and never sitting down, / I work too hard, I slog away, / From morning until evening. / Philanthropists, be nicer to me; / I am as worthy as all your animals. / CHORUS: Love me like you love youranimals / Yourdogs, your cats and your bulls! (repeat) I work relentlessly for nothing; / The exploiter is my picador; / [...] Sensitive men that you are, / Protest against my torturers! / CHORUS [...] / When I'm sixty, / The boss says "He's too old!" / He sends me to the abattoir / Like an old lame horse. / Instead of kowtowing / Before my cruel tormenters, / Love me like you love your animals, / Your dogs, cats and your bulls! (repeat). (Jouy, 1888, p. 157)

Statements of this kind give an indication of the varying, sometimes ambivalent, attitudes that members of the revolutionary left have adopted toward animal protection. For some revolutionaries, worrying about animals is unworthy of the socialist avant-garde, because "pity for animals and zoophilia [are] bourgeois sentiments, which go hand in hand with cruelty toward men" (La Revue socialiste, 1887, p. 81). For others, though, demanding higher standards of animal protection is a way of denouncing the falseness of the charitable works of the dominant strata of society. Members of the latter group took the view that we should not overlook the fact that domestic animals and workers are equally exploited, and, moreover, by people who take pride in their own compassionate and protective paternalism. Campaigns in favor of establishing a more just social order - which would abolish the various means the powerful use to dominate - should therefore include animals in the ranks of the weak, the subjugated and the docile, on behalf of whom the revolt against the strong should be led. The article by Charles Gide, "Une classe de travailleurs oubliés" (A class of forgotten workers), published in July 1888 in La Revue socialiste, is an important expression of this tradition:

I want to defend the cause of a particular class of worker and employee: a large class, because it has millions of members; a miserable class, because, 
in return for being fed just enough not to die of starvation, they are forced to perform the most difficult tasks, in chains, and under the whip; a class who are all the more in need of protection because they cannot defend themselves, they do not have the wit to strike and are too kind-hearted to revolt; I am talking about domesticated animals. It seems [to me] that working men should harbor fraternal feelings for working animals, their humble companions in labor and suffering [...]. I am not certain if animals are our brothers because of the laws of heredity and because we have common origins; but I am sure - and that is enough for me - that they are our brothers because of an indestructible common experience of work and suffering, and because of the solidarity forged in the common struggle for our daily bread. (Gide, 1888, p. 51)

A year later, in 1887, Marie Huot, the founder of the Popular League against Vivisection, published an article in La Revue socialiste entitled "Le Droit des animaux" (The rights of animals), in which she sought to demonstrate the extent to which concerning oneself with the fate of animals is very much a part of "the ideal pursued by socialists" (Huot, 1887, p. 47). She described involvement in the animal protection cause as a salutary preparation not for gentleness, but for revolt against the powerful, and stressed the need to "protect the patient from the torturer and, applying the laws of compensation, through pity, come to love the victims of tyranny and hate the tyrants" (Huot, 1887, p. 55): "Gentle with the weak and tough with the strong - that is our motto. We are the champions of the all the humble ones, the destitute, the bullied, and we believe that, because of that, we are the pioneers of a better future" (Huot, 1887, p. 53).

That being the case, it is easier to understand how causes which, as we have seen, were initially supported by members of the social elites, managed to rally a new cohort of working-class militants, who were calling for revolution. Thus, despite the fact that in the peripheral regions bullfighting had the support of socialist deputies, representatives of "Parisian social democracy" were quick to "state their opposition to the ferocious games from the South" (La Revue socialiste, 1887 , p. 81). On 11 December 1886, at a meeting presided over by Félix Pyat, "Louise Michel, Marie Huot, Dr. Castelnau and other prominent socialists" spoke up to "condemn the importers of bloody performances of Roman decadence" (La Revue socialiste, 1887, p. 81). These new opponents brought novel shock tactics, which were very different from those used by the original, very respectable, animal protectionists. More than anyone else, Huot >stood out for her provocative declarations and adoption of direct action which, far from avoiding "scandal," deliberately 
courted it. Huot, a journalist with revolutionary sympathies, believed that rebelling against the crimes of vivisectionists and the crimes of toreadors were two aspects of the same struggle, and suggested that bullfights were a sort of "public vivisection [...] for the amusement of the multitude" (Huot, 189ob, p. 8). She organized collective actions, in bullrings and public demonstrations, which would today be called zaps, namely sudden attacks against a target which is denounced using verbal aggression and shocking performance tactics (Patouillard, 1998; Broqua and Fillieule, 2009).

It was in 1887 when we undertook this horrible task which consists of going to arenas to be beaten up, the law in one hand and a whistle in our mouths [...]. On 19 January 1887 - passing from words to action I went with about twenty of my friends to the racecourse, where the first bullfight was taking place. Our pockets stuffed with high-pitched whistles - we took several spare whistles each because we knew that people would grab them from us - determined to stand up to anyone and anything, come hell or high water [...]. [W]e split up into groups of two or three and spread out, intending to take it in turns to create a disturbance. When one group was removed, another group would take over, and so on, until the end of the performance, which we aimed not just to disrupt, but to actually prevent from taking place [...]. As soon as we blew our whistles, all the bullfighting fans jumped on us and, on the terraces, ten meters above the course, a hilarious scene ensued [...]. [M] y nose was bleeding almost as much as the bull's. Two Paris guards, on horseback [...] grabbed the colleagues who were standing to the right and left of me [...] and I had to give way at the same time as the seams of my dress which, unfortunately, were not very strong at the sides. After we left, scuffles broke out around our little groups of friends in various parts of the arena, causing the performance to be interrupted on three occasions. Because they could not be removed in any other way, the protestors were thrown over the seats; they received kicks in the face and their clothes were left in tatters. (Huot, Les Courses de taureaux, 1890, pp. 11-12)

In the last decade of the 19th century, another leading figure on the revolutionary left was moved to join the wave of antibullfighting protests. Séverine, the disciple of the communard Jules Vallès, who she succeeded as editor of the Cridu peuple, had articles published in many newspapers, and quickly made a reputation for herself as a hard-hitting journalist with strongly political convictions. In 1886, already at the helm of the Cri $d u$ peuple, she organized collections for the striking miners of Decazeville and 
Vierzon; in 1890 she went down to the bottom of a mine where there had been a firedamp explosion; in 1892, dressed as a worker, she joined striking "sugar breakers." Her frequent appeals for charitable donations to the poor earned her the nickname "Our Lady with a Tear in Her Eye" (Couturiau, 2001). The libertarian journalist - who stated "I love first of all the poor, then animals, then [other] people" - also wanted to make the public more aware of the ill-treatment of animals. In 1888, she denounced the conditions in which many horses, exploited by their unscrupulous owners, spent the ends of their lives, and opposed a campaign against stray dogs launched by the Paris prefect (Couturiau, 2001, p. 126). From 1890 onward, many of the articles she wrote attacked plans to allow bullfights to be held in France; in 1895, in Nîmes, some bullfighting fans set upon a woman who they mistook for Séverine, whom they "could not forgive for having stirred up such violent controversy over their corridas" (quoted in Couturiau, p. 270).

This appropriation of the animal protection cause by a faction of the libertarian left also extended to the antivivisection movement, whose leadership was initially made up of members of the old social elites. Although, once again, Marie Huot stood out from other activists because of her fierce, uncompromising commitment, ${ }^{46}$ she was far from being the only revolutionary socialist to consider opposition to vivisection to be a vital part of the struggle against social injustice. On reflection, this rallying of spokespeople for the proletarian cause to the antivivisectionist ranks is not actually very surprising. As we have already seen, opposition to vivisection was originally a kind of reaction to the accreditation strategies of members of the bourgeoisie, who sought to derive prestige from their mastery of scientific experimentation. This reaction initially came from members of the old dominant classes, concerned that the basis of their authority would be brought into question, but later another kind of opposition, from the other end of the social scale, saw members of the working class join the struggle against scientific and medical interest groups, seen as a fully integrated part of the triumphant bourgeoisie. These new antivivisectionists were attacking the arrogance of scientists and doctors of bourgeois origin, who, they believed, treated their poorest patients as being of negligible importance, nothing more than material for the experiments they used to establish their domination. In the opinion of these "socialists who were concerned about the suffering and the lives of the exploited," it should be

46 One of the most spectacular zaps carried off by the of the president of the Popular League against Vivisection was when she hit Professor Brown-Séquard with an umbrella as he was performing an operation on a live rabbit at the Collège de France. 
forbidden "for experimenters to turn their research laboratories into torture chambers." They believed that the agony that vivisectionists inflicted on animals reflected a general lack of sensitivity to the weak, whether they were animals or humans:

[F]or those people, humaneness and pity are ridiculous things. We also see this from the way doctors and medical students treat sick people in hospitals, regarding them as merely things to be experimented on, whose suffering and lives are of no importance [...]. We only need to think of the sinister Dr. Joyeux from Reims, who enjoys inoculating his poor female patients with cancer. (La Revue socialiste, vol. 6, 1887, p. 299; and vol. 14, 1891, p. 116)

In 1887, gangs of medical students set about disrupting one of Marie Huot's talks. The "pasteurist boorishness" of these young men, who rolled around making animal noises in order to prevent the lecture from taking place, outraged the socialists and strengthened their resolve to attack the practice of vivisection:

What a sad spectacle it is to see these young students scoffing or responding with taunts at any mention of feelings of humaneness or pity for the weak! [...] We left so we would not have to hear the whistles which would inevitably have greeted the reading of "Le Crapaud," Victor Hugo's moving poem. Social revolution is surely imminent, as the bourgeoisie of tomorrow promises to be even more rotten, selfish and blind than today's and yesterday's. (Dramard, 1887 , p. 203)

In England, the birthplace of the antivivisectionist movement, the rallying of working-class and socialist members to the cause happened later. Between 1903 and 1911, during a series of mobilizations against vivisection, it became apparent that the social composition of the antivivisection movement had changed. There were still a number of establishment figures among its ranks, but they no longer predominated. The numbers of middle-class women, some of whom were simultaneously involved in the suffragette movement, which was campaigning for votes for women, continued to rise. ${ }^{47}$

47 The parallel engagements of a number of prominent figures in the movement does not, of course, mean that all the women who were calling for votes for women were militant antivivisectionists, or that all opponents of vivisection were feminists committed to the cause of political equality between the sexes. 
Perhaps more surprisingly, at least at first sight, antivivisection campaigns were joined by growing contingents of socialist, Marxist and trade union activists. The changing composition of the antivivisection movement was reflected in the Brown Dog Affair which, in 1907, led to riots which were widely reported in the London press. In 1906, in the working-class borough of Battersea, a socialist stronghold, the World League against Vivisection erected a statue of a dog as a memorial to the numerous victims of vivisection. The statute was accompanied by an epitaph which urged anyone who read it to rise up against this abominable practice:

In Memory of the Brown Terrier Dog Done to Death in the Laboratories of University College in February 1903, after having endured Vivisection extending over more than two Months and having been handed from one Vivisector to Another Till Death came to his Release. Also in Memory of the 232 dogs vivisected at the same place during the year 1902. Men and Women of England, how long shall these Things be? (Lansbury, 1985a, p. 14)

Many scientists and doctors in London regarded this monument - and the countless antivivisectionist pamphlets which described them as appalling torturers - as outrageous, intolerable attacks on the medical profession and the wider scientific community. In November 1907 a group of medical students equipped with hammers tried to attack the statue but the police, with the help of working-class residents of the neighborhood, prevented them from doing so. The incident ended in the arrest of ten medical students, some of whom received fines. The next day around a hundred other students, holding effigies of the brown dog on sticks, held a demonstration to protest against the treatment of their classmates. In December 1907, student groups organized a protest to coincide with the annual Oxford and Cambridge rugby match. The plan was to recruit rugby supporters to their cause, then mount an expedition to capture the statue, and throw it in the Thames. When the demonstrators reached Battersea they were met by workers who forced them toward the city center, where the march broke up and scuffles with the police ensued (Mason, 1997, p. 51). In the following weeks, medical students were involved in many incidents and brawls. Students particularly targeted suffragettes, who were campaigning for votes for women: "[T] he students, and increasingly the public, regarded antivivisection and votes for women as two parts of a single movement" (Lansbury, 1985a, p. 17).

Thus women, whether they had bourgeois or revolutionary backgrounds, appeared to have played a major role in the transformation of animal 
protectionism into a movement highly critical of the domination of the weak by the strong. Indeed, it seems reasonable to suggest that women activists were drawn to identify with the figure of the exploited animal by the fact that they themselves had experienced masculine domination. A few lines written by Séverine seem particularly apposite in this regard. In 1903, the journalist, who was a proponent of women's rights - to study, to divorce and to have an abortion - wrote a children's book, Sac-à-tout: mémoires d'un petit chien, the memoirs of an abandoned dog which she had taken in. The preface of this book draws a clear parallel between the female condition and the condition of animals:

Because I am "just a women," because you are "just a dog," because, though at different levels on the social ladder of beings, we both represent species which are inferior to the masculine sex - so bursting with perfection the feeling of having been accorded inferior status has created greater solidarity between us, and a more perfect understanding. (Quoted in Le Garrec, 2009, p. 55)

When Séverine wrote these lines she was already an experienced journalist, and during her career had taken every opportunity to denounce the all too common phenomenon of men exercising domination over women with impunity. In a series of autobiographical articles, published in 1892, entitled "The Eternal Masculine," Séverine describes her wedding night as legalized rape, during the course of which as an innocent young woman, totally unprepared for what awaited her, and placed like a prey before a predator, she discovered with horror subordination to the brutal sexuality of a man. In 1897, memories of the feelings she experienced as a young woman living through this ordeal seemed to fuel the anger expressed in her account of the Bazar de la Charite fire, which she witnessed: more than a thousand people in a blazing shed, an indescribable crush of bodies and, in the end, a death toll of 115 women and [...] only five men! The vast majority of the representatives of the male sex "fled, and not only did they not save anyone, but they pushed and forced their way through and over the female bodies, kicking, punching, stamping and striking out with their canes" (quoted in Jaeger-Wolff, 2007, p. 33).

Séverine was only one of a number of female animal protectionists who vociferously protested against the domination and exploitation of the "weak sex" by the "strong sex." In 1892, Marie Huot, the president of the Popular League against Vivisection, was also the first woman to publicly demand free access to abortion and contraception (Autain, 2002, p. 5). In fact, as 
we mentioned in the previous chapter, Huot's passionate account of the sensations derived from caressing animals was probably not unconnected to her desire to avoid, if not all heterosexual relations, then at least the obligation to confine herself to the roles of procreation and motherhood. The journalist Marguerite Durand, who was instrumental in setting up the first pet cemetery at Asnières, is better known to historians of feminism for having founded, in 1897, La Fronde, a feminist newspaper entirely produced by women (from the typography to the writing of all the articles). Similarly, Camille du Gast, before her election to the presidency of the SPA, had already made a name for herself by excelling in activities which had traditionally been regarded as exclusively male preserves. Born into an upper middle-class Parisian family, in 1890 she married Jules Crespin, the son of wealthy businessman. The couple were extremely well off, and du Gast decided to devote herself to extreme sports. In 1895, she performed a parachute jump from the basket of a hot air balloon, after making a perforation in the balloon, which had reached an altitude of 1,300 meters. In 1901, at a time when a woman getting behind the wheel of an automobile was widely regarded as immoral, she took part in the Paris-Berlin motor race and finished 3 oth in a field of 154 men. In 1904, her application to compete in the fourth Gordon Bennett Cup race was rejected by the sporting committee of the Automobile Club of France, who decided that it was not appropriate for a member of the "weak sex" to participate in such an arduous race. The woman whom the Herald Tribune dubbed "the greatest sportswoman in the world" then turned her attentions to the new sport of motor boat racing. In 1905, she narrowly escaped death while competing in the transMediterranean Algiers-Toulon race, the disastrous conclusion of which received wide press coverage. The following year she took up the life of an explorer and crossed Morocco on horseback (Jaeger-Wolff, 2007). In 1921, du Gast contributed a chapter, entitled "The Role of Sports in the Victory of Feminism," to Fifty Years of Feminism, 1870-1920, published by the French League for the Rights of Women, in which she recounts her sporting exploits, and argues that female participation in sport can be a first step toward the emancipation of women. Eight years later, as we noted earlier, du Gast, sportswoman and explorer, became the first woman president of the SPA.

In Great Britain as well animal protectionists were often involved in movements which sought to defend women against male domination. Frances Power Cobbe, to take just one example, far from confining herself to antivivisection campaigning, was well known for her campaigning for domestic violence legislation, and for votes for women. Her article "Wife Torture in England" was influential in the debates leading up to the 
passage of the 1878 Matrimonial Causes Act, which allowed women victims of violent husbands to obtain separation orders. This leading antivivisection campaigner was also on the executive council of the National Society for Women's Suffrage in the UK. Certain details of Cobbe's biography point to her having direct personal experience of both gender discrimination and the precarious existence lived by many dependent women. When she was a child, her father, a Dublin magistrate, neglected her, and favored her four elder brothers. At the age of twenty she experienced a crisis of faith which led her to question immortality, the divinity of Christ and the Trinity, as well as the divine inspiration of the Bible. After her mother's death she told her father about her doubts, whereupon he turned her out of the house. A year later she was allowed to return to the family home, and she took on the role of housekeeper. When she wrote her first book, Essay on the Theory of Intuitive Morals, in 1855, Cobbe was obliged have it published under a male pen name, since revealing that such a text had been written by a woman would have provoked a scandal. Two years later, after her father's death, she was granted a derisory annual allowance, as if the late custodian of paternal authority wished to remind his rebellious daughter that women would never escape their dependence on men (Dardenne, 2003). Frances Power Cobbe never married, but for thirty-four years she and the sculptress Marie Lloyd lived as a lesbian couple (Marcus, 2006, pp. 41-44).

Thus, in certain historical contexts, there seem to be affinities between support for the cause of animal protection and a commitment to feminism arising from personal experience of gender discrimination. There are other experiences of discrimination which can predispose certain individuals to identify with animal victims, and subsequently rally to the animal protection cause. Thus, the manner in which the Nazis treated populations they regarded as inferior also seems to have helped create a sensibility which probably had a bearing on the decision of certain militants to join the movement in the second half of the 2oth century. In one chapter of his book Eternal Treblinka the American historian Charles Patterson mentions several Jewish activists who could trace their commitment to animal welfare to feelings they experienced in ghettos or concentration camps: as a child Marc Berkowitz, a Canadian opponent of animal experimentation, witnessed an experimental operation conducted by Josef Mengele; "Hacker," a member of the underground organization the Animal Liberation Front, which was founded in 1976, was interned in Auschwitz, where he was tattooed with a number, like a branded steer; Alex Herschaft, the founder of the Farm Animal Reform Movement, an organization based on the East Coast of the 
United States, spent part of his childhood in the Warsaw Ghetto (Patterson, 2007, pp. 205-237). The pronouncements of these activists frequently drew attention to the close analogy between, on the one hand, their own and their family members past suffering and, on the other hand, the continuing mistreatment of animals:

I know from personal experience what it is like to be treated like a worthless object, to be hunted down by the murderers of my family and friends, to ask myself every day if I would ever see the sun rise again, to be crammed in a cattle truck on the way to being massacred. (Patterson, 2007, p. 211)

Animals are weak, they cannot make themselves heard, they cannot help one another or help themselves. We too were in the same position. (Patterson, 2007, p. 206)

My mother has no grave, but if she had one, I would dedicate it to geese. I was once a goose, too. (Patterson, 2007, p. 208)

Biomedical research laboratories, productivity-driven agriculture and abattoirs are faceless complexes where society carries out its dirty work abusing and murdering innocent sensitive creatures. These are our Dachaus our Buchenwalds our Birkenaus. Like respectable middle-class Germans we have quite a clear idea of what goes on in these places, but we do not want to face up to reality. (Patterson, 2007, p. 213)

Although the testimony given by animal protection activists is eloquent, the positions defended by Patterson in Eternal Treblinka are, in my opinion, seriously flawed, due to their reliance on crude theoretical generalizations. I would argue that the analogies drawn between the Shoah and the current treatment of animals are worth mentioning insofar as they provide illustrations of the diversity of experiences which can contribute to an individual identifying with animal victims. This perception of equivalence between oneself and a mistreated animal must be regarded as one of the many prior sensibilities capable of contributing - in proportions which can vary greatly depending on the individuals and the militant organizations - to the process of joining the cause. The fact that a propensity to identify with the animal victim sometimes is a result of experiences previous to joining the movement should not lead us to overlook the fact that such a propensity can equally be greatly intensified, suggested, or even generated, as soon as 
those who are have converted to the cause put into operation the sensitizing device whose properties we will now outline. ${ }^{48}$

\section{Expose the torturers, help the victims}

Whether they identified with animal victims, or acted on other motivations examined in the previous chapters, the activist strategies deployed by entrepreneurs of the animal cause in the last third of the 19th century changed and made more complex the underlying emotional economy of animal protection. These activists increasingly used sensitizing devices which differed greatly from the methods which had been hitherto used to attempt to change the mores of the general public. Whereas previously the emphasis was on prohibiting violent scenes from public places, now it was a matter of actually tracking down, and exposing hidden acts of cruelty, which happened away from the public gaze. In 1883, Frances Power Cobbe published Light in Dark Places, an indictment of vivisection illustrated with many etchings directly lifted from physiology manuals: knives, scalpels, used pliers and scissors; equipment set up to hold in place dogs and rabbits whose flanks had been opened with several incisions; a frog's nerves attached to a measuring instrument; a machine to produce artificial respiration in guinea pigs, etc. In doing this, the book aimed to expose images of vivisection to as many people as possible, so that they could understand, having experiences feelings of disgust, the need to abolish such an intolerable practice:

[W]e gathered together and displayed some of the instruments and apparatus from the physiological laboratory, and showed different ways of immobilizing victims, as well as examples of various experiments, in order to give a reader who was prepared look for a few moments a clearer idea of the work of the "torture chambers of science" than they could have obtained by reading a large number of printed descriptions (without pictures). (Cobbe, 1884, p. 5)

48 For the theoretical foundations which enable a distinction to be drawn between, on the one hand, affective experiences which could increase the probability of an individual joining the movement, and, on the other hand, the emotions expressed by activists when they attempt to recruit as many supporters as possible, see my article, (Traïni, 2010). 
The production and distribution of material of this kind became a classic sensitizing device for activists who sought to reveal the widespread hidden suffering of animal victims:

People have no idea what vivisection consists of; it would therefore help our cause to show members of the public the terrifying spectacle of the torture to which harmless creatures are subjected, all in the name of science. Mrs. Fairchild-Allen, who organized an antivivisection exhibition in Chicago, tells us that the crowds who flocked to see it contemplated the exhibits with a mixture of shock and horror, while the vivisectionists themselves looked embarrassed or extremely irritated.(BSFCV 12 [1898], p. 8)

Increased visibility leading to increased sensitivity: the procedure worked even more effectively because antivivisectionists arranged images in such a way as to maximize their emotional impact. In one pamphlet produced by the Society for the Protection of Animals from Vivisection, the image of a dog on a vivisectionist's operating table is placed next to a picture of a Saint Bernard holding between his paws a little girl who he has just saved from drowning (Dardenne, 2003, p. 241); the titles which accompany these images - "How we treat animals, how animals treat us" - adds to the indignation of anyone who looks at the pamphlet. Opponents of vivisection use a wide variety of juxtapositions of this kind which provoke revulsion at practices which subject the figure of the dog - so loved and loving - to such excruciating pain. In one SPA newsletter the denunciation of the way the vivisectionist treats the "tireless friend," a "dog who burns with love," in the poem "Dogs and Vivisection," has more impact for having been preceded by another poem, entitled "The Savior," whose verses praise the heroism of a dog who rescues a drowning infant (BSPA, 1908, p. 166). In fact, since the end of the 19th century, the building of animal shelters and opposition to vivisection had been mutually reinforcing causes, as animal protectionists were particularly concerned that abandoned dogs be captured and used in animal experimentation laboratories. In $188_{3}$, backers of the first SPA animal refuge declared that their primary intention was to "save dogs from the dog pound, which ordinarily serves as a waiting room for the amphitheater of vivisection" (BSPA, 1883, p. 137). Several years later the Popular League against Vivisection was running four animal shelters, where homes were offered to "poor abandoned dogs, saved from vivisection" (BSPA, 1908, p. 260). Sensitization initiatives which aimed at having members of the public imagine their own pet being tortured by vivisectionists were a great 
success: they made a big contribution to the recruitment of new supporters, many of whom were women.

One key part of the antivivisectionist sensitizing device was to invite personal testimonies, where an individual would give an account, in public, of a scandalous situation which they had witnessed, and explain how it had affected them personally (Mehl, 2003). The personal testimony aims to provoke compassion from a distance by revealing the suffering of an unknown victim which requires a collective political response (Boltanski, 1993). In this regard, animal protection entrepreneurs were particularly determined to examine acts of cruelty committed in private and in secrecy, and had no qualms about using what we would now call infiltration to further their cause. So, in 1874, the British feminist journalist Anna Kingsford, whose interest in vivisection had been sparked by an article by Frances Power Cobbe, decided to study medicine in Paris in order to gather evidence in support of the view that experimenting on animals served no useful purpose. Kingsford, who was one of the first women to obtain a medical degree, joined the International Association for the Total Suppression of Vivisection on her return to London, and wrote numerous articles calling for the practice to be outlawed.

By this time, opponents of vivisection appeared convinced of the necessity to force their way into laboratories. They felt sure that revealing, in sordid detail, what happened in these labs would revolt the senses and sicken the hearts of the public. Take, for example, the following comment from the Zoophilist, from September 1893:

The account that you are about to read [has been] signed by eye witnesses, and gives an idea of the horrors committed in physiology laboratories under the ingenious pretext of scientific research. On June $12^{\text {th }}$ at half past two we arrived at the laboratory of Professor ***. Upon opening the door we immediately heard the sound of groans and cries, and as we entered the room we saw attached to a table a little poodle which was mutilated, covered in blood, fully conscious and apparently suffering greatly. [There follows a long and detailed description of the painful operations performed on the animals.] (BSFCV 10 [1894], p. 35)

In 1900, two Swedish women, the Countess Louise Lind-af-Hageby and Liesa Schartau, horrified by what they saw when visiting the Pasteur Institute in Paris, founded the Swedish Anti-Vivisection Society. Two years later they enrolled to study at University College London, partly to acquire the medical knowledge they needed to be able to make well-informed attacks on the practice, but mainly to report upon the actions of vivisectionists, 
observed at close quarters. The two young women kept a detailed dairy of the experiments they witnessed which they published, in 1903, under the evocative titles Eye-Witnesses and The Shambles of Science: Extracts from the Diary of Two Students of Physiology. The eyewitness evidence of the two students provided a "frightening account of the various experiments carried out on cats and dogs," and made every effort to "make this work appear to be 'a kind of butchery"' (Kean, 1998, p. 141). These books caused a lot of controversy, in particular a passage from The Shambles ofScience-describing the experiments carried out on an old brown dog - which convinced animal welfare campaigners to erect a statue in the dog's memory. As we have seen, this provoked a series of demonstrations, clashes and riots.

When attempting to stir up the emotions which will rally as many people as possible to a cause the choice of vocabulary is, of course, crucial. One of the lexical fields most often used by opponents of vivisection is the language of exposure: the investigation which reveals hidden crimes; the unmasking of criminals; the uncovering of charlatans who thought they could act with impunity. In this regard, the writing of the president of the Popular League against Vivisection is exemplary (Huot, 1890a; 189ob). Whether engaged in direct action in laboratories or in bullrings, Huot is confident that she will "enlighten public opinion"; "bring to light the torture that takes place in laboratories, while also revealing certain experiments carried out on hospital patients"; reveal "in more or less veiled terms, the shameful dealings, the shady tricks and the appalling things which go on in the corridors of those abattoirs"; and "struggle against corruption." In fact it is a matter of ripping the masks from the faces of the guilty so that they can be seen as they really are, in the clear light of day. Thus, those who claim to be champions of reason - laboring for the good of all humanity - can expect to have their less noble qualities and motives brought to everybody's attention: namely a cruelty all the more alarming because it appears sophisticated; a curiosity which is both gratuitous and unhealthy; a thirst for celebrity and an unscrupulous desire for riches. Under the white coats of these apparently civilized scientists, suggest the antivivisectionists, there are monsters about whom society is entitled to fear the worst.

The protection societies are there to listen to all the protests, and to put up as many obstacles as possible to stop the multitude of sterile experiments which never reveal anything, other than the presumptuousness and cruelty of the men who have performed them (BSPA, 1861, p. 367).

[A rich donor to the SPA] thought that thousands and millions of creatures should no longer die in incredible pain, subject to exquisite scientific 
tortures, in order to demonstrate phenomena which have been observed and known about for a long time, and should certainly not serve as advertising for charlatans, or be used to satisfy the brutal appetites and unhealthy curiosity of those whom our fathers did not even give the right to desecrate corpses. (BSPA, 1876, p. 375)

We are opposed to this distressing spectacle of a whole generations of practitioners, slowly desensitized, progressively hardened and conditioned by anatomical and micrographic research, who end up believing that they are obliged, because of an esprit de corps, because of their memories of their student days, or out of professional duty, to consider the suffering of living things to be of minimal importance [...]. By applying the methods of a fanatic, what we start by doing to animals we will end up doing to human beings. (BSFCV 1 [1884], p. 5)

Thus, in the opinion of antivivisectionists, what goes on behind the closed doors of laboratories is all the more deserving of exposure because the practices of vivisectionists pose a serious threat to the wider society. We also should note that the sensitizing device used to denounce vivisection has undeniable affinities with two emerging literary genres; firstly crime fiction, where the reader follows clues which reveal the identity of guilty parties, and secondly, and to an even greater extent, with so-called sensation novels, which could be seen as forerunners of serial killer novels. The development of the antivivisection movement coincided with the publication of a number of novels featuring doctors whose behavior was guided not by reason but by horrifying sexual urges. PaulFaber, Surgeon (1878), by George Macdonald, and The Professor's Wife (1881), by Leonard Graham, both feature female characters driven to madness by husbands who use them in their experiments. Wilkie Collins, after corresponding with Frances Power Cobbe, wrote Heart and Science (1883), in which one Dr. Benjulia takes pleasure in tormenting animals, women and young girls (Lansbury, 1985b). This kind of fiction encourages certain representations and fears to take hold, and in 1888, when the London press was full of Jack the Ripper stories, a rumor went around antivivisectionist circles which generated more feelings of compassion toward laboratory animals: the criminal was allegedly actually a vivisectionist who, tired of cutting up animals, had now turned his attentions to women. ${ }^{49}$

49 This is a new version of the old argument that violence toward animals leads to violence toward human beings. The new element here is that the "suspects" are no longer from the uneducated classes, but individuals who claim to be acting in the name of a superior scientific rationality. 
In actual fact, opponents to the practice frequently suggested that one of the main motivations of vivisectionists was the satisfaction of abject sexual impulses. Antivivisection activists recommended their supporters to avoid entering into social relationships - and a fortiori marriage - with doctors who practiced vivisection because of the risk that they would, sooner or later, try to involve them in depraved sexual practices (Lansbury, 1985b). The level of fear which the figure of a doctor with highly questionable sexual inclinations could generate can be explained by considering a series of complementary factors specific to the particular context of the time. First of all it was in the Victorian era when there was a peak in levels of modesty, this sensibility which, according to Nobert Elias, is "characterized by a propensity to protect one's privacy, be it physical (the body, in particular the sexual organs) or moral (personal feelings)" (Heinich, 1997, p. 41). Such a sensibility was particularly developed among women of the middle classes, who lived in a milieu where the utmost importance was attached to both the inviolability and privacy of the home, and among wives who resisted nonprocreative extramarital sexuality. Furthermore, the development of an eminently masculine, even sexist, medicine, entailed a heavy medicalization of women's bodies, which were regarded as having a solely procreative purpose. During childbirth, midwives increasingly bowed to the superior obstetric competence claimed by the male doctors. More importantly, women were now obliged to have gynecological examinations, which sometimes felt like being "raped using medical instruments" (quoted in Walkowitz, 1995, p. 450). In other words, given the simultaneous intensification of sexual modesty and progress made in the field of gynecology, women were at the time particularly receptive to the idea that there were no limits to the intrusive procedures carried out on women's bodies by members of the medical profession.

At the Salpêtrière Hospital [Maria Desraismes angrily reports] a moment does not go by when the most immoral, scandalous experiments are not being conducted on the phenomena of hypnotism and suggestion [...]. Neither the sex, nor the wishes of the subject are respected. The flesh is scratched, injected, larded, and cut into [...]. This violation of the human persons is carried out in public and nobody protests. (BSFCV 4 [1886], p. 32)

Thus, the fact that women saw similarities between animal vivisection and the ordeal of gynecological examinations helps to explain the large number of female participants in the antivivisectionist movement (Lansbury, 
"1985b). The movement found it relatively easy to recruit middle-class women because the sensitizing devices of the entrepreneurs of the cause made them wary of potential abuses of power, of intrusive curiosity, and of hidden sexual motivations on the part of doctors. Such suspicions intensified the uncomfortable feelings these women experienced when they had to undergo medical examinations.

So, the sensitizing devices of opponents of vivisection contributed to the evolution of the cause, by provoking feelings which modified the emotional economy of the animal protection movement. Of course, for activists, a loathing of violence and cruel treatment of animals had always been major motivations behind their commitment to the cause. Nevertheless, they thought of themselves first and foremost as educators, even ascetics, who were best placed to define the norms which should prevail, for the greater good of all. As we have seen, this conferred great importance on sensitizing devices which relied on the presentation of awards, and other rewards. It also led them to show a certain level of benevolence to those who mistreated animals. In their role of educators the activists would employ salutary initiatives to encourage these individuals to give up their deplorable habits. Coachmen awarded certificates of good conduct by the SPA, cattle breeders honored for the care with which they treated their animals, butchers commended for their slaughtering techniques, etc., were all participants in an emotional economy which invited the recipients of praise to feel gratitude toward the educators who rewarded them. Vigilance and pedagogical gentleness from animal welfare campaigners on one side, gratitude and pride from the penitent deviants on the other, constituted a demopedic emotional register which innervated the first few decades of the animal protection movement. The mobilizations which developed from the last third of the 19th century onward, on the other hand, introduced emotional registers which for analytical purposes should be clearly distinguished (see Table 1).

The first major change - which resulted from the evolutions analyzed in the preceding chapters of our book - was that the emotional reactions linked to the fate of animals moved from being a secondary concern to being at the heart of the emotional economy valued by activists. The register of tenderness, which developed in parallel to mobilizations in favor of building animal shelters for dogs and helping stray cats, therefore invited animal protectionists to play the role of rescuers who, by "just listening to their hearts," would ease the suffering of animals, who were assumed to be grateful. These charitable actions were certainly no longer aimed at those coarse individuals who need to be civilized, but at "the poor little dogs and cats who are looking for sustenance and affection," and the "doggies and kitties who just want to lick your 


\section{Graph 4 The emotional registers of animal protection}

\begin{tabular}{|c|c|c|c|}
\hline & $\begin{array}{l}\text { Demopedic } \\
\text { Register }\end{array}$ & $\begin{array}{l}\text { Tenderness } \\
\text { Register }\end{array}$ & Exposure Register \\
\hline $\begin{array}{l}\text { FIRST HISTORICAL } \\
\text { OCCURRENCES }\end{array}$ & $\begin{array}{l}\text { The First Protection } \\
\text { Societies (1840-1870) }\end{array}$ & $\begin{array}{l}\text { First shelters for } \\
\text { abandoned dogs } \\
(1870-1890) \\
\text { Feeding Stray Cats }\end{array}$ & $\begin{array}{c}\text { Antivivisection } \\
\text { Mobilizations } \\
(1875-1911)\end{array}$ \\
\hline $\begin{array}{l}\text { PREFERRED SENSITIZ- } \\
\text { ING DEVICES }\end{array}$ & $\begin{array}{l}\text { Alarmist descriptions } \\
\text { of "barbaric" behavior } \\
\text { in public spaces } \\
\text { Sermons } \\
\text { Pedagogical materials } \\
\text { Rewards }\end{array}$ & \begin{tabular}{|} 
Touching images of \\
animals \\
Poignant descrip- \\
tions of abandoned \\
animals \\
Spectacle of the care \\
given to animals
\end{tabular} & $\begin{array}{l}\text { Investigative } \\
\text { operations aiming to } \\
\text { expose acts of cruelty } \\
\text { carried out in secret } \\
\text { Pamphlets exposing } \\
\text { those guilty of cruelty }\end{array}$ \\
\hline $\begin{array}{l}\text { VOCATION OF THE } \\
\text { BENEFACTORS }\end{array}$ & $\begin{array}{l}\text { Educator } \\
\text { Ascetic }\end{array}$ & Rescuer & $\begin{array}{c}\text { Dispenser of Justice } \\
\text { Liberator }\end{array}$ \\
\hline $\begin{array}{l}\text { SOURCE OF } \\
\text { ACCREDITATION OF } \\
\text { BENEFACTORS }\end{array}$ & $\begin{array}{l}\text { Moral intellectual and } \\
\text { scholarly excellence }\end{array}$ & \begin{tabular}{|} 
Sensitivity ("listens to \\
their heart") \\
Engagement in \\
immediate remedial \\
action
\end{tabular} & $\begin{array}{l}\text { Courage needed } \\
\text { to stand up to the } \\
\text { powerful } \\
\text { Operations to rescue } \\
\text { victims from their } \\
\text { tormentors }\end{array}$ \\
\hline $\begin{array}{l}\text { THE TARGET OF THE } \\
\text { CHARITABLE ACTIONS }\end{array}$ & $\begin{array}{l}\text { The ignorant man, } \\
\text { the deviant }\end{array}$ & \multicolumn{2}{|c|}{ The animal victim } \\
\hline $\begin{array}{l}\text { THE GRATEFUL } \\
\text { RECIPIENT OF THE } \\
\text { BENEFACTOR'S } \\
\text { ACTION }\end{array}$ & $\begin{array}{c}\text { The ignorant man } \\
\text { who becomes } \\
\text { educated }\end{array}$ & \multicolumn{2}{|c|}{ The animal freed from suffering } \\
\hline $\begin{array}{l}\text { THE FATE OF THE } \\
\text { ANIMAL }\end{array}$ & Secondary concern & \multicolumn{2}{|c|}{ Central concern } \\
\hline $\begin{array}{l}\text { TRANSFORMATION } \\
\text { OF THE DEVIANT }\end{array}$ & Central concern & \multicolumn{2}{|c|}{ Secondary concern } \\
\hline \multirow[t]{2}{*}{$\begin{array}{l}\text { EMOTIONS } \\
\text { EXPRESSED AND } \\
\text { SOLICITED }\end{array}$} & $\begin{array}{l}\text { Repugnance toward } \\
\text { deviant practices } \\
\text { Relatively benevolent } \\
\text { attitude toward the } \\
\text { reformable deviant }\end{array}$ & \begin{tabular}{|c} 
Compassion for \\
the fate of needy \\
creatures \\
Tenderness and signs \\
of mutual affection
\end{tabular} & $\begin{array}{l}\text { Indignation, horror } \\
\text { towards hidden acts } \\
\text { of cruelty } \\
\text { Contempt and anger } \\
\text { toward deviants }\end{array}$ \\
\hline & $\begin{array}{c}\text { Gratitude of } \\
\text { the repentant } \\
\text { deviant toward his } \\
\text { benefactors }\end{array}$ & $\begin{array}{l}\text { Gratitude of the } \\
\text { animals toward its } \\
\text { benefactors }\end{array}$ & $\begin{array}{l}\text { Gratitude of the } \\
\text { animal toward its } \\
\text { benefactors } \\
\text { The deviants fear the } \\
\text { benefactors }\end{array}$ \\
\hline
\end{tabular}


hand" (Huot, 1890a). In other words the rescued animals also appear in the rescuers' debt and, in return for the care that is lavished on them, show their benefactors gratitude, which is the best reward of all. The emotional register of tenderness is so powerful that even today it underpins the commitment to animal protection of a majority of activists. Historically, the register of tenderness laid the foundations for the development of a third register, which is in particular need of delimitation as its partisans are sometimes keen to distance themselves from the register of tenderness. The emotional register of exposure, in fact, paved the way for an emotional economy which allowed those who dedicated themselves to the animal cause to experience and express emotional states of a new kind. First of all, the investigative aspect to their campaigning, and the need to deploy effort to expose hidden acts of cruelty provide the activist with the excitement which can be derived from tracking down the guilty. Like detective characters who began to appear in crime fiction around the same time the protectors of animals track down the hidden evidence of the torturers' misdeeds. The register of unveiling also includes other emotions. First of all, there are the emotions provoked by practices which seem all the more horrible, repugnant and disturbing because the torturers appear to believe that they carry them out with impunity. Then, of course, there is also compassion for the animal victims, which is greater when they resemble an affectionate and loyal companion. Finally, last but not least, there is the anger directed at the torturer, as well as the desire to punish him by making him suffer the same fate which he reserved for those poor innocent animals: "those who would torture such a noble beast [wrote the author of a poem calling for a revolt] I would like to punish by vivisection" (BSPA, 1908, p. 166). In other words, it is no longer a matter of gently reforming the deviants who transgress norms. One cannot reasonably expect repentance from torturers, who display such monstrousness that we can feel no common humanity with them. In the end only force can prevent such dangerous creatures from committing their misdeeds. In other words, the emotional register of unveiling tends to lead to the setting up of agonistic sensibilities, which cause militants to value emotional states of the kind experienced during struggles, fights, and altercations with clearly identifiable enemies. In fact, it is this system of interdependent emotions - which culminates in avenging anger being directed at one's opponent - which incites animal protectionists to act as avengers, in no way fearing to confront, physically if necessary, those who torture defenseless animals. In fact, the blows with her umbrella directed at Professor Brown-Séquard by Marie Huot provided a model which later generations of activists - setting themselves up as avengers even liberators - would be inspired by, almost a century later. 


\section{Emotions, countermobilization, delegitimation}

The descriptive tasks which the notion of a sensitizing device entails invite the researcher to make a clear analytical distinction between, on the one hand, the emotions that this device was intended to provoke and, on the other hand, the emotional reactions actually generated, some of which were not anticipated by the promoters of the cause. Such a distinction seems indispensible for the analysis of the interactions and, to an even greater extent, the knock-on effects, between the various protagonists capable of influencing the course of a given series of mobilizations. From this perspective, the successive phases which characterize the antivivisection movement at the end of the 19th and beginning of the 2oth centuries allow the impact and the varying nature of the effects induced by the emotional register of exposure to be observed. Initially, British opponents of vivisection could celebrate having alerted not only to an increasingly determined activist base, but also to the highest levels of government. In 1876, after extensive lobbying by the antivivisectionist movement, the British Parliament passed the Cruelty to Animals Act, which stipulated that vivisection could only be performed by licensed scientists. Opponents of the practice considered that the legislation should have included provisions for independent monitoring of vivisectionists, while members of the scientific community saw the act as putting up "obstacles to scientific research," as well as being an intolerable "humiliation of scientists" (Cyon, 1883, p. 5). In 1883, the Contemporary Review followed by the Journal de médecine de Paris published "The antivivisection agitation," in which Elie de Cyon, a Russian physiologist, expressed his indignation that the "silly accusations of the antivivisectionists" could lead the English authorities to produce

humiliating decrees which put the monitoring of scientific research in the hands of police officers and informers [...]. Under the influence of this pseudo-humanitarian movement, British legislators have allowed themselves to enact measures which are both an assault on the personal dignity of scientists, and an offense against science itself. (Cyon, 1883, pp. 4-5)

Such "regulation of scientific research by the police" (Cyon, 1883, p.5) appears all the more disgraceful because it seems to substantiate the suspicions and fears stirred up by the antivivisectionist sensitizing devices: namely the allegation that physiologists, who pursue this practice in the secrecy of their laboratories, are only seeking "the satisfaction of cruel instincts" (Cyon, 
1883, p. 10). For the physiologist - who emphasizes a contrario the controlled rationality of vivisection protocols - antivivisectionists employed tactics which sought to manipulate public opinion, by taking advantage of a naïve trusting public. "Angry meetings, defamatory pamphlets, exasperating posters, mass petitions" (Cyon, 1883, p. 10) were the product of the "silliness" and "underhandedness" which were typical of these unscrupulous opponents. Antivivisectionists were also accused of quoting physiologists out of context and twisting their words, as well as falsifying illustrations taken from their manuals, in order to horrify and shock. Thus the Russian scientist writes of how uncomfortable he felt when he discovered that some British vivisectionists had taken from his book Méthodique physiologique "illustrations which they had rearranged then put on massive notices which were displayed all over England under the title "The Horrors of Vivisection" (Cyon, 1883, p. 5):

Each anatomical illustration was accompanied by a caption which was made to appear to be a quotation from the text of the book: "For the experiments to be successful the animals have to suffer a great deal" - "Students are requested to arrive early at the laboratory: we will be cooking the animals alive" and other nonsense of this kind. (Cyon, 1883, p. 7)

Most dishonest and misleading of all, one poster included an illustration which did not feature in the physiologist's book. It represented a monkey attached to the vivisection table, its eyes looking up at the sky and its paws making a begging gesture, as the vivisectionist, depicted with the face of fierce old man covered in warts, sniggered as he approached his victim. Cyon was critical of his British colleagues who, faced with such extreme tactics, confined themselves to being "modestly self-effacing," running a "purely defensive campaign," and adopting an "alarmed attitude [...] [which] seriously compromised the important matters which are so dear to them" (Cyon, 1883, p. 7).

Agitation should have been met with counteragitation, petitions with counterpetitions, in short the weapons that the enemies of sciences used so skillfully and perfidiously should have been taken up and used against them. We had been attacked by virulent personalities: why did we not reply using ad hominem attacks which would have confounded our crafty opponents, ridiculed the fanatics, ripped from one agitator his mask of humaneness, and exposed as bogus the scientific prestige 
of another? The scientists had seen their doctrines and experiments hatefully misrepresented in public meetings: why did they not write pamphlets to enlighten the masses, who had been tricked by slanderers? (Cyon, 1883, pp. 6-7)

Statements like these are a striking demonstration of the range of different effects produced by the emotional register of unmasking, mobilized by antivivisectionists. At the very moment when this register was facilitating the mobilization of growing numbers of - mostly women - supporters, it also created a sentiment of outrage among scientists and convinced them of the need to mount a countermobilization with a view to restoring their unfairly undermined dignity. Thus, in 1882, British scientists organized themselves to counter the campaigns of the antivivisectionists by founding the Association for the Advancement of Medicine by Research which, in 1908, became the Research Defence Society, which is still active today. The countermobilization was particularly effective, largely as a result of lobbying at the highest levels of British government (Turner, 1980, p. 108). In fact, the antivivisection bills presented every year from 1876 to 1884 , were all rejected by MPs, who were increasingly receptive to the arguments of the scientists. The provivisectionist movement also benefitted from a number of important scientific discoveries, news of which had a significant impact on public opinion. Such discoveries helped efforts to discredit those who, until then, argued that the vivisection served no useful purpose, and did nothing except feed the unhealthy curiosity and appalling cruelty of vivisectionists. Of particular significance in this regard was the production, in 1894, by Émile Roux and A.L.F. Martin, of the antitoxin for diphtheria, which up until that time had a fatality rate of $40 \%$ among infected newborn babies. By administering a diphtheria antitoxin injection, developed using animal experimentation, doctors were able to reduce this figure to $10 \%$. It is not difficult to appreciate the considerable impact that this scientific advance had on families used to regular attacks of the disease, which killed four out of ten infected infants (Turner, 1980, p.115). The counteroffensive launched by the scientific and medical communities against those who described them as "cruel monsters" (Cyon, 1883, p. 10) was devastating not only for the antivivisectionists, but also for the wider animal protection movement.

In order to refute the antivivisectionists' accusations of cruelty, scientists would sometimes just repeat a number of standard arguments. First of all they would argue that the criticisms of detractors of vivisection were undermined by the fact that their condemnations of brutality toward animals were very selective. While quick to denounce the fate of laboratory animals, 
supporters of the antivivisection cause could be strangely unaffected by other acts of violence, which they condoned, or even committed themselves.

M. Zöllner's opuscule concluded with a petition to be sent to the Reichstag. The list of signatures at the end of this document make for strange reading. What first strikes the reader is the large number of names of members of the general staff of the Prussian army. One would never have suspected so much compassion for suffering and for frogs from these famously tough military men, who built quite a reputation for humaneness during the war of 1870-1871 [...]. What a joke! What Pharisaism! Individuals who ban scientists from sacrificing a few animals in order to further the progress of science and to save the lives of innumerable sick people, regard it as perfectly normal to sacrifice thousands of human lives in colonial wars, which are really just about commercial gain! The lives of frogs and rabbits are sacred, there is no scientific progress which can excuse a physiological experiment. But slay soldiers in their tens of thousands, destroy cities, provoke the tears of widows, mothers and orphans, just to be sure that bondholders will be paid their coupons, that, on the other hand, is quite legitimate and shocks nobody. (Cyon, 1883, p. 14)

I really don't understand how members of the [antivivisectionist] "League" can take pleasure in watching a steeplechase, during which quite apart from the suffering inflicted on the horses - the lives of jockeys, stable boys, etc., are put in danger [...]. The only purpose of horseracing is to make money for those lords who, while they are discussing the antivivisection bill, are delaying the passage of the agricultural bill intended to stop the most disgraceful of vivisections: that of the Irish peasantry. There is one thing which has always struck me about members of the English race: their profound hypocrisy, as well as their boundless selfishness [...]. I would like to see the banning of hunting with hounds, where horses, dogs, foxes, deer and trackers are subjected to completely pointless torture. (Borel, 1883, p. 9)

As the above quotations show, the condemnation of the selective indignation of antivivisectionists has closely similarities with the classic argument according to which showing compassion for animals betrays an indifference to the fate of human beings. The new turn that the debate took was that - thanks to a series of medical discoveries made by scientists who used vivisection techniques - supporters of vivisection could now argue that 
the suffering of animals, which so mortified antivivisectionists, should be weighed against the many human lives saved as a result of the scientists' research. Furthermore the scientists were put in a better position to cast doubt over the humaneness of the "ambitious, pugnacious antivivisectionist, who uses the love of animals as a pretext for noisy demonstrating" (Magnan, 1884, p. 275).

If an experiment on an animal could save her son's life, she says, she would still be totally opposed to it, as she would not want to owe her son's life to the life of an animal. Besides, human pain bothers her very little, whereas she finds the sight and the idea of an animal suffering most upsetting. (Magnan, 1884, p. 276)

So the extravagant acts of the antivivisectionists could be said to reveal once again the reversal of values constituted by "the hatred of humanity and the love of animals" (Magnan, 1884, p. 276). At the end of the 19th century scientists went further, however, by strengthening this venerable stereotype with a series of positivist theories which brought further discredit on animal protectionists. Drawing on their knowledge of human nature, scientists went to some lengths to demonstrate that having antivivisectionist tendencies - far from simply resulting from a debatable philosophical choice - was purely and simply pathological. In 1884, Valentin Magnan presented a paper to the Biological Society entitled "On the Madness of Antivivisectionists." The French psychiatrist took the opportunity to recount the incident, after which he was obliged to leave England in a hurry (see above, Chapter 5):

At the congress in Norwich, in 1874 , as I was about to repeat the experiments comparing the effects of alcohol and absinthe, a number of individuals burst into the room. At the head of the group was a raving lunatic with wild eyes and a flushed complexion. He took out a knife and cut a strap which was holding down a dog's paw. When he made to continue with what he was doing, I gently took him to one side and asked two assistants to restrain him, exactly as I am in the habit of doing with insane individuals if they become agitated. I then got on with my demonstration. I regret that I was not able to obtain any information about the medical past of this impulsive person, but if I had I am certain we would have discovered that he is suffering from a long-standing condition, which would have explained this strange outburst of anger. (Magnan, 1884, p. 277) 
In fact, the above extract comes at the end of a long passage during which Valentin Magnan offers an account of the behavior of three "sick people": one of whom was a vegetarian and the other two antivivisectionists. For each of them, the psychiatrist notes examples of their eccentric behavior, provoked by their constant concern for the suffering of animals: feeding stray dogs, taking in large numbers of cats, going into abattoirs to plead with butchers to stop their killing, collecting pieces of glass which could injure a horse if it fell, hurling abuse at coachmen who use a whip, remonstrating with passengers who do not allow animals the time they need to rest, etc. The doctor's examination equally takes into account the "other kinds of strangeness" experienced by the three individuals (Magnan, 1884, p. 274): superstitions, hallucinations, ideas that they are being persecuted, fear of being touched, lack of "the reserve appropriate to their sex," etc. Then the theorist of the hereditary madness of degenerates goes even further, revealing the family medical histories behind these remarkable clinical cases..$^{50}$ The psychiatrist's diagnosis is clear and unequivocal:

This strange contrast between a constant concern for animals and indifference to people is an anomaly which could come as a surprise, given the mental lucidity which these sick people display, but which becomes a clinically unsurprising, when one takes into account the strange and unusual character of their intellectual degeneration. (Magnan, 1884, 277)

In this body of ideas which they are captivated by, creatures who are oversensitive, have unbalanced minds, or are mentally defective find many issues in which they take a great interest. These matters take on such an exaggerated importance that eventually delirium ensues [...]. Of course this is not a new kind of pathology, simply an episodic syndrome, one of the various ways in which hereditary madness can manifest itself. (Magnan, 1884, p. 269)

The psychiatrist's analysis was taken to be sufficiently authoritative for it to be regularly quoted and disseminated. In 1886, Honoré Saury, in his Étude clinique sur la folie héréditaire: les dégénérés (Clinical study of hereditary

$5^{0}$ The mothers of two of these women died in a state of dementia, after suffering from chronic delusions. In spite of the lack of information about the family background of the third individual, the psychiatrist did not hesitate to diagnose their morbid agitation as "a more active display of their native disposition." We should note that there is reason to believe that one of the portraits of an antivivisectionist is of Marie Huot. 
madness: The degenerates), repeats almost word for word Magnan's analysis and concludes, in the chapter devoted to mania, that "morbid sensitivity," "the love of animals, transformed into a troublesome zealous attitude, and a perpetual torment, may be regarded as pathological" (Saury, 1886, p. 116). Later in the same year Jules Dejerine repeats these views, in L'Hérédité dans les maladies du système nerveux (Heredity in diseases of the nervous system), and makes reference to Magnan in presenting the "madness of the antivivisectionists" as a pathology having certain similarities to agrophobia, dipsomania - leading to the abuse of intoxicating liquors - or even other obsessive-compulsive disorders such as the fear of touching things, excessive doubts, etc. (Dejerine, 1886, pp. 71-72). Similarly, in the edition of $L a$ Semaine vétérinaire (The veterinary week) published on 10 November 1889, an editorial condemns the "blindness" and the excesses of the antivivisectionists: "[W] hen the scientist looks at an animal which is tied down and twitching, he sees a scientific problem which needs solving. But try explaining that to these unhinged people, whose madness, in the opinion of Dr. Magnan, must be hereditary" (La Semaine vétérinaire, 1889, p. 707). Henceforth commentators did not hesitate to unquestioningly classify animal protection as a pathology. In 1893, the Guide pratique des maladies mentales: séméiologie, pronostic, indications (The practical guide to mental illnesses: Medical semiology, prognosis, indications) included an entry for Zoophobia-Zoophilia which indicated that "certain individuals have an exaggerated affection for animals - zoophilia - to which they would sacrifice all human beings. Antivivisectionists, who are mostly women, belong to this category of sick people" (Sollier, 1893, p. 363). Therefore, the term "zoophilia" - which previously denoted one of the highest forms of philanthropy - was now relegated to the domain of psychopathology. ${ }^{51}$ In 1903 , in Les Obsessions et la psychasthénie (Obsessions and psychasthenia), Pierre Janet describes a patient, who he diagnosed as suffering from zoophilia, as seeming to be more upset at the death of her cat, than at the death of one of her children. Gilbert Ballet in Traité de pathologie mentale (A treatise of psychopathology) reported the case of a man who would faint at the sight of a sick animal, but who also forced his servants to witness public executions (Buettinger, 1993, p. 282). In the United States, in 1909, Charles Loomis Dana,

$5^{1}$ Subsequently, the clinical significance of the term evolved further to denote the sexual perversion consisting of having unnatural relations with animals. Today, as a result of this semantic degradation, initiated by the medical community, French animal protection advocates, unlike their Italian counterparts, avoid the term zoophile, which has a long history, when referring to their activities. 
the president of the American Neurological Society, drawing on the work of Janet and Ballet, concluded that what he called "zoophile-psychosis" was a distinct type of obsessive disorder. This diagnosis, like Magnan's analysis, was widely picked up and quoted, in order to discredit the supporters of a cause which was increasingly being regarded as suspect. In July 1910 a New York Times editorial warned readers of the newspaper of the existence of "strange people - the antivivisectionists. Unfortunate victims of what Dana calls zoophilic neurosis, for whom the love of animals seems to lead to a veritable hatred of human beings." A year later, following an antivivisectionist demonstration, the leader writer of the Medical Record pointed out that victims of this mental illness were often "women who pamper their pets and love them much more than they love babies" (Buettinger, 1993, p. 285).

In actual fact, the campaigns to delegitimize antivivisectionists were made more violent by their reliance on a combination of both scientific and sexist prejudices. The feminization of the cause, which went hand in hand with the development of the emotional registers of tenderness and unmasking, frequently led scientists to emphasize what they saw as the unseemliness of this mobilization, orchestrated as it was by women who were abandoning the functions to which their physiology naturally suited them. When women start finding preoccupations beyond those required of a wife and a mother it was regarded as abnormal, almost pathological:

In fact, anyone who has attended a meeting of this society will realize that Dr. Magnan was being perfectly serious in his assertions. It is a depressing spectacle to see the attitude of the women and old maids of the society when a speaker, in love with his own sentimentality and dramatizing his story in a most exaggerated way, describes, holding back the tears, the suffering of a guinea pig being used in laboratory experiments by some scientist or other. I would not advise M. Brown-Séquard to venture into this crowd of hysteromaniacs. (La Semaine vétérinaire, 1889, p. 706)

I call "sincere agitators" those who, because they have nothing else to do, or out of pathological eccentricity, or hysterical sentimentality, join this movement, convinced that they are engaged in compassionate, charitable work. Do I need to point out again that most of them are women, or rather old maids? If my opponents rush to contradict me, I would challenge them to name me one leader of this group who is a rich young woman, pretty and of a loving disposition, or a single young woman who has found, in her domestic life, all the affection she needs. (Cyon, 1883, p. 11) 
Once again, the suggestion was that the antivivisection movement was made up of women who, without exception, did not know their place. One particular target of advocates of animal experimentation was Anna Kingsford who, after obtaining her medical degree, campaigned for the creation of antivivisectionist societies. She frequently found herself reminded of how tasks should be properly distributed along gender lines. In 1883, in response to the creation of a society in Geneva, Henri Kleffler published Les Missions "humanitaires" des dames anglaises sur le continent: la vivisection, son utilité, sa morale, réponse à la campagne antivivisectionniste de Mme le Dr Anna Kingsford (The "humanitarian" missions of English ladies on the continent: Vivisection, its usefulness, its morality, reply to the antivivisectionist campaign of Dr. Anna Kingsford). Adopting a courteous tone, and a long-winded style of writing, the author undertook to demonstrate that Kingsford's behavior was quite inappropriate to a person of her sex:

As Mme Kingsford is the personification of the antivivisectionist ideal and has undertaken to spread its message on the continent, defying the entire medical profession, she can expect not only to be the subject of personal attacks, but also, which is worse, to have her competence on such matters questioned, because she is a woman. I have my doubts about her competence because of my doubts about the ability of a woman's intelligence to act and perform in the same way as a man's. Female intelligence is not inferior to male intelligence, but, as they oppose each other, they must have different applications. I am keen to demonstrate this, making the most of the rare case that Mme Kingsford has been kind enough to provide, and contribute to the analysis of this question [...]. Women's emancipation is an excellent idea, providing that women remain women and do not try to become men in their intelligence or character. That, in my opinion, it the truth of the matter. (Kleffler, 1883, pp. 9 and 14)

At the time, the consensus in medical circles was that women, by nature, tend to be impulsively emotional and that, if they are deprived of the soothing tasks associated with the household and motherhood, they will inevitably fall victim to the kind of attacks typical of hysteria. In fact, scientific controversy, which requires "reflexive controls" peculiar to masculine intelligence, can only lead women to leave their "natural role," thus preventing them from "remaining consistent with the intellectual sex that nature imposed on them" (Kleffler, 1883, pp. 8 and 12). Dr. Borel, a surgeon in Neufchâtel, is more explicit in his exasperation over women's claims to be able to perform a role normally reserved for men: 
A lady by the name of Mme Kingsford - who must be a medical doctor - gave several talks, some time ago, in Geneva, on the topic of antivivisection. From her name we can suppose that she is English. We may seriously wonder whether she bought her medical title in Philadelphia [...]. If a female doctor - in this case the aforementioned Mme Kingsford - does not have sufficiently developed cerebral powers to understand such studies, how can we admit that the large audiences at her lectures could, however much they applaud, really understand the topic? (Borel, 1883, pp. 20-21)

Thus, at the end of the 19th century scientists countermobilized and, using the weapons of pathologization and gender discrimination, greatly contributed to the depiction of the animal protectionism as a movement which attracted "sick people and blinkered fanatics" (BSPA, 1912, p. 89), most of whom were "old maids" with time on their hands, hysterical and starved of affection. As a result of the countermobilization of scientists, from the last quarter of the 19th century onward, animal protectionists increasingly complained of being scoffed at, of having their beliefs ridiculed, and being victims of name-calling. By now being an activist required unprecedented quantities of determination and stubbornness:

You did not seem to have found it demeaning when you leaned down toward the humblest ones and came to their aid. In that you showed courage, you braved the mockery and the sarcasm, and I warmly congratulate you for that (applause). Continue to be brave! Don't expect any respect! It is of little importance if they called you "mother of the animals," or "crazy," or "mad old thing"! If you want to reach your objective you must be deaf to insults. (BSPA, 1933, p. 10)

All these changes had a profound impact on the cause of animal protection. In fact, at the very moment when powerful emotional registers allowed more activists - most of them women - to be recruited, certain elites, who had previously supported the cause, left it and as a result the movement's reputation suffered. It would take many long decades before the animal welfare cause, often scoffed it for being the hobbyhorse of "little old ladies with their doggies," recovered from the loss of legitimacy it suffered, from the last quarter of the 19th century onward. In fact, it was only in the second half of the 2oth century that the cause found other sources of legitimacy thanks, firstly, to the success of various campaigns to sensitize the public to the fate of wild animals and, secondly, the rise of the discipline of animal ethics in universities throughout the English-speaking world. 


\section{A decreasingly "wild" nature}

\section{From the exploitation to the contemplation of species}

In the previous chapter we examined the sequence of events which led to specialists in the fields of physiological sciences and medicine turning their back on the animal welfare cause. Natural scientists, on the other hand, while in the process of reorganizing their various disciplines, not only continued to lend their support to the cause, but actually made a great contribution to reinvigorating it. In order to analyze their participation in the transformation of the animal welfare movement it will be necessary to give a brief account of the evolution of the status of the natural sciences within the hierarchy of the sciences. In this regard it is worth mentioning how, for extended periods, botany and zoology have been regarded as particularly promising fields of scientific enquiry. Within these disciplines the seminal works of Bacon and Linnaeus laid the foundations for future developments in scientific method and thus, at the beginning of the 19th century, naturalists had high hopes of making decisive contributions to the period of rapid and accelerating progress on which Western societies were then embarking. From this perspective, the development of the natural sciences can be seen to have enabled certain ideas about "pristine natural environments" - places where undomesticated flora and fauna predominate - to be modified in a useful way. Initially these territories, located on the margins of civilization, were regarded as wildernesses, namely places where nature was left untouched by man - and so allowed to be molded in a chaotic fashion by luxuriant vegetation, violent rapids and storms - but densely populated by a wide variety of animal species. Such habitats, seen as disordered and unpredictable, and inhabited by ferocious animals, inevitably invited suspicion and fear and were regarded as no place for civilized man to set foot. Such ideas came to be challenged by the application of the scientific rationality of the natural sciences, which were the key not only to reducing the strangeness of wild lands by making them an object of study, but also to taming the forces which prevailed there, and to harnessing them for the good of civilization. If all thick forests, treacherous rivers, ferocious animals and primitive inhabitants could be researched and understood by science then instead of provoking fear, they would be seen as an invaluable resource, destined to contribute to the boundless moral and economic development which western societies saw as the future of humanity. In fact the London Zoological Society and the Société zoologique d'acclimatation 
in Paris, founded in 1826 and 1854 respectively, were both set up with the goal of harnessing untamed nature for maximum profit in mind. As we saw in Chapter 3, the missions undertaken by British and French natural scientists were closely integrated into their countries' colonial enterprises. The introduction, acclimatization and domestication of species recovered from their original natural habitats were regarded as conclusive evidence of the social utility of zoology..$^{52}$ That there were close ties between zoological societies and animal welfare societies is hardly worth restating. These two kinds of organization, as we have seen, shared the common project of reducing "chaotic violence" by endorsing a demopedic emotional register which was perfectly suited to the accreditation of its members. We should also mention not only the development of prestigious institutions such as zoological societies and national museums but also, at a local level, the proliferation of a large number of societies for enthusiastic amateur botanists, entomologists and ornithologists (Raffin and Ricou, 1985). Thus, the 19th and 2oth centuries witnessed a craze for collection: indeed the removal of so many specimens by hoards of enthusiasts, all in the name of science, resulted in serious depletion of fauna in the most accessible wild areas.

Nineteenth-century zoologists, while presenting themselves as the guarantors of the optimal exploitation of animal resources, were also among the first to express concern over certain forms of overexploitation. In the process of attempting to classify complete taxonomies zoologists inevitably noted that a number of species had become extinct as a direct result of coming into contact with man, and collectors in particular. These included the auroch in Poland in 1627; the dodo in Mauritius in 1670; the Steller's sea cow - a close cousin of the manatee - in 1768 , and the great auk in 1844 . What is more, the laws explaining the disappearance of species were well known in scientific circles: Principles of Geology by Charles Lyell, published in 1830, confirmed the idea of extinction, while The Origin of Species, by Charles Darwin, explains its main features (Matagne, 2002, pp. 19-21). Now the devastating effect of certain types of hunting - greatly intensified by colonial competition to capture as many natural resources as possible - threatened the survival of some of the most prized species. The arrival of heavily armed European hunters, drawn to countries like Kenya and Uganda by the abundance of game, provoked a drop in wild

$5^{2}$ We should note that the founding and great popularity of zoos in London and Paris contributed to the idea of the civilizing mission of colonialism insofar as they were part of a project to painstakingly study and classify the wide variety of animals inhabiting the territories of the European colonial empires. 
animal populations. Zoologists and animal protectionists reacted by calling for the authorities to pass conservationist legislation and international treaties to protect the most endangered species. In the 186 os, under pressure from British naturalists, a series of laws were passed to protect endangered species such as the seals in the Bering Sea (Matagne, 2002, p. 21). In 1900, after talks between the Germans and the British centering on the need to regulate hunting linked to the ivory trade in East Africa, the Convention for the Preservation of Wild Animals, Birds and Fish in Africa - the first international treaty for wildlife preservation - was signed by six countries. As early as the 1870 os the leadership of the French SPA was quick to praise such initiatives, whose pedagogical aspect they found particularly to their liking.

In 1873 The Animal World noted that an act had been passed outlawing the widespread killing of elephants in the Madras Presidency [...]. We feel obliged to express regret that a similar decree has not been passed banning the widespread slaughter of buffalo and many other animals in the same country. (BSPA, 1876, p. 356)

The conservation of useful animal species, including wild animals, by protecting them from senseless slaughter, has always seemed to us to be one of the desiderata of animal protection. It is for this reason we have proposed joining the campaign undertaken by Mr. Frank Buckland, an English naturalist, calling for an international treaty on ban seal hunting, and you have accepted our proposal. (BSPA, 1875, p. 89)

The precept of species conservation, which had been formulated in response to the excessive exploitation of colonial resources, was before long transposed to situations which had been observed on metropolitan territories. Indeed, it would have been illogical not to show the same concern for wild animals inhabiting metropolitan territories as had been voiced over species living in relatively distant overseas territories.

It is quite right that we should protect certain species of fish from this extermination at sea. Our late lamented vice president Dr. H. Blatin dedicated an interesting chapter of his book Our Cruelty to Animals to this very topic. He focused on the problem of the relentless drive to exterminate large sea mammals. Should he not have extended his arguments to the slaughter of large quantities of sea fish as well as to the necessity of protecting species of freshwater fish from extermination? What questions 
need raising here in this connection? Freshwater fish are threatened not only by the fisherman, but also by the outflow of water from city drains and factories, from the mechanical actions produced by watermills, as well as waterfalls and eddies. (BSPA, 1876, p. 363)

In England, in 1868, the report of the ornithologist Alfred Newton - On the Zoological Aspect of the Game Law - attracted the attention of the authorities to the threat posed by bird hunting to several species of sea birds on the Isle of Wight and at Flamborough Head: Parliament reacted by passing the Sea Birds Preservation Act which banned hunting and the collection of eggs during the nesting season. As mentioned earlier, animal protectionists were even more concerned about the fate of insectivorous birds, who are friends of the farmer. As early as 1865 the Times newspaper alerted the danger to crops posed by the plagues of insects which resulted from the massacre of these small birds. The British Bird Protection Society was founded in 1868, and the Association for the Protection of British Birds two years later. These two campaigning organizations, in collaboration with the RSPCA, successfully lobbied for laws protecting wild birds during the nesting season, which went onto the statute books in 1872 and 1876 . Two decades later, in 1894, at the International Congress for the Protection of Animals in Geneva, one of the main topics of discussion was the protection of wild birds.

These campaigns to protect nondomesticated species were evidence of a significant change in the way animal protectionists sought to represent nature. On the one hand, the already well-established preoccupation with remedying the economic scandal caused by the irresponsible plundering of limited resources was still a recurrent theme in their discourses. At the same time, however, the growing acknowledgement of the essential contribution made by insectivorous birds to the agricultural economy paved the way for different, more novel, lines of reasoning which invited enlightened elites to rethink the relationship between man and wild animals, not only in terms of domestication and exploitation but also as a matter for mutual cooperation. According to James Turner, the particular attention paid to the plight of insectivorous birds greatly contributed to "the formulation, although still in a rudimentary and hesitant form, of a completely new ethics of human treatment of other forms of life" (Turner, 1980, p. 125). The acknowledgement of the need to protect insectivorous birds, by going against the conception of nature as a ferocious entity to be tamed and subjugated by man, presented a challenge to the supremacy of humans. Human beings were thus placed in a less exalted position within a fragile natural world, which was now to be regarded as a seamless network made 
up of interdependent elements, a system based on mutual support where the contribution of even the smallest creature has an impact on all other forms of life (Turner, 1980, p. 127). In fact, intemperate treatment of animals shocked animal protectionists not only because of the danger it represented to the future survival of localized resources but also, and more importantly, because it constituted a more general threat to complex and fragile ecological balances. Henceforth the focus would broaden from the wild animal in isolation to its complex interactions with the natural habitat on which its survival depended. While such a conception could be said to renew the medieval idea of the great chain of being, as well as being inspired by Romanticism, it above all prefigured the new forms of legitimization which, in the second half of the 2oth century, the animal welfare movement would borrow from the newly constituted science of ecology. In 1877, however, when the German zoologist Karl Möbius coined the term "biocoenosis" to refer to a community of interdependent animals and vegetables, it was in the context of a discussion of the problem of excessive preoccupation with economic returns, in this particular case the overexploitation of oyster beds. The term was only embraced by ecological science from the 1920s onward (Matagne, 2002, pp. 106 and 143).

So, the nature of the backing the animal protection cause received from natural scientists changed significantly between the 19th and 2oth centuries. Their invaluable support can be interpreted as both a link and a break with the past. The great prestige which naturalists enjoyed did, in fact, provide a precious link with the past at a moment when many leading figures in animal protection societies feared that the new waves of recruits - most of whom were essentially preoccupied with protecting cats and dogs - would infect the cause with a high degree of sentimentality which they believed unworthy of the movement's founders. Countering this worrying development, the new emphasis on the protection of wild animals and their natural habitats provided a timely renewal of the societies' pedagogical vocation, which used the demopedic emotional register best suited to reforming the intemperance of deviants. It also provided continuity with the past insofar as protectors of wild nature - by replacing the image of nature as fierce and needing to be tamed with the very different conception of nature as fragile and needing to be treated carefully and thoughtfully - intensified the iterative demand for humans to behave more gently and less aggressively. Nevertheless, more radical developments led naturalists involved in campaigns for the protection of wild animal species to gradually distance themselves from certain positions taken by their predecessors. They rejected the view that it was the job of natural scientists 
to involve themselves in the capture and maximal exploitation of natural resources, and came to see the role of natural science as the protection of ecological balance in those natural environments which were placed under threat by human activity. Thus, 2oth-century naturalists took the view - under the influence of ecological theories - that "the progress of nature is dependent on the withdrawal of humans [...]. The best subject for scientific study is nature which has been untouched by man [...]. Human intervention is always regarded as regressive: humans are always portrayed as disruptive intruders in ecosystems" (Fabiani, 1985, p. 85). From this perspective the presence of wild animals is regarded as the clearest indicator of the authentic virginity, imagined or regained, of an ecosystem. ${ }^{33}$ For naturalists in the second half of the 2oth century the preservation of wild animals and their "natural" habitats now means protecting them from former allies - fishermen, hunters, furriers, cattle breeders, foresters and farmers - who continue to regard them as simple economic resources.

It should also be noted that naturalists' adoption of a more ecological perspective was partly due to their realization that the exploitation of natural resources - to which their predecessors had devoted their scientific talents - was responsible for the significant acceleration in the rate of species extinction. The condemnation of this phenomenon by specialists in disciplines like ornithology, entomology, ethology, etc., was a reaction to the worrying decline in the numbers of species available for scientific investigation. Moreover, we should add that statements about the urgent need to maintain ecological balance also contributed to highlighting the social usefulness of a science which, over the second half of the 19th century - despite its promising beginnings - had been leapfrogged in the hierarchy of scientific disciplines by physics, physiology and molecular biology, among others. Consequently, there was a tendency to dramatize natural science research by focusing on ecological balance: "[P]resenting the program and conclusions of academic ecology in a dramatic way enables ecological problems to be regarded as issues of major public concern, and to have ecology recognized as an important scientific discipline" (Fabiani, 1985 , p. 81).

The very gradual nature of these developments is reflected in the history of the Société zoologique d'acclimatation. At the end of the 19th century this organization, dedicated to the optimal exploitation of animal resources,

53 The reintroduction of wild species, such as wolves, bears, lynx, is the most paradoxical outcome of this new approach, for which the carefully calculated intervention of man is required, in order to retrieve the best possible natural balance, as defined by ecologists. 
was already beginning to express concern over the threat posed by human activity to the survival of certain species. "Thus, in 1884, the main topics [it] investigated were the reforestation of Algeria, poaching and overhunting, the lack of fishways on French watercourses, and the decrease in the number of wild animal species (including the wolf) on the national territory" (Raffin and Ricou, 1985, p. 63). In 1906, members of the Société nationale d'acclimatation were behind the Friends of the Elephant Society whose aim was to protect this species from the threat of extinction. In 1912 a special section of the zoological society founded the Ligue pour la protection des oiseaux (League for the Protection of Birds) whose members, several decades later, would campaign vigorously to shorten the hunting season for migratory birds (Traïni, 2003a). Out of a desire to remove "protected species" from exposure to the threats posed by humans, members of the society campaigned in favor of the creation of first "reserves," and later national parks, for the purposes of conservation. In 1913, the running of the Sept-Îles bird sanctuary was handed over to the League for the Protection of Birds in order to stop the massacring of birds by hunters. In 1923, the Zoological Society organized the first International Conference for the Protection of Nature, held in Paris, and in 1931 founded La Terre et la vie, a review aimed at an educated readership, to increase awareness of habitat conservation, the natural sciences, ethnography, etc., both in France and abroad" (Raffin and Ricou, 1985, p. 64). At the same time the society made some land purchases in conservation areas which allowed it to create first the Camargue Zoological and Botanical Reserve in 1927, then, in 1935 and 1936, nature reserves in Néouvielle and Lauzanier. A year later members of the society were behind a National Parks bill (the Sérot Bill). In 1960, the progressive shift in the main preoccupations of the society since its creation in 1854 was reflected in its name change, from the National Acclimatization Society to the National Society for the Protection of Nature (SNPN). It is worth pointing out that the many local societies made up of enthusiastic amateurs, founded during the 19th century, went through similar transformations and formed a dense network of associations campaigning for the protection of wild animals, which eventually united in 1968 to form the French Federation of Societies for the Protection of Nature. ${ }^{54}$

In parallel with the transformation of well-established zoological societies naturalists worked to create new campaigning organizations dedicated to the protection of wild animals. Prominent among these was the British biologist

54 This federation, which in 1990 was renamed France nature environnement, includes 3,000 affiliated associations. 
Sir Julian Huxley, who came from a family of distinguished scientists. In the second half of the 1930s he was the secretary of the Zoological Society and also ran London Zoo and Whipsnade Wild Animal Park. Drawing on his background in zoology, Huxley wrote a report on the destruction and likely disappearance of wild animals in East Africa. Several individuals, including the businessman Victor Stolan, encouraged him to create an organization to address the problems to which the report drew attention, and in 1961, with three British ornithologists, he founded the World Wildlife Fund (WWF). More than twenty years later, in 1986, the WWF was renamed the World Wide Fund for Nature reflecting the fact that the organization's activities now extended to the protection of natural habitats as well as wild animals. The WWF, which has 4,700,000 members worldwide, and whose motto is "for a living planet," has the stated aims of stopping the degradation of the planet's natural environment and encouraging mankind to live in harmony with nature.

Thus, in the second half of the 2oth century, the rise to prominence of ecological thinking reinstated the scientific legitimacy of a cause previously undermined by the burgeoning importance attached to domestic pets by a high proportion of later waves of grassroots activists. Nevertheless, and paradoxically, protectors of wild animals succeeded in increasing public awareness of their messages by relying not only on their scientific expertise, but also to sensitizing devices borrowed from the emotional register of tenderness. Thus, in 1961 the WWF adopted the representation of a panda for its logo. The logo, which would soon be recognized around the world, consists of the figure of an animal which bears a striking resemblance to a child's cuddly toy. Similarly, shortly after Brian Davies founded the International Fund for Animal Welfare (IFAW), in Canada in 1969, the organization launched a campaign against seal hunting. Brigitte Bardot, the iconic French film actress, loaned her support to the campaign, posing for a photo which appeared on the cover of Paris Match, showing her lying on the ice holding a baby seal. The photograph quite deliberately encourages the viewer to regard the seal as a cute little "bundle of love," rather than as a wild animal, and the shocking contrast between this image and television pictures of hunters, armed with sticks, smashing seals' skulls must have greatly contributed to winning over the public to the cause. These two examples not only illustrate what subsequently became standard, widely used strategies, but also draw our attention to the need to analyze the way in which developments in audiovisual media have been a valuable tool for bringing the animal protectionist message to a wider public. More specifically, it is worth pointing out how some entrepreneurs for the cause worked to cultivate a feeling of familiarity with wild animals living in far-off countries, which was necessary for the register 
of tenderness - created with reference to the kind of direct relationships one can have with pets - to be extended to wild animals (including species with a reputation for "ferocity"). Such a process, as we will see, results from two mutually reinforcing phenomena: on the one hand, the progressive transformations in the attitudes endorsed by natural scientists, discussed above, and on the other hand the development of the audiovisual entertainment industry. It is for this reason that it is well worth examining the careers of two ecological activists, Jacques Cousteau and Christian Zuber, who were not only campaigning natural scientists, but who also in the course of their careers succeeded in entertaining and informing the public.

In 1940, Cousteau, who had served in the French Navy as an intelligence officer, took refuge in Megève, where he met the skier, mountaineer and filmmaker Marcel Ichac. Ichac made adventure documentaries and had directed the 1938 film Karakoram documenting the first French expedition to the Himalayas. The two men found they had a shared enthusiasm: they both wanted to make films which introduced the general public to spectacular corners of the world which had been hitherto little known and inaccessible. While Ichac's particular interest was in mountainous areas, Cousteau was drawn to exploring the world under the sea. In 1943, thanks to the invention of waterproof housing for cameras, he made the first French film to be shot under the sea - Par dix-huit mètres de fond (18 meters deep) - filmed without the use of breathing apparatus in the Embiez Islands, which won first prize at the Congress of Documentary Films. For his second film, Épaves (Wrecks), made with Phillipe Tailliez, Cousteau and the engineer Émile Gagnan invented the modern open-circuit-demand-scuba, which greatly facilitated the exploration of the sea bed. Admiral Lemonier saw the film and was so impressed that he invited the filmmakers to set up a Navy Undersea Research Group in Toulon. While there, Cousteau made contacts within the scientific world and, thanks to the access he was given to several maritime archeology expeditions, produced a number of spectacular films, including Carnet de plongée (Diving log), which was awarded a prize at the 1951 Cannes Film Festival. At the beginning of the 1950s Cousteau left the navy to devote himself to oceanography full time. He founded the Campagnes océanographiques françaises (the French Oceanographic Campaigns), and in 1957 was made director of the Oceanographic Museum in Monaco. Cousteau, like a character out of Jules Verne, explored the seas and rivers of the world at the helm of his ship, the Calypso, and, while engaged in scientific research, also made a series of spectacular films featuring multicolor fish, sharks, squid, dolphins and whales. In 1956 Le Monde du silence (The silent world), codirected with Louis Malle, won the Palme d'Or at the Cannes 
Film Festival. A meeting with US media companies (ABC, Metromedia and NBC) then led to the creation of the series of documentaries entitled The Undersea World of Jacques Cousteau, which captured the imagination of viewers by incorporating features from the adventure film genre: the commander in the red wooly hat as the leading man; sequences featuring various marine species filmed in close-up; the courage of divers in the face of danger; scientific research conducted in situations full of suspense, etc. ${ }^{55}$

The series was the forerunner of a new kind of television show - which over the years became a well-established genre - that turned wild species, which had hitherto been the least visible creatures and even regarded as strange and threatening, into objects of calm contemplation by viewers sitting in the comfort of their living rooms. This important contribution to the development of television entertainment should not, however, lead us to overlook the militant dimension of Cousteau's work. Very early in his career he began to share the concerns that many natural scientists already had about the irreversible effects of human activity on the survival of certain wild species. The explorer and filmmaker soon realized that filming the ocean depths was a way of showing how quickly and seriously human activity was damaging natural habitats. His films would conclude with an epilogue enumerating his concerns and warning that unless conservationist measures were promptly taken a number of marine species would soon be faced with extinction. So in fact "the man in the red woolly hat" offered to the demopedic register of animal protection a particularly effective type of sensitizing device: "[P] eople protect and respect what they love [he stated], and to make them love the sea it is just as important to fill them with wonder as to inform them." In the US in 1974 he extended his activities beyond filmmaking and set up the Cousteau Society, which was dedicated to the protection and improvement of the quality of life of present and future generations. Over the following decades the genre which Cousteau pioneered - the adventure documentary with an environmentalist message - flourished to such a degree that it would now be something of a challenge to draw up an exhaustive list of films of this kind. If we just take France as an example, the work of Nicolas Hulot and Yann Arthus Bertrand, campaigning for the protection of the planet and wild animals, clearly drew inspiration from Cousteau and the voyages of the Calypso.

In 1968, theyear when the filming of The Undersea World ofJacques Cousteau got underway, the journalist, writer and filmmaker Christian Zuber started working on what would become the weekly zo-minute television show Caméra

55 The many episodes of the series, filmed between 1968 and 1977, were broadcast and rebroadcast all around the world. 
au poing. The syncretic nature of Christian Zuber's motivations and beliefs merit a brief commentary, given the success of this series of spectacular wildlife documentaries, broadcast throughout the 1970s, which led the filmmaker to be seen as a particularly committed and persuasive advocate of the animal cause. Indeed, after his career as a documentary maker during which the protection of the natural world was a recurrent and dominant theme, the man behind Caméra au poing went on to become a director of both WWF France and the Bardot Foundation. In the light of his family background, Christian Zuber's campaigning can be regarded as the continuation and development of a tradition which was inspired by both the natural sciences and Protestant morality (see box). In any case it is undeniable that the success of the Christian Zuber's shows - which, once again, marked the birth of a popular television genre - provides support for our thesis that the cinema - and to an even greater extent television - when fronted by activists with campaigning agendas, contributed to a change in the way the natural world came to be represented.

\section{The Protestant Ethic, the natural sciences and animal protection: The Monod family}

The affinities between the Protestant Ethic and the spirit of capitalism have been well documented since the appearance Max Weber's seminal work of the same name (Weber, 1999). Much less discussed is the fact that the Protestant preoccupation with demonstrating that one is a "righteous person in the eyes of the Lord" can lead individual Protestants to embark on "symbolic crusades" (Gusfield, 1986). Indeed, as we have already stressed, Protestant members of the upwardly mobile middle classes played an essential role in the development of the English animal protection movement. In the French context, where first Catholic and then secular traditions have been in the ascendancy, a number of Protestant families have down the generations provided a number of defenders of the animal rights cause. One noteworthy example is provided by the descendants of the pastor Jean Monod (1765-1836), many of whom were also pastors themselves. In 1897, one of Jean Monod's great-grandsons, Édouard Monod (1867-1913) was probably the author of the poem "Bullfighting," dedicated to the president of the SPA. The poem is reminiscent of a Puritan sermon, and expresses indignation at the sensual pleasures in which the weak indulge: "What a fine spectacle it is to celebrate slaughter / To mercilessly torment an angry animal [...] / And to take pleasure in its suffering / Sublime voluptuousness, worthy of a noble heart! [...] You should know, however, blind populace, / That God is indignant and growing weary, [...] and you should know that he will pass judgment upon you" (BSPA, 1897, p. 34). Jean Monod's most well-known descendant was, however, Théodore Monod (19022000). Monod was a distinguished natural scientist, whose father and grandfather 
were also pastors, and whose lifelong attachment to the Museum of Natural History began in 1921, when he won a scholarship to study for a PhD there. After carrying out research into worms and crustaceans he turned his attention to desert flora and fauna, which he investigated during numerous expeditions to the Sahara. Alongside his scientific work, Monod soon came to the attention of a wide general readership through a series of books which vividly related the sensations and feelings he had experienced on his travels through sublime desert landscapes. In 1989 Karel Prokopp made an acclaimed television special about him entitled The Old Man and the Desert, which received a lot of press coverage. Thanks to this documentary and all the subsequent newspaper articles and interviews published about it, Monod achieved a media profile comparable to those of other prominent campaigning scientists and ecological activists, such as Jacques Cousteau, Haroun Tazief, Albert Jacquard and Yves Coppens. Monod had been an outspoken opponent of bullfighting since the 1930s but it was really only from the 1990 onward that he actively loaned his by now celebrity support to several groups such as the Rassemblement des opposants à la chasse (the Anti-Hunting League), as well as to a number of organizations involved in the various antibullfighting campaigns of the time. In one of his last books, Théodore Monod made a point of emphasizing how he regarded his views on the suffering of animals to be an extension of the theological reflections of his father, the pastor Wilfred Monod (Monod, 1997). Christian Zuber (1930-2005), on the other hand, a grandson of Édouard Monod, who himself at the end of the 19th century had been outspoken opponent of bullighting, made a name for himself for questioning prevalent human attitudes to wild animals: his documentary films represented wild animals as being worthy of human care and contemplation. Coming up to the present day, Alain Monod, a grandnephew of Théodore Monod and attorney at the Council of State and Court of Cassation, is the vice president of the board of directors of the Cuvre d'assistance aux bêtes d'abattoir (OABA; the Association for the Protection of Animals in Slaughterhouses). Alain Monod has stated that he believes that the work of this campaigning organization continues to draw inspiration from his great-uncle's thinking. In addition another family member, Marie-Françoise Lheureux, the wife of a cousin of the Monod and Zuber families, was the founder, in 1997, of the Groupement de réflexion et d'action animal libération (GRAAL; Animal Liberation Action and Study Group) (interview, 22/01/09) ${ }^{56}$.

56 Between 2005 and 2011 I arranged 68 interviews with French militants representing 34 separate organisations. Thirty-five of these interviews were conducted by me; the rest by a team of four PhD students and a postdoctoral researcher in political science (Blancaneaux Romain, Emperador Badimon Montserrat, Franquemagne Gael, Kumeda Maryna, Lejeune Caroline, Renou Gildas). 
It is worth noting that the animal documentary genre - which became a television staple from the 1970s onward - enjoyed particular success with young viewers. In fact, wild animals, by being transformed into a television spectacle, joined domestic pets, cuddly toys, and cartoon and comic strip characters in constituting the imaginary bestiary of children in developed societies. This phenomenon greatly contributed to a single identical emotional register being applied to various categories of animals which had been hitherto treated separately: family pets, domesticated animals and wild animals ("useful animals" and "pests"). This development was not without consequences: we know that the second half of the 1970 saw the appearance of a new cohort of often radical activists who, as children, were members the first generation exposed to the new televisual and cinematic representations of "wild" nature. From the end of the 1960 s onward the entertainment industry produced several shows which made a significant contribution to spreading the belief that wild animals - which had historically been regarded as ferocious and threatening - were in fact in need of compassion and care. Tales of real and fictional characters who dedicated their lives to rescuing wild animals provided material for creating spectacular productions, which would arouse the emotions of viewers. This was the case when, in 1966, Columbia Pictures produced a film adaptation of Born Free, the autobiography of Joy Adamson, a naturalist born in Austria in 1910. Her husband George, a British subject born in India in 1906, came to Kenya in 1924. George engaged in activities typical of settlers in colonial Africa: first in prospecting for gold, then cattle trading, and finally organizing safaris. In 1938 he joined the Kenyan Game Department and became a senior district game warden in the north of the country. Nicknamed "Baba ya Simba," "the father of the lions" in Swahili, George Adamson, with Joy, took home and raised some lion cubs who had been orphaned when their mother had been killed by hunters, a not uncommon occurrence in Kenya at the time. The book and film tell the story of Elsa, the lioness whom Joy started bottle feeding when she was a cub and raised to adulthood. The couple grew extremely fond of the animal but eventually decided to return her to the wild. In fact the film was a kind of homage to the changing attitude of a man who, after coming to regard a prey animal as a creature worthy of kindness and love, carefully returns her to her natural habitat, before beating a quiet retreat. By telling the story of an ex-hunter who used to take part in safaris, the film bears witness to the transformation of the representation not only of wild animals, but also of the ways in which former colonizers can interact with African wildlife. Former colonies, once prized as places to go hunting, are now regarded as spaces which need to 
be preserved, and which provoke emotions from a register of tenderness which now extends to wild animals. ${ }^{57}$

In this context, we should also mention the American television series Daktari,,$^{8}$ which ran for eighty-nine episodes in the second half of the 1960 s, and was inspired by the life of Sue Hart, a graduate of the Royal Veterinary College in London, who from 1964 onward used her professional skills to care for wild animals in Kenya. The series portrayed the devotion and heroism of a veterinary surgeon whose patients included wild animals who came to be treated like family members (Judy, the chimpanzee, and Clarence, the lion, two of the main characters, were clearly very attached to her). The impact of this kind of show on the development of the animal protection movement, though difficult to measure precisely, should not be overlooked: firstly, they have contributed to modifying the representation of the natural world by extending the emotional register of tenderness to concern for the immediate reduction in the suffering of animal species which most people would never encounter in their everyday lives; secondly, the fact that these shows were aimed at children would introduce young viewers to the possibility of pursuing a career as a veterinary scientist. There is indeed evidence to suggest that some veterinary students, motivated by a desire to devote themselves to the compassionate treatment of animals, have been most upset on discovering that a high proportion of job opportunities within their chosen profession actually involve working with animals bred for the meat industry. In fact, many practitioners who feel this way find that working in clinics and refuges run by campaigning animal protection organizations gives them the opportunity to have the kind of emotions they expected to experience as a vet, after watching Daktari or the Joy Adamson films as children.

We can therefore see that an awareness of the development of professional fields such as the natural sciences, veterinary science, and the audiovisual arts is necessary to properly understand the evolution of the animal protection movement from the 1960 s onward. Indeed, as a result of these changes numerous campaigning organizations were set up whose existence would

57 A similar evolution is reflected in the title of the show mentioned above-Caméra au poing (which could be translated as "Armed with a camera") - which suggests that the lethal weapons used during safaris have been superseded by filming equipment. The hunting trophies reserved for a few rich hunters have now been replaced by spectacular close-up images of animals, which can be enjoyed by potentially unlimited numbers of television viewers.

$5^{8}$ Broadcast on CBS between 1966 and 1969, Daktari was broadcast in France on the first channel of the French Public Broadcasting Network (Office de radiodiffusion-Télévision française, ORTF) from 1969 onward. 
have been inconceivable in the previous century. Following the success of the WWF many similar organizations were set up, including associations with narrower remits such as FERUS/Ours-Loup-Lynx Conservation in France, whose campaigning activities cover bears, wolves and lynx and their habitats, and Sur la piste du loup or the UK Wolf Conservation Trust, which seeks to protect wolves. These organizations will sometimes work with veterinary scientists to rescue wild animals which may have been hit by a road vehicle, or be suffering after receiving electric shocks from high voltage power lines, or be affected by oil spills. Furthermore there are a number of associations which, combining the work of animal refuge groups with an international overseas aid perspective, have built refuges to rescue and treat wild animals from the other side of the world, such as the Great Ape Project founded in 1994, SOS Orangutan, HELP Congo (Habitat ecologique et liberté des primates), etc.

\section{Technological ferocity, industrial slavery}

The animal protection cause has, over the last two hundred years, inevitably been greatly influenced by one of the defining features of the 19th and 2oth centuries. An important characteristic of this period, in particular the 19th century, was the prevalence of great optimism about the future of humanity. Scientific and technological progress appeared to offer the promise of unending progress and economic development as well as increasingly peaceful and civilized social mores. As we have already noted, antivivisectionists expressed skepticism and concern about such scientific triumphalism. Nevertheless the fragile social status of the antivivisection cause - due to the decline of their elites, sexism, and the fact that many campaigners belonged to economically exploited social categories - could do little to dampen the widespread enthusiasm generated by unprecedented rates of scientific progress and economic innovation. There were, however, a number of major events in the 2oth century which significantly curbed the optimism of the previous century. The two World Wars, and in particular the use of the atomic bomb at the end of the Second World War, provided clear evidence that, in certain situations, technological progress, far from being instrumental in promoting peace, could actually lead to scenarios of unprecedented deadliness. Later, in the second half of the 2oth century, a long string of ecological disasters - the introduction of the myxomatosis virus to control the wild rabbit population in 1950, the use of the Agent Orange by US to defoliate the jungles of Vietnam, the Amoco Cadiz oil spill 
in 1978, chemical pollution, the shrinking of the Aral Sea, etc. - showed the extent to which economic and technological development could lead to massive and irreversible harm to the environment. These disasters, and others like them, led to a turning point in the history of animal protection by providing compelling reasons for action. The new conceptions of nature discussed in the previous chapter were reinforced and made more complex. Animal protectionists no longer confined themselves to echoing the concern of natural scientists over the way animal species and "biodiversity" were increasingly endangered. Even more fundamental questions were being asked, about the potential of man's use of technology to constitute a threat to all life forms cohabiting on the planet. From this perspective, animals who had become the direct and indirect victims of scientific, military and industrial activity became symbols of the subjugation of all living things - humankind included - to a model of economic development which was out of control. In fact, in the second half of the 1960s new cohorts of activists found inspiration in sensitizing devices and emotional registers first developed by 19 th pioneers of the movement to promote a new, more radical version of the cause.

Images of Hiroshima and Nagasaki inevitably had a profound impact on moral entrepreneurs engaged in the struggle to limit mankind's aggressive and warlike tendencies. To the specter of violence, nuclear technology added the fear of the extermination of all forms of life on the planet. In 1958, in reaction to this threat, a group of American Quakers attempted to sail a ship near the Bikini Atoll to protest against H-bomb tests (Ollitrault, 2008, p. 139). Quakers had arrived in North America from Britain in the second half of the 17th century. Central to Quaker philosophy is the belief that all creatures possess within them a divine spark. They refuse to commit acts of violence against any "enemy," and have a long tradition of engaging in peaceful protest, against slavery, war and the oppression of minorities (Louis, 2004). The way these Protestant dissenters generally choose to protest is by "bearing witness." To bear witness consists of demonstrating one's moral disapproval in a nonviolent way by gathering together with victims with whom one feels solidarity. In fact the project to occupy the Bikini nuclear testing sites was very much in line with well-established Quaker protesting tradition. In 1969, in protest at nuclear testing in western Alaska a group of Quakers, joined in Canada by militant ecologist members of the Sierra Club and some Americans who had sought refuge in Canada to avoid conscription for the war in Vietnam, founded the Don't Make a Wave Committee (Ollitrault, 2008). The purpose of this initiative was to alert the media to the fact that the nuclear testing risked causing tsunamis which could endanger 
populations living along the Canadian coast. The antinuclear activists spent much on the time on their ship, in the waters around the island of Amchitka, admiring the beautiful scenery and observing seals, whales and other wild marine species (Hunter, 2004).

In 1971 some of the younger members of this group founded Greenpeace and from then on extended their campaigning beyond antinuclear pacifism to embrace the defense of the natural world from harmful human intervention. When US nuclear testing was suspended the founders of Greenpeace largely focused on campaigns to show solidarity with wildlife, whales in particular. The organization soon became well known for its spectacular tactics: activists in small inflatable boats would place themselves between the harpoons and the whales which were being hunted for their meat. Greenpeace's use of direct action represented a clear departure from the Quaker tradition of bearing witness: the activists' objective was to have images of their interventions appear on television screens around the world. ${ }^{59}$ Thus they organized commando operations which aimed not only to rescue peaceful cetaceans but also to film suspenseful action sequences which grab the attention of television viewers. Clips of activists protecting whales with their bodies constituted a particularly effective sensitizing device as they followed the kind of format which appealed to the makers of television news programs: they were short, rhythmic, "punchy" and "sexy" (Lemieux, 200o). Distant viewers, sitting in front of their televisions, were invited to feel compassion for whales, who owed their survival to the daring acts of brave dispenser of justice, intervening to prevent the whalers from doing their horrifying work. The fact that such devices provoked these emotions not only enabled the campaign's message to reach a wide audience - who otherwise may have remained unaware of the practices Greenpeace were condemning - but also helped activists find the resolve to overcome their fear of physical confrontation with the tormenters of these defenseless animals. In other words, we find here all the characteristics of the register of exposure devised by 19th-century antivivisectionists to combat the widespread mistreatment of domestic pets. We can, however, note two ways in which the application of this strategy had progressed. Firstly, in planning their tactics Greenpeace activists were able to exploit resources which resulted from new developments in the media. Secondly, in extending to wildlife an emotional register formerly reserved to domestic animals, they facilitated - in a way which was both complementary and

59 It is worth noting that no fewer than five of the eleven members of first antinuclear testing expedition off the west coast of Canada were journalists (Ollitrault, 1999, p. 161). 
distinct - the convergence of the emotional resources of both the animal protection and ecological movements, which have already been identified. Thus the progressive extension of the emotional register of tenderness, and subsequently the emotional register of exposure, toward all animals treated equally no doubt constituted the main reorientation of the animal protection movement in the 1960 s and $70 \mathrm{~s}$. This gradual shift in the representations of the animal world led to a form of radicalization of the movement which appeared to be largely fueled by indignation aroused by the victimization of animals. These changes also resulted in, firstly, mobilizations against the hunting of wild animals, and, secondly, renewed impetus being given to campaigns against the use of animals for experimentation.

In 1963, a number of active members of the League against Cruel Sports, which had been founded in 1924, decided that they were no longer prepared to confine their opposition to hunting to staging peaceful demonstrations. The organization that they founded, the Hunt Saboteurs Association, quickly came to the attention of the public because of their adoption, during the course of their antifoxhunting campaigns, of the risky tactic of standing together in front of the assembled horses and hounds, in order to disrupt the hunt. ${ }^{60}$ En 1971, Ronnie Lee, a law student from London, organized a group of hunt saboteurs, based in Luton, who resolved to undertake operations to prevent cubhunting (the training of foxhounds by having them hunt young foxes). In 1972 Lee's group decided to adopt more militant tactics involving the liberation of animals which had subjected to treatment which they considered intolerable. The group engaged in illegal commando operations, targeting animal research laboratories and intensive chicken farms, with the objective of liberating as many animals as possible (Tonutti, 2007, pp. 96 and 115). They named themselves the Band of Mercy, reviving the name of an RSPCA youth group founded in 1875 by Catherine Smithies. Arrested during an attack on a laboratory animal breeding center, Ronnie Lee was sentenced to three years in prison and while incarcerated went on hunger strike in order to obtain vegan food. The media coverage of Lee's hunger strike and his trial provided welcome publicity for the Band of Mercy and its cause. In 1976 Ronnie Lee was released from prison and, together with thirty activists who had formed a support committee for him during his incarceration, founded the Animal Liberation Front (ALF). A US branch of the ALF emerged in 1979, with American activists carrying out the first

6o Such operations can be dangerous for participants, as demonstrated by the deaths, in 1991 and 1993, of hunt saboteurs Tom Worby and Mike Hill, both crushed by vehicles while on antihunt protests. 
operations inspired by the direct action tactics of the British founders of the organization. In 1987 the ALF claimed responsibility for fourteen raids on animal testing laboratories in California alone. The previous year the California attorney general had referred to the ALF as a "terrorist" organization (Jasper and Nelkin, 1992, pp. 33-34). One of the ALF's most successful operations was a raid on laboratories in the University of Pennsylvania, during which they removed videotape footage containing horrific images of experiments carried on baboons. The tapes were handed over to People for the Ethical Treatment of Animals (PETA) who used them to make the film Unnecessary Fuss.

Subsequently members of the ALF and PETA - determined to embrace the vocation of liberator - have produced and disseminated shocking images intended to denounce the horrors of animal experimentation and intensive farming. The realistic nature of this campaigning material is heavily reliant on infiltration and firsthand accounts by witnesses, which are characteristic of the register of exposure. Moreover this new generation of activists has been quick to exploit the growing potential of the Internet. On the one hand this alternative communication network enables the rapid spreading of sensitizing devices by organizations and individual supporters and organizations to ever increasing numbers of potential sympathizers around the world. What is more, the Internet is a tool which facilitates supple and informal organizational structures, which enable the transnationalization of sensitizing devices, instructions and methods of operation. Hence "any group of vegetarians or vegans who carry out actions according to ALF guidelines have the right to regard themselves as part of the ALF." ${ }^{\prime \prime}$ Since the organization was founded, in England in 1976, activist groups in around forty countries have taken advantage of this inclusive policy to claim allegiance to the ALF. The first operation on French soil for which the ALF claimed responsibility, on their website, was carried out in October 2009 and resulted in the liberation of 4,200 minks from a fur farm.

The growing concern over the abuse of livestock is an even clearer case of the progressive shift of the emotional registers of tenderness and exposure toward animals whose welfare had been previously overlooked. It is certainly true, as discussed earlier, that the treatment of livestock and draught animals was a central concern of the pioneering activists for the cause. Nevertheless these activists were scandalized by the violence and economic negligence of livestock workers, and not by the suffering of animals destined for human consumption. Activists who sought to protect livestock in the 
second half of the 2oth century, on the other hand, demonstrated an altogether different emotional economy in their attitudes toward them. The case of Ruth Harrison is exemplary. When, in 1961, she read a leaflet produced by the Crusade against All Cruelty to Animals which denounced the suffering of calves and chickens in factory farms it made a deep impression on her. Harrison's parents were admirers of Henry Salt and she, like them, followed a vegetarian diet and was a Quaker (Van de Weerd and Sandilands, 2008). In fact, Harrison's emotional reaction to the Crusade against All Cruelty to Animals leaflet led her to decide to conduct an investigation into the lives of the victims of agribusiness. She visited several intensive livestock operations and obtained a clear idea of the impact on livestock of the recent and massive industrialization of farming. Her investigation also provided material for her book Animal Machines: The New Factory Farming Industry, published in 1964, which denounced as scandalous the fact that the food industry treated animals like a raw material to be processed at the lowest possible cost. Partly as a response to the impact of Animal Machines the British government set up the Brambell Committee - which Ruth Harrison sat on - to produce a report which would take into account the ethical questions which arose from the adoption of intensive farming methods. In 1966, the Ministry of Agriculture set up an independent committee, the Farm Animal Welfare Advisory Committee, which was required to make recommendations about the welfare of animals in the livestock production sector. Finally, in 1968, the scandalous state of affairs denounced by Harrison led to the passing of a law, which included measures related to ensuring the welfare of livestock.

Over the next few years in Britain and the rest of Europe many other organizations were set up to campaign against the treatment of livestock by the agribusiness sector. In 1967 dairy farmer Peter Roberts founded Compassion in World Farming (CIWF) in protest at the excessive industrialization of livestock production which had profoundly changed livestock farming over the previous few decades. CIWF has mounted a series of campaigns against the factory farming of calves, the use of hormones, as well as appropriate ways in which animals are transported and slaughtered. The CIWF makes regular appeals to consumers to boycott eggs laid by battery hens, veal, foie gras, etc. With the support of the British CIWF similar organizations were set up in eight other European countries: in France, in 1994, Ghislain Zuccolo, after completing an internship at CIWF's British headquarters, founded the Protection mondiale des animaux de ferme ${ }^{62}$ It should be

62 Interview $\mathrm{n}^{\circ} 20$ with Ghislain Zuccolo, Protection des animaux de la ferme (Protection for Farm Animals), Paris, June, 2008. 
noted that an important part of the work of CIWF activists consists of representing animals bred for human consumption as creatures worthy of tenderness. Peter Roberts argued that we should extend the way we treat our domestic pets to the individual animals in a herd of livestock, who have been hitherto regarded as interchangeable. "His approach applied the understanding developed toward domestic animals, namely that they had individual characteristics, to animals of the farmyard, usually perceived as an undifferentiated type. The application of individual sensibilities would, he hoped, create a sense of compassion where it had not previously existed" (Kean, 1998, p. 200).

\section{Bringing moral philosophy up to date}

The efforts of campaigners to continue to extend the emotional registers of tenderness and exposure to laboratory animals and livestock also benefited from the support of a group of intellectuals who began to take an interest in animal rights. In 1964, as we mentioned above, the publication of Animal Machines by Ruth Harrison generated a lot of debate and commentary in the press. In 1965, Richard Ryder, a psychologist who had himself been involved in animal research, read an article in the Sunday Times about the way human treatment of animals which made a deep and lasting impression on him (Tonutti, 2007, p. 107). Several years later, in 1970, he published several texts denouncing the abuse of animals, and coined the terms "speciesism" and "antispeciesism" which soon entered the language. Richard Ryder explained the use of the word "speciesism" by arguing that the discrimination which permitted the exploitation of animals was analogous to racism or sexism. In contrast, antispeciesism describes the attitude of those who reject discriminating not only between humans and nonhuman species, but also between different animal species. Antispeciesism calls for "granting equal consideration to the suffering of all sensitive creature irrespective of the species [...]. From the point of view of physical suffering, which is always experienced on an individual level, the last surviving blue whale is equal to any chicken" (Vilmer, 2008, p. 51). While at Oxford University Richard Ryder became associated with a group of students and moral philosophers known as the Oxford Group. In 1972, Stanley and Roslind Godlovitch and John Harris, who were members of the group, edited a collection of essays entitled Animals, Men, and Morals: An Enquiry into the Maltreatment of Non-Humans. It was in a review of this book that Peter Singer first used the term "animal liberation," which he later used as the title of his own 
canonical text on the subject, often referred to the "Bible of antispeciesism." In 1976 the American Tom Regan, who had contacts with the group during his time in Oxford three years before, coedited with Singer the collection Animal Rights and Human Obligations. Over the next few years writers such as Andrew Linzey, Paul Clark and Mary Midgley made important contributions to the discussions around animal rights issues started by the Oxford Group (Vilmer, 2008, pp. 43-44).

It is important to stress that the actors in this network of contacts, in which ideas were exchanged and articles published, were inevitably motivated by academic concerns. In other words, for professionals in the normative disciplines of philosophy and law, thinking critically about the behavior of humans toward animals provided an opportunity to break new academic ground, engage with difficult issues and exercise their intellectual virtuosity; in short, to develop these disciplines from the point of view of their own criteria of excellence. Furthermore for the moral philosophers involved in the project - keen to distance themselves from the figure of the thinker ensconced in an ivory tower playing with purely abstract concepts - animals rights represented an opportunity to enrich their discipline with a specialization which, by analyzing the indignation caused by various ways in which animals are treated, demonstrated their ability to engage more directly with the world. Thus, in the preface of his 1971 thesis, Peter Singer wrote that philosophers must "go beyond the neutral analysis of words and concepts which was, until recently, characteristic of contemporary British and American philosophy" (quoted in Jasper and Nelkin, 1992, p. 91). The fact that professional moral philosophers have specific preoccupations also transpires when we note that for them human relations with animals are but one of the building blocks needed to construct their new normative system. Peter Singer's work, for example, addresses not only animal rights issues, but also euthanasia, the proper treatment of comatose patients, senile individuals, and the severely mentally handicapped. ${ }^{63}$ Moreover philosophers, being principally concerned with establishing the internal coherence of their systems of precepts, are liable to take up the defense of positions unlikely to attract widespread support. So, for example, based on the principle that humans should do nothing to prevent animals from living in a "natural" way, some antispeciesists consider keeping animals as pets is immoral (Jasper and Nelkin, 1992, p. 9). In other words, ethical imperatives

63 Some of Peter Singer's arguments provoked outraged reactions from organizations representing families of the disabled 
can invite the animal protection movement to adopt positions likely to alienate itself from one of its main categories of supporter.

It will now be apparent why relations between contemporary militant groups and animal ethics thinkers are both complex and ambiguous. Having seen throughout this book how the animal protection movement has always included individuals and groups with a variety of contrasting even contradictory viewpoints this should come as no surprise to us. Nevertheless we should be careful to avoid a popular misconception regarding a period during which animal protectionism arguably underwent a radical transformation. It concerns the writings of Peter Singer. It is not uncommon for Peter Singer's book to be described as a "Bible" which triggered a new social movement. It is sometimes given credit for provoking an "animal rights movement" or even an "animal liberation movement." This is probably partly due to the fact that Singer's book, entitled Animal Liberation was first published in 1975, just one year before Ronnie Lee, on his release from prison, founded the Animal Liberation Front. So the book and organization had similar names, and the book was first published just before the organization was founded. But this does not allow us to infer a relationship of causality between Singer's work and the radicalization of a movement, which led some activists to advocate direct action, resulting in the organization of commando operations. Indeed, the change in sensibilities which led some activists to advocate direct action in order to liberate animal victims occurred well before the publication of Singer's book. Without having to go back as far as Marie Hulot, wielding her umbrella against vivisectionists at the end of the 19th century, it should be noted that the first hunt saboteur operations - which predated the use of direct action by the Animal Liberation Front - were carried out a decade before the publication of the "antispeciesist Bible." In other words the adoption of the animal cause by ALF activists certainly had more in common - albeit in a different socio-historical context - with the campaigning of figures like Marie Hulot, Louise Michel and Séverine than with the engagement of professional philosophers with questions related to human relations with nonhuman animals. Identification with animal victims and revulsion at the various abuses of the powerless by the powerful were probably their main motivations, rather than any wish to contribute to the philosophical debates around antispeciesist issues. ${ }^{64}$

64 We can only talk in terms of probability here because individuals who resort of illegal acts, and who are sometimes labeled as "terrorists" by the police, are elusive research subjects, and publish few documents which disclose biographical details about themselves. 
Nevertheless it would be mistaken to suggest that Singer's book and wider public awareness of issues raised by the antispeciesists had no impact on animal right mobilizations from 1976 onward. Such was the success of the "Bible of antispeciesism" that grass roots activists would refer to it when giving an account of how they became involved in the movement. Having said that, it could influence each individual differently, as the composite nature of the work made it susceptible to be read and interpreted in various ways. So while in the first part of the book - which undoubtedly appealed the most to philosophers - the author discusses the extent to which utilitarian principles can be used to develop a consequentialist animal ethics, in the second, more accessible, part Peter Singer gives an account of industrial livestock production in terms which could not fail to move even the most hard-hearted reader (Singer, 1993). In other words, the book probably owed its success to its use of a sensibilization device which closely resembled the one used by the antivivisectionist authors of Light in Dark Places and The Shambles of Science, published in 1883 and 1903, respectively, and so the almost obligatory references to Animal Liberation by activists did not necessarily imply that they actually adhered to Peter Singer's philosophical enterprise.

In only a minority of cases do animal welfare groups present a commitment to the animal ethics movement as an indispensible part of their involvement in animal protection. One example, in France, are the contributors to the review Les cahiers antispécistes. Réflexion et action pour l'égalité animale, founded 1991, who regard the publishing and discussion of antispeciesist texts as militant project in itself. Other activists, on the other hand, simply used texts such as Animal Liberation to provide an intellectual rationale for their activities, for which they had their own preexisting motives. Their involvement in the cause did not extend to contributing to animal rights discussion forums. Thus, Joyce Tischler, who founded the Animal Legal Defense Fund in 1979, stated that when she came across this book, as a law student, it made a deep impression on her: "Singer's book influenced us all. It gave us a philosophy on which to hang our emotions, feelings, sentimentality [...]. It gave us an intellectual hat to put on our heads" (Jasper and Nelkin, 1992, p. 93). The same could be said for Henry Spira who, because of the successful campaigns he led against the American Museum of Natural History in Manhattan, in 1976, and the cosmetics firm Revlon, in 1980 , is considered as the most important pioneering campaigner against animal testing. Although when Spira was a student in New York he took a class by Peter Singer who, in turn, wrote a biography of his former student entitled Ethics into Action: Henry Spira and the Animal Rights Movement 
(1998), his animal rights career cannot be solely attributed to his having taken this class. Born into a Jewish family which fled Nazi Germany when he was just 10 years old, Spira had already been a civil rights activist before concentrating his attentions on the defense of animals. As Henry Spira himself said, the final part of his campaigning career should not be seen in isolation from his previous activism: "Animal liberation was the logical extension of what my life was all about - identifying with the powerless and the vulnerable, the victims, dominated and oppressed" (quoted in Jasper and Nelkin, 1992, p. 26).

Other activists had even more tenuous links with the philosophy of animal rights. Specialists in this discipline were open to accusations that they devoted all their energies to debates whose subtle reasoning, complex theories and interminable discussions about matching strategy with final objectives were not compatible with an affective economy which could be of practical help in furthering the animal cause. Thus Peter Singer - despite having drawn on sensitizing devices from the register of exposure in his work to successfully generate support - sometimes faced criticism for overintellectualizing the issues. Singer himself made no secret of the fact that he did not approve of people who surrounded themselves with domestic pets. Indeed, as one surprised activist, who had themselves taken in eight cats, commented: "[H]e's very highly evolved intellectually, but there's no emotion, no feeling [...]. He's cerebral, not an animal lover" (Jasper and Nelkin, 1992, p. 93). Similarly, Georges Cave, who in 1981 founded TransSpecies Unlimited, and who himself had a PhD in philosophy, was very critical of the academic tone of the discussions adopted by the promoters of antispeciesism: "[T]here is something morally abominable about the 'objective' debates on moral issues which generally take place in university context, when a propelling sense of moral outrage is altogether lacking" (Jasper and Nelkin, 1992, p. 99).

Finally there are other activists who, despite never having read a single antispeciesist text, will quote Singer's book, or use the term "antispeciesism," in order to link their engagement with a serious intellectual enterprise. In other words, the fact that respected academic authors have written and published books on antispeciesism has given a renewed intellectual legitimacy to a cause which had previously suffered from being associated with supposedly feminine excesses of emotion. From 1975 onward, thanks to the involvement of not only philosophers, but also vigorous young men who used tactics developed by left-wing protest groups, the animal protection movement has been able to present itself as being engaged in the defense of fundamental rights, which is widely regarded as a particularly progressive 
and reflective activity. In Anglo-Saxon countries the adoption of "rights talk" has allowed entrepreneurs of the cause to claim a double legitimacy, derived from philosophy forums as well as the fact that they are following in the footsteps of predecessors who distinguished themselves in earlier struggles, such as members of the civil rights movement. In fact, speaking of an "animal rights movement," far from merely describing a new series of mobilizations in favor of animal protection, is a way of redoubling the work of (re)legitimization and situating of the campaigning in a political lineage already undertaken by one of the more recent cohorts of activists.

The perspective given by the history of several centuries of animal protection traced in the preceding chapters can give us a more precise view of the nature of developments at the end of the 1970s. First of all, it is clear that initiatives which were often regarded as radically innovative are better treated as the prolongation and intensification of early trends first established by pioneers of the cause. Thus antispeciesism undoubtedly echoes the leveling of compassion which in the 19th century caused promoters of democratic equality to be moved by the suffering of creatures like the toad. The antispeciesists of the following century, on the other hand, are more reasoned and systematic, allowing no exceptions and requiring a rigorous discipline which resembles a form of secular asceticism. Thus today an antispeciesist who aims to be consistent - unlike Émile Zola, despite the compassion he showed toward some animals - should accord the same treatment not only to a wolf and a sheep, but also to a rat, a fly, a cockroach, etc. It should also be added that when, in order to avoid being complicit in the slaughter of animals, antispeciesists adopt a vegan diet they are part of a continuing centuries-old trend for activists to demand the reduction of forms of violence which are mistakenly regarded as being normal. Furthermore, the ideal types which result from our genealogical analysis enable us to draw distinctions between mobilizations which are bracketed together within a new "animal rights movement." When authors such as Peter Singer and Henry Spira refer to "animal liberation" they tend to lump together two very different strains of activism. Some activists, such as the ALF, interpret the term "animal liberation" literally, as drawing on an emotional register of exposure to justify the use of direct action to rescue animal victims from the clutches of their tormenters. For activists such as Henry Spira - whom Peter Singer presents as a model of "ethics in action" - the term "animal liberation" is used more metaphorically to indicate a pragmatic course of action aimed at gradually changing behaviors. More precisely the "ten rules for change" suggested by Henry Spira provide a demopedic register to reform the deviant behavior of consumers in general 
and laboratory experimenters in particular (Singer, 2005). ${ }^{65}$ The model of an animal rights activist favored by two of the best known promoters of animal ethics is therefore much closer to the traditional figure of the pedagogue than to that of the liberator, who is an apologist for the direct action methods of the Animal Liberation Front.

65 In particular, Rules 5 and 6 - "Don't divide the world into saints and sinners," "Seek dialogue and attempt to work together to solve problems" - which express a charitable attitude to the deviants, whom the benefactors attempts to redirect onto the right path. 



\section{Conclusion}

This essay makes no claims to being an exhaustive account of the history of animal protection. My more modest aim has been to reveal the complexity of a cause which has too often been reduced to a number of simplistic stereotypes. The campaigns undertaken over the last two centuries to reform the way humans treat animals have had many and various motivations. The animal protection cause is not a creature of the left, the right nor the center, neither can it be characterized as a wholly reactionary or progressive movement: indeed, it has attracted support from individuals coming from every political tradition. Neither a simple pretext to test the philosophical reflections of an enlightened elite, nor the outflowings of feelings by hysterical groups, the study of the many forms of animal protection shows that collective mobilizations depend on activists striving to reconcile emotional reactions and discursive reflections (Traïni, 2010a). It was as a result of such work that successive generations of animal welfare entrepreneurs succeeded in effecting changes in attitudes toward animals, changes which were influenced by a multitude of factors including the underlying trend toward the decreasing tolerance of violence; competition between different forms of accreditation; the process of differentiation between "Them" versus "Us"; the different reactions of individuals confronted with domination; the growing importance of domestic pets; the social division of tasks along gender lines; the evolution in the subject matter and the criteria of excellence in both scientific disciplines and moral philosophy; the complete transformation of the veterinary profession and the news and entertainment industries; and the trauma experienced during the wars of the 2oth century and environmental catastrophes.

As well as enabling us to give a complex account, genealogical analysis yielded a number of ideal type distinctions which will be indispensible for future investigation of animal protection: on the one hand the demopedic emotional registers of tenderness and exposure; on the other the vocations and modus operandi favored by activists who presented themselves as preceptors, ascetics, rescuers, dispensers of justice or liberators. As with any other Weberian ideal type, these figures present a picture in which the various categories are clearly distinct: in reality, the observed facts are never so clear and distinct. Furthermore, a historical perspective is clearly all the more essential because the distinctive features identified seem, over time, to be increasingly and inextricably interwoven. The other element borrowed from the sociology of Max Weber is the imperative of 
axiological neutrality, which requires the researcher not to subordinate the description of the processes observed to their own normative judgments. Regarding mobilizations conducted by moral entrepreneurs this imperative would appear to be particularly difficult to follow since activists, and their critics, will always accuse sociologists of not presenting their point of view in a sufficiently positive light. Be that as it may, sociology must not only avoid making value judgments, but also refrain from thinking that it can replace normative stances. Grasping the fundamentally equivocal nature of animal protection, understanding the heterogeneity of underlying motives and reasons for the various mobilizations which have marked its history undoubtedly constitute the best way of convincing ourselves that today no one can claim to be completely indifferent to way human beings treat animals. Is that going too far, or not far enough? Each of us must provide their own normative and prescriptive reply. 


\section{Bibliography}

\section{Primary sources}

Borel, F., Sur le vif. Considérations sur la vivisection. Paris: Sandoz et Thuillier, 1883.

BSFCV, Bulletin de la société française contre la vivisection. Paris: Bibliothèque Nationale de France, microfilm M-496o.

BSIZA, Bulletin de la société impériale zoologique d'acclimatation. Paris: Bibliothèque Nationale de France, NUMP-6634.

BSPA, Bulletin de la société protectrice des animaux. Paris: Bibliothèque Nationale de France, microfilm M-8525.

Cobbe, Frances Power, Italics: BriefNotes on Politics, People, and Places in Italy. London: Trübner, 1864.

—, Lumière dans les ténèbres. Paris and Lausanne: Société française contre la vivisection, Société vaudoise contre les abus de la vivisection, 1884 .

Cyon, Elie de, L'Agitation antivivisectionniste. Paris: A. Parent, 1883.

Dejerine, Jules, L'Hérédité dans les maladies du système nerveux. Paris: Asselin et Houzeau, 1886.

Dramard, Louis, "Une conférence anti-vivisectionnisteXXX," La Revue socialiste 6 (1887), pp. 202-203.

Engels, Friedrich, La Situation de la classe laborieuse en Angleterre. Paris: Éditions sociales, 1960 [1st ed. 1845].

Fremaux, Alexandre-Joseph, Recherches pratiques sur la mortalité prématurée, ou la Vérité sur les causes et les désastres du choléra-morbus épidémique et autres maladies. Paris: édition de l'auteur, 1864 .

Gide, Charles, “Une classe de travailleurs oubliés," La Revue socialiste 8 (1888), pp. 51-53.

Hamilton, Darren, "I Loved Horse meat So Much, I'll Treat the Family: Sun Man Eats Dish at Heart of Food Scandal," The Sun, 18 February 2013.

Hunter, Robert, The Greenpeace to Amchitka: An Environmental Odyssey. Vancouver: Arsenal Pub., 2004.

Huot, Marie, "Le Droit des animaux," La revue socialiste 6 (1887), pp. 47-56.

—, La grande Découverte de M. Brown-Séquard, conférence faite le 13 avril 1890 au théâtre du Paradis latin. Paris: Ligue populaire contre la vivisection, 189oa.

—, Les Courses de taureaux à Paris $(1887,1889,1890)$, conférence faite le 11 juin 1890 à la salle des Capucines. Paris: Ligue populaire contre la vivisection, $189 \mathrm{ob}$.

Huré Jeune, Le Zoophile, ou le Défenseur des animaux, recueil d'histoires et faits anecdotiques sur les animaux en général et les espèces chevaline, canine et féline en particulier, précédé d'une notice sur les séances de la Société protectrice des animaux, Paris, reliure inconnue, 1855.

Jouy, Jules, Les Chansons de l'année. Paris: Editions Bourbier et Lamoureux, 1888.

Kleffler, Henri, Les Missions “humanitaires” des dames anglaises sur le continent: la vivisection, son utilité, sa morale, réponse à la campagne antivivisectionniste de Mme le Dr Anna Kingsford. Genève: H. Georg, 1883 .

Lescure, Françis, Défense des animaux. L'exemple de Fernand Méry. Vétérinaire humaniste. Nantes: Ouest Editions, 1995.

Magnan, Valentin, Recherches sur les centres nerveux. Alcoolisme, folie des héréditaires dégénérés, paralysie générale, médecine légale. Paris: G. Masson, 1884.

Mery, Fernand, Médecin des bêtes. Le roman d'une vocation. Paris: Robert Laffont, 1961. 
Mézières, Alfred, Éducation morale et instruction civique à l'usage des écoles primaires. Paris: Librairie Delagrave, 1883 .

Michel, Louise, Mémoires de Louise Michel. Ecrits par elle-même. Paris: Maspéro, 1976 [1st ed. 1886].

Mieussens, Dimitri, L'exception corrida: de l'importance majeure d'une entorse mineure, Paris, L'Harmattan, 2005.

Monod, Alain, "Théodore Monod et le vivant. Du naturalisme à l'humanisme" (n.d.) http://www. oaba.fr/pdf/th_monod.pdf.

Monod, Théodore, "Nature vivante et foi chrétienne: l'animal: objet, compagnon ou frère?," in Georges Chapoutier and Jean-Claude Nouët (eds.), Les droits de l'animal aujourd'hui. Paris: Arléa-Corlet, 1997, pp. 37-64.

Noguès, Georges, "Constantinople en 1864," Revue contemporaine 78 (1865), pp. 5-37.

Phillips, Richard, A Dictionary of the Arts of Life and Civilisation. London: Sherwood \& Co., 1833.

Roche, A. Édouard, Les Martyrs du travail. Manuel du propriétaire et du conducteur d'animaux de trait. Le cheval, 4th ed. Paris: Librairie Delagrave, 1880.

—, Les Martyrs du travail (le cheval, l'ane, le mulet, le boeuf): notions de médecine vétérinaire: conseils aux agriculteurs à propos des animaux utiles et nuisibles, 6th ed. Paris, 1882.

Saury, Honoré, Étude clinique sur la folie héréditaire: (les dégénérés). Paris: A. Delahaye et $\mathrm{E}$. Lecrosnier, 1886.

Séverine, Line: 1855-1867. Paris: Crès, 1921.

Singer, Peter, "Henry Spira: Faire avancer le schmilblick," trans. Antoine Comiti and Estiva Reus, Les Cahiers antispécistes 24 (January 2005), http://www.cahiers-antispecistes.org/ spip.php?article256.

—, La Libération animale. Paris: Grasset, 1993.

Sollier, Paul, Guide pratique des maladies mentales: séméiologie, pronostic, indications. Paris: Masson, 1893 .

Tristan, Flora, Promenades dans Londres: ou l'aristocratie et les prolétaires anglais. Paris: Maspero, 1978.

\section{Academic secondary sources}

Agulhon, Maurice, "Le Sang des bêtes: le problème de la protection des animaux en France au XIX” siècle," Histoire vagabonde, vol. 1. Paris: Gallimard, 1988, pp. 243-282.

Ariès, Philippe, L'Homme devant la mort. Paris: Éditions du Seuil, 1977.

Autain, Clémentine, “Féminismes et sexualité: 'jouissons sans entraves!," Mouvements 2/20 (2002), pp. 30-36.

Baratay, Éric, "Comment se construit un mythe: la corrida en France au XXe siècle," Revue d'histoire moderne et contemporaine 44/2 (1997), pp. 307-330.

Barrows, Susanna, Miroirs déformants. Réflexions sur la foule en France à la fin du XIX esiècle. Paris: Aubier, 1990.

Bédarida, François, La Société anglaise. Du milieu du XIX siècle à nos jours. Paris: Seuil, 1990.

Bentham, Jeremy, Introduction to the Principles of Morals and Legislation, XVII, § 1, IV, no. 1. Oxford: Clarendon Press, 1907 [rep. 1823 ed.].

Boltanski, Luc, La Souffrance à distance. Morale humanitaire, médias et politiques. Paris: Métailié, 1993.

Bourdieu, Pierre, "Le capital social," Actes de la Recherche en sciences sociales 31 (1980), pp. 2-3.

Bromander, Lennart, "The Vivisection Debate in Sweden in the 1880s," in Nicolaas A. Rupke (ed.), Vivisection in Historical Perspective. London: Croom Helm, 1987, pp. 214-235. 
Broqua, Christophe and Olivier Fillieule, "Act up ou les raisons de la colère," in Christophe Traïni (ed.), Émotions ... mobilisation! Paris: Presses de science Po, 2009, pp. 141-167.

Brown, Antony, Who Cares for Animals? 150 Years of the RSPCA. London: William Heinemann, 1974.

Buettinger, Craig, "Antivivisection and the Charge of Zoophil-psychosis in the Early Twentieth Century," The Historian 15/2 (1993), pp. 277-289.

Charlot, Monica, and Roland Marx, La Société victorienne. Paris: Armand Colin, 1978.

Corbin, Alain, "Coulisses," in Philippe Ariès and Georges Duby (eds.), Histoire de la vie privée, vol. 4. Paris: Seuil, 1987 .

Couturiau, Paul, Séverine, l'insurgée. Monaco: Éditions du Rocher, 2001.

Dardenne, Émilie, Frances Power Cobbe (1822-1904): militante victorienne. Deux causes un engagement, PhD diss., Université de Rennes-II, 2003.

—, "Portrait de Henry Stephens Salt. Penseur et militant aux engagements multiples," Les Cahiers antispécistes 24 (2005), http://www.cahiers-antispecistes.org/spip.php?article263.

Déloye, Yves, École et citoyenneté. L'individualisme républicain de Jules Ferryà Vichy: controverses. Paris: Presses de la FNSP, 1994.

—, Sociologie historique du politique, La Découverte. Paris: 3rd ed., 2007.

— and Claudine Haroche, Le sentiment d'humiliation. Paris: In Press Éditions, 2006.

Duprat, Catherine, "Pour l'amour de l'humanité": le temps des philanthropes. La philanthropie parisienne des Lumières à la Monarchie de Juillet, vol. 1. Paris: CTHS, 1993.

Elias, Norbert, The Germans: Power Struggles and the Development of Habitus in the Nineteenth and Twentieth Centuries, ed. Michaël Schröter. Cambridge: Polity Press, 1996.

—, La Civilisation des moeurs. Paris: Calmann-Lévy, 1973.

—, La Dynamique de l'Occident. Paris: Calmann-Lévy, 1975.

—, La Société de Cour. Paris: Flammarion, 1985.

—, La Solitude des mourants. Paris: Christian Bourgeois Editeur, 1987.

— and Eric Dunning, Sport et civilisation. La violence maîtrisée. Paris: Fayard, 1994.

— and John L. Scotson, Logiques de l'exclusion, Enquête sociologique au cœur des problèmes d'une communauté. Paris: Fayard, 1997.

Fabiani, Jean-Louis, "Science des écosystèmes et protection de la nature," in Anne Cadoret (ed.), Protection de la nature. Histoire et idéologie. De la nature à l'environnement. Paris: L'Harmattan, 1985, pp. 75-83.

Faucher, Florence, "Manger vert. Choix alimentaires et identité politique chez les écologistes français et britanniques," Revue française de science politique 48/3-4 (1998), pp. 437-457.

Fillieule, Olivier (ed.), Le désengagement militant. Paris: Belin, 2005.

Fleury, Georges, La belle Histoire de la SPA. Paris: Grasset \& Fasquelle, 1995.

Foucault, Michel, Surveiller et punir. Naissance de la prison. Paris: Gallimard, 1975.

Grier, Katherine C., "Childhood Socialization and Companion Animals: United States, 1820-1870," Society \& Animals Journal of Human-Animal Studies 7/2 (1999), pp. 95-120.

Guarnieri, Patrizia, "Moritz Schiff (1823-96): Experimental Physiology and Noble Sentiment in Florence," in Nicolaas A. Rupke (ed.), Vivisection in Historical Perspective. London: Croom Helm, 1987, pp. 105-124.

Gusfield, Joseph R., Symbolic Crusade: Status Politics and the American Temperance Movement. Urbana and Chicago: Illini Books, 1986 [1st ed. 1963].

Hamilton, Susan, Animal Welfare \& Anti-vivisection 1870-1910: Frances Power Cobbe. History of feminism, New York, Routledge, 2004.

Haroche, Claudine, "Des formes et des manières en démocratie," Raisons politiques 1 (2001), pp. 89-110. 
Harrison, Brian, "Animals and the State in Nineteenth-Century England," English Historical Review 88 (1973), pp. 786-820.

Heinich, Nathalie, « L'Esthétique contre l'éthique, ou l'impossible arbitrage : de la tauromachie considérée comme un combat de registres », Espaces et Sociétés, nº69/2, 1992; pp. 39-53.

Heinich, Nathalie, La Sociologie de Norbert Elias. Paris: La Découverte, 1997.

Hirschman, Albert O., Les Passions et les intérêts. Paris: Presses Universitaires de France, 1980.

Hubscher, Ronald, Les Maîtres des bêtes. Les vétérinaires dans la société française (XVIII ${ }^{e}-X X^{e}$ siècle). Paris: Odile Jacob, 1999.

Jaeger-Wolff, Elisabeth, La dernière Amazone: Biographie romancée de Camille Crespin du Gast (1868-1942). Haguenau: Editions du Bastberg, 2007.

Jasper, James M., and Dorothy Nelkin, The Animal Rights Crusade: The Growth of a Moral Protest. New York: The Free Press, 1992.

Jobert, Arthur, "L'Aménagement en politique, ou ce que le syndrome Nimby nous dit de l'intérêt général," Politix 42 (1998), pp. 67-92.

Käppeli, Anne-Marie, "Scènes féministes," in George Duby and Michèle Perrot (eds.), Histoire des femmes en Occident, vol. 4. Paris: Plon, 1992, pp. 495-525.

Kean, Hilda, Animal Rights: Political and Social Change in Britain since 180o. London: Reaktion Books, 1998.

Kete, Kathleen, The Beast in the Boudoir: Petkeeping in Nineteenth-Century Paris. Berkeley and Los Angeles: University of California Press, 1994.

Knibiehler, Yvonne, "Corps et cœurs," in George Duby and Michèle Perrot (eds.), Histoire des femmes en Occident, vol. 4. Paris: Plon, 1992, pp. 351-387.

Lansbury, Coral, "Gynaecology, Pornography and the Anti-vivisection Movement," Victorian Studies 28 (1985b), pp. 413-437.

-, The Old Brown Dog: Women, Workers, and Vivisection in Edwardian England, Madison, University of Wisconsin Press, 1985 a.

Lemieux, Cyril, Mauvaise presse. Une sociologie compréhensive du travail journalistique et de ses critiques. Paris: Métailié, 2000.

Leteux, Sylvain, "L'Hippophagie en France. La difficile acceptation d'une viande honteuse," Terrains \& travaux 9 (2005), pp. 143-158.

Li, Chien-hui, "A Union of Christianity, Humanity, and Philanthropy: The Christian Tradition and the Prevention of Cruelty to Animals in Nineteenth-Century England," Society \& Animals Journal of Human-Animal Studies 8/3 (2000), pp. 265-285.

Littré, Émile, Dictionnaire de la langue française, 2004 [1st ed. 1863-1872].

Louis, Jeanne-Henriette, "Le pacifisme des quakers américains, substrat d'une promesse presque évanouie?," Matériaux pour l'histoire de notre temps 75 (2004), pp. 86-95.

Marcus, Sharon, "Entre femmes: l'amitié et le jeu du système dans l'Angleterre victorienne," Revue d'histoire moderne et contemporaine 53/4 (2006), pp. 32-52.

Mason, Peter, The Brown Dog Affair: The Story of a Monument that Divided the Nation. London: Two Stevens, 1997.

Matagne, Patrick, Comprendre l'écologie et son histoire, Lausanne, Delachaux \& Niestlé, 2002.

Mehl, Dominique, "Le témoin, figure emblématique de l'espace privé/public," in Daniel Cefaï and Dominique Pasquier (eds.), Les sens du public. Publics politiques, publics médiatiques. Paris: Presses Universitaires de France, 2003, pp. 489-502.

Melson, Gail, Les animaux dans la vie des enfants. Paris: Payot, 2009.

Offerlé, Michel, Sociologie des groupes d'intérêt. Paris: Montchrestien, 1994.

Ollitrault, Sylvie, "De la caméra à la pétition-web: le répertoire médiatique des écologistes," Réseaux 17/98 (1999), pp. 153-185. 
—, Militer pour la planète. Sociologie des écologistes. Rennes: Presses Universitaires de Rennes, 2008.

Palmatier, Robert Allen, Speaking of Animals: A Dictionary of Animal Metaphors. Westport: Greenwood Press, 1995 .

Patouillard, Victoire, “Une colère politique. L'Usage du corps dans une situation exceptionnelle: le zap d'Act Up," Sociétés contemporaines 31 (1998), pp. 15-36.

Patterson, Charles, Un éternel Treblinka. Paris: Calmann-Lévy, 2007.

Pelosse, Vincent, “Imaginaire social et protection de l'animal. Des amis des bêtes de l'An X au législateur de 1850," L'Homme 21/4 (1981), pp. 5-33, and 22/1 (1982), pp. 33-51.

Pierre, Éric, Amour des hommes, amour des bêtes. Discours et pratiques protectrices dans la France duXIX $X^{e}$ siècle, PhD diss., Université d'Angers, 1998.

—, "L'Hippophagie au secours des classes laborieuses," Communications 74 (2003), pp. 177-200.

Raffin, J.-P., and G. Ricou, "Le lien entre les scientifiques et les associations de protection de la nature: approche historique," in Anne Cadoret (ed.), Protection de la nature. Histoire et idéologie. De la nature à l'environnement. Paris: L'Harmattan, 1985, pp. 61-74.

Ritvo, Harriet, The Animal Estate: The English and Other Creatures in the Victorian Age. Cambridge, MA: Harvard University Press, 1989.

Rosanvallon, Pierre, Le Sacre du citoyen. Histoire du suffrage universel en France, Paris, Gallimard, 1992.

Saumade, Frédéric, Des sauvages en Occident. Les cultures tauromachiques en Camargue et en Andalousie. Paris: MSH, 1994.

—, Les Tauromachies européennes. La Forme et l'histoire, une approche anthropologique. Paris: CTHS, 1998.

Snow, David A., E. Burke Rochford, Steven K. Worden, and Robert D. Benford, "Frame Alignment Processes, Micromobilization and Movement Participation," American Sociological Review $5^{1}$ (1986), pp. 464-481.

Thomas, Keith, Dans le jardin de la nature. La mutation des sensibilités en Angleterre à l'époque moderne. Paris: Gallimard, 1985.

Tocqueville, Alexis de, De la démocratie en Amérique, vol. 2. Paris: Gallimard, 1993.

Tonutti, Sabrina, Diritti animali: storia e anthropologia di un movimento. Udine: Forum, 2007.

Traimond, Bernard, "Un conflit de représentation: la République et la corrida. La révocation du maire de Dax en 1894," in Maurice Agulhon (ed.), Cultures et folklores républicains. Paris: Comité des travaux historiques et scientifiques, 1995, pp. 185-191.

Traïni, Christophe, "Aficionados et opposants à la tauromachie. Les formes plurielles de la civilisation," Politix 64 (2003b), pp. 103-125.

- Les Braconniers de la République. Les conflits autour des représentations de la Nature et la politique. Paris: Presses Universitaires de France, 2003a.

—, "Des sentiments aux émotions (et vice-versa). Comment devient-on militant de la cause animale?," Revue française de science politique 6o/2 (2010a), pp. 335-358.

—, «Dramaturgie des émotions, traces des sensibilités. Observer et comprendre des manifestations anti-corrida,» Ethnographiques.org 21 (2010b), http://www.ethnographiques.org/ Dramaturgie-des-emotions-traces.

—, La Musique en colère. Paris: Presses de Science Po, 2008.

—, "L'Opposition à la tauromachie," in Christophe Traïni (ed.), Émotions ... mobilisation! Paris: Presses de Sciences-po, 2009, pp. 193-213.

Tröhler, Ulrich, and Andréas-Holger Maehle, "Anti-vivisection in Nineteenth-Century Germany and Switzerland: Motives and Models," in Nicolaas A. Rupke (ed.), Vivisection in Historical Perspective. London: Croom Helm, 1987, pp. 149-187. 
Turner, James, Reckoning with the Beast: Animals, Pain and Humanity in the Victorian Mind. Baltimore: Johns Hopkins University Press, 1980.

Van de Weerd, Heleen, and Victoria Sandilands, "Bringing the Issue of Animal Welfare to the Public: A Biography of Ruth Harrison (1920-2000)," Applied Animal Behaviour Science 113 (2008), pp. 404-410.

Vilmer, Jean-Baptiste Jeangène, L'Éthique animale. Paris: Presses Universitaires de France, 2008. Walkowitz, Judith, "Sexualités dangereuses," in George Duby and Michèle Perrot (eds.), Histoire des femmes en Occident, vol. 4. Paris: Plon, 1992, pp. 389-418.

Weber, Max, L'Éthique protestante et l'esprit du capitalisme. Paris: Plon, 1999 [1st ed. 1905].

Wilhelm, Patrice, "Sympathie et douceur démocratiques," in Pierre Ansart and Claudine Haroche (eds.), Les sentiments et le politique. Paris: L'Harmattan, 2007, pp. 71-84. 


\section{A brief chronology}

1751 William Hogarth's engravings The Four Stages of Cruelty highlight the way violence toward animals generates crime (Great Britain, hereafter GB).

1800-1802 Parliamentary bills aiming to outlaw bullbaiting (GB).

1802 The French National Institute proposes the following questions for discussion "To what extent is the barbaric treatment of animals a question of public morality?" and "Is it desirable to pass legislation on these matters?" (France, hereafter F).

1809 Setting up of abattoirs in Paris (F).

1822 Passage onto the statute books of "The Cruel Treatment of Cattle Act," also known as "Martin's Act" (GB).

1824 Foundation of the Society for the Prevention of Cruelty to Animals (GB).

1824-1825 Public dissections by the French physiologist François Magendie cause a scandal in London (GB).

1840 Queen Victoria expresses her support for the SPCA which changes its name to the RSPCA, the Royal Society for the Prevention of Cruelty to Animals (GB).

1846 The Société protectrice des animaux, founded in Paris, is the ninth national society of its kind in Europe (F).

1850 Passage of the loi Grammont (Grammont Law) (F).

1854 Foundation of the Société impériale zoologique d'acclimatation (F).

1860 Mary Tealby founds the Temporary Home for Lost and Starving Dogs. In 1871 it changes its name to the Battersea Dogs \& Cats Home and is still operating today (GB).

1863 In Florence the Irish writer, social reformer and activist Frances Power Cobbe leads a protest campaign against the vivisectionist activities of German physiologist Moritz Schiff.

1865 The newspaper Le Siècle publishes articles criticizing the treatment of horses during corridas. Three years later, the Englishman Colam, who got into the bullring in Islington as a protest, is given an award by the Société protectrice des animaux $(\mathrm{F})$.

1868 Foundation of British Bird Protection Society (GB). 
1869 The Sea Birds Preservation Act, the first legislation for the protection of wild species in Europe, is passed (GB).

1873 The Beulé circular bans bullfighting on French soil for reasons of public order and the defense of public morality $(\mathrm{F})$.

1874 The French psychiatrist Valentin Magnan is forced to flee Great Britain after being accused of cruelty by the RSPCA for carrying out vivisections (GB).

1875 Frances Power Cobbe founds the Society for the Protection of Animals Liable to Vivisection (GB).

1881 The Société protectrice des animaux opens its first shelter for dogs $(\mathrm{F})$.

1882 British scientists found the Association for the Advancement of Medicine by Research, which organizes a violent campaign targeting antivivisectionists (GB).

$1883 \quad$ Foundation of the French Anti-Vivisection Society and the Popular Anti-Vivisection League.

1884 Valentin Magnan diagnosed antivivisectionism as an hereditary illness $(\mathrm{F})$.

1886 A circular confirms the banning of bullfighting in which the bull is killed $(\mathrm{F})$.

1888 Judging them too costly to run, the Société protectrice des animaux closes its dog shelters $(\mathrm{F})$.

$1891 \quad$ Henry Salt founds the Humanitarian League and publishes Animals' Rights Considered in Relation to Social Progress (GB).

$1894 \quad$ Heated debate between bullfighting aficionados in the South of France and the SPA, which organizes an intense campaign against bullfighting (F).

1895 The government deports Mazzantini, a Spanish bullfighter who planned to perform in Bayonne $(\mathrm{F})$.

1897 In the lower chamber of the French parliament deputies from the South of France speak out in defense of the corrida. The following year a number of Southern mayors found the Fédération des cités du Midi for the purpose of defending bullfighting (F).

1899 Three hundred members of the Société protectrice des animaux resign from the organization in protest at the lack of consideration that the leadership gives to the dog shelters $(\mathrm{F})$. 
$1900 \quad$ French deputies pass a law banning the corrida by 414 votes to 67 . Gaston Doumergue tables an amendment which authorizes the holding of corridas in any "permanent bullring" which dates back to before 1 January $1900(\mathrm{~F})$.

1900 The Convention for the Preservation of Wild Animals, Birds and Fish in Africa is the first international treaty for the conservation of wild animal species.

1902 The first Teddy Bear is a roaring commercial success in the United States.

1903 The "Brown Dog Affair": The publication of the testimony of two Swedish medical students triggers an antivivisection campaign (GB).

1911 Bullfighting towns in the South of France join forces to oppose antibullfighting bills (F).

1912 The League for the Protection of Birds is founded under the aegis of the Société nationale d'acclimatation $(\mathrm{F})$.

1924 Foundation of the League against Cruel Sports (GB).

1925 The new president of the Société protectrice des animaux is elected after promising to build an extension to the society's dog shelter (F).

$1926 \quad$ Foundation of the Confédération Nationale des sociétés protectrices des animaux $(\mathrm{F})$.

1929 Camille du Gast becomes the first female president of the Société protectrice des animaux $(\mathrm{F})$.

1953 Fernand Méry founds the Association des amis des bêtes (F).

1956 The Silent World by Jacques Cousteau wins the Palme d'Or at the Cannes Film Festival (F).

1960 The National Acclimation Society is renamed the National Society for the Protection of Nature (F).

$1961 \quad$ Foundation of the World Wildlife Fund (WWF) (GB).

1963 Creation of the Hunt Saboteur Association (GB).

1964 Ruth Harrison publishes Animal Machines: The New Factory Farming Industry (GB).

$1967 \quad$ Creation of Compassion in World Farming (GB).

1968 Start of filming of the series The Undersea World of Jacques Cousteau.

1968 French television viewers watch Caméra au poing by Christian Zuber then, the following year, the US series Daktari, first broadcast in the US in 1966 on CBS (F). 
1969 In Canada, the creation of the International Fund for Animal Welfare to campaign against seal hunting. Brigitte Bardot appears on the cover of Paris Match: "Save the Baby Seals" (F).

$1970 \quad$ Fernand Méry founds the Conseil national de la protection animale $(\mathrm{F})$.

1971 Greenpeace is founded in Canada.

1972 Members of the Hunt Saboteur Association create the Band of Mercy and organize commando operations to liberate laboratory animals (GB).

1974 The National Council for the Protection of Animals launches the campaign "Man's Twelve Duties toward Animals" (F).

1975 Publication of Animal Liberation by Peter Singer.

1976 Creation of the Animal Liberation Front (GB).

1976 Henry Spira heads a protest campaign against animal experimentation at the American Museum of Natural History in Manhattan.

1976 "La Charte de l'animal" (The animal charter) leads to the passing of the animal protection law of 10 July $1976(\mathrm{~F})$.

1976 Founding of ROC, the Rassemblement des opposants $a$ la chasse (Anti-Hunting Federation) (F).

1977 Founding of the Ligue française des droits de l'animal (LFDA, French Animal Rights League) (F).

1979 First Animal Liberation Front operations carried out on US soil.

1980 The founding of PETA, People for the Ethical Treatment of Animals, in the US. 


\section{Index}

8th International Congress of Animal Protection Societies 112

1789 Revolution 62

abattoirs 22-25, 27, 137, 141, 152

ABC 166

acclimatization $46,15^{8}$

Acclimatization Society of Paris 31

accreditation procedures 80,82

activism 7, 9, 23, 122, 181, 182

Act to Prevent the Cruel and Improper

Treatment of Cattle 12

Actualités de Paris, Ici les bêtes 120

Adamson, George 169

Adamson, Joy 169

Aesop 98, 122

aficionados 69, 70, 76-78, 90

Agent Orange 171

agronomist 29

agronomy 30

Agulhon, Maurice 8, 13, 22, 26, 41, 43, 70, 75, 99,127

Alaska 172

Albazar 84

ALF 174, 175, 179, 182

Alfort veterinary school 32

Algiers-Toulon race 135

Alliance pour la suppression des corridas 78

altruism 7

Amchitka 173

American Humane Society 122

American Museum of Natural History 180

American Neurological Society 154

Amoco Cadiz oil spill 171

anarchists $7,61,125$

Anglican 43, 63, 64

Anglo-Irish 64

angora goats 36

Angriffslust 18

animal cause $20,40,100,122,125,138,146,167$, 179,181

animal drivers 47

Animal Friends' Society 26

animality 59,60

Animal Legal Defense Fund 180

Animal Liberation Action and Study Group 168

Animal Liberation Front 136, 174, 179, 183

animal liberationists 8

animal liberation movement 179

Animal Machines 176, 177

animal protection initiatives 125

animal protectionists $30,34,36,46,49,53$,

$64,66,67,69,70,72-74,78,89,98,104,114$, $126,127,129,134,135,139,144,151,156,159$, 160,172 animal protection movement $7,8,11,13,20,24$, $27,35,37,72,82,88,100,102,112,121,124,144$, $149,167,170,174,179,181$

animal refuges 7

animal rights $7-9,11,14,15,101,167,177,178$, 180-182

animal rights activism 7

animal rights activists 101

animal rights campaigners 7

animal rights movement $7,8,15,179$

Animals, Men, and Morals 177

animal testing $8,175,180$

animal welfare $11,17,20,21,23,25,26,29,31,39$, 40, 42-44, 47, 48, 50-53, 55-57, 61, 62, 91, 94 , $96,98,99,103,106,110,115,118-120,125,136$, $141,144,156,157,161,180,185$

animal welfare activists 40,53

animal welfare movement $57,96,157$

animal welfare organizations 40, 118

anthropophagy 84

Anti-Hunting League 168

antisentimentalism 113

antispeciesism $7,97,177,180-182$

antivivisection $14,65,86-88,100,105,122$,

$131-133,135,139,142,147,149,150,155,15^{6}, 171$

antivivisectionism 63,85

Archbishop of Westminster 66

Arcueil 113

Arles 76

ascetic(s) 8o, 82, 125, 144, 185

Asnières 107, 135

asses 12

Association for Promoting Rational Humanity toward the Animal Creation 62

Association for the Advancement of Medecine by Research 149

Association for the Protection of Animals in Slaughterhouses 168

Association for the Protection of British Birds 160

auroch $15^{8}$

Auschwitz 136

Austria 12, 169

Automobile Club of France 135

avengers 125,146

axiological neutrality 186

Bacon 157

Ballet, Gilbert 153, 154

Band of Mercy 55

Bank of England 85

Bardot, Brigitte 164

Bardot Foundation 167

Bataille 78

bats 36 
Battersea 112, 133

Bavaria 12,17

Bayonne 74

Bazar de la Charité 134

bearbaiting 33,63

bears $41,61,123,162,164,169,171$

Beautiful Joe 122

Beauvoir, Sir John de 12

Bel Paese 13

benefactor 48

beneficiary 48

Benjulia, Dr. 142

Bentham, Jeremy 95, 96

Bergh, Henry 13

Berkowitz, Marc 136

Berlin 135

Bernard, Claude 9o, 91, 97, 139

Berquin 98

Bertrand, Yann Arthus 166

bestiality $59,60,62,74,76,78,109$

bestiary 169

Beulé circular 71

Biarritz 13

Bible $81,136,178-180$

Bible Christian Church 81

Bikini Atoll 172

Billault, Monsieur 67

biocoenosis 161

Biological Society 151

biology 63,162

Birkenau 137

Black Beauty 122

Blake, William 95

Blatin, Henri 29, 32, 53, 82, 84, 114, 115, 159

Bloodsports 33

bonuses $47,49,5^{1}$

Borel 150, 155, 156

Born Free 169

Boston Society 110

botanist 86

botany 157

Bourbon Restoration 83

bouvines 75

Brambell Committee 176

Brassens, Georges 120

Brigitte Bardot 8

Brindisi 13

British Army 64

British Bird Protection Society 160

British Medical Association 65

British Union for the Abolition of Vivisection 88

Brittany 93

Brizieu 98

Brown Dog Affair 133

Brown-Séquard, Professor 131, 146, 154

Bruneau slaughter mask 47

Brussels 112

BSFCV 8, 14, 101, 139, 140
BSIZA 8,36

BSPA $8,12,13,25,27,29-31,34-37,39,41-51$, 53-56, 61, 63, 64, 67-75, 77, 89, 90, 98-100, 103, $104,106-108,110,112,113,115,117,118,139,141$, $142,146,156,159,160,167$

Buchenwald 137

Buckland, Mr. Frank 159

budgerigars 121

buffalo 159

bullbaiting $33,34,60,70$

Bulletin de la société française contre la vivisection 8

Bulletin de la société impériale zoologique d'acclimatation 8

Bulletin de la société protectrice des animaux 8,12

bullfighting 41, 63, 66-71, 73-78, 8o, 90, 129-131, 168

bullfighting clubs 76

bullrings $8,130,141$

bull-running 71,73

bulls $33,41,67,68,75,128$

Burdett-Coutts, Baroness Angela 48

Burns, Robert 94

Bushman 61

butcher(s) 22-25, 32, 40-42, 47, 49, 64, 73, 119,

144,152

Buxton, Thomas Fowell 11

calves 21, 24, 42, 176

Calypso 165,166

Camargue Zoological and Botanical Reserve 163

Cambridge 96, 133

Camelin, Camille 37

Caméra au poing 167,170

Campagnes océanographiques françaises 165

campaigners $7,12-14,27,40,47,48,51,53,69,97$, $98,101,116,125,141,144,171,177$

Canada 164, 172, 173

Cannes Film Festival 165

capital punishment 96

Carnet de plongée (Diving log) 165

Carpenter, Edward 97

Carpenter, Mary 86

carter 26, 40, 48, 101

Castelnau, Dr. 129

cats $7,29,104,108,110-112,115,116,118,119,121$, $124,128,141,144,152,161,181$

cattle $11,20,24,34,41,45,47,63,64,104,116,119$, $137,144,162,169$

Caucasus 83

CBS 170

centaur 59

Central Society for the Improvement of Canine Races 105

challengers $78,79,85$

China 9

chivalry 19 
Christian 39, 55, 62, 79, 81, 87

Christianity 20,63, 79, 85, 87

Church 11, 62, 79

Church of England 64

Circassians 84

circuses 8

Cirque d'hiver 99

citizens $21,50,57,74,76,77$

civilizing mission $43,44,63,158$

civilizing process $18,59,79,104$

Clarence, the lion 170

Clark, Paul 178

Clemenceau, Georges 99

clergy $11,29,53,79,85$

clergymen 11,54

coachman (-men) 26, 34, 39, 40, 46-49, 60, 97,

$113,122,15^{2}$

coachmen-grooms 47

Cobbe, Frances Power 14, 64, 65, 85, 86, 88, 105, $122,135,136,138,140,142$

cock $34,59,71$

cockfighting $33,34,70,80$

cocks 68

Coleridge, Samuel Taylor 95

collective mobilizations 9, 69, 185

Collège de France 131

Collins, Wilkie 142

colonial anthropology 61

Columbia Pictures 169

Comité radicalement anti-corrida 78

commando operations $8,173,174,179$

Committee for Horses 27

Communist Manifesto 127

Comparative anatomy 60

compassion $30,44,47,49,61,63,69,86,89,93$,

$94,96,98-100,102,104,111,125-127,140,142$, $146,150,169,173,177,182$

Compassion in World Farming 176

Comtesse Antonin de Noailles 90

Congress of Documentary Films 165

Conseil national de la vie associative 7

Constantinople 84

Contemporary Review 147

Continent 13,85

Convention for the Preservation of Wild

Animals, Birds and Fish in Africa 159

Cooper, Anthony Ashley 85

Coppens, Yves 168

Coran 98

corporal punishment 96

corrida $69-78$

Council for Public Instruction 31

Council of State 168

countermobilization(s) $16,77,88,147,149,156$

Countess of Corneillan 54

Countess of Ségur 121

courses landaises 75

courses provençales 75

Court of Cassation 168
Cousteau, Jacques 165, 166, 168

Cousteau Society 166

cows 12,124

Cri du peuple 130

crime fiction 142,146

criminals $39,61,71,141$

Croix bleue 120

Cruelty to Animals Act 88, 147

Crusade against All Cruelty to Animals 176

Cry of Nature 81

Cyon, Elie de 147-150, 154

Dachau 137

Dagestan 83

Dahomey 74

Daily News 65

Daktari 170

Dana, Charles Loomis 153,154

Darwin, Charles 6o, 158

Darwinism 61

Davies, Brian 164

Dax 76

Decazeville 130

Decroix, Émile 32, 115

Dejerine, Jules 153

de Knyff, Baron 90

Delamarre, Georges 120

demonstrations $8,64,101,130,141,174$

de Monteux, Dr. Dumont 26

demopedic 43, 57, 115, 158, 161, 166, 182, 185

demopedic emotional register 144, 158, 161

Deraismes, Maria 90

Desgraupes, Pierre 120

Desraismes, Maria 143

Dessinge, Mme 112

dietary vegans 81

diphtheria 149

distinctions $47,59,62,100,182,185$

doctors $29,82,86,87,89,90,109,113,115$,

$$
131-133,142-144,149
$$

documentaries $7,165,167$

dodo $15^{8}$

$\operatorname{dog}(\mathrm{s}) 7,25,39,41,45,59,61,64,65,76,84,88$, $98,104-108,110,112-124,127,128,131,133,134$, $138,139,141,144,15^{0-152,161}$

domestic animals $13,27,40,46,72,103,128$, 173,177

domestic pets $117,119,121,164,169,173,177,181$, 185

donkeys 21, 37, 47, 127

Donon, Mme 112

Don't Make a Wave Committee 172

Dreyfus Affair 99

dromedaries 36

Dublin 64,136

Duchess of Kent 17

Ducis 98

Du Gast, Camille 118, 135

Durand, Marguerite 135 
Duruy, Victor 55

Dutrone, Monsieur 45

Earl of Shaftsbury 85

East Coast 136

ecological activists $81,165,168$

ecologists 162

economic scandal 160

educators 43,144

eggs $7,57,82,160,176$

Elements of Morality for the Use of Children 39

Eliasian hypothesis 44

elite(s) $18,19,21,33,40,48,5^{0}, 53,57,61,72,78$,

$86,129,131,156,160,171,185$

Elsa, the lioness 169

Embiez Islands 165

emotional economy $48,49,94,101-103,112,113$, $116,138,144,176$

emotional register of exposure $146,147,174,182$

emotions $15,17,19,47,57,61,62,69,71,77,78$, $99,106,111,114,138,141,146,147,169,170$, 173,180

Empress Eugénie de Montijo 76

Engels, Friedrich 20,127

England 11, 12, 14, 20, 22, 23, 25, 29, 39, 50, 63, $66,70,74,79,85,89,96,98,118,122,132,133$, $135,148,151,160,175$

English Channel $13,14,23,85$

Enlightenment 82

equestrianism 83

Erasmus 59

established group $79,83,85,86$

Establishment 11

Eternal Treblinka 136, 137

Ethical vegans 82

etiquette manuals 21

Eton 96

European 9, 14, 18, 20, 33, 40, 53, 59, 61, 63, 66, $79,84,106,158,176$

Evangelist 43

exploitation of animals $7,21,35,177$

Fabian Society 96

factory farms 8,176

Faculty of Sciences 31

Fairchild-Allen, Mrs. 139

Falloux Law 40

Farm Animal Reform Movement 136

Farm Animal Welfare Advisory Committee 176

Farm boys 47

Faubourg Saint-Honoré 119

Fédération des luttes pour l'abolition de la corrida 78

Félibrige movement 77

feminists 111,132

feminization $88,117,118,154$

femmes publiques 108

Ferry, Jules 56

FERUS/Ours-Loup-Lynx Conservation 171 fishing 34

Flamborough Head 160

Florence 13, 65

Fondation assistance aux animaux 118

Fondation Brigitte Bardot 118

Fontainebleau 12

food safety 23

Fouinet, Ernest 98

fox-hunting 34

France $7,8,12,14,22,23,26,36,37,40,41,43,50$ $53,56,62,64,66,70-73,75,76,78,82,84,89$, $90,99,116,118,121,131,163,166,170,176,180$

France nature environnement 163

Franco-British comparison 9

Frankfurt 47

French Academy of Sciences $3^{1}$

French Association against Tobacco Abuse 32

French Empire 36

French Federation of Societies for the Protection of Nature 163

French League for the Protection of Horses 83

French League for the Rights of Women 135

French Medical Board 86

French National Library 8

French Navy 165

French Revolution 62, 95

French Society against Alcohol Abuse 32

French Society against Vivisection 90

Friends of the Elephant Society 163

Friry, François 118

fur $8,82,175$

Gagnan, Émile 165

Gandhi 96

Gaubert, Mr. 107

Gavroche 100

Gelert 105

gender $118,136,155,156,185$

Gennevilliers 116, 118

geologist 8,86

German $17,18,39,65,88,123,127,161$

Germany 12, 14, 64, 181

Gide, Charles 128, 129

Godlovitch, Roslind 177

Godlovitch, Stanley 177

Goodenough, Evelyn 123

Gordon Bennett Cup race 135

gorillas 7

Gospels 79

Graham, Leonard 142

Grammont, General Jacques Philippe Delmas de $13,36,41,83$

Grammont Law 13, 40, 49-51, 120

Grand Duke Nicholas 17

gratitude $48,74,110,113,144,146$

Great Ape Project 171

great apes 61

great auk 158

Great Britain 11, 14, 20, 33, 39, 41, 43, 80, 106, 135 
Greenpeace 173

Greenwood, Reverend Thomas 62

Greyfriars Bobby 105

Grosselin prize $5^{6}$

Groupement de réflexion et d'action animal libération 168

Guillaumin, Mr. 107

guinea pigs 121

gynecological examinations 143

Habitat ecologique et liberté des primates 171

Hachette 54

Hacker 136

hackney carriages 21

hares 21

Harris, John 177

Harrison, Mr. 64

Harrison, Ruth 176, 177

Hart, Sue 170

hedgehogs 36

Herald Tribune 135

Hérault 119

Herschaft, Alex 136

Hill, Mike 174

Himalayas 165

Hinduism 81

hippophagy $32,83,115$

Hiroshima 172

Hirschman, Albert 19, 20, 33

Hogarth, William 39

horse-drawn $21,27,35$

horse meat $31,32,82-84$

horses 12, 21, 22, 26, 29, 35, 51, 67-70, 73, 83, 104, $115,116,119,122,127,131,150,174$

hounds $68,150,174$

House of Commons 64,85

Hugo, Victor 99-102, 132

Hulot, Nicolas 166, 179

Humanitarian League 96, 97

humanitarians 127

humanization 60

Hunt Saboteurs Association 174

Huot, Marie 9o, 109, 111, 112, 129-132, 134, 135 , $141,146,152$

Huxley, Sir Julian 164

hygenist 113

hygienists 82,87

hypnotism 143

hysteria 155

Ichac, Marcel 165

India $9,31,96,169$

Indian 61

Indonesia 85

insectivores 36

inspectors $5^{0}, 51,53,5^{6}$

intellectuals $78,96,99,177$

International Association for the Total

Suppression of Vivisection 140
International Conference for the Protection of Nature 163

International Fund for Animal Welfare 164

Isle of Wight 160

Italy $13,64,65$

Jack the Ripper 142

Jacobinism 62

Jacquard, Albert 168

Janet, Pierre 153, 154

Jaurès, Jean 99

Jesse, George R. 105

Journal de médecine de Paris 147

journalist $76,109,119,126,130,134,135,140,166$

Jouy, Jules 127,128

Joyeux, Dr. 132

judiciary 11, 29, 53, 85

Judy, the chimpanzee 170

July monarchy 29

Kennel Club 105

Kenya $158,169,170$

Kenyan Game Department 169

Kete, Kathleen 105

Killing for Sport 97

Kingsford, Anna 140, 155, 156

laboratory experiments 7,154

Labour Party 96

Ladies' Kennel Club 105

La Fontaine 98, 122

La Fronde 135

Lalinde 44

Lamarck, Jean-Baptiste 60

Lamartine, Alphonse de 98

L'Ami des bêtes 99

La Nazione 65

Languedoc 78

La Protection française 116

La Réaction agricole 27

La Revue socialiste 128, 129, 132

Larousse, Pierre 99

La Semaine vétérinaire 153,154

L'Assistance aux animaux 116

La Terre et la vie 163

Laurent, Mlle 117

Lauzanier 163

League against Cruel Sports 174

League for the Protection of Birds 163

Le Crapaud 101, 132

Le Crapeau 102

Le Cri du peuple 126

leeches 36,125

Lee, Ronnie 174

Le Figaro 9o, 99, 100, 108

legitimate violence 17

Leipzig Trade Fair 123

Leiris 78

Le Monde du silence (The silent world) 165 
Lemonier, Admiral 165

Le Parisien libéré 121

Le Picador 76

Le Revolté 127

Les cahiers antispécistes 180

Le Toréador 76

Le Torero 76

Lheureux, Marie-Françoise 168

liberators 146,185

Ligue populaire contre la vivisection 14

Ligue pour la protection des oiseaux 163

Lind-af-Hageby, Countess Louise 140

Linnaeus 157

Linzey, Andrew 178

lions 123,169

Liverpudlians 11

livestock 35, 119, 175-177, 180

Lloyd, Marie 136

Lombroso, Cesare 61

London 11-14, 24, 34, 39, 47, 50, 64, 65, 81, 89, $112,127,133,140,142,158,170,174$

London Zoo 164

London Zoological Society 157

l'ORTF 170

Luchon 42,73

Luton 174

Lyell, Charles 158

lynx 162,171

Lyon 12,116

Macdonald, George 142

MacMahon 71

Madras Presidency 159

Magendie, François 64

Magnan, Valentin 65, 74, 151-154

Malle, Louis 165

Malthusian 109

Manhattan 180

manners $17,43,59,60,71,72,74,81,93$

Manning, Henry Edward 66, 85

Marquess of Westminster 25

Marquis of Mostcick-Gozom 89

Martin, A.L.F. 149

Martin, Richard 11, 64

Martin's Act 12, 27, 50, 65

Martin, Senator Louis 75

Marx, Karl 20, 79, 127

Massachusetts Society 110

Masson, Mme 112

Matrimonial Causes Act 136

Mauritius 158

Mazzantini 74

MDFCTA 34

meat $7,21,22,31-33,67,76,80,81,84,96,97$, 170,173

Medical Record 154

medicine 29, 64, 87, 90, 91, 140, 143, 157

Mengele, Josef 136

Méry, Fernand 119-121
Methodist 79

Metromedia 166

Metropolitan Drinking Fountain and Cattle Trough Association 34

mice 123

Michelet, Jules 99

Michel, Louise 125-127, 129, 179

Middle Ages 18, 21, 93, 104

Midgley, Mary 178

militant activities 7

Milliès-Lacroix, Raphaël 77

Mines Act of 184286

Minister of Education 55,56

Minister of the Colonies 77

Minister of the Interior 67,77

ministers $54,56,127$

Ministry of Agriculture 53, 56, 176

Ministry of Agriculture and Trade 53

Ministry of Education 53, 56

Ministry of Public Instruction 37

minks 8,175

Mistral, Frédéric 77

mistreatment of animals 13,137

mobilization(s) 9, 16, 27, 31, 33, 41, 43, 44, 59, 62, $65,75,77,78,91,116,120,132,144,147,149$, $154,174,180,182,186$

Möbius, Karl 161

Monaco 120, 165

Monin, Dr. 61

monkey(s) 61, 62, 85, 148

Monod, Édouard 167

Monod, Jean 167

Monod, Wilfred 168

Mont-de-Marsan 77

Montherlant 78

moral entrepreneurs $9,16,20,44,49,71,96,125$, 172,186

moral philosophy 7,185

motives 15

mules $12,21,37,41$

Munich 47

Museum of Natural History 168

mutual cooperation 160

Nagasaki 172

Naples 13

Napoleon I 23

National Acclimatization Society 163

National Assembly 40

National Council for the Protection of Animals 120

nationalism 62,73

National Natural History Museum 31

National Parks bill 163

National Society for the Protection of Nature 163

National Society for Women's Suffrage 136

National Union against Vivisection 90

natural sciences $157,163,167,170$ 
Navy Undersea Research Group 165

NBC 166

Néouvielle 163

Nero, Tom 39, 40

Netherlands 13

Neufchâtel 155

Newcastle-upon-Tyne 105

Newton, Alfred 160

New York City 34

New York Times 154

Neyrat, Adrienne 99

Nice 116

NIMBYism 21

Nîmes $41,76,131$

nobility $31,53,82,84$

nobles 19,26

Noguès, Georges 83,84

Norbert Elias 9, 17, 20, 21, 93, 103

Nord et Pas de Calais 25

Normandy 116

North American 9

Northern Ireland $5^{\circ}$

obsessive-compulsive disorders 153

Oceanographic Museum 165

OEuvre d'assistance aux bêtes d'abattoir 168

ostriches 36

Oswald, John 81

overexploitation 158,161

Oxbridge 11

oxen $12,21,37$

Oxford 85,133

Oxford Group 177

Oxford University 85,177

Padua 59

Palace of Justice, Padua 59

Palme d'Or 165

pantheism 100

panther 59

Par dix-huit mètres de fond (18 meters deep) 165

Paris $8,12,13,22-24,26,41,47,48,53,54,64,66$, $67,72,75,76,90,112,115,116,119,130,131,135$, $140,158,163,164$

Paris Commune 125

Pariset, Dr. 44

Parliament 11, 24, 33, 53, 78, 85, 88, 147, 160

Pasteur 45

Pasteur Institute 140

Patterson, Charles 136, 137

People for the Ethical Treatment of Animals 175

personal testimonies 140

pests $36,37,169$

PETA 175

petitions 8,148

pharmaceutical industry 8

Philadelphia $34,112,156$ philanthropist(s) $31,48,85,127$

philanthropy $9,23,43,86,99,153$

physicians 85

physiognomy 61

physiology $63,138,140,154,162$

picador 68,128

pigeons 68

pigs $21,123,138$

Pinon Duclos de Valmer, Viscount 12, 82

Place du Combat 41

pleonasm 60

Point de vue-Images du monde 120, 121

Poland 158

polar bear(s) 7,124

political activists 9

political ecology 9

political science 9

Pomeranians 105

Pope Gregory III 31

Popular Anti-Vivisection League 111

Popular League against Vivisection 90, 112, 129, $131,134,139,141$

popular violence 57,70

Positivism 63

positivist theories 151

pounds $112,115,127$

preceptor 125

Prefect of Landes 77

Prefect of Police 27

prescripters 80

prevention of cruelty 40,126

primary school teachers $53,54,56,57$

Primo de Rivera, Miguel 69

Prince Adalbert 17

Prince Jerome Napoleon 17

Prince Ranier 120

Princess Frederica of Hanover 13

Princess Matilda 17

Principles of Geology $15^{8}$

private sphere $107,108,111,112$

prizes $47,48,55,5^{6}$

Prokopp, Karel 168

prostitution 108

Protection mondiale des animaux de ferme 176

Protection Society 45,67

Protestant 6o, 79, 82, 167, 172

Protestantism 20, 81

Provençale 77

provivisectionist movement 149

Prussian army 150

public health $23,32,83$

public sphere 111

punishment $13,44,46$

punk 7

Puritan 167

Pyat, Félix 129

Pyrenees 66, 73, 74 
Quaker(s) 17, 122, 172, 173, 176

Quasimodo 100

Queen Victoria 11, 13, 17

rabbit(s) 123, 131, 138, 150

rabies 45

Rassemblement des opposants à la chasse 168 reasons $15,32,67,73,83,90,96,172,186$

Réflexion et action pour l'égalité animale 180 Regan, Tom 178

register of pity 114

regulations $8,51,117$

Reichstag 150

Reims 132

religious belief 9,61

Renaissance 59

Renaud, Line 120

Renault, Professor 32

Republic 57, 74, 78, 100

republican civic order 57

republicanism 99

republicans 57

rescuer 125

Research Defence Society 149

Revlon 180

rewards $46-48,103,144$

Reynard 122

rhinoceroses 7

riots of $1830-183241$

Roberts, Peter 176

Robinet, Dr. 83

Roche, A. Édouard 34, 37, 48

Romanticism 161

Romantic poets 94,98

Romantics 98

Rome 13

Rothschild, James and Arthur de 17

Roux, Émile 149

Royal Commission 88

Royal Society for the Prevention of Cruelty to Animals 11

Royal Veterinary College 170

RSPCA $11-14,17,23,25,39,40,50,53,61,63,65$, $88,97,118,122,127,160,174$

RTL 121

Russia 13, 17, 49, 64

Ryder, Richard 177

Sac-à-tout 122,134

Sahara 168

Saint Bernard 124

Saint-Esprit-lès-Bayonne 76

Saint-Germain 23

Saint-Hilaire, Isidore Geoffroy 31, 32, 36

Saint-Honoré 23

Saint-Maur 116

Saint Petersburg 13

Salpêtrière Hospital 143

Salt, Henry Stevens 96, 97, 176
Salzmann, Christian-Gotthilf 39

Sanderson, Burdon 65

Sanson, Monsieur 45

Sarlabot II 45

Sarlabot III 45

Saunders, Margaret Marshall 122

Saury, Honoré 152, 153

scandalization 15

Schartau, Liesa 140

Schiff, Moritz 65

school(s) 37, 48, 53-57, 70, 86, 103, 123

scientific experimentation 14,131

scientists $63,65,85,86,88,91,131,133,141,147$,

149-151, 154, 156, 157, 161, 164-166, 168, 171, 172

Scotland 50

Sea Birds Preservation Act 160

seal hunting 159, 164

Second Republic 40, 75, 98

Second World War 171

self-control 19, 46, 57, 79, 8o, 103, 125

sensation novels 142

sensibilities $20-22,27,33,42,57,60,69,137,146$, 177,179

sensitizing device(s) 15, 44, 47, 68, 69, 106, 113, $114,124,138-140,142,144,147,164,166,172$,

$173,175,181$

sentient beings 96

Sérot Bill 163

Séverine $76,109,110,122,126,127,130,134,179$

Sévigné, Marquise de 93, 94

Sewell, Anna 122

Shaftesbury, Lord 85

sheep 12, 21, 22, 24, 37, 42, 100, 182

Shoah 137

shooting 34,68

shopkeeper 40, 44

Sierra Club 172

silkworms 36

Singer, Peter 177-183

slavery $96,171,172$

Smithfield Market 23, 24

Smithies, Catherine 55, 174

Smith, William 60

socialist $76,96,99,128,129,131,132$

Société française contre la vivisection 14

Société protectrice des animaux 12, 118

Société zoologique d'acclimatation $36,157,162$

Society for the Abolition of Vivisection 14

Society for the Prevention of Cruelty to

Animals 11, 13, 33, 40

Society for the Protection of Animals $23,32,50$, $56,75,90,139$

Society for the Protection of Animals Liable to Vivisection $14,65,88$

Society for the Suppression of Vice 33

Society for the Suppression of Wanton Cruelty to Animals 11

sociologist $8,17,18$

solidarity $7,102,129,134,172,173$ 
SOS Orangutan, HELP Congo 171

South of France $72,73,75,76$

South, the $70,72,73,75^{-78}, 129$

SPA 12, 13, 17, 23-26, 29, 31, 32, 34-37, 39, 41,

$43-45,47,48,50-54,56,61,66-68,70,71,75$, $76,82-84,89,90,98,99,102,103,106,110$, $112-118,121,127,135,139,141,144,159,167$

Spain $67,69,73,85$

SPCA 11, 12, 112

speciesism 177

Specola 65

Spira, Henry 180-182

Spirit of Capitalism 19

squirrel 36,85

State 62

Steiff, Margaret 123

Steller's sea cow 158

Stolan, Victor 164

street urchin 100

strict vegetarians 81

Stuttgart 123

suffering of animals $21,40,93,98,102,103,126$,

$127,144,151,152,168,175$

suffragette movement 132

Sunday Times 177

Surat 31

Sur la piste du loup 171

Sweden 14

Swedish Anti-Vivisection Society 140

Switzerland 12, 14

sympathy $25,35,61,93,94,100,102,109,125$

Tailliez, Phillipe 165

taureau à la corde 75

Tazief, Haroun 168

technology 172

Teddy Bear 123

Ten Hours Act of 184786

Thames 133

The Four Stages of Cruelty 39

The Old Man and the Desert 168

The Origin of Species 60,158

theory of evolution 60

The Reward of Cruelty 39

The Undersea World of Jacques Cousteau 166

Third Republic 76, 77

Thome-Patenôtre, Jacqueline 121

Thompson, Frances Maria 26

tiger 62

Times 160

Tischler, Joyce 180

toads 36,80

Tocqueville, Alexis de 17, 93, 94, 103

Tonkin 74

Tophane 84

toreadors 130

Toulon 165

toxicology 64

tracts 7 transitional object 123

transnational 14

Trans-Species Unlimited 181

Trinity College Cambridge 62

Trion 37

Tristan, Flora 127

Turin 13

Turner, James 11, 17, 33, 39, 40, 6o, 61, 81, 87, 106, $112,149,160,161$

Tuscany 65

Uganda 158

UK Wolf Conservation Trust 171

Ulrich 74,76

Uncle Tom's Cabin 122

United States 13, 85, 122, 137, 153

Universal Exposition 67

University College London 140

University of Pennsylvania 175

Valette, Claude Auguste 55

Valjean, Jean 100

Vallès, Jules 122, 130

vegans 7,175

vegetarianism 80

Vegetarian Society 81,96

Verne, Jules 165

veterinarian(s) 29, 32, 82, 115, 119, 120

veterinary medicine $30,37,121$

veterinary science $30,35,119,170$

Victoria Street Society $64,65,85$

Vierzon 131

Vietnam 171, 172

violence of men 126

Viscount of Valmer 36

vivisection $8,14,63-66,74,85-90,127,130-132$, $138-144,146-150,155$

volunteers 7,74

Walsh, John Henry 105

Walt Disney Studios 123

Warsaw Ghetto 137

Weber, Max 19, 20, 167, 185

Wesley, John 80

whales $7,165,173$

Whipsnade Wild Animal Park 164

Wilberforce, William 11, 6o

wild animals $7,97,104,121,124,156,159-161,163$, $164,166,168-171,174$

wild boar 41

Winnicott, Donald 123

wolf/wolves $37,41,100,124,162,163,171,182$

women activists 134

Worby, Tom 174

World League against Vivisection 133

World Wide Fund for Nature 164

World Wildlife Fund (WWF) 164, 171

WWF France 167 
yak(s) 36, 45

Yonne 37

Yourkevitch, Mme de 9o, 116

Zola, Émile 37, 99, 100, 107, 108, 182

Zöllner, M. 150

Zoological Society 163,164

zoology $31,157,158,164$

zoophile(s) 23, 111, 112, 153, 154 zoophilia $23,43,54,100,128,153$

zoophilist 66,140

zoophobia 153

zoos 158

zootechnics 35

zootechny 119

Zuber, Christian 165-168

Zuccolo, Ghislain 176 